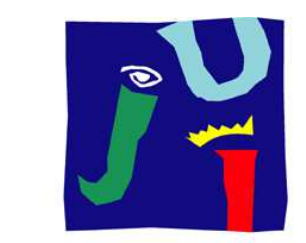

\title{
UNIVERSITAT
}

JAUME•I

\section{Tres ensayos en Finanzas del Comportamiento}

\author{
TESIS DOCTORAL
}

Salvador Navarro Montoliu

Directores: Juan Carlos Matallín Sáez Amparo Soler Domínguez 



\section{Dedicatoria}

A Carmen y Joaquín, mis padres 



\section{Agradecimientos}

Quiero dar mi más sincero agradecimiento a mis directores de tesis, Juan Carlos Matallín Sáez, por su guía permanente, su constante apoyo y dedicación, y a Amparo Soler Domínguez, por su estímulo incondicional, entrega y tiempo. Gracias por vuestra ayuda y esfuerzo, sin los cuales esto nunca hubiera sido posible. 



\section{Presentación}

Podemos definir las finanzas del comportamiento (behavioral finance) como aquella área de conocimiento centrada en el estudio del comportamiento de las personas y su toma de decisiones en el ámbito financiero, especialmente en las decisiones de inversión en los mercados financieros. Esta disciplina admite, que más allá de la perfecta racionalidad de los inversores, existen sesgos emocionales y cognitivos que afectan a la toma de decisiones. En este contexto, la presente tesis se estructura en tres capítulos, de modo que en cada uno ellos se analizará un sesgo o anomalía de finanzas del comportamiento. En el primer capítulo se analizará la paradoja de los dividendos (dividend puzzle), en el segundo el efecto disposición y en el tercer capítulo el efecto calendario.

Palabras clave: finanzas del comportamiento, paradoja de los dividendos, efecto disposición, efecto calendario. 



\section{Índice de contenidos}

1. Capítulo 1: Introducción y metodología de investigación....................................1

2. Capítulo 2: Dividend Puzzle...............................................11

2.1 Introducción...........................................................11

2.2 Revisión bibliográfica.............................................14

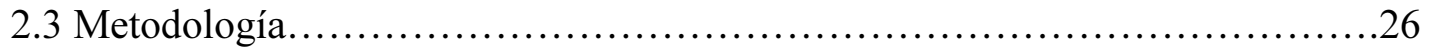

2.3.1 Estrategias de inversión basadas en dividendos......................26

2.3.2 Medidas de evaluación de resultados.............................28

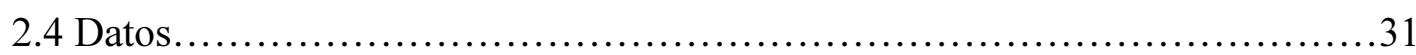

2.4.1 Muestra y período de análisis.....................................31

2.4.2 Rentabilidad por dividendo......................................33

2.4.3 Datos factores medidas de eficiencia.............................37

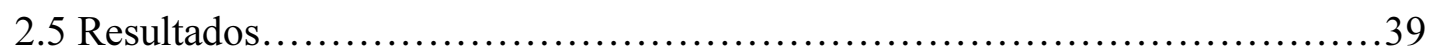

2.5.1 Resultados carteras de inversión basadas en dividendos................39

2.5.2 Eficiencia de carteras.........................................44

2.5.3 Análisis de robustez en subperíodos muestrales.....................47

2.6 Conclusiones...................................................6 60

3. Capítulo 3: Análisis del efecto disposición en los fondos SR....................63

3.1 Introducción.......................................................63

3.2 Datos y metodología............................................... 70

3.3 Resultados.......................................................... 77 
3.3.1 Análisis inicial de los flujos monetarios de los fondos. .77

3.3.1.1 Resultados pasados y flujos monetarios...................77

3.3.1.2 Eficiencia pasada y flujos monetarios......................81

3.3.1.3 Nivel de riesgo y flujos monetarios........................84

3.3.1.4 Nivel de gastos y flujos monetarios........................86

3.3.2 Análisis mediante regresión de los flujos monetarios de los fondos.....89

3.3.2.1 Resultados pasados y flujos monetarios....................89

3.3.2.2 Eficiencia pasada y flujos monetarios......................93

3.4 Conclusiones.......................................................96

4. Capítulo 4: Efecto Calendario................................................99

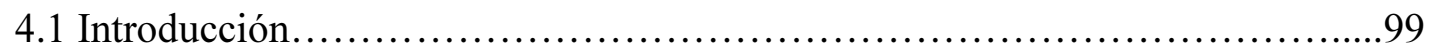

4.2 Datos y metodología......................................................

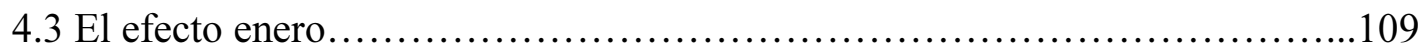

4.3.1 Revisión bibliográfica.............................................109

4.3.2 Resultados...................................................113

4.3.2.1 Análisis totalidad período muestral.......................113

4.3.2.2 Análisis robustez subperíodos muestrales....................122

4.3.3 Resumen resultados análisis efecto enero............................129

$4.4 \mathrm{El}$ efecto día de la semana.................................................

4.4.1 Revisión bibliográfica........................................... 131

4.4.2 Resultados.............................................................

4.4.2.1 Análisis totalidad período muestral.........................137

4.4.2.2 Análisis robustez subperíodos muestrales...................149

4.4.3 Resumen de los resultados del efecto lunes y viernes..................159 
4.5 El efecto cambio de mes (TOTM). .160

4.5.1 Revisión bibliográfica.......................................... 160

4.5.2 Resultados.................................................... 162

4.5.2.1 Análisis totalidad período muestral........................163

4.5.2.2 Análisis robustez subperíodos muestrales...................170

4.5.3 Resumen del análisis del efecto cambio de mes.....................177

$4.6 \mathrm{El}$ efecto vacaciones............................................... 178

4.6.1 Revisión bibliográfica........................................178

4.6.2 Resultados................................................... 182

4.6.2.1 Análisis totalidad período muestral.......................183

4.6.2.2 Análisis robustez subperíodos muestrales...................200

4.6.3 Resumen de los resultados del análisis del efecto vacaciones..........213

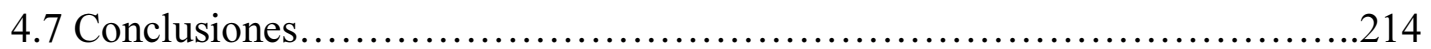

5. Capítulo 5: Conclusiones, contribuciones y futuras líneas de investigación......217

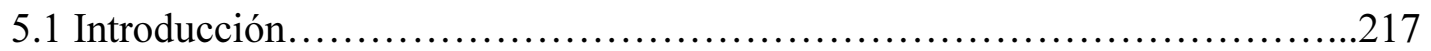

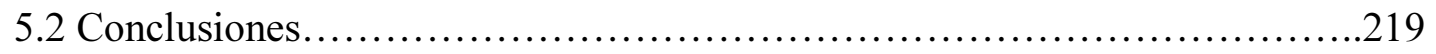

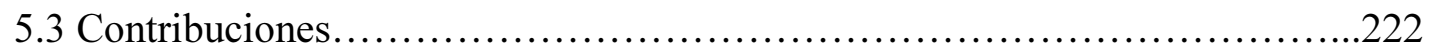

5.4 Futuras líneas de investigación.......................................223

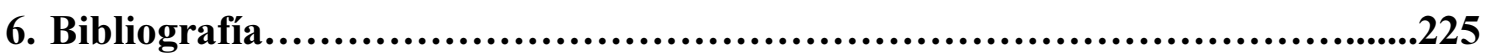





\section{Capítulo 1}

\section{Tntroducción y metodología de investigación}

Desde que los psicólogos Daniel Kahneman y Amos Tversky (1979) presentaron su estudio innovador centrado en Behavioral Finance o Finanzas del Comportamiento (FC a partir de ahora), esta temática se ha convertido en una de las áreas de investigación que ha experimentado un mayor crecimiento y notoriedad en las últimas décadas en el marco de la economía financiera. Prueba de su importancia fue el reconocimiento en forma de distinción mediante la concesión del Premio Nobel de Economía a Daniel Kahneman y Vernon Smith en 2002, por "haber integrado aspectos de la investigación psicológica en la ciencia económica, especialmente en lo que respecta al juicio humano y la toma de decisiones bajo incertidumbre". Una de las definiciones más claras y concisas que podemos encontrar sobre las FC es la de Sewell (2007) quien las define como: "el estudio de la influencia de la psicología en el comportamiento de los inversores y el efecto consiguiente en los mercados". Pero si vamos un poco más allá de esta definición observamos que mientras las finanzas convencionales han evolucionado hacia las teorías modernas de cartera y mercados eficientes, las FC investigan los problemas psicológicos y sociológicos que influyen en el proceso de toma de decisiones de los individuos, grupos y organizaciones. Las finanzas convencionales siguen siendo la pieza central, sin embargo, la psicología y la sociología son catalizadores que se integran dentro de este campo de estudio. Por lo tanto, para estudiar las FC debemos tener familiaridad o nociones básicas de los conceptos de psicología, sociología y finanzas. Dentro de la literatura de las FC se distinguen dos niveles: macro versus micro. Así, por un lado, en las FC macro, se estudian "anomalías" bajo la hipótesis de los mercados eficientes $(E M H)$ y se apoyan en modelos de comportamiento que en última 
instancia pueden explicarlas (De Bondt y Thaler, 1985). Por otro lado, las FC micro estudian el comportamiento de los inversores individuales, cuyos sesgos no son explicados por los modelos tradicionales que incorporan el comportamiento racional (Odean, 1999).

Las teorías financieras tradicionales se basan en la hipótesis de los mercados eficientes, hipótesis introducida por Markowitz (1952) y desarrollada posteriormente por Fama (1970). La hipótesis supone que los mercados financieros incorporan toda la información pública y postula que los precios de las acciones reflejan toda la información disponible, se basa en los supuestos de racionalidad, maximización de los beneficios y mercados eficientes. En esa misma línea, Ross (2001) incide en la relación existente entre la existencia de información y eficiencia, estableciendo que: a mayor información disponible, mayor eficiencia del mercado. Posteriormente, Grossman y Stiglitz (1980) postulan sobre la imposibilidad de los mercados perfectamente eficientes. Es razonable pensar que si éstos no fueran ineficientes los inversores no tendrían ningún incentivo para adquirir información costosa para aprovechar las oportunidades de inversión disponibles y, dada esta imposibilidad, Campbell et al. (1997) sugieren la idea de la eficiencia relativa. La cuestión de la ineficiencia de los mercados así como las imperfecciones del mercado bursátil han sido temas ampliamente estudiados por un gran número de investigadores desde la década de los 60: Stigler (1967), Rosenberg et al. (1985), Shefrin (2007), Ackert y Deaves (2010), Verheyden et al. (2015), entre otros. Desde el punto de vista de las FC son los sesgos heurísticos y los efectos del contexto los determinantes de las anomalías e ineficiencias en los mercados, produciendo una variación en el precio de los activos con respecto a sus valores fundamentales.

En la década de los 80, empiezan a emerger estudios experimentales que incluyen datos bursátiles y las evidencias aportadas sugieren que la hipótesis de los mercados eficientes puede no ser aplicable en todos los casos (Levy y Levy, 2002; Barberis et al., 2001), por ejemplo, cuando los inversores se enfrentan a decisiones de inversión y en contextos de incertidumbre, ya que a menudo éstos muestran un comportamiento de inversión irracional. Hirshleifer et al. (2006) afirman que los inversores irracionales pueden obtener ganancias superiores a las de los inversores racionales vía plusvalías cuando los precios de las acciones están influidos por un análisis fundamental realizado por compañías de inversión. Esto ocurre porque los inversores irracionales actúan secuencialmente guiados por sus sentimientos y aquellos que invirtieron primero se benefician de los que invirtieron más tarde y que empujaron los precios en la misma dirección que los primeros. Varios autores han demostrado que en una economía donde interactúan los inversores racionales e irracionales, la irracionalidad puede tener un impacto sustancial y de larga duración sobre los precios (Jo y Kim, 2008). Para Uzar y 
Akkaya (2013) las FC se basan en la noción de "racionalidad limitada"; este término se utiliza para designar la elección racional que tiene en cuenta las limitaciones de los seres humanos en la toma de decisiones racionales, como las limitaciones cognitivas, las del conocimiento, las de capacidad de cálculo, entre otras, que son el resultado de la naturaleza humana básica y actúan como límites del pensamiento racional. La racionalidad limitada ha ofrecido un modelo en el que la maximización de la utilidad es sustituida por el de la satisfacción.

En la década de los 90, gran cantidad de estudios aportando evidencias contrarias a los mercados eficientes motivaron que las FC empezaran a ganar legitimidad como un campo de estudio propio dentro de la Economía (Shiller, 2003). Estas posturas contrarias han motivado un gran debate en el campo de la economía financiera, y han atraído a un gran número de académicos a dedicar grandes esfuerzos de investigación en esta área durante los últimos tiempos (Brav y Heaton, 2002; Coleman, 2007). Desde el trabajo de Kahneman (2002), el enfoque de las FC ha proporcionado resultados que son relevantes para la evaluación de la calidad de las decisiones de inversión (Campello, 2012), por ejemplo, en el ámbito de la fijación del precio de los activos, en las últimas décadas, los investigadores han intentado descubrir e interpretar anomalías en la rentabilidad bursátil, como reacciones a las noticias y eventos extremos (Bange y Miller, 2004; Hwang y Salmon, 2004).

En este contexto, Lo (2004) propone una alternativa a los mercados eficientes, la Hipótesis del Mercado Adaptativo, o AMH (Adaptive Market Hypothesis), ésta se basa en teorías interdisciplinarias que constan de racionalidad, sistemas complejos, biología y psicología evolutivas. La $A M H$ es un intento de conciliar las teorías económicas basadas en la hipótesis de mercados eficientes con la Economía del comportamiento, mediante la aplicación de los principios de la evolución de las interacciones financieras: la competencia, la adaptación y la selección natural. Uno de los principales beneficios de la $A M H$ es su capacidad para describir entornos de inversión complejos, concretamente es capaz de explicar la aversión a las pérdidas, la reacción exagerada y los sesgos de comportamiento. En los últimos años la $A M H$ ha recibido una creciente atención en la literatura académica y los resultados parecen muy prometedores existiendo una serie de estudios con una fuerte evidencia en relación a la conducta adaptativa y la rentabilidad bursátil (Hull y McGroarty, 2014; Manahov y Hudson, 2014; Ghazani y Araghi, 2014). Siguiendo esta misma línea de investigación, Markiewicz y Pick (2014) prueban que los modelos de aprendizaje adaptativo son capaces de replicar las expectativas de encuestas realizadas a expertos en previsión a una serie de factores macroeconómicos y financieros. Entre otros resultados, los autores encuentran que los 
modelos de aprendizaje adaptativo describen las expectativas de la encuesta mejor que lo hacen los típicos modelos de series temporales, y que el modelo de aprendizaje adaptativo muestra un parámetro de ganancias constantes conseguidas especialmente bueno. Además, Soufian et al. (2014) tratan de arrojar luz sobre una alternativa a la hipótesis de los mercados eficientes debido a la dependencia de ésta a la completa racionalidad de los inversores, entre otras cuestiones.

Adicionalmente, las FC han añadido nuevas hipótesis acerca de las limitaciones cognitivas de los modelos tradicionales de las finanzas (Kahneman, 2003) adaptando estas nuevas hipótesis para que puedan explicar mejor el comportamiento del mercado en comparación con la hipótesis de los mercados eficientes (Tseng, 2006). Olsen (2008) analiza cómo la disonancia cognitiva es el principal problema entre las FC y la teoría financiera tradicional. La disonancia cognitiva hace referencia a la tensión o desarmonía interna de mantener al mismo tiempo dos pensamientos, ideas o creencias que están en conflicto entre sí, y describe con precisión el problema de creer en las teorías financieras tradicionales y, al mismo tiempo, aceptar los hechos probados de las FC. Edmans (2011) describe errores cognitivos en los modelos de valoración de activos de inversión subestimando el capital intangible, como puede ser el caso de la satisfacción de los empleados que se contabiliza como costes de hoy, pero que repercute positivamente en la generación de unos mayores beneficios en el futuro. Los expertos de las FC sostienen que los inversores están más afectados por errores cognitivos que por los sesgos de comportamiento (Jureviciene y Jermakova, 2012). Hytönen et al. (2014) estudian los orígenes de la dependencia en el proceso de toma de una elección arriesgada, utilizando imágenes de resonancia magnética funcional (fMRI), encontrando que el aumento del apetito por el riesgo tras las ganancias y las pérdidas se relaciona con una mayor actividad de los procesos cerebrales afectivos y la disminución de los procesos cerebrales relacionados con la deliberación. Además las perspectivas de la neurociencia justifican el proceso dual (es decir, cognitivo y afectivo) como la base neuronal humana que racionaliza los factores racionales e irracionales que influyen en la toma de decisiones (Camerer et al., 2004; Shimp et al., 2015).

Billett et al. (2014) utilizan datos de encuestas para investigar cómo los precios de las acciones dependen de la percepción de prestigio de la marca y la familiaridad. Sus resultados señalan que las acciones de compañías de mayor prestigio tienen ratios más altos de valoración y cargas negativas en el factor $H M L$ de Fama y French. Para Kim y Kim (2014) la confianza de los inversores con respecto a empresas específicas se ve afectada por los rendimientos anteriores pero no tiene ninguna capacidad de predicción sobre los rendimientos futuros, volatilidad, o volumen; al contrario Siganos et al. (2014) 
utilizando el Índice de Felicidad Nacional Bruta de Facebook (FGNHI) para medir el sentimiento diario a nivel nacional, documentan la existencia de una relación positiva y simultánea entre sentimiento y rentabilidad, seguido de una vuelta a la media durante las semanas siguientes. Pantzalis y Park (2014) también encuentran esa relación simultánea positiva entre los resultados de los encuentros deportivos cerca de las sedes de las empresas y los rendimientos de las acciones de estas empresas, seguida de una vuelta a la media. Jacobsen et al. (2014) utilizan un conjunto de encuestas cuantitativas para estudiar las diferencias en el optimismo entre hombres y mujeres. Encontrando que los hombres son más optimistas que las mujeres, y que esta diferencia explica las diferencias sistemáticas en la asignación de activos. Huber et al. (2014) muestran que la asimetría positiva al principio causa sobreprecio y la negativa infravaloración, y que estos desajustes de precios desaparecen con el aprendizaje.

La literatura que trata las FC también ha examinado el papel de las redes sociales, la confianza entre sus miembros y la sociedad en la toma de decisiones financieras (Chantarat y Barrett, 2007; Cassar y Wydick, 2010). Estos trabajos han llegado a la conclusión de que los ahorros financieros y las operaciones de inversión están relacionadas no sólo con las variables económicas, sino también con variables tales como el nivel de confianza, la reciprocidad, el altruismo y la asociación entre los individuos. Algunos de estos estudios indican que la existencia de confianza a veces parece reducir o eliminar el uso de la información disponible en la toma de decisiones financieras de los individuos. Además de esta investigación dentro de las FC, en las tres últimas décadas, varios gobiernos han creado una amplia variedad de programas públicos para proporcionar educación financiera y económica para el público en general. Estos programas a menudo han sido introducidos como parte de los estudios empíricos que miden el nivel general de conocimientos financieros dentro de la población con el fin de evaluar el impacto de los programas de educación financiera sobre el comportamiento financiero posterior (Lyons, 2005, 2010; De Meza et al., 2008; Lusardi, 2008). Estos programas se basan en la hipótesis de que la educación y la información financiera producen personas mejor informadas que luego, sobre la base de modelos de ciclo de vida y la hipótesis de las expectativas racionales, puedan tomar decisiones óptimas en relación con el ahorro y la inversión. La discusión de si los programas de educación financiera tienen efectos permanentes sobre el comportamiento financiero de un individuo sigue abierta. La mayor parte de la literatura empírica concluye que la educación financiera no necesariamente se traduce en cambios de comportamiento, especialmente en el corto plazo (Duflo y Sáez, 2003; Holm y Rikhardsson, 2006; Booij et al., 2008; Mastrobuoni, 2009). La mayoría de los autores señalan que tales resultados 
son el producto de las dificultades y deficiencias en la planificación y diseño de los programas (Lyons et al., 2006; Hung et al., 2009).

Los principales críticos hacia las FC, como Fama (1998), se apoyan en la teoría de los mercados eficientes, pero además éste argumenta que muchos de los hallazgos en las FC se contradicen entre sí y que, en definitiva, las FC parecen ser únicamente una colección de anomalías valoradas fuera del mercado o explicadas con argumentos de microestructura del mercado. Además, otros autores críticos, como es el caso de Myagkov y Plott (1997), entre otros, sostienen que el comportamiento observado experimentalmente no es aplicable a situaciones de mercado, la existencia de oportunidades de aprendizaje y de competencia asegurará al menos una aproximación cercana al comportamiento racional. Otros estudios señalan que las teorías cognitivas, tales como la teoría prospectiva, son modelos de toma de decisiones que no generalizan el comportamiento económico y que sólo son aplicables al tipo de problemas de decisión instantánea presentados a los participantes de experimentos o encuestas. Los economistas tradicionales son también escépticos de las técnicas de base experimental y de las encuestas que se utilizan generalmente en la Economía del comportamiento ya que éstas deben ser diseñadas con cuidado para evitar sesgos sistémicos, el comportamiento estratégico y la falta de compatibilidad de incentivos. Debido a la dificultad de eliminar estos problemas muchos economistas han sido críticos ante los resultados obtenidos mediante estos procedimientos. Rabin (1998) rechaza estas críticas, afirmando que los resultados suelen ser reproducidos en diversas situaciones y países, pudiendo conducir a una buena comprensión teórica. Otros autores, como Shiller (1981) sostienen que las teorías de modelos eficientes han fallado hasta tal punto que es imposible atribuir este fracaso a un error de datos, de índice de precios o a cambios en las leyes fiscales. Suárez-García y Gómez-Ullate (2014) consideran que existe un gran número de evidencias y pruebas suficientes de la ineficiencia de los mercados que han sido descuidadas teóricamente y que han sido tratadas como simples anomalías. En contraposición a esta postura encontramos un gran número de estudios que asocian la existencia de las FC como resultado de un sesgo de selección de los datos en el ámbito de la investigación, bien conocido como data snooping (Sullivan et al., 2001; Cho et al., 2007; Baker et al., 2008).

De una forma integradora, Ritter (2003) asegura que las FC no pueden ser consideradas como una disciplina separada de las Finanzas sino una parte de la corriente principal de las mismas. Esta tendencia es tan fuerte que es necesario redefinir y ajustar los fundamentos de las finanzas tradicionales para los nuevos puntos de vista de las FC (Spindler, 2011). De hecho muchos autores consideran que las FC son complementarias a las finanzas clásicas ya que pretenden explicar los fenómenos que no pueden ser 
justificados por éstas (Birau, 2012; Singh, 2012) como el comportamiento de los inversores y que son igual de necesarias ambas (Sadeghnia et al, 2013). Las teorías de las FC que se basan en los modelos de las finanzas tradicionales pueden ayudar a los inversores a entender mejor su propio comportamiento y, por lo tanto, ayudarles a mejorar su proceso de toma de decisiones (Kannadhasan, 2006; Sewell, 2007), pero no sólo ayudan a los inversores individuales, sino también a los gestores de inversión que pueden entender sus propios sesgos de comportamiento así como los de sus clientes (Opiela, 2005). En este sentido, Wong y Quesada (2009) analizan algunos ejemplos de la Economía experimental y la Psicología para explicar una serie de tendencias recientes como la falta de planificación futura, la baja tasa de ahorro resultante, la enorme variabilidad económica entre personas y países, la reciente crisis financiera, los excesos de consumo y la inversión en economías desarrolladas o en vías de desarrollo.

A partir de la revisión de la literatura se obtienen las siguientes conclusiones: i) Las FC están inmersas en un proceso de constante evolución y siguen progresando en la actualidad; no sólo en cuanto a cantidad sino también en la calidad de los trabajos publicados; ii) Difícilmente se puede lograr una maximización del beneficio total si no se tiene en cuenta el comportamiento, rasgos y/o sesgos individuales de los inversores, analistas o gestores de carteras; iii) En la actualidad no existe una teoría generalmente aceptada y única de las $\mathrm{FC}$, sino que existen una gran variedad de teorías $\mathrm{y}$ metodologías disponibles. Como rasgo general se ha hecho hincapié en la identificación de las anomalías de los mercados que se pueden explicar por varios rasgos psicológicos de los individuos o grupos; iv) Las FC actúan como un complemento y no como un sustituto de la teoría financiera tradicional, ya que explican los fenómenos que no pueden ser explicados por ésta; v) Todavía existe una amplia controversia dentro de las FC entre los defensores de las mismas, quienes las consideran una rama dentro de la economía, y los detractores quienes asocian su existencia a simples anomalías del mercado.

Históricamente la metodología utilizada para el estudio de las FC ha sido el análisis de anomalías particulares observadas en el mercado a través de encuestas y observaciones experimentales, aunque en los últimos años han adquirido especial relevancia los estudios realizados con imágenes por resonancia magnética funcional como los de Vermeer et al. (2014) y Brevers et al. (2017). Pero una de las principales críticas que han recibido las FC (Myagkov y Plott, 1997) es que el comportamiento observado experimentalmente no es aplicable a situaciones reales de mercado. Específicamente, la metodología a seguir en la presente tesis consistirá en la selección y análisis de tres anomalías del mercado con el objetivo de contrastar empíricamente su existencia, a través de datos históricos y reales. Para la selección de las tres anomalías a estudiar se 
empleará la clasificación de Shefrin (2002), al ser la metodología más ampliamente utilizada en la literatura internacional. Para Shefrin, las anomalías o ineficiencias del mercado vienen determinadas por dos grandes causas: los sesgos heurísticos y la dependencia del contexto. El sesgo heurístico es el proceso por el cual las personas averiguan las cosas por ellos mismos, generalmente, a través del método de prueba y error, es decir, sin utilizar un análisis estrictamente racional. Este proceso lleva frecuentemente a los agentes económicos a conclusiones erróneas o a simplificar en exceso los procesos de decisión produciendo la realización errores sistemáticos. La dependencia del contexto justifica que las decisiones de una persona puedan estar influenciadas por la manera en que se describe el escenario en el que se toma la decisión, es decir, el contexto en el que es presentado un problema afecta al decisor en su decisión sobre el mismo. En base a esto, Shefrin (2002) clasifica las anomalías o ineficiencias del mercado en dos grandes grupos: economic behavior (aquellas que están relacionadas con el comportamiento económico), como el efecto disposición, el efecto donación, el comportamiento gregario, la falacia del coste hundido, entre otras; y market prices and returns (aquellas que están relacionadas con los precios del mercado y la rentabilidad), como el dividend puzzle, la paradoja de la prima de riesgo y el efecto calendario, entre otros.

Para el desarrollo de la tesis hemos elegido el efecto disposición del grupo de las economic behavior y el dividend puzzle y el efecto calendario del grupo de las market prices and returns, definiéndose como sigue:

- El dividend puzzle o paradoja de los dividendos, es un concepto de finanzas en el que las empresas que pagan dividendos son recompensadas por los inversores con rentabilidades más elevadas que aquellas que no los pagan, a pesar de que, según muchos economistas, no debe importar a los inversores si una empresa paga dividendos o no.

- El disposition effect o efecto disposición es una anomalía de las FC, según la cual los inversores tienden a vender rápidamente los activos que han aumentado su valor y a mantener aquellos que han disminuido de valor. Es decir, los inversores están menos dispuestos a reconocer las pérdidas, pero más dispuestos a reconocer las ganancias.

- El calendar effect o efecto calendario hace referencia a las anomalías que se producen en la rentabilidad de las acciones relacionadas con determinadas fechas del calendario (bien sea el mes del año, el día de la semana o días festivos, entre otros). Dentro de esta anomalía analizaremos: el efecto enero, el efecto día 
de la semana, el efecto cambio de mes (TOTM) y el efecto vacaciones. Muchos de los efectos calendario han disminuido, desaparecido o incluso se han invertido desde que fueron descubiertos, por eso uno de los apartados de este capítulo será el estudio de su evolución temporal.

El estudio de estas tres anomalías se realizará en los mercados financieros españoles y estadounidenses, dada su relevancia, accesibilidad y disponibilidad de la información, considerando la premisa de que se cumplen estas tres hipótesis: i) Mercados eficientes; ii) Racionalidad de los agentes económicos; iii) Existencia de oportunidades de aprendizaje y competencia. El dividend puzzle y el efecto calendario serán analizados a través de los índices más representativos de los mercados bursátiles españoles (el Índice General de la Bolsa de Madrid (IGBM), el Ibex 35, el Ibex Medium Cap, el Ibex Small Cap y el Ibex Top Dividendo) y el efecto disposición a través del estudio del comportamiento de los inversores en fondos de inversión socialmente responsables de Estados Unidos.

Recientes trabajos (Thaler y Sunstein, 2008; Akerlof y Shiller, 2009; Wong y Quesada, 2009) dentro del campo de las FC sugieren que la crisis financiera, en parte, es consecuencia del exceso de confianza dentro de los colectivos y de los sesgos cognitivos en las personas, que a menudo les llevan a invertir excesivamente en activos de riesgo o mostrar demasiada inclinación hacia la asunción del riesgo; a pesar de las señales contrarias del mercado que están basadas en información disponible, clara y real. En ese sentido, Shiller $(2005,2008)$ fue uno de los primeros autores que puso de relieve el papel de la confianza y su contagio social con la volatilidad de los mercados financieros. Además, Akerlof y Shiller (2009) identifican esta confianza con los "espíritus animales" de Keynes y argumentan que en estos patrones de creencias subyacen las distintas fases económicas de auge financiero o de crisis, que llevan a los individuos a tomar decisiones subóptimas de inversión, de ahorro o de consumo, contaminándose entre sí a través de lo que los autores llaman el "multiplicador de confianza". Este multiplicador de confianza se podría definir como el cambio que se produce en los ingresos como resultado de un cambio de una unidad de confianza. Thaler y Sunstein (2008), también sugieren que el contagio social y la racionalidad limitada son los principales factores que subyacen en la actual crisis financiera global. Los autores afirman que una de las causas de la catástrofe de las hipotecas de alto riesgo o subprime ha sido que la mayoría de los titulares de las mismas no entendían las condiciones de los préstamos. Para Shefrin (2009) la principal causa de la crisis es un fenómeno psicológico y no es una cuestión de análisis fundamental. Era evidente que las pérdidas, dominantes en el mercado, eran causadas por el comportamiento de búsqueda de riesgo, mientras que el excesivo optimismo y la tendencia a la parcialidad 
actuaron como factores determinantes de la crisis, y no otros factores fundamentales, como el terrorismo, el alza de los precios del petróleo, o los cambios destructivos en el clima, etc. Por todo lo expuesto, en cada capítulo se abordará el análisis del comportamiento de cada una de las anomalías durante la crisis financiera global de 2008 . 


\section{Capítulo 2}

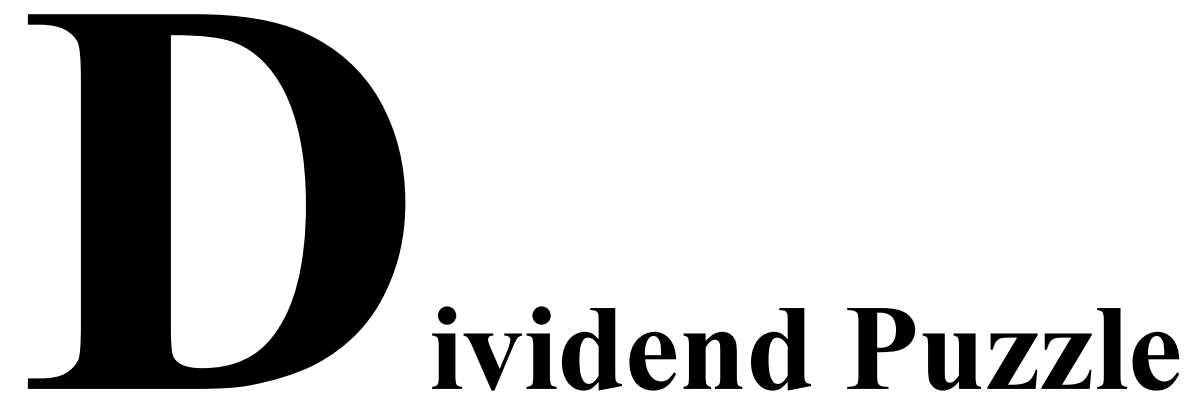

\subsection{Introducción}

El dividend puzzle, o paradoja de los dividendos, es un concepto financiero que sostiene que aquellas empresas que pagan dividendos son recompensadas por los inversores con una revalorización superior de sus acciones con respecto de aquellas que no los pagan. Este fenómeno se erige en contraposición de la postura de gran número de economistas quienes defienden que los inversores deberían ser indiferentes ante esta hipótesis.

Normalmente cada empresa establece, según su política de dividendos, un adecuado equilibrio entre distribución o retención de beneficios, es decir, qué cuantía de los beneficios obtenidos se va a retener en forma de reservas y qué parte se va a distribuir en forma de dividendos. Así, desde el punto de vista del inversor, la política de dividendos no debería tener ningún efecto sobre el proceso de valoración de la empresa ya que al ser partícipe de la empresa debería ser indiferente ante cualquiera de las dos posibilidades: i) obtener los dividendos y ii) que éstos sean reinvertidos en la empresa contribuyendo en última instancia a la creación de valor. Sin embargo, en la práctica bajo la influencia de imperfecciones del mercado tales como impuestos, costes de transacción y otras cuestiones como las asimetrías de información, problemas de agencia, factores psicológicos, incertidumbre, cuestiones relacionadas con la Economía del comportamiento, entre otras, la política de dividendos cobra mayor relevancia, tanto 
para los gerentes de las empresas como para los accionistas, potenciales inversores o analistas de mercado. De hecho, no sólo los directivos muestran un cuidado especial en sus decisiones de pago de dividendos y en el cambio de éstas; en este sentido es reseñable la fuerte reacción que experimentan los mercados frente a los cambios en los dividendos, y más aún, a las omisiones de éstos y al pago de nuevos, como lo demuestran Aharony y Swary (1980), y Michaely et al. (1995).

En este contexto, el estudio influyente de Miller y Modigliani (1961) -a partir de ahora MM- muestra que, bajo el supuesto de mercado de capitales eficiente, la decisión de pago de dividendos es irrelevante porque no crea ni destruye valor para los accionistas. En tal supuesto, para un inversor es indiferente invertir en una empresa que paga dividendos que en una que no los paga. El razonamiento en el que se apoyan MM es que los flujos de efectivo que representan los dividendos, son recompensados, a través de unas mayores ganancias de capital en el momento que se realiza la venta de la acción. Así, los dividendos que la empresa no ha repartido han sido reinvertidos en la misma para generar un mayor valor e incrementar el precio de cotización de la acción.

En contraposición a esta teoría, Lintner (1956) y Brav et al. (2005) postulan sobre la conveniencia de establecer unas reglas muy claras en la política de fijación de dividendos; esta postura es acorde a la práctica real que han venido aplicando las empresas durante las últimas tres décadas; estas reglas entrarían en conflicto y serían incomprensibles desde la postura de considerar esta decisión irrelevante.

En este contexto, las Finanzas del Comportamiento (FC) suponen un ámbito en el que articular ambas argumentaciones. En las FC es de especial importancia la dependencia del contexto, ya que éste condiciona el proceso de toma de decisiones de los inversores. Es lógico que tomen una decisión en función de la forma o el contexto en la que se les presenten los problemas de decisión. El enfoque hedónico implica que el inversor prefiere unos contextos en vez de otros y que siempre tiende a elegir aquellos contextos que le proporcionen un mayor placer en el corto plazo; pudiendo así satisfacer sus expectativas prefiriendo las acciones que pagan dividendos sobre las que no los pagan. Cuando la cotización de las acciones sube, el pago de los dividendos se convierte en un plus añadido a las ganancias de capital, y cuando ésta baja, éstos pasan a ser un "colchón" para el inversor para compensar las posibles pérdidas futuras de capital, de ahí la preferencia de los inversores por las acciones que distribuyen dividendos en efectivo.

Dado este sesgo cognitivo o anomalía provocada por la dependencia del contexto, la igualdad entre las rentabilidades de una acción que paga dividendos frente a otra que no, 
que postula el modelo de MM, se rompe presentando la acción que paga dividendos una mayor rentabilidad frente a aquella que no los paga.

Así, este capítulo plantea como principal objetivo de investigación analizar empíricamente si el dividend puzzle se presenta en un entorno real, específicamente para el mercado financiero español, identificándose además como cuestión de investigación adicional el análisis de la robustez del efecto en diferentes subperíodos muestrales, centrándonos especialmente en la reciente crisis financiera de 2008.

En definitiva, este capítulo aborda un tema de gran importancia para la Economía Financiera ya que inicialmente realiza una exhaustiva revisión de la literatura, que aporta argumentos al trade-off existente entre la estructura de capital y la teoría de dividendos para el caso español. Para ello en los sucesivos epígrafes se abordarán metodologías centradas en estrategias de inversión basadas en dividendos, así como medidas de evaluación de resultados. Para posteriormente, presentar los datos reales objeto de análisis cuyos resultados se detallarán siguiendo los siguientes criterios: resultados de carteras de inversión basados en dividendos, eficiencia de carteras y análisis de robustez en subperíodos muestrales. Finalmente, se detallarán las conclusiones. 


\subsection{Revisión bibliográfica}

Uno de los temas relevantes de discusión de los últimos 50 años dentro del mundo de las finanzas, y especialmente en las FC, ha sido la política de reparto de dividendos o más comúnmente conocido como el problema del dividendo o "dividend puzzle". Esta sección presenta un compendio de los principales estudios, tanto teóricos como prácticos, que han versado sobre esta temática y en todas sus vertientes.

Como principales trabajos clásicos que han servido de base para el posterior desarrollo de la literatura sobre el dividend puzzle podemos destacar los de Lintner (1956) y MM (1961).

Uno de los trabajos pioneros, es el de Lintner (1956) quien afirma que las empresas establecen a largo plazo un coeficiente/ratio objetivo de reparto de dividendos (target payout ratio), es decir, deciden establecer un porcentaje fijo sobre los beneficios anuales, para el pago de dividendos a sus accionistas, con la creencia de que esta estabilidad en el cobro de dividendos les dará seguridad en sus pautas de consumo-inversión y les evitará costes de transacción; al contrario que si el flujo de dividendos fuese cambiante. En contraposición, otros autores (Gaver y Gaver, 1993; Barclay et al., 1995) creen que la política de dividendos de las empresas viene determinada por diversos problemas informativos, contractuales que se dan entre los diferentes agentes económicos y sus opciones de crecimiento.

MM (1961) demostraron que en un mercado de capitales eficiente -donde no existen ni costes de transacción, ni impuestos, ni información asimétrica, ni problemas de agencia, entre otros- la política de dividendos de la empresa es irrelevante en cuanto a su efecto sobre el valor de las acciones. Dado que el valor de las mismas no viene determinado por el mayor o el menor pago de dividendos sino por su capacidad de generar beneficios y el tipo de riesgo, los autores sostienen que el riesgo de la empresa se determina por el grado de riesgo de sus flujos operativos de efectivo, no por la forma en que distribuyen sus beneficios. Una teoría alternativa, y más antigua, sobre el efecto de la política de dividendos en el valor de una empresa es la teoría del "pájaro en mano" (Gordon, 1959) en la cual los dividendos aumentan el valor de la empresa, según esta teoría en un mundo de incertidumbre y de información imperfecta, los dividendos se valorarían de forma diferente a las ganancias de capital; los inversores preferirían el "pájaro en mano" de los dividendos en efectivo en lugar de la esperanza de futuras ganancias de capital.

La presente revisión bibliográfica se ha decidido estructurar en cinco apartados, los tres primeros destinados a los considerados motivos tradicionales que tienden a afectar a la 
política de reparto de dividendos de las empresas como son los impuestos, la información asimétrica y los costes de agencia, el cuarto a las Finanzas del Comportamiento (eje de la tesis) y a los principales factores que aportan éstas como causas del dividend puzzle: the behavioral life cycle ${ }^{l}$, racionalidad limitada, hábitos de conducta, entre otras; y por último un apartado final, el cual se ha centrado en consideraciones adicionales de estudio como otras posibles explicaciones a la paradoja y una pequeña revisión de los principales trabajos a nivel nacional.

\section{Impuestos}

Para MM un supuesto de mercado eficiente es un mercado sin impuestos o en su defecto, con impuestos iguales para los dividendos que para las ganancias de capital. Pero el sistema impositivo de muchos países ofrece distintos tratamientos fiscales, como es el caso estadounidense donde puede observarse un tratamiento fiscal favorable a las ganancias de capital en comparación con los dividendos (La Porta et al., 2000). En 2003, el congreso estadounidense aprobó una ley que incluya un cambio importante en la tributación de las inversiones: las ganancias de capital y los dividendos tributaban igualmente a una tasa máxima del 15\%, eliminando la penalización de impuestos a los dividendos. Después de que el proyecto de ley fue propuesto y antes de ser aprobado, Microsoft anunció que empezaría a pagar dividendos por primera vez en sus 28 años de historia. En Alemania donde las desventajas fiscales no son tan significativas, encontramos el trabajo de Amihud y Murgia (1997) quienes sugieren otras razones, además de los impuestos, para explicar el reparto de dividendos de las compañías. Esta tributación más desfavorable de los dividendos junto al teorema de la irrelevancia de los dividendos, convierten a los dividendos en un tema controvertido, llegando a ser considerado por Brealey y Myers (2003) como uno de los diez problemas financieros no resueltos.

Dada esta asimetría fiscal, Brennan (1970) afirma que los accionistas prefieren las ganancias de capital a los dividendos. Sin embargo, esta afirmación se encontraba en clara contradicción con la realidad observable en los mercados financieros, donde se pagaban millones de euros a los accionistas cada año. En la literatura consiguiente, se identifica que existe una fuerte relación positiva entre rentabilidad total esperada antes de impuestos y la rentabilidad por dividendo. (Black y Scholes, 1974; Litzenberger y Ramaswamy, 1979). En particular Black y Scholes (1974) apoyan la irrelevancia de la política de dividendos en un mundo con costes de transacción e impuestos, pero no encontraron ninguna evidencia de un efecto de impuestos en su estudio. Así, no hay

\footnotetext{
${ }^{1}$ Según este enfoque los individuos deciden en base a reglas llamadas compartimentos mentales.
} 
evidencia de que las diferencias en rentabilidad de los dividendos conduzcan a diferencias en rentabilidad total de las acciones. Los autores postulan que si las empresas pagaban dividendos era porque los accionistas encontraban ventajas que superaban al pago de impuestos, así como la obtención de ingresos periódicos para propósitos de consumo.

Fisher Black publica en 1976 el artículo "The dividend puzzle" (en homenaje al cual se ha dado nombre a este capítulo) que gira básicamente sobre estas dos preguntas: i) por qué las empresas pagan dividendos y ii) por qué los inversores prestan atención a los dividendos. En su análisis Black sostiene que cuando los impuestos se agregan al marco de MM las empresas deberían eliminar el pago a los accionistas, aunque obviamente en gran medida no lo hacían. Esta contradicción evidente llevó a la famosa declaración de Fisher Black (1976): "Cuanto más estudiamos el problema de los dividendos, más nos parece un rompecabezas, con piezas que simplemente no encajan entre sí". Entonces, en un contexto donde los dividendos tributen más que las ganancias de capital, y donde no se graven las ganancias de capital hasta que se materialicen, una empresa que no pague dividendos será más atractiva para un inversor que una similar que sí que los pague. Ello hará que aumente el precio de la empresa que no paga dividendos y provocará que muchas estén tentadas de eliminarlos. Como argumento a favor al pago de los dividendos, se identifica que el pago de dividendos puede mitigar el problema potencial de la sobreinversión ya que reduce la cantidad de flujos de caja libres. En conclusión, Black no encuentra ninguna razón convincente para el pago de los mismos. Posteriormente, Feldstein y Green (1983) retoman los estudios de Black indicando que la política -casi universal- de pagar dividendos es uno de los principales puzles existente en las finanzas corporativas.

A finales de los años 80, Miller (1986) reconoce que la preferencia observada por los dividendos en efectivo es uno de los puntos débiles en la base de las teorías actuales. La proliferación de teorías condujo a Ang (1987) a afirmar que la sobredimensión de justificaciones, en contraste a su escasez inicial, hace quizá más difícil de resolver el rompecabezas del dividendo ya que su explicación no es ni simple ni obvia dando cabida a diferentes y dispares puntos de interés. Con el paso del tiempo y la desaparición de los tratamientos fiscales desfavorables entre las ganancias de capital y los dividendos, entre otros motivos, ha llevado a numerosos autores a estudiar de nuevo las preferencias de las empresas y los inversores hacia los dividendos. (Robin, 1991; Michaely, 1991).

Recientemente, Jacob y Jacob (2013) realizan la encuesta internacional más completa sobre los efectos de los impuestos sobre la política de dividendos, mediante el análisis 
de empresas de 25 países para el período 1990-2008. Los autores aportan fuertes argumentos a favor de la visión tradicional de la fiscalidad de los dividendos, a considerar: la penalización de los impuestos sobre los dividendos frente a las ganancias de capital está estrechamente relacionada con la propensión de las empresas a pagar dividendos y recomprar acciones, así como con la cantidad de pagos de dividendos y recompra de acciones que realizan.

\section{Información asimétrica}

Por otro lado, Pettit (1972) observó que el importe del dividendo pagado parece llevar gran información acerca de las perspectivas de una empresa; esto puede ser evidenciado por las fluctuaciones del precio de las acciones. De acuerdo a su análisis un aumento (disminución) de los dividendos puede ser interpretado como noticias favorables (adversas) en cuanto a evolución y mejores (peores) perspectivas a futuro. Con posterioridad, aparecen las teorías de los modelos de "señales" (información asimétrica) para el pago de dividendos, expuestas por Ross (1977) y Brealey et al. (1977), y desarrolladas por Bhattacharya (1979), John y Williams (1985), Miller y Rock (1985), entre otros. Los autores sugieren que son los directivos de las empresas quienes deciden el nivel de pago de dividendos, los utilizan como un mecanismo para enviar "señales" al mercado, en concreto a los inversores, sobre el estado de la empresa. Los directivos tienen un incentivo para enviar al mercado estas señales cuando creen que el valor actual de sus acciones es inferior a su valor intrínseco. El pago de un mayor dividendo se asocia al aumento de la confianza en la empresa y sirve como indicador de credibilidad al mercado y confirma una situación interna favorable de ésta. Así, la implicación de la hipótesis de señalización de dividendos es que las empresas que incrementan (disminuyen) los dividendos en efectivo deben experimentar reacciones de los precios positivas (negativas). Esta teoría de señalización fue respaldada por un estudio realizado por Baker y Powell (1999) a los directores corporativos y sus puntos de vista sobre la relación entre la política de dividendos y el valor de la empresa. Las evidencias empíricas han reflejado resultados mixtos a la señalización de los dividendos. Por un lado, gran cantidad de evidencias muestran que un aumento en los dividendos está relacionado positivamente con incrementos del precio de las acciones en fechas próximas al anuncio del cambio de dividendos, entre otros autores, Aharony y Swary (1980); Asquith y Mullins (1983) y, Kalay y Loewenstein (1986). Por otro lado, algunos estudios como los de Watts (1973) y Gonedes (1978) no admiten la hipotética relación entre los cambios de dividendos y ganancias futuras.

Sin embargo, Miller y Scholes (1983) basándose en la teoría de las expectativas racionales, cuestionan el estudio de Litzenberger y Ramaswamy (1979). La fuerte 
correlación positiva entre los rendimientos de los dividendos y rendimientos totales que Litzenberger y Ramaswamy interpretaron como un efecto fiscal negativo de los dividendos sobre el precio de las acciones podría ser, según la idea de Miller y Scholes, un efecto de la "información" comunicada al mercado vía el anuncio de dividendos. Ambos autores replicaron el estudio de Litzenberger y Ramaswamy, pero eliminando todos los sucesos en los que el dividendo fue anunciado y repartido el mismo mes. Con ello llegaron a la conclusión de que el efecto fiscal no alcanzaba más del 4\% (lejos del $23 \%$ del estudio anterior), siendo prácticamente despreciable y, por lo tanto, pudiendo apoyar la idea de la irrelevancia de la política de dividendos.

En 1988, la investigación de Healy y Palepu (1988) demuestra que las empresas al anunciar la supresión del pago de dividendos tienen cambios negativos en sus rentabilidades, mientras que las empresas que anuncian pagos de dividendos tienen cambios positivos en sus rentabilidades, tanto antes como después del cambio de la política de dividendos. Convenientemente, Farrelly y Baker (1989) encuestan a inversores institucionales para conocer sus puntos de vista sobre los dividendos. Basando su estudio en 130 respuestas, la evidencia demuestra que estos inversores institucionales consideran que un aumento del dividendo tiene un efecto positivo sobre el precio de la acción. Los encuestados también muestran una preferencia por las ganancias de capital sobre la recepción de dividendos como fuente de retorno. Así, está ampliamente aceptado que los pagos de dividendos pueden servir como señales a los agentes participantes del mercado. Sin embargo, la evidencia reciente ha aumentado la incertidumbre respecto a la información transmitida cuando una empresa disminuye su dividendo, según Jensen y Johnson (1995). Por ejemplo, DeAngelo et al. (1992) demuestran que una reducción de dividendos conlleva un aumento significativo en las ganancias de la empresa. Espitia y Ruiz (1996) afirman que la reacción del mercado no la provoca en sí el anuncio de dividendos, sino el anuncio de un dividendo distinto del esperado, produciéndose el efecto informativo sólo en caso de que los inversores identifiquen diferencias entre sus expectativas y la información trasmitida por los anuncios de dividendos.

Numerosos estudios indican que las recompras de acciones ordinarias por parte de la propia empresa puede señalar que éstas están infravaloradas. Según Comment y Jarrell (1991) e Ikenberry et al. (1995, 2000) los anuncios de recompra de acciones ordinarias están estrechamente relacionados con rentabilidades positivas anormales, un resultado que apoya la hipótesis de la infravaloración de la recompra de acciones comunes. En el trabajo de Grullon y Michaely (2000) podemos observar que mientras que el porcentaje total de pago de dividendos y recompra de acciones ha sido constante alrededor del 26\%-28\%, durante las últimas décadas, ha disminuido la proporción de pago de 
dividendos. Así, desde 1974 a 1998, la relación de recompras aumento del 3,7\% al $13,6 \%$, mientras que el ratio de dividendos cayó del 22,3\% al 13,8\%. Además. Grullon y Michaely (2002) muestran que las empresas han sustituido gradualmente las recompras de acciones por dividendos. Estos resultados arrojan luz hacia una posible respuesta al dividend puzzle.

Según Brealey et al. (2005), los directivos de las empresas prefieren pagar un dividendo menor y sólo si en el futuro parece viable, los deciden aumentar; con el fin de evitar la reducción de los dividendos. Dado que los dividendos pueden convertirse en una señal para los inversores debido a la existencia de información asimétrica de la gerencia, Brealey y Myers (2003) argumentan que el aumento del dividendo indica optimismo de la administración acerca de las ganancias futuras y por lo tanto afecta el precio de las acciones. En esta misma línea Rodríguez et al. (2003), en los años 1998 y 1999, observaron que en las empresas cotizadas españolas primaba el objetivo de mantener los dividendos en cuantía constante frente a la opción de repartir todos los años el mismo porcentaje de beneficios. Recientemente, Liu y Espahbodi (2014) encuentran que gran parte de la actividad de gestión de las empresas que pagan dividendos está enfocada a mantener los beneficios constantes, con la intención de mantener el dividendo del año anterior.

Por otro lado, Skinner y Soltes (2011), entre otros, encontraron una relación positiva entre la reacción en el precio de las acciones y los cambios inesperados en los dividendos, mientras que Benartzi et al. (1997) y Grullon et al. (2005) sostienen que los resultados no muestran pruebas que señalen esa hipótesis. Skinner y Soltes (2011), también especularon que la investigación empírica no siempre es prueba de que las decisiones de distribución de dividendos revelen las perspectivas de las empresas o cambios en los beneficios futuros, en parte debido a que la política de dividendos se ha suavizado, además de ser conservadora en el tiempo.

\section{Costes de agencia}

Deshmukh (2005) sostiene que las explicaciones a la política de distribución dividendos se clasifican en al menos tres categorías de imperfecciones del mercado, tales como: costes de agencia, información asimétrica y los costes de transacción. Los costes de agencia derivan de problemas de agencia entre propiedad y gerencia; estas consideraciones pueden ofrecer otra explicación para el pago de dividendos. Así, Easterbrook (1984) sostiene que las empresas pagan dividendo para ayudar a reducir los costes de agencia entre los accionistas y los directivos. El pago de dividendos aumenta la frecuencia con la que las empresas tienen que acudir a los mercados, con el fin de 
recaudar capital adicional y en este proceso las empresas se someten a su supervisión y control. Jensen (1986) hace una argumentación similar basada en las relaciones de agencia estableciendo que los gerentes pagan dividendos para reducir los flujos libres de efectivo que podrían utilizar para financiar inversiones subóptimas; dichas inversiones les podrían beneficiar a ellos, pero disminuirían la riqueza del accionista. En relación a inversiones subóptimas, Harford (1999) muestra que las empresas con mayor liquidez son más propensas a hacer adquisiciones y que también son más propensas a pagar de más por las mismas. Harford et al. (2005) afirman que ello es especialmente cierto si la empresa está mal gestionada, ya que se derrocha el dinero en efectivo a través de adquisiciones. Estos estudios sugieren que las adquisiciones son un medio, pero no el único, a través del cual los problemas de agencia impactan en el valor de la empresa, en casos particulares de las empresas mal gestionadas y con superávit en efectivo.

Sin embargo, Officer (2007) sugiere en su estudio la importancia del pago de dividendos para reducir los problemas de agencia, siguiendo con esta línea John y Knyazeva (2008) muestran que las empresas con un gobierno corporativo débil serán más propensas a pagar dividendos. Cuanto mayor sean los costes de gestión y gobernabilidad, más probable será la distribución de dividendos. Hellström e Inagambaev (2012) sostienen que las empresas deben pagar el flujo libre de caja excesivo como dividendos a los accionistas con el fin de evitar los conflictos entre propiedad y dirección. En caso contrario, los administradores pueden perseguir intereses propios en lugar de maximizar el valor de la empresa y la consiguiente creación de riqueza para los accionistas.

Desde otro prisma, Fidrmuc y Jacob (2010) conjeturan que la naturaleza normativa social de la cultura influye en el carácter de las relaciones de agencia y determina la legitimidad y la aceptación de las diferentes estrategias de pago de dividendos entre diferentes países. Así, estableciendo relaciones entre diferencias culturales y dividendos de empresas sitas en 41 países, sus resultados demuestran que la cultura tiene un efecto sustancial sobre las políticas de pago de dividendos de compañías de todo el mundo. Destacándose que las empresas establecidas en países que presentan determinadas dimensiones culturales, tales como: niveles elevados de individualismo en la sociedad, bajos niveles de distancia entre la riqueza y sin apenas existencia de diferencias de poder, y en sociedades con bajos niveles de aversión a la incertidumbre generalmente reparten mayores dividendos. Ben-David (2010) propone la idea de que el pago de dividendos se haya convertido en una norma social, aunque inicialmente tenía como función la mitigación de los problemas de agencia o como un indicador de las perspectivas del funcionamiento futuro de la empresa. Además, en una reciente síntesis de la investigación académica sobre la política de dividendos corporativa, Farre-Mensa 
et al. (2014) concluyen que entre los motivos tradicionales del pago de dividendos en las empresas (impuestos, información asimétrica y los costes de agencia) las evidencias más consistentes están a favor de los problemas de agencia. Por otro lado, Ersoy y Çetenak (2015) examinan el impacto de la gestión de los propietarios en la política de dividendos de las empresas industriales que cotizan en la bolsa de Estambul, encontrando una relación positiva entre la propiedad y la gestión de los dividendos, además de llegar a la conclusión de que la rentabilidad, las inversiones y las oportunidades de crecimiento son eficaces con el pago de dividendos.

\section{Finanzas del Comportamiento}

Shefrin y Statman (1984) desarrollan la siguiente teoría sobre los dividendos: the behavioral life cycle; ésta se basa en la teoría del autocontrol del inversor racional individual presentada por Thaler y Shefrin (1981) y la teoría de decisión bajo incertidumbre descrita por Kahneman y Tversky (1979). Shefrin y Statman sostienen que el pago de dividendos y la generación de efectivo por la venta de acciones no son sustitutivos perfectos. Estos autores afirman que muchos inversores preferirán el pago de dividendos altos o bajos según la situación demográfica en que se encuentren (según el ciclo vital), por ejemplo, los individuos jubilados prefieren un dividendo estable y alto para ayudar a financiar su consumo diario. De hecho, Shefrin y Statman (1984) encontraron evidencias empíricas de que existe coherencia en su teoría.

Desde otra perspectiva, Frankfurter y Lane (1984) describen varias teorías económicas del comportamiento para el caso de los dividendos. Unas consisten en que los hábitos pueden reflejar factores culturales y sociales en lugar del comportamiento económico racional (Waller, 1988), otras implican racionalidad limitada, que reconoce que un individuo no puede evaluar todas las opciones posibles según lo requerido por la racionalidad económica (Golembiewski, 1988), pero concluyen con la idea de que muchos gestores son conscientes de que los inversores perciben a los dividendos como indicadores de que se genera valor y, por lo tanto, pagarlos es importante, bien sea de forma constante, porcentual o creciente. Waller (1988) se centra en el concepto del hábito (entendido como una falta de reflexión ante un determinado comportamiento) en el pensamiento económico y sugiere que diferenciar entre los hábitos rutinarios y los aspectos socializados del comportamiento habitual puede proporcionar una herramienta adicional útil para el análisis de políticas institucionales. En concreto, Waller (1988) señala que en las empresas y en término general en las economías, la existencia de comportamientos continuados basados en la falta de reflexión puede ser un serio inconveniente ya que algunas empresas se ven ancladas al pago dividendos porque es difícil cambiar unos hábitos arraigados. Miller (1986) sostiene que la consideración de 
elementos ligados al comportamiento para explicar la política de dividendos es natural pues aparecen muchas anomalías que al ser analizadas pueden llevar a la interpretación errónea de la evidencia empírica. Estos autores afirman que en la medida que la conducta afecta a las decisiones sobre dividendos, las implicaciones son relevantes sólo para los inversores individuales quienes invierten directamente cantidades moderadamente reducidas. También abordando aspectos de percepción y psicológicos, para Cyert y March (1993) los dividendos son percibidos como un valor seguro y sostienen que los inversores prefieren el pago de dividendos, a la rentabilidad o posibles ganancias retenidas porque intentan evitar incertidumbres. Esto es solamente un fenómeno psicológico porque los inversores podrían obtener el mismo rendimiento para el consumo mediante la venta de sus acciones. Según Allen y Michaely (2003), si un inversor quiere recibir un ingreso regular y fijo puede elegir entre dos alternativas: La primera es, comprar acciones que paguen dividendo, y la segunda es, comprar acciones que no pagan dividendo y vender parte de su cartera de acciones de una forma regular y programada.

\section{Consideraciones adicionales}

Frankfurter y Wood (1997) afirman sobre la política de dividendos lo siguiente: "no puede ser modelada matemáticamente y uniformemente para todas las empresas siempre", dado que las imperfecciones afectan diferentemente a las empresas; así, la política de dividendos puede variar sustancialmente de una empresa a otra. Por lo tanto, no todas las empresas deben tener la misma política de distribución de dividendos. Así, otros estudios, como Fama y French (2001) observan una disminución considerable en el porcentaje de empresas estadounidenses que pagan dividendos entre 1980 y 1990. Mientras que el 66,5\% de las empresas no financieras de NYSE, AMEX, y Nasdaq pagaban dividendos en 1978, sólo el 20,8\% lo hizo en 1999. Otra tendencia bien documentada era la reducción drástica de la rentabilidad por dividendo. Por ejemplo, entre 1980 y 2000, la rentabilidad por dividendo de las empresas S\&P 500 descendió de $5,4 \%$ a $1,1 \%$, y el porcentaje de ganancias que las empresas dedicaban al pago dividendos alcanzó un mínimo histórico. En este estudio encontraron además tres características que afectan la decisión de pagar dividendos: tamaño, oportunidades de inversión y rentabilidad. Aunque independientemente a éstas, las empresas eran menos propensas a pagar dividendos. Von Eije y Megginson (2006) también observaron un descenso en la proporción de dividendos pagados por empresas de quince países de la Unión Europea entre los años 1989 y 2003. Después de analizar las oportunidades de crecimiento, rentabilidad y tamaño, encontraron que el número de dividendos que pagaban era menor de lo esperado. 
Otros autores, ahondan en la cuestión de ausencia de linealidad en el pago de dividendos, como es el caso de Baker y Wurgler (2002) quienes sostienen que a lo largo de la historia los dividendos han desaparecido y reaparecido mostrando evidencia de una falta de consistencia en cuanto a su importancia. Además, más allá de los posibles efectos inherentes a las crisis de los mercados, éstos se caracterizaron por una movilidad de los inversores observada hacia las empresas que precisamente distribuyen dividendos. Así, en el análisis de Brav et al. (2005) se realizaron entrevistas a casi 400 directores financieros de empresas estadounidenses con respecto al objetivo de su política de dividendos. Una minoría del $28 \%$ afirma que los define en un porcentaje en base al beneficio obtenido, mientras que la gran mayoría en términos de dividendo por acción o de crecimiento. Por lo tanto, aunque la política de dividendos sigue estando definida a largo plazo, en sintonía con la encuesta de Lintner, parece que en la actualidad existen objetivos adicionales y que los directivos no se ajustan de manera tan estricta a los mismos.

Desde el punto de vista teórico, DeAngelo y DeAngelo (2006) se posicionan contrarios al teorema de la irrelevancia de MM mostrando que esta proposición está basada en ciertos supuestos, y que no es el resultado de un análisis realista. MM sólo consideran en su modelo las políticas de dividendos óptimas, es decir, aquellas que distribuye el $100 \%$ de los flujos libres de caja (FLC) en todos los períodos, excluyendo aquellas políticas de dividendos no óptimas, consistentes en un reparto inferior a la totalidad de los FLC, pero que también pueden afectar al valor de la empresa. DD afirman que MM derivan su conclusión textual de que "sólo la política de inversión es importante" en base a esta restricción artificial, que fija la política de dividendos en un grado óptimo. Esa es la razón por la que sólo la política de inversión afecta al valor, en el modelo de MM. Ante una relajación de los supuestos de MM que permite la retención de los FLC, la elección de la política de dividendos ya no es irrelevante, porque es posible que los directivos puedan elegir una política de dividendos que destruya el valor creado por las decisiones de inversión. Así, DeAngelo y DeAngelo (2006) concluyen que tanto la política de dividendos como la de inversión afectan al valor de la empresa ya que de ellas dependen los flujos de efectivo, que son percibidos por los accionistas, y son éstos los que determinan el valor de la empresa.

En la misma línea de investigación, varios autores sostienen que el equilibrio entre retención y distribución de beneficios, tiende a cambiar durante el ciclo de vida de la empresa, y así la política de dividendos debe reflejar esta evolución. Entonces, Grullon y Michaely (2002), y DeAngelo et al. (2006), entre otros autores, señalan que los dividendos tienden a ser pagados por las empresas consolidadas o maduras debido a que tienen una mayor rentabilidad y menos oportunidades de inversión atractiva, mientras 
que las empresas jóvenes se enfrentan a oportunidades de inversión relativamente abundantes con recursos limitados por lo que la retención de beneficios domina a la distribución. Al-Malkawi (2007) afirma que las empresas que se encuentran en su etapa de crecimiento, tienden a pagar un dividendo menor y atraen a unos inversores que desean plusvalías, mientras que las empresas que se encuentran en etapa de madurez, pagan dividendos más altos y atraen a un perfil de inversores que prefieren un ingreso inmediato en forma de dividendos. Al-Malkawi (2007), distingue el efecto clientela entre: i) los inversores que son atraídos por efectos fiscales y argumenta que los inversores que hacen frente a altos impuestos prefirieren aquellas empresas que pagan pocos o ningún dividendo para obtener rentabilidad a través del precio; y ii) los inversores que son atraídos por el nivel de los costes de transacción, y sugiere que en el caso de los pequeños inversores, éstos dependen del pago de dividendos para satisfacer sus necesidades y prefieren empresas que satisfacen esta necesidad porque no pueden pagar los altos costes de transacción de la venta de sus acciones.

Otros aspectos ligados al argumento del pago de dividendos consideran el contexto de reciente crisis económica que ha implicado un notable aumento de pérdidas entre las empresas, así Hoberg y Prabhala (2009) concluyen que los cambios en el riesgo sistemático e idiosincrásico del mercado, que aumentan con la volatilidad futura, pueden explicar el comportamiento en el pago de dividendos. Además, Lie (2005) confirma que las empresas que históricamente han experimentado una alta volatilidad en los ingresos tienden a no pagar dividendos. Por otro lado, también existe una creciente literatura que estudia el movimiento conjunto entre los mercados de acciones y bonos, como los trabajos de Baele et al. (2010) y Campbell et al. (2013) que enfatizan la importancia del tiempo como variable y sobre su naturaleza en las correlaciones entre el mercado de acciones y el mercado de bonos.

Recientemente, Procianoy y Vancin (2014) abordan los factores que influyen en el pago de dividendos desde una nueva perspectiva, teniendo en cuenta una visión legal y contractual al respecto. Estos autores diferencian las empresas que sólo distribuyen los dividendos estrictamente obligatorios para el cumplimiento de la legislación y de sus estatutos, de entre las empresas que los pagan por encima de los mínimos establecidos, valiendo como señal al mercado de que esta decisión fue tomada en base a criterios propios. Por otro lado, Inyiama et al. (2015) consideran que, bajo el supuesto de un mercado perfecto, son los inversores quienes crean dividendos mediante la disposición de sus acciones y, por lo general, a un mínimo coste; con lo cual la política de dividendos es muy irrelevante y poco atractiva. 
A nivel nacional y distinguiendo entre otros países podemos destacar el estudio de Giner y Fumás (1995), en el cual los autores observan que la política de dividendos de las empresas es relativamente rígida según el modelo propuesto por Lintner (1956), pero se rechaza claramente que sea insensible a cambios de las condiciones económicas que desenvuelven a la empresa, además sugieren que las empresas que tengan entre su accionariado a bancos tendrán significativamente una política de dividendos más estable, reduciendo la necesidad de utilizar la política de dividendos para enviar señales al mercado. La presencia de bancos entre el accionariado de una compañía facilita la comunicación entre acreedores financieros y gestores, disminuyendo los problemas de asimetría de la información. Además, Díez y López (2001) afirman que las empresas ajustan parcialmente su política de dividendos en función de su situación económicofinanciera y de sus políticas tanto de inversión como de financiación. Otros autores, como García-Borbolla y Larrán (2005), entre otros, confirman en sus resultados que, en general, hay que atribuir importancia a las variables clásicas propuestas por Lintner (1956) en Holanda, Reino Unido, Alemania, España, Francia, Italia y Suiza, evidenciando que la liquidez, salvo en Reino Unido, y el endeudamiento, salvo en Alemania y Holanda, no ejercen influencia alguna sobre el volumen de dividendos repartidos. Sin embargo, sí que se observa la importancia de los dividendos como señales que se envían al mercado para los casos de Holanda y Reino Unido, países de influencia anglosajona, y en Francia e Italia, países de influencia continental, pero no en España. Posteriormente, Palacín-Sánchez (2007) observa que muy frecuentemente las empresas cotizadas españolas definen su objetivo en política de dividendos en términos de tasa de reparto. Sánchez y di Pietro (2011) aprecian una relación significativa y positiva, para las empresas cotizadas españolas durante el período 1995- 2004, entre los cambios en la política de dividendos y los cambios en las ganancias, apoyando la hipótesis del valor informativo de los dividendos. 


\subsection{Metodología}

\subsubsection{Estrategias de inversión basadas en dividendos}

Para contrastar empíricamente la hipótesis del dividend puzzle, se plantea la creación de dos carteras de inversión, la primera formada por las empresas que más dividendos distribuyen del Ibex 35 y la segunda con las que menos dividendos distribuyen, para seguidamente proceder a estudiar cuál de las dos ha obtenido una mayor rentabilidad. Se incluyen las dos hipótesis siguientes para simplificar la confección de las carteras y el cálculo de las rentabilidades: i) ausencia de impuestos y ii) negociabilidad y divisibilidad de todos los activos, pudiéndose negociar libremente y sin regulaciones restrictivas.

El primer paso en el proceso de formación de las carteras de inversión es la ordenación de los valores que componen el Ibex 35, cada año del período muestral, en función de su rentabilidad por dividendo y de mayor a menor.

A continuación, se introduce la terminología utilizada en el presente trabajo:

D $+=$ Cartera formada por los activos que presentan una mayor rentabilidad por dividendo.

D- = Cartera formada por los activos que presentan una menor rentabilidad por dividendo ${ }^{2}$.

Es reseñable que para la selección de los activos que forman la cartera $\mathrm{D}+$, en el período $\mathrm{t}$, se eligen las $7^{3}$ empresas que hayan obtenido una mayor rentabilidad por dividendo en el período $t-1$, que serán las que compondrán la cartera de inversión $\mathrm{D}+$. Así, dado que los 7 valores que forman la cartera de inversión vienen determinados por la rentabilidad del período $t$-1, y el período muestral considerado es de 1999 a 2014, el primer año de formación de la cartera de inversión será el año 2000.

El siguiente paso es el establecimiento de la inversión inicial en cada una de ellas, dado que cada cartera está compuesta por 7 valores se ha decidido invertir 7.000 euros por

${ }^{2}$ El índice Ibex 35 se caracteriza por el elevado número de empresas del mismo que distribuyen dividendos, esta peculiaridad ha obligado a flexibilizar el criterio de formación de la cartera D-, pasando de estar formada únicamente por las empresas que no distribuyen dividendos a estar formada por empresas que no distribuyen o que los distribuyen en menor medida.

${ }^{3}$ Se han elegido 7 valores para la formación de cada una de las carteras porque el Ibex 35, como su propio nombre indica, está compuesto por 35 valores, y el valor 7 representa el quintil del índice. 
cartera, es decir, 1.000 euros por valor. Por lo tanto, cada cartera está equiponderada, es decir, todos los valores tienen el mismo peso específico dentro de la misma. Por otro lado, para determinar el precio de compra para cada valor se toma el precio de cierre del primer día hábil de cotización del período $t$. A modo de ejemplo, puede observarse la composición de la cartera D+ a fecha 3 de enero del 2000 en el Cuadro 2.1. Merece especial mención que unas de las hipótesis de trabajo inicialmente planteada es la divisibilidad de los activos.

\section{Cuadro 2.1: Composición inicial de la cartera D+}

Este cuadro muestra la composición inicial de la cartera D+, el 3 de enero del año 2000.

\begin{tabular}{lcc}
\hline Activo & Ticker & Rentabilidad por dividendo \\
\hline Banco Bilbao Vizcaya & BBV & $5,01 \%$ \\
Acerinox & ACX & $3,70 \%$ \\
Banco Popular & POP & $2,99 \%$ \\
Iberdrola & IBE & $2,73 \%$ \\
Amper & AMP & $2,53 \%$ \\
Bankinter & BKT & $2,52 \%$ \\
Uralita & URA & $2,42 \%$ \\
\hline
\end{tabular}

Fuente: Programa NetStation de Infobolsa.

Convenientemente, para la creación de la cartera D-, el proceso coincide pero se aplica el criterio contrario. Específicamente, se eligen las 7 empresas que hayan obtenido una menor rentabilidad por dividendo en el período $t-1$, y una vez identificadas se procede a la composición de la cartera de inversión D-. El resultado se muestra en el Cuadro 2.2.

\section{Cuadro 2.2: Composición inicial de la cartera D-}

Este cuadro muestra la composición inicial de la cartera D-, el 3 de enero del año 2000.

\begin{tabular}{lcc}
\hline Activo & Ticker & Rentabilidad por dividendo \\
\hline Catalana de Gas & CTG & $0,56 \%$ \\
Fomento de Construcciones y Contratas & FCC & $0,48 \%$ \\
Viscofán & VIS & $0,33 \%$ \\
Corporación Financiera Alba & ALB & $0,28 \%$ \\
NH Hoteles & NHH & $0,00 \%$ \\
Sol Meliá & SOL & $0,00 \%$ \\
Telefónica & TEF & $0,00 \%$ \\
\hline
\end{tabular}

Fuente: Programa NetStation de Infobolsa.

Ambas carteras se exponen a un proceso de reestructuración anual, siendo liquidadas el último día del período $t$ - 1 , para ser reconstruidas el primer día del período $t$ con una nueva selección de activos (basada en los mismos criterios de selección expuestos anteriormente). Como se ha anunciado anteriormente, una de las hipótesis de trabajo es 
la ausencia de costes de transacción incluyendo los gastos de custodia, gestión y otros, que sí que repercuten en el cálculo del valor liquidativo de un fondo de inversión. Por lo tanto, el valor liquidativo $(t-1)$ de cada una de las carteras coincidiría con el nuevo valor de inversión $(t)$. Y así sucesivamente el proceso se repetirá durante todo el período muestral.

Se define el valor liquidativo como el sumatorio del valor de todos los activos que componen la cartera calculado con los precios de cierre. Así,

$$
\text { Valor Liquidativo }=\sum_{n=1}^{n}\left(P_{i t} N_{i}\right)
$$

Donde:

$P_{i t}=$ Precio de cierre del activo $i$ valorado el último día hábil de cotización

$N_{i}=$ Número de acciones del activo $i$

El precio de cierre de cada activo es ajustado por: dividendos, ampliaciones de capital, reducciones de capital, splits y contrasplits.

Como se ha comentado anteriormente las carteras de inversión se revisan y reestructuran anualmente según los criterios establecidos, pero el seguimiento de las mismas se realizará de forma mensual a través de la evolución de sus valores liquidativos, considerando como precio de cierre el del último día hábil de cotización de cada mes.

\subsubsection{Medidas de evaluación de resultados}

Para poder inferir la existencia del dividend puzzle en el mercado español se van a formar carteras basadas en su nivel de rentabilidad por dividendos y luego se analizarán sus resultados, tanto el rendimiento como su performance o eficiencia. La metodología de formación de carteras ha estado muy extendida en la literatura financiera y desde Carhart (1997) ha sido frecuente la formación de carteras de una forma dinámica bajo algún criterio o característica para luego finalmente evaluar los resultados obtenidos por dichas carteras y así contrastar el efecto de dicho criterio o característica. 
Para Matallín y Fernández (1999) la gestión de una cartera no se debería medir únicamente por su rentabilidad, sino también por el riesgo asociado a dicha cartera para conseguir esa rentabilidad, por ello es necesario realizar un estudio exhaustivo de los resultados obtenidos, es decir, estudiar la performance o eficiencia de la cartera mediante el análisis de la estructura y composición de sus resultados (Suárez, 1986). Para ello se utilizarán medidas de performance, que se pueden definir como las expresiones que relacionan el binomio rentabilidad/riesgo, ofreciendo un valor con el que poder comparar diferentes carteras de inversión. El origen de las medidas de performance, se puede encontrar en la década de los 60, en los trabajos de Treynor (1965), Sharpe (1966) y Jensen (1968). Treynor toma el exceso de rentabilidad de una cartera (medido como la rentabilidad bruta menos la correspondiente tasa libre de riesgo) y lo divide por la beta de la cartera. Sharpe al contrario divide el exceso de rentabilidad por la desviación típica de la cartera. Así, mientras que Treynor se centra en el riesgo sistemático o no diversificable de una cartera, Sharpe se enfoca en el riesgo total medido por la desviación típica de la rentabilidad. Jensen a diferencia de los anteriores se centra en la rentabilidad anormal, definida como aquella obtenida en exceso sobre la rentabilidad esperada según el modelo CAPM. El modelo CAPM es un modelo de valoración de activos desarrollado principalmente por Sharpe (1964), Lintner (1965) y Mossin (1966), basado en los trabajos anteriores de Harry Markowitz sobre la diversificación y la teoría moderna de carteras. Aportaciones posteriores de Black (1972) han contribuido a que sea también conocido como modelo Sharpe-Lintner-Black. En este sentido, el alfa de Jensen o performance de la cartera se identifica con la constante $\alpha_{p}$ del modelo (2),

$$
R_{p t}-R_{f t}=\alpha_{p}+\beta_{p}\left(R_{m t}-R_{f t}\right)+\varepsilon_{p t}
$$

donde $R_{p t}$ representa la rentabilidad de la cartera $p, R_{f t}$ refleja la rentabilidad del activo libre de riesgo, $\beta_{p}$ se asocia al riesgo sistemático o de mercado de la cartera $p$, tal como se define en la expresión (3),

$$
\beta_{p}=\frac{\operatorname{Cov}\left(R_{p t}, R_{m t}\right)}{\operatorname{Var}\left(R_{m t}\right)}
$$

por último, $R_{m t}$ representa la rentabilidad del mercado y $\varepsilon_{p t}$ el término de error del modelo.

Para el modelo CAPM, en el cual se basa el alfa de Jensen, cierta evidencia empírica ha demostrado que las rentabilidades medias a largo plazo están significativamente 
relacionadas con la beta, pero en contraposición han aparecido estudios que muestran casos en que el modelo no parece aportar una adecuada medición. Algunos de estos casos son las empresas pequeñas que presentan rentabilidades superiores a las que el modelo predice y las empresas con bajo valor contable que han tenido una rentabilidad significativamente mejor a la esperada. En base a esto Fama y French (1993) desarrollan un modelo lineal con dos factores adicionales SMB (Small Minus Big) y HML (High Minus Low) para explicar la rentabilidad de los activos. En consecuencia, el modelo (4) también puede utilizarse para evaluar la eficiencia de una cartera, donde la constante tiene una interpretación similar a la existente para el alfa de Jensen, pero ahora habiendo ajustado el riesgo no sólo a un factor de riesgo, sino a tres factores.

$$
R_{p t}-R_{f t}=\alpha_{p}+\beta_{p, m}\left(R_{m t}-R_{f t}\right)+\beta_{p, s m b} R_{s m b, t}+\beta_{p, h m l} R_{h m l, t}+\varepsilon_{p t}
$$

El modelo tradicional de valoración de activos, CAPM utiliza una sola variable para describir el rendimiento de una cartera con los rendimientos del mercado, en contraste, el modelo de Fama-French añade dos variables más para reflejar la exposición de la cartera a estos dos factores. Así, $R_{s m b, t}$ o factor tamaño, formado por la diferencia de rentabilidad entre carteras de acciones pequeñas y carteras de acciones grandes. El factor $R_{h m l, t}$ formado por la diferencia de rentabilidad entre carteras con acciones de mayor valor (alto ratio entre valor contable y valor bursátil) y acciones de menor valor o en crecimiento (bajo ratio entre valor contable y valor bursátil).

Aunque las carteras de inversión se reestructuraran anualmente, el seguimiento de las mismas se hace de forma mensual, por consiguiente se deben aplicar datos mensuales a ambos modelos para su cálculo. La expresión (5) muestra el cálculo de la rentabilidad de la cartera,

$$
R_{p t}=\frac{\text { Valor Liquidativot }- \text { Valor Liquidativot }-1}{\text { Valor Liquidativot }-1}
$$




\subsection{Datos}

\subsubsection{Muestra y período de análisis}

Los datos utilizados en esta investigación son el resultado de un exhaustivo proceso de búsqueda, recopilación y selección a través del programa de e-trading de mercados financieros NetStation de Infobolsa, así como del operador Bolsas y Mercados Españoles (BME) que centraliza todos los mercados de valores y sistemas financieros españoles.

A diferencia de otros países, en España no existe una única bolsa donde cotizan todas las empresas, sino que existen las cuatro bolsas siguientes: Madrid, Barcelona, Bilbao y Valencia. El mercado continuo español es un mercado electrónico que comunica de forma directa a las cuatro plazas españolas a través del Sistema de Interconexión Bursátil Español (SIBE). Este sistema asegura un único punto de liquidez por valor y facilita una comunicación directa y en tiempo real entre las Bolsas. De esta manera se forma un único precio y un único libro de órdenes por valor, permitiendo la difusión automática de toda la información de la contratación.

Actualmente el mercado continuo español está compuesto por casi ciento cincuenta empresas cotizando. Dentro del mismo hay varios índices de referencia como: El Ibex 35, el Ibex Medium Cap, Ibex Small Cap, Ibex Top Dividendo e índices sectoriales, entre otros. Pero sin lugar a dudas el más significativo es el Ibex 35, el principal índice bursátil de referencia de la bolsa española, usado como referente nacional e internacional y subyacente en la contratación de productos derivados. Este índice principal está compuesto por los 35 valores de mayor liquidez de entre los cotizados en el Sistema de Interconexión Bursátil de las cuatro Bolsas Españolas. Técnicamente es un índice de precios, ponderado por capitalización bursátil (al contrario que el Dow Jones que todas las empresas que lo forman tienen el mismo peso) y ajustado por el capital flotante de cada compañía integrante del mismo. El capital flotante hace referencia al número de títulos efectivamente en circulación en el mercado, es decir, que no pertenecen a una participación directa considerada de control (capital cautivo y, por tanto, no circulante en el mercado). La ponderación máxima admitida en las revisiones del índice para un componente es del 20\%. Actualmente las empresas con mayor capitalización bursátil, es decir, con mayor ponderación dentro del índice son: Banco Santander, Telefónica, BBVA, Inditex, Iberdrola y Repsol.

Las inclusiones y exclusiones de valores dentro del índice vienen determinadas por un comité de expertos denominado Comité Asesor Técnico (CAT). Este comité se reúne normalmente dos veces al año (junio y diciembre) y las actualizaciones se hacen 
efectivas el primer día hábil de julio y el primer día hábil de enero de cada año. Aunque también podrían celebrarse reuniones extraordinarias si se produjeran circunstancias extraordinarias, como por ejemplo una OPA, entre empresas que forman parte del índice.

Existen dos condiciones para incorporar un valor al Ibex 35: la primera es que su capitalización media computable en el índice deberá ser superior al 0,30\% de la capitalización media del índice durante el período de control; la segunda es que haya sido contratado por lo menos en la tercera parte de las sesiones de ese período. No obstante, de no cumplirse dicha condición, la empresa también podría ser elegida para formar parte del índice si estuviese entre los 20 valores con mayor capitalización. Dado todo lo expuesto y el exhaustivo control al que son sometidas las empresas que lo componen, ya sea por BME, la CNMV o por los propios mercados, serán las empresas del Ibex 35 las que servirán de base para nuestra investigación. A partir de la composición inicial del Ibex 35 así como la consideración de las sucesivas inclusiones y exclusiones de las compañías dentro del mismo, se elabora la composición inicial del índice para el primer día de cotización de cada año. Se observa que un gran número de compañías han sido sometidas a OPAs, algunas han sido absorbidas, otras se han fusionado o simplemente han desaparecido y no es hasta el año 2000 cuando el índice empieza a presentar cierta estabilidad en su composición. De ahí que se tenga en consideración como período muestral para nuestra investigación: desde enero de 1999 hasta junio de 2014, e incluir únicamente en la composición del índice las empresas que estén actualmente en cotización. Tras aplicar estos criterios, la muestra resultante está compuesta por cincuenta y dos empresas, tal como se puede apreciar en el Cuadro 2.3. 
Cuadro 2.3: Muestra de empresas objeto del estudio

Este cuadro contiene las cincuenta y dos empresas que forman nuestra muestra distribuidas por sectores básicos.

\begin{tabular}{ccc}
\hline Petróleo y Energía & Mat.Basicos, Industria y Construcción & Bienes de Consumo \\
\hline ENAGAS & ABENGOA CLASE A/B & EBRO FOODS \\
ENDESA & ACCIONA & GRIFOLS CLASE A \\
GAS NATURAL SDG & ACERINOX & INDITEX \\
IBERDROLA & ACS & VISCOFAN \\
RED ELECTRICA & ARCELORMITTAL & \\
REPSOL & ERCROS & \\
& FCC & \\
& FERROVIAL & \\
& GAMESA & \\
& OHL & \\
& SACYR & \\
& TECNICAS REUNIDAS & TUBACEX \\
URADEUS \\
Uervicios de Consumo & URALITA & AMPER \\
ABERTIS & Servicios Financieros e Inmobiliarios & Tecnología y Telecomunicaciones \\
ATRESMEDIA & BANCO POPULAR & INDRA \\
DIA & BANCO DE SABADELL & JAZZTEL \\
IAG & BANCO SANTANDER & TELEFONICA \\
MEDIASET ESPAÑA & BANKIA & \\
MELIA HOTELS & BANKINTER & \\
NH HOTEL GROUP & BBVA & \\
PRISA & BOLSAS Y MERCADOS ESPANOLLES & \\
SPS & CAIXABANK & \\
POSEGUR & COLONIAL & \\
& CORPORACION FINANCIERA ALBA & MAPFRE \\
\hline
\end{tabular}

Fuente de los datos: Bolsa de Madrid.

Además, como se puede observar en el Cuadro 2.3, los sectores predominantes en la economía española de las últimas décadas han sido la industria y la construcción, con el $27 \%$ del total de las empresas, seguidos por los servicios financieros e inmobiliarios con el $21 \%$, es decir, a nivel agregado estos dos sectores representan casi la mitad de la muestra.

Así, para nuestro estudio se utiliza el Ibex 35, pero además se toma también como referencia el Ibex 35 con dividendos que se compone de los mismos valores, ajustes y criterios de cálculo que el Ibex 35, añadiendo un ajuste técnico. Éste consiste en la reinversión en el propio índice de los pagos de dividendos ordinarios $\mathrm{u}$ otras retribuciones a los accionistas asimilables al pago de éstos.

\subsubsection{Rentabilidad por dividendo}

El Cuadro 2.4 muestra varios estadísticos descriptivos de los dividendos pagados por las empresas del Ibex 35 . 


\section{Cuadro 2.4: Dividendos pagados}

Este cuadro muestra el número de empresas que componen el Ibex 35 para cada año del período muestral de enero de 1999 a diciembre de 2013, el porcentaje de las mismas que pagan dividendos, la media de dividendos pagados, la mediana, la desviación típica, el percentil $10 \%$ y el percentil $90 \%$.

\begin{tabular}{|c|c|c|c|c|c|c|c|}
\hline Año & $\mathrm{N}^{0}$ de empresas de la muestra & Distribuyen dividendos & Media & Mediana & Desviación estándar & Percentil 10\% & Percentil 90\% \\
\hline 1999 & 21 & $18(86 \%)$ & $0,4840 €$ & $0,4206 €$ & $0,4338 €$ & $0,0000 €$ & $0,8252 €$ \\
\hline 2000 & 18 & $17(94 \%)$ & $0,4277 €$ & $0,3430 €$ & $0,3454 €$ & $0,1002 €$ & $0,8790 €$ \\
\hline 2001 & 21 & $17(81 \%)$ & $0,3908 €$ & $0,3450 €$ & $0,3731 €$ & $0,0000 €$ & $0,7813 €$ \\
\hline 2002 & 22 & $18(82 \%)$ & $0,3776 €$ & $0,3104 €$ & $0,3640 €$ & $0,0000 €$ & $0,7720 €$ \\
\hline 2003 & 20 & $17(85 \%)$ & $0,4806 €$ & $0,3850 €$ & $0,4159 €$ & $0,0000 €$ & $0,9615 €$ \\
\hline 2004 & 24 & $23(96 \%)$ & $0,5540 €$ & $0,4280 €$ & $0,4070 €$ & $0,1741 €$ & $1,0540 €$ \\
\hline 2005 & 26 & $26(100 \%)$ & $0,5571 €$ & $0,4760 €$ & $0,3837 €$ & $0,2400 €$ & $1,0983 €$ \\
\hline 2006 & 26 & $26(100 \%)$ & $0,7242 €$ & $0,5575 €$ & $0,5969 €$ & $0,2122 €$ & $1,4318 €$ \\
\hline 2007 & 26 & $25(96 \%)$ & $0,8125 €$ & $0,6635 €$ & $0,6355 €$ & $0,1585 €$ & $1,4607 €$ \\
\hline 2008 & 28 & $27(96 \%)$ & $0,8679 €$ & $0,5994 €$ & $0,8323 €$ & $0,1575 €$ & $1,8640 €$ \\
\hline 2009 & 30 & $29(97 \%)$ & $1,0388 €$ & $0,6050 €$ & $1,2664 €$ & $0,1780 €$ & $2,1422 €$ \\
\hline 2010 & 32 & $31(97 \%)$ & $0,6923 €$ & $0,4591 €$ & $0,5959 €$ & $0,1301 €$ & $1,4733 €$ \\
\hline 2011 & 33 & $32(97 \%)$ & $0,8011 €$ & $0,5000 €$ & $0,7302 €$ & $0,1180 €$ & $1,8201 €$ \\
\hline 2012 & 36 & $31(86 \%)$ & $0,7230 €$ & $0,4757 €$ & $0,7454 €$ & $0,0000 €$ & $1,8840 €$ \\
\hline 2013 & 34 & $28(82 \%)$ & $0,6320 €$ & $0,3850 €$ & $0,7217 €$ & $0,0000 €$ & $1,6381 €$ \\
\hline
\end{tabular}

Fuente: Programa NetStation de Infobolsa. 
En la expresión (6) definimos la rentabilidad bruta por dividendo, $R_{B D t}$, como el cociente entre el sumatorio de los dividendos brutos recibidos en el período t, $D_{t}$ y el precio de cierre de la acción el primer día hábil de cotización del período $t, P_{t}$.

$$
R_{B D t}=\frac{D_{t}}{P_{t}}
$$

Una de las hipótesis iniciales de trabajo en la formación de las carteras de inversión era la no presencia de impuestos, por lo tanto, la rentabilidad bruta por dividendo será igual a la neta, no diferenciando en el trabajo entre ambas. Aplicando la expresión (6) obtenemos la rentabilidad por dividendos de las acciones de la muestra. El Cuadro 2.5 muestra diferentes estadísticos descriptivos.

Una vez calculada la rentabilidad anual por dividendo de cada valor, para el período $t$, se procede a ordenar los valores que componen el Ibex 35, en orden descendente en función de la rentabilidad obtenida. Es decir, las empresas que tengan una mayor rentabilidad por dividendo estarán en la parte superior, y las que menor rentabilidad por dividendo presente se posicionarán en la parte inferior. Y así se repetiría el proceso para cada año del período muestral.

Del análisis de los Cuadros 2.4 y 2.5 destacamos que el Ibex 35 es un índice que se caracteriza porque la gran mayoría de las empresas que lo componen distribuyen dividendos y por la elevada rentabilidad asociada a los mismos. En el período analizado el 92\% de las empresas del índice distribuyeron dividendos, con una rentabilidad media anual del 3,11\%, y un dividendo medio repartido por acción de $0,64 €$.

También destacamos que la rentabilidad media por dividendo antes de la reciente crisis financiera (1999-2007) era del 2,32\% y en la crisis (2008-2013) del 4,30\%, se ha incrementado un $85 \%$, frente al dividendo medio pagado que sólo ha aumentado un $48 \%$, ha pasado de $0,53 €$ a $0,79 €$ por acción. Es decir, la rentabilidad media por dividendo se ha incrementado casi el doble que el dividendo bruto medio pagado. Esto tiene su explicación en la fórmula de la rentabilidad bruta por dividendo en la cual el precio de las acciones ha disminuido significativamente por la crisis financiera, provocando que el ratio aumente en mayor porcentaje que el dividendo pagado.

Como se acaba de comentar, el Ibex 35 es un índice que se caracteriza porque la mayoría de las empresas que lo componen pagan dividendos, en nuestro período muestral una media del $92 \%$ de las empresas que lo componían los pagaban, llegando incluso al $100 \%$, en algunos años. Por lo tanto, la cartera D- no podrá estar compuesta 


\section{Cuadro 2.5: Rentabilidades por dividendo}

Este cuadro muestra el número de empresas que componen el Ibex 35 modificado para cada año del período muestral de enero de 1999 a diciembre de 2013 , el porcentaje de las mismas que pagan dividendos, la rentabilidad media por dividendo, la mediana, la desviación típica, el percentil 10\% y el percentil 90\%.

\begin{tabular}{|c|c|c|c|c|c|c|c|}
\hline Año & $N^{0}$ de empresas de la muestra & Distribuyen dividendos & Media & Mediana & Desviación estándar & Percentil 10\% & Percentil 90\% \\
\hline$\overline{1999}$ & 21 & $18(86 \%)$ & $1,63 \%$ & $1,58 \%$ & $1,37 \%$ & $0,00 \%$ & $2,99 \%$ \\
\hline 2000 & 18 & 17 (94\%) & $1,75 \%$ & $1,83 \%$ & $1,04 \%$ & $0,32 \%$ & $3,20 \%$ \\
\hline 2001 & 21 & $17(81 \%)$ & $1,84 \%$ & $1,94 \%$ & $1,40 \%$ & $0,00 \%$ & $4,01 \%$ \\
\hline 2002 & 22 & $18(82 \%)$ & $1,80 \%$ & $1,75 \%$ & $1,44 \%$ & $0,00 \%$ & $3,91 \%$ \\
\hline 2003 & 20 & $17(85 \%)$ & $2,58 \%$ & $2,36 \%$ & $1,70 \%$ & $0,00 \%$ & $4,61 \%$ \\
\hline 2004 & 24 & $23(96 \%)$ & $2,73 \%$ & $2,76 \%$ & $1,10 \%$ & $1,59 \%$ & $4,05 \%$ \\
\hline 2005 & 26 & $26(100 \%)$ & $2,88 \%$ & $2,84 \%$ & $0,97 \%$ & $1,91 \%$ & $4,13 \%$ \\
\hline 2006 & 26 & $26(100 \%)$ & $3,06 \%$ & $2,47 \%$ & $1,92 \%$ & $1,65 \%$ & $4,14 \%$ \\
\hline 2007 & 26 & $25(96 \%)$ & $2,64 \%$ & $2,66 \%$ & $1,28 \%$ & $1,11 \%$ & $4,05 \%$ \\
\hline 2008 & 28 & $27(96 \%)$ & $3,13 \%$ & $2,83 \%$ & $1,67 \%$ & $0,86 \%$ & $4,61 \%$ \\
\hline 2009 & 30 & $29(97 \%)$ & $5,87 \%$ & $5,06 \%$ & $4,00 \%$ & $2,81 \%$ & $9,27 \%$ \\
\hline 2010 & 32 & $31(97 \%)$ & $3,62 \%$ & $3,48 \%$ & $1,99 \%$ & $1,07 \%$ & $5,66 \%$ \\
\hline 2011 & 33 & $32(97 \%)$ & $4,89 \%$ & $5,33 \%$ & $2,64 \%$ & $1,66 \%$ & $7,75 \%$ \\
\hline 2012 & 36 & $31(86 \%)$ & $4,57 \%$ & $4,06 \%$ & $3,08 \%$ & $0,00 \%$ & $7,83 \%$ \\
\hline 2013 & 34 & $28(82 \%)$ & $3,74 \%$ & $3,30 \%$ & $2,81 \%$ & $0,00 \%$ & $7,19 \%$ \\
\hline
\end{tabular}

Fuente: Programa NetStation de Infobolsa. 
únicamente por empresas que no paguen dividendos, sino que también deberá estar compuesta por empresas que los paguen, por ello para aproximarse lo máximo posible a la condición de no pago de dividendos, se elegirán para su composición aquellas empresas que presenten una menor rentabilidad por dividendo.

\subsubsection{Datos factores medidas de eficiencia}

Como se ha comentado en el apartado 2.3.2 para medir la eficiencia de las carteras se han usado dos de las medidas de eficiencia más utilizadas en la literatura, el alfa de Jensen y la constante del modelo de tres factores de Fama y French. Por otro lado, para el desarrollo de los modelos emplearemos los siguientes datos:

Como activo libre de riesgo $\left(R_{f t}\right)$ se utilizará el índice AFI Repo a un día sobre deuda pública calculado en términos mensuales. Los datos se han obtenido de la empresa de asesoramiento y formación, Analistas Financieros Internacionales (AFI).

La elección de la referencia de rentabilidad del mercado adecuada es muy importante para la elaboración del capítulo ya que la utilización de una referencia equivocada puede llevar a respuestas erróneas en los análisis y las conclusiones del trabajo, por eso como referencia de la rentabilidad del mercado o benchmark, se han utilizado el Ibex 35 y el Ibex 35 con dividendos, dado que las empresas que forman las dos carteras están integradas dentro de los dos índices. La utilización de ambos está motivada con el fin de poder comparar las carteras con dos referencias diferentes, una que añada los dividendos a su cálculo como el Ibex 35 con dividendos y otra que no como el Ibex 35 . La fuente de los datos de los dos índices para el cálculo de las rentabilidades ha sido el programa NetStation de Infobolsa.

La utilización del Ibex 35 con dividendos como referencia de la rentabilidad del mercado tendrá una incidencia directa sobre el trabajo dado que el primer valor del Ibex 35 con dividendos se remonta al 30 de julio de 2003, y el primer valor liquidativo de las carteras al 3 de enero del 2000, por lo tanto, en las partes del capítulo que se utilice el Ibex 35 con dividendos como referencia el período muestral se verá reducido, del 30 de julio de 2003 al 30 de junio de 2014. El Cuadro 2.6 muestra algunos estadísticos descriptivos de estos datos.

Los factores de $S M B$ y $H M L$ para estimar el modelo de tres factores de Fama y French (1993) se han calculado siguiendo la metodología de Andreu y Sarto (2016) a partir de datos obtenidos de Morningstar. 


\section{Cuadro 2.6: Referencias de rentabilidad del mercado}

Este cuadro muestra el número de observaciones, media, media anualizada, mediana, desviación típica, percentil 10\% y percentil $90 \%$ de las referencias de rentabilidad utilizadas en el capítulo: el índice AFI Repo a un día como referencia de rentabilidad de un activo libre de riesgo, el Ibex 35 y el Ibex 35 con dividendos como referencias de rentabilidad del mercado, en términos mensuales.

\begin{tabular}{|c|c|c|c|c|c|c|c|c|}
\hline & Período muestral & Observaciones & Media & Media anualizada & Mediana & Desviación estándar & Percentil 10\% & Percentil 90\% \\
\hline AFI Repo a 1 día & De enero de 2000 a junio de 2014 & 174 & $0,18 \%$ & $2,11 \%$ & $0,17 \%$ & $0,13 \%$ & $0,01 \%$ & $0,36 \%$ \\
\hline Ibex 35 & De enero de 2000 a junio de 2014 & 174 & $0,15 \%$ & $1,77 \%$ & $0,64 \%$ & $6,03 \%$ & $-6,97 \%$ & $6,67 \%$ \\
\hline Ibex 35 con dividendos & De julio de 2003 a junio de 2014 & 131 & $0,90 \%$ & $10,78 \%$ & $1,32 \%$ & $5,77 \%$ & $-6,12 \%$ & $7,13 \%$ \\
\hline
\end{tabular}

Fuente de los datos: AFI y Programa NetStation de Infobolsa. 


\subsection{Resultados}

\subsubsection{Resultados carteras de inversión basadas en dividendos}

El proceso de evaluación y seguimiento de las dos carteras se ha realizado a través de la evolución mensual del valor liquidativo de cada una de ellas, para ello se ha procedido a actualizar mensualmente las carteras tomando como referencia el último día hábil de cotización de cada mes durante todo el período muestral.

A continuación, se ha elaborado un gráfico con la evolución de los valores liquidativos de las dos carteras:

Figura 2.1: Evolución del valor liquidativo de las carteras de inversión Gráfico de la evolución del valor liquidativo mensual de las carteras D+ y D- en el período muestral de enero de 2000 a junio de 2014. El gráfico está compuesto por 174 observaciones.

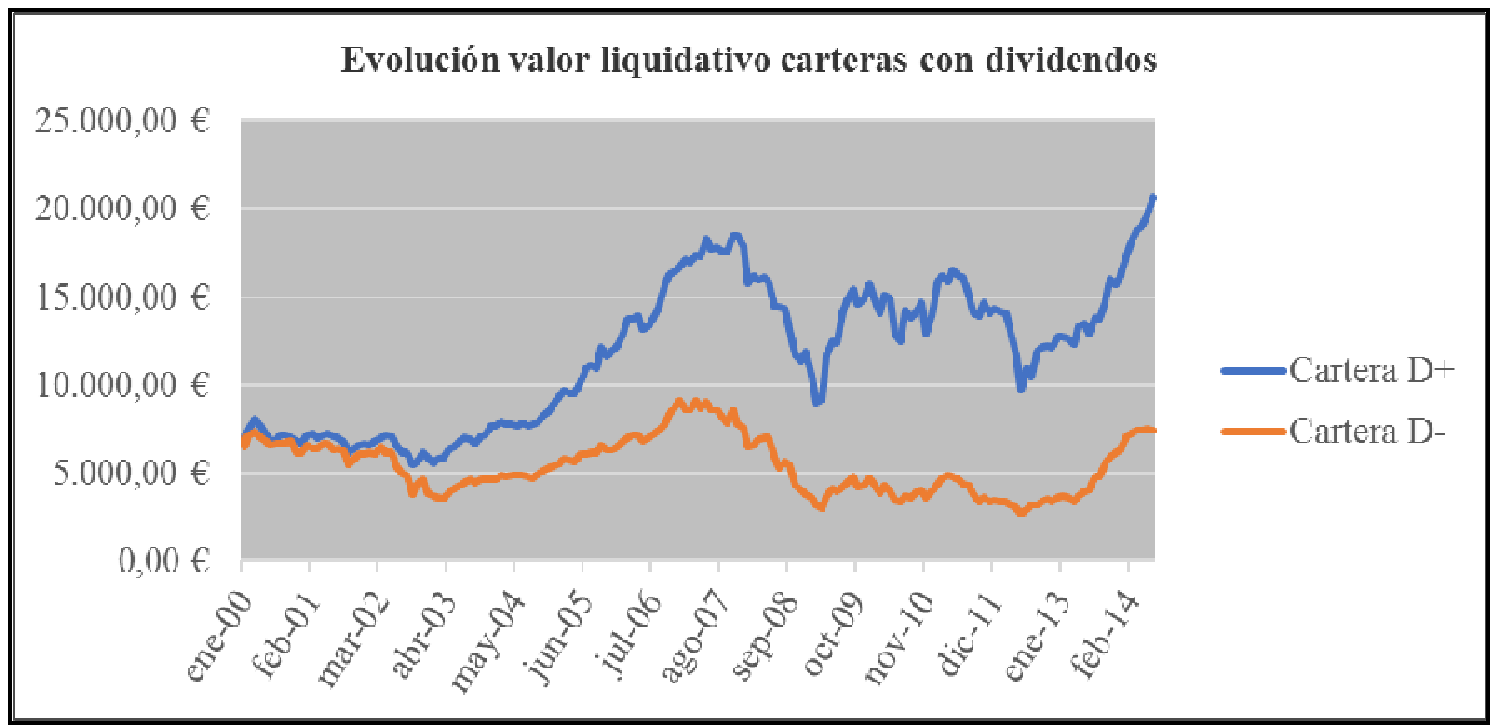

Fuente: Programa NetStation de Infobolsa.

El gráfico recoge el período comprendido entre enero de 2000 a junio de 2014 con un total de 175 observaciones o valores liquidativos por cartera. El valor liquidativo inicial para las dos carteras es el mismo, 7.000 euros, a fecha 3 de enero del 2000, que corresponde a la inversión inicial. Ésta es la única observación que se realiza el primer día hábil de cotización del mes, el resto de observaciones se toman el último día. Del gráfico se puede destacar que los valores liquidativos la cartera $\mathrm{D}+$ se posicionan siempre por encima de los de la cartera D-, durante todo el período muestral, lo que indica, que la cartera $\mathrm{D}+$ es más rentable que la D-, durante todo el período analizado.

Se observa además, que el valor liquidativo final de las dos carteras es muy significativo siendo el valor liquidativo final de la cartera D+ un 180,06\% superior al de la D-. Tal como muestra el Cuadro 2.7, la cartera D+ presenta una rentabilidad media anual del 


\section{Cuadro 2.7: Evolución de las carteras de inversión en el período muestral total}

Este cuadro muestra el valor liquidativo inicial y final de las carteras D+ y D-, para el período muestral total, de enero de 2000 a junio de 2014 , la rentabilidad media anual y total de cada una de las carteras y la descomposición de éstas en función de su origen: vía precio o vía dividendo.

\begin{tabular}{|c|c|c|c|c|c|c|c|c|}
\hline Cartera & Valor liquidativo inicial & Valor liquidativo final & Rentabilidad media anual & Vía precio & Vía dividendo & Rentabilidad total & Vía precio & Vía dividendo \\
\hline$\overline{\mathrm{D}+}$ & $7.000 €$ & $20.683,89 €$ & $13,48 \%$ & $3,13 \%$ & $10,35 \%$ & $195,48 \%$ & $45,44 \%$ & $150,04 \%$ \\
\hline D- & $7.000 €$ & $7.385,43 €$ & $0,38 \%$ & $-1,88 \%$ & $2,26 \%$ & $5,51 \%$ & $-27,30 \%$ & $32,81 \%$ \\
\hline
\end{tabular}

\section{Cuadro 2.8: Evolución de las carteras de inversión, sin dividendos, en el período muestral total}

Este cuadro muestra el valor liquidativo inicial y final de las carteras D+ y D-, excluyendo de su cálculo los dividendos, para el período muestral total, de enero de 2000 a junio de 2014, la rentabilidad media anual y total de cada una de las carteras y la descomposición de éstas en función de su origen: vía precio o vía dividendo.

\begin{tabular}{|c|c|c|c|c|c|c|c|c|}
\hline Cartera & Valor liquidativo inicial & Valor liquidativo final & Rentabilidad media anual & Vía precio & Vía dividendo & Rentabilidad total & Vía precio & Vía dividendo \\
\hline $\mathrm{D}+$ & $7.000 €$ & $10.180,78 €$ & $3,13 \%$ & $3,13 \%$ & $0,00 \%$ & $45,44 \%$ & $45,44 \%$ & $0,00 \%$ \\
\hline D- & $7.000 €$ & $5.088,68 €$ & $-1,88 \%$ & $-1,88 \%$ & $0,00 \%$ & $-27,30 \%$ & $-27,30 \%$ & $0,00 \%$ \\
\hline
\end{tabular}

\section{Cuadro 2.9: Evolución del Ibex 35 en el período muestal total}

Este cuadro muestra el valor liquidativo inicial y final del Ibex 35, para el período muestral total, de enero de 2000 a junio de 2014, la rentabilidad media anual y total. El Ibex 35 únicamente presenta rentabilidad vía precio ya que excluye de su cálculo los dividendos.

\begin{tabular}{|c|c|c|c|c|c|c|c|c|}
\hline Cartera & Valor liquidativo inicial & Valor liquidativo final & Rentabilidad media anual & Vía precio & Vía dividendo & Rentabilidad total & Vía precio & Vía dividendo \\
\hline Ibex 35 & $11.610,00$ & $10.923,50$ & $-0,41 \%$ & $-0,41 \%$ & $0,00 \%$ & $-5,91 \%$ & $-5,91 \%$ & $0,00 \%$ \\
\hline
\end{tabular}


$13,48 \%$ viniendo conducida en un $23 \%$ vía precio y en un $77 \%$ vía dividendo. La cartera D- presenta una rentabilidad positiva, pero escasa, gracias a la vía dividendo que compensa a la rentabilidad negativa obtenida por la vía precio.

A continuación, se ha eliminado el cobro de los dividendos en el cálculo del valor liquidativo de las dos carteras, obteniendo el siguiente gráfico:

Figura 2.2: Evolución del valor liquidativo de las carteras de inversión sin dividendos

Gráfico de la evolución del valor liquidativo mensual de las carteras D+ y D-, excluyendo de su cálculo los dividendos, en el período muestral total, de enero de 2000 a junio de 2014. El gráfico está compuesto por 174 observaciones.

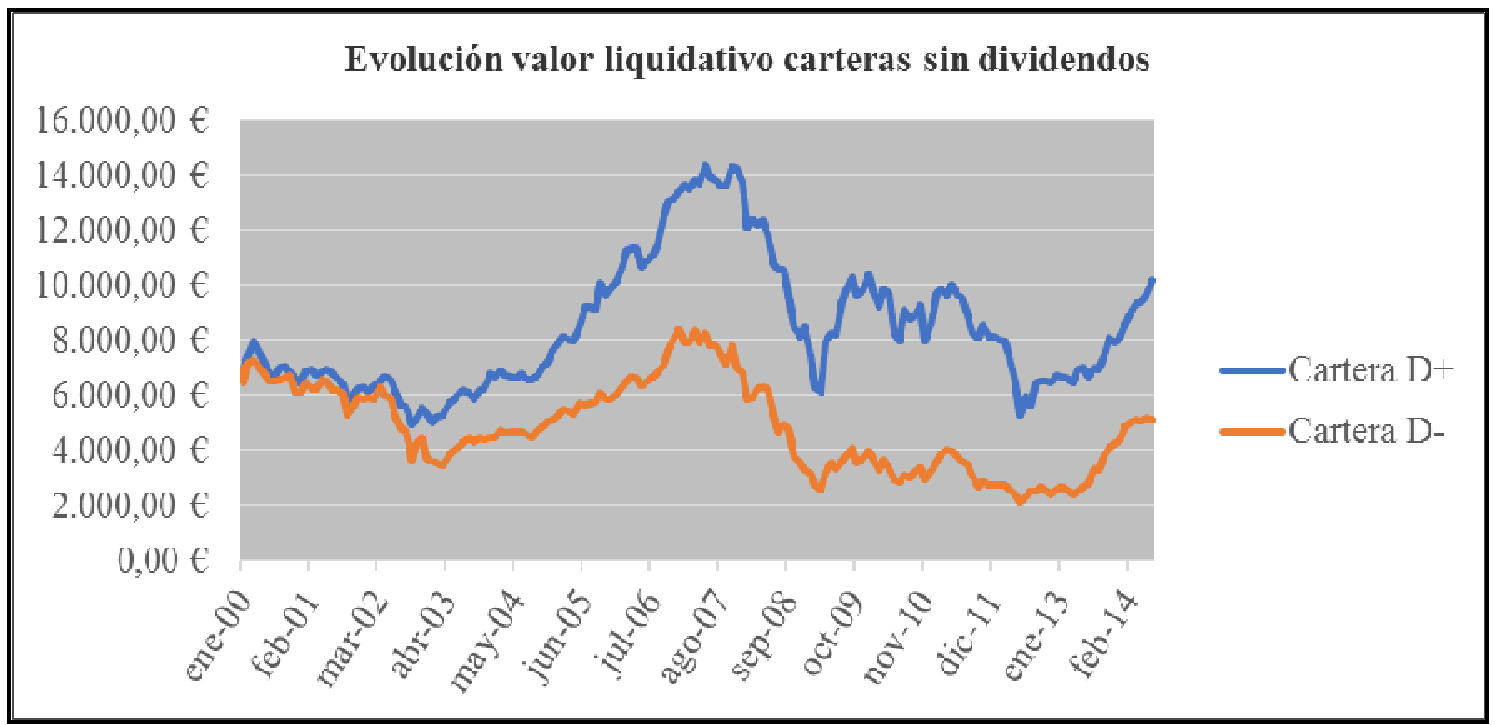

Fuente: Programa NetStation de Infobolsa.

Como era presumible la evolución de los gráficos de la Figura 2.1 y la Figura 2.2 es muy similar, la única variación de un gráfico frente a otro es que los valores liquidativos de la Figura 2.2 son inferiores a los de la Figura 2.1, al no incluir ésta en su cálculo los dividendos.

Como se puede ver en el Cuadro 2.8 el valor liquidativo final de la cartera $\mathrm{D}+$ sigue siendo superior al de la cartera D-, pero esta diferencia entre ambos valores se ha reducido, siendo ahora el de la cartera D+ únicamente el doble que el de la cartera D-. La rentabilidad media anual de la cartera D+ es del 3,13\% y la de la cartera D- del $-1,88 \%$, siendo ahora ambas iguales a la rentabilidad vía precio al haber eliminado los dividendos. La cartera $\mathrm{D}+$ no es sólo más rentable por los dividendos que distribuyen los valores que la componen sino también por la vía precio; lo cual implica que las acciones que presentan una mayor rentabilidad por dividendo tienen una mayor demanda por parte de los inversores que aquellas que no la presentan o la presentan más 
baja, obteniendo un mayor precio de cotización y, por lo tanto, unas mayores ganancias de capital en el momento de la venta. Este resultado puede interpretarse como una evidencia a favor de la existencia del dividend puzzle.

El Cuadro 2.9 muestra la rentabilidad del Ibex 35 durante el mismo período muestral que las dos carteras de inversión. En este período el Ibex 35 obtiene una rentabilidad negativa vía precio igual que la cartera D-, pero menos negativa ya que el índice no sólo está compuesto por las empresas que no pagan dividendos o los pagan en menor medida como la cartera D- sino también por las empresas que pagan y pagan más lo que hace que presente una rentabilidad superior a la cartera D-, al estar estas últimas más demandadas. Cabe recordar que el Ibex 35 excluye los dividendos de su cálculo, por lo tanto, sólo presenta rentabilidad vía precio.

Como se ha especificado en el punto anterior como referencia de mercado o benchmark se ha utilizado, además del Ibex-35, el Ibex 35 con dividendos viéndose así reducido el período muestral, por lo tanto, ahora se va a proceder a replantear los cálculos anteriores para este nuevo subperíodo.

Tal como muestra el Cuadro 2.10, en este subperíodo la rentabilidad media anual de las dos carteras ha aumentado, habiendo experimentado el incremento más significativo la cartera D- que pasa de una rentabilidad positiva del $0,38 \%$ a una del $6,02 \%$, estando ésta compuesta en un $72 \%$ vía dividendo y un $28 \%$ vía precio.

En el Cuadro 2.11 se muestran los resultados cuando no se incluyen los dividendos cobrados en las carteras. En este cuadro se aprecia que los resultados anteriores se vuelven a repetir, pero las dos rentabilidades medias de las dos carteras se han incrementado, habiéndose incrementado más la D- que pasa de rentabilidad negativa a positiva.

Para este subperíodo se obtienen los mismos resultados que en el período muestral total, aunque con unas mayores rentabilidades para las dos carteras, la cartera D+ no es sólo más rentable por los dividendos que pagan las compañías que la componen sino también porque éstas obtienen un mayor precio de cotización de sus acciones y unas mayores ganancias de capital en la venta. 


\section{Cuadro 2.10: Evolución de las carteras de inversión en el subperíodo muestral}

Este cuadro muestra el valor liquidativo inicial y final de las carteras D+ y D-, para el subperíodo muestral de julio de 2003 a junio de 2014, la rentabilidad media anual y total de cada una de las carteras y la descomposición de éstas en función de su origen: vía precio o vía dividendo.

\begin{tabular}{|c|c|c|c|c|c|c|c|c|}
\hline Cartera & Valor liquidativo inicial & Valor liquidativo final & Rentabilidad media anual & Vía precio & Vía dividendo & Rentabilidad total & Vía precio & Vía dividendo \\
\hline$\overline{\mathrm{D}+}$ & $6.982,98 €$ & $20.683,89 €$ & $17,97 \%$ & $5,94 \%$ & $12,03 \%$ & $196,20 \%$ & $64,89 \%$ & $131,31 \%$ \\
\hline D- & $4.455,76 €$ & $7.385,43 €$ & $6,02 \%$ & $1,66 \%$ & $4,36 \%$ & $65,75 \%$ & $18,08 \%$ & $47,67 \%$ \\
\hline
\end{tabular}

\section{Cuadro 2.11: Evolución de las carteras de inversión, sin dividendos, en el subperíodo muestral}

Este cuadro muestra el valor liquidativo inicial y final de las carteras D+ y D-, excluyendo de su cálculo los dividendos, para el subperíodo muestral de julio de 2003 a junio de 2014, la rentabilidad media anual y total de cada una de las carteras y la descomposición de éstas en función de su origen: vía precio o vía dividendo.

\begin{tabular}{|c|c|c|c|c|c|c|c|c|}
\hline Cartera & Valor liquidativo inicial & Valor liquidativo final & Rentabilidad media anual & Vía precio & Vía dividendo & Rentabilidad total & Vía precio & Vía dividendo \\
\hline$\overline{\mathrm{D}+}$ & $6.174,46 €$ & $10.180,78 €$ & $5,94 \%$ & $5,94 \%$ & $0,00 \%$ & $64,89 \%$ & $64,89 \%$ & $0,00 \%$ \\
\hline D- & $4.309,52 €$ & $5.088,68 €$ & $1,66 \%$ & $1,66 \%$ & $0,00 \%$ & $18,08 \%$ & $18,08 \%$ & $0,00 \%$ \\
\hline
\end{tabular}

\section{Cuadro 2.12: Evolución del Ibex 35 y del Ibex 35 con dividendos en el subperíodo muestral de julio de 2003 a junio de 2014}

Este cuadro muestra el valor liquidativo inicial y final del Ibex 35 y el Ibex 35 con dividendos, para el subperíodo muestral de julio de 2003 a junio de 2014 , la rentabilidad media anual y total de cada una de las carteras y la descomposición de éstas en función de su origen: vía precio o vía dividendo. Para el Ibex 35 sólo vía precio, ya que excluye de su cálculo los dividendos.

\begin{tabular}{|c|c|c|c|c|c|c|c|c|}
\hline Cartera & Valor liquidativo inicial & Valor liquidativo final & Rentabilidad media anual & Vía precio & Vía dividendo & Rentabilidad total & Vía precio & Vía dividendo \\
\hline Ibex 35 & $7.061,70 €$ & $10.923,50 €$ & $5,01 \%$ & $5,01 \%$ & $0,00 \%$ & $54,69 \%$ & $54,69 \%$ & $0,00 \%$ \\
\hline Ibex $35 \mathrm{D}$ & $9.755,30 €$ & $25.358,00 €$ & $14,65 \%$ & $5,01 \%$ & $9,64 \%$ & $159,94 \%$ & $54,69 \%$ & $105,25 \%$ \\
\hline
\end{tabular}


El Cuadro 2.12 muestra una comparativa entre las rentabilidades del Ibex $35 \mathrm{y}$ el Ibex 35 con dividendos para este subperíodo muestral. La rentabilidad media anual del Ibex 35 con dividendos es casi el triple que la del Ibex 35. El 34\% de la rentabilidad del Ibex 35 con dividendos procede de la vía precio, es decir del Ibex 35, y el 66\% restante de la vía dividendo. Recordemos que el Ibex 35 únicamente presenta rentabilidad vía precio, por lo tanto, la rentabilidad del Ibex 35 con dividendos será, por un lado, la propia del Ibex $35 \mathrm{y}$, por el otro, la aportada por los dividendos.

\subsubsection{Eficiencia de carteras ${ }^{4}$}

Como se ha comentado en el punto 2.3.2 anterior, para medir la eficiencia de una cartera no es suficiente con observar la rentabilidad obtenida por esta cartera, sino que también se tiene que estudiar el riesgo asociado a la misma para obtener dicha rentabilidad. Por lo tanto, para analizar este binomio rentabilidad-riesgo, así como realizar un estudio exhaustivo de los resultados obtenidos en el apartado anterior aplicaremos dos de las medidas de performance más usadas como son el alfa de Jensen en la expresión (2) y el alfa del modelo de tres factores de Fama y French del modelo (4).

En primer lugar, se estimará el alfa de Jensen y el modelo de tres factores de Fama y French usando como referencia de rentabilidad del mercado el Ibex 35. Como se observa en el Cuadro 2.13, el modelo que presenta un mejor ajuste para las dos carteras es el modelo de tres factores de Fama y French, con mayores $\mathrm{R}^{2}$. Todos los factores son significativos para los dos modelos y las dos carteras excepto el factor $H M L$ para la cartera D-.

La eficiencia de las carteras, en ambos modelos alcanza valores similares. En términos anualizados, el valor añadido para la cartera D+ oscila entre el 7,71\% (modelo de 1 factor) y el 7\% (modelo de 3 factores) y para la cartera D- los valores son respectivamente $1,66 \%$ y $1,15 \%$. Lo cual indica que la cartera compuesta por las acciones que más dividendos pagan obtendrá una rentabilidad específica por su composición muy superior a la D- compuesta por las acciones que no pagan o pagan menos. Si bien los resultados sólo son estadísticamente significativos para la cartera $\mathrm{D}+$.

En segundo lugar, se aplicará el alfa de Jensen y el modelo de tres factores de Fama y French, siendo la referencia de rentabilidad del mercado el Ibex 35 con dividendos. El

\footnotetext{
${ }^{4}$ Todas las carteras objeto de análisis incluyen el cobro de dividendos.
} 


\section{Cuadro 2.13: Alfa de Jensen y modelo de tres factores de Fama y French, considerando el Ibex 35 como factor del mercado}

Este cuadro muestra los coeficientes de regresión de los modelos del alfa de Jensen y el modelo de tres factores de Fama y French, para las carteras D+ y D-, y la diferencia entre ambas, en el período muestral total, de enero de 2000 a junio de 2014, siendo la referencia de rentabilidad del mercado el Ibex 35. La ecuación de regresión del modelo del alfa de Jensen se define en (2) y la del modelo de tres factores de Fama y French en (4).

$$
\begin{aligned}
& R_{p t}-R_{f t}=\alpha_{p}+\beta_{p}\left(R_{m t}-R_{f t}\right)+\varepsilon_{p t} \\
& R_{p t}-R_{f t}=\alpha_{p}+\beta_{p, m}\left(R_{m t}-R_{f t}\right)+\beta_{p, s m b} R_{s m b, t}+\beta_{p, h m l} R_{h m l, t}+\varepsilon_{p t}
\end{aligned}
$$

\begin{tabular}{|c|c|c|c|c|c|c|}
\hline & \multicolumn{3}{|c|}{ Alfa de Jensen } & \multicolumn{3}{|c|}{3 Factores de Fama y French } \\
\hline & D+ & D- & D+ - D- & D+ & D- & D+ - D- \\
\hline \multirow[t]{2}{*}{ Constante anualizada } & $7,71 \%$ & $1,66 \%$ & $6,05 \%$ & $7,00 \%$ & $1,15 \%$ & $5,85 \%$ \\
\hline & {$[0,0027]$} & {$[0,6643]$} & {$[0,1468]$} & {$[0,0014]$} & {$[0,7486]$} & {$[0,1409]$} \\
\hline \multirow[t]{2}{*}{$\beta_{\mathrm{p}} / \beta_{\mathrm{p}, \mathrm{m}}$} & $\mathbf{0 , 8 5 8 4}$ & 0,9569 & $-0,0986$ & $\mathbf{0 , 8 3 7 9}$ & 1,0485 & $-0,2106$ \\
\hline & {$[0,0000]$} & {$[0,0000]$} & {$[0,0874]$} & {$[0,0000]$} & {$[0,0000]$} & {$[0,0007]$} \\
\hline \multirow{2}{*}{$\beta_{\mathrm{p}, \mathrm{smb}}$} & - & - & - & 0,1414 & 0,3268 & $-0,1854$ \\
\hline & - & - & - & {$[0,0005]$} & {$[0,0000]$} & {$[0,0117]$} \\
\hline \multirow[t]{2}{*}{$\beta_{\mathrm{p}, \mathrm{hml}}$} & - & - & - & 0,2784 & $-0,0077$ & $\mathbf{0 , 2 8 6 1}$ \\
\hline & - & - & - & {$[0,0000]$} & {$[0,9067]$} & {$[0,0001]$} \\
\hline $\mathrm{R}^{2}$ & 0,7777 & 0,6575 & 0,0169 & 0,8422 & 0,7010 & 0,1199 \\
\hline
\end{tabular}

Nota: los valores entre corchetes son la probabilidad crítica (p-values). En negrita, valores significativos para un nivel de significación del 5\%. 
Cuadro 2.14: Alfa de Jensen y modelo de tres factores de Fama y French, considerando el Ibex 35 con dividendos

Este cuadro muestra los coeficientes de regresión de los modelos del alfa de Jensen y el modelo de tres factores de Fama y French, para las carteras D+ y D-, y la diferencia entre ambas, en el subperíodo muestral de julio de 2003 a junio de 2014, siendo la referencia de rentabilidad del mercado el Ibex 35 con dividendos. La ecuación de regresión del modelo del alfa de Jensen se define en (2) y la del modelo de tres factores de Fama y French en (4).

$$
\begin{aligned}
& R_{p t}-R_{f t}=\alpha_{p}+\beta_{p}\left(R_{m t}-R_{f t}\right)+\varepsilon_{p t} \\
& R_{p t}-R_{f t}=\alpha_{p}+\beta_{p, m}\left(R_{m t}-R_{f t}\right)+\beta_{p, s m b} R_{s m b, t}+\beta_{p, h m l} R_{h m l, t}+\varepsilon_{p t}
\end{aligned}
$$

\begin{tabular}{|c|c|c|c|c|c|c|}
\hline & \multicolumn{3}{|c|}{ Alfa de Jensen } & \multicolumn{3}{|c|}{3 Factores de Fama y French } \\
\hline & D+ & D- & $\overline{D+-D-}$ & $\mathbf{D +}$ & D- & D+ - D- \\
\hline Constante anualizada & $\begin{array}{c}1,51 \% \\
{[0,5424]}\end{array}$ & $\begin{array}{c}-2,87 \% \\
{[0,5305]}\end{array}$ & $\begin{array}{c}4,38 \% \\
{[0,3618]}\end{array}$ & $\begin{array}{c}3,02 \% \\
{[0,1708]}\end{array}$ & $\begin{array}{c}-3,72 \% \\
{[0,3412]}\end{array}$ & $\begin{array}{c}6,74 \% \\
{[0,1255]}\end{array}$ \\
\hline$\beta_{\mathrm{p}} / \beta_{\mathrm{p}, \mathrm{m}}$ & $\begin{array}{c}0,9959 \\
{[0,0000]}\end{array}$ & $\begin{array}{c}0,9650 \\
{[0,0000]}\end{array}$ & $\begin{array}{c}0,0309 \\
{[0,6526]}\end{array}$ & $\begin{array}{c}0,8914 \\
{[0,0000]}\end{array}$ & $\begin{array}{c}1,0430 \\
{[0,0000]}\end{array}$ & $\begin{array}{c}-0,1516 \\
{[0,0541]}\end{array}$ \\
\hline$\beta_{\mathrm{p}, \mathrm{smb}}$ & $\begin{array}{l}- \\
-\end{array}$ & $\begin{array}{l}- \\
-\end{array}$ & $\begin{array}{l}- \\
-\end{array}$ & $\begin{array}{c}0,1548 \\
{[0,0021]}\end{array}$ & $\begin{array}{c}0,6453 \\
{[0,0000]}\end{array}$ & $\begin{array}{c}-0,4905 \\
{[0,0000]}\end{array}$ \\
\hline$\beta_{\mathrm{p}, \mathrm{hml}}$ & $\begin{array}{l}- \\
-\end{array}$ & $\begin{array}{l}- \\
-\end{array}$ & - & $\begin{array}{c}0,2729 \\
{[0,0000]}\end{array}$ & $\begin{array}{c}0,0710 \\
{[0,4004]}\end{array}$ & $\begin{array}{c}0,2019 \\
{[0,0346]}\end{array}$ \\
\hline $\mathrm{R}^{2}$ & 0,8599 & 0,6283 & 0,0016 & 0,8938 & 0,7395 & 0,1981 \\
\hline
\end{tabular}

Nota: los valores entre corchetes son la probabilidad crítica (p-values). En negrita, valores significativos para un nivel de significación del 5\%. 
Cuadro 2.14 muestra que las rentabilidades obtenidas en ambos modelos presentan resultados similares al apartado anterior, es decir, con unas rentabilidades de la cartera $\mathrm{D}+$ superiores a la de la cartera D-, aunque las rentabilidades de ambas carteras se han reducido sensiblemente, incluso volviéndose negativa en la cartera D-, debido al cambio de referencia de la rentabilidad del mercado. Ello se justifica porque el Ibex 35 con dividendos presenta una mayor rentabilidad al añadir a su cálculo los dividendos pagados por las empresas y el Ibex 35 excluirlos. El ajuste de la cartera D+ sigue siendo mejor en ambos modelos, y el modelo de tres factores de Fama y French presenta un mejor ajuste que el del alfa de Jensen, aunque ninguna de las alfas de las dos carteras es significativa e igual que ocurría en el cuadro anterior, ninguna de las diferencias de rentabilidades tampoco. El coeficiente $\beta_{p, h m l}$ del factor $H M L$ para la cartera D- continúa presentando ausencia de significatividad, circunstancia ésta que se repite durante todo el trabajo. En resumen, cuando se utiliza como cartera de referencia el Ibex 35 con dividendos la performance de las carteras no es significativamente distinta de cero.

\subsubsection{Análisis de robustez en subperíodos muestrales}

Actualmente existe una amplia bibliografía sobre la crisis financiera de 2008, sus orígenes y expansión, tanto a nivel nacional como internacional. Así, Álvarez (2008) estudia la banca española y la actual crisis financiera, Alamá y Fuertes, (2009) presentan una cronología de la crisis económica tratando las debilidades de la globalización y la economía española en el contexto nacional. En el contexto internacional, Barrell y Davis (2008) analizan la evolución de la crisis durante 2007 y 2008, Acharya et al. (2009) tratan las causas y los remedios de la crisis, Demyanyk y Van Hemert (2011) observan la crisis financiera y las hipotecas subprime.

La reciente crisis financiera global tuvo su punto de origen en el año 2008 en Estados Unidos, su desencadenante fue una fuerte burbuja inmobiliaria que estalló provocando una profunda crisis crediticia e hipotecaria. El acontecimiento que marcó simbólicamente la crisis fue la quiebra de uno de los mayores bancos de inversión del mundo, Lehman Brothers, el 15 de septiembre de ese mismo año, seguido del colapso de la aseguradora AIG así como de las compañías hipotecarias Fannie Mae y Freddie Mac. El principal detonante de esta crisis fueron las llamadas hipotecas subprime que engloban a una casuística especial de hipotecas. Éstas son utilizadas para la adquisición de viviendas, destinadas preferentemente a clientes de escasa solvencia, con un nivel de riesgo de impago superior a la media, y por lo tanto, ofertadas a un tipo de interés en consonancia al riesgo subyacente. Así, el tipo de interés durante los primeros años de la 
crisis financiera se redujo notablemente con el fin de atraer a más clientes e incentivar el crecimiento económico.

Dado el elevado riesgo que conllevaban estos productos para las entidades financieras la Reserva Federal estadounidense, delimitó la concesión de estos créditos, estableciendo estrictos límites que fueron de alguna forma manipulados, sacando a la luz unos créditos opacos fuera del balance a través de la venta de la deuda en forma de bonos o titularización de créditos. El problema fue que muchos de los compradores de esa deuda desconocían el verdadero riesgo que entrañaba. Se pasó de tener en 2002 un volumen del 7\% de créditos subprime, en Estados Unidos, al 12,5\% en 2007. El problema surge cuando la reserva federal empieza a elevar los tipos de interés de forma progresiva, y por consiguiente el aumento de las cuotas de los créditos concedidos; esto hizo aumentar la morosidad y el nivel de ejecuciones, no sólo en las hipotecas subprime sino en todas las hipotecas en general. En principio se podría suponer que los impagos estaban cubiertos por el valor inmobiliario subyacente a los activos inmobiliarios, pero, como se ha comentado anteriormente, Estados Unidos estaba inmerso en una burbuja inmobiliaria y como consecuencia el precio de las viviendas estaba sobrevalorado. Ya que muchos activos inmobiliarios fueron adquiridos por mera especulación y con el estallido de la burbuja, las entidades financieras se encontraban en situación de disponer de un crédito impagado y con una garantía real (la vivienda) con valor cero o mucho menor que el del crédito concedido para su compra.

Pero no fue éste el único factor detonante de la crisis, entre otros factores podemos destacar: la inflación de las materias primas, la crisis alimentaria y energética mundialprovocada por el aumento de los precios-, la caída de la confianza en los mercados, la amenaza de recesión mundial, entre otros motivos. Dada la globalización mundial de los mercados financieros la crisis se transmitió rápidamente a Europa y, por consiguiente, a España. Europa y el Banco Central Europeo, no fueron capaces de prever la crisis y además reaccionaron con retraso y de forma poco eficiente a ella. Entre otras medidas, se llevaron a cabo políticas de austeridad y reducción del gasto público que provocaron la caída del crédito y la financiación, y por ende del consumo y la producción. Las principales medidas adoptadas por el ejecutivo europeo, el Consejo de Asuntos Económicos y Financieros (Ecofin), y el BCE, fueron garantizar los depósitos personales al menos en 50.000 euros y reducir la tasa de interés de referencia del 4,25\% al $1,25 \%$.

En España, la principal consecuencia de la crisis fue el fuerte crecimiento del nivel de desempleo, provocado especialmente por el estallido de una burbuja inmobiliaria y la caída del sector de la construcción. Precisamente, la caída del sector de la construcción, 
trajo consigo la caída del sector financiero e inmobiliario, pilares ambos del crecimiento de este país en las últimas décadas. Recordemos que el 50\% de las compañías del Ibex 35 son de los sectores de la industria y construcción, y servicios financieros e inmobiliarios y que, a finales de 2007, el 60\% de los créditos de los bancos y cajas españoles estaban ligados directamente a actividades relacionadas con la construcción. Todo ello fue caldo de cultivo para la ejecución del rescate de la banca y la nacionalización de numerosas entidades financieras: Caja Castilla-La Mancha, CajaSur, Caja Mediterráneo-CAM, Novacaixagalicia, Caixa Catalunya, Unnim y Bancaja, con cuantiosas ayudas públicas.

Un gran número de autores como: Thaler y Sunstein (2008), Shiller (2008), Shefrin (2009), entre otros, argumentan que la reciente crisis financiera global tiene su origen en factores psicológicos y no de análisis fundamental, por esto en este punto del capítulo vamos a realizar un estudio del comportamiento del dividend puzzle durante la crisis.

Son numerosos los trabajos de investigación que han diferenciado en los mercados financieros los períodos de crisis y de expansión para su estudio, como Sawicki (2009) que estudia la política de dividendos y el gobierno corporativo en el sudeste asiático en los períodos pre- y post-crisis durante el período 1994-2003, Ayadi et al. (2011) analizan los modelos de negocio bancario europeo en escenarios de pre- y post-crisis, Ben-David et al. (2012) presentan nuevas evidencias sobre el comportamiento comercial de los hedge funds durante la crisis financiera de 2007-2009, reduciendo sus participaciones accionariales, Guo (2015) observa la relación causal entre la rentabilidad bursátil y el crecimiento económico real en períodos pre- y post-crisis en China, entre otras.

En primer lugar, con ayuda del programa VisualChart (aplicación financiera de análisis bursátil) se realiza la Figura 2.3, un gráfico del Ibex 35 durante el período muestral de enero de 2000 a junio de 2014 (período de análisis de nuestras carteras de inversión) para identificar los períodos de expansión y crisis.

En el gráfico del Ibex 35, se puede distinguir cuatro tendencias principales, dos alcistas y dos bajistas, intercalándose entre sí: la primera tendencia que se identifica es una tendencia bajista desde marzo de 2000 a octubre del 2002, seguida de una tendencia alcista hasta diciembre de 2007, para luego volver a una tendencia bajista hasta julio de 2012 y finalizar con otra tendencia alcista hasta junio de 2014. Dentro del período bajista de enero de 2008 a julio de 2012, se identifica una tendencia alcista secundaria de marzo de 2009 a diciembre de 2009; pero en ningún caso pasa de ser secundaria al no poder romper la tendencia bajista principal. Pero sin duda, el punto de inflexión del 
gráfico es diciembre de 2007, éste es el punto en el cual se rompe con una tendencia alcista de más de cinco años de duración y empieza la crisis financiera global actual.

Figura 2.3: Evolución del Ibex 35 en el período muestral total

Gráfico de la evolución del Ibex 35 durante el período muestral de enero de 2000 a junio de 2014 , identificando las diferentes tendencias alcistas y bajistas que se producen en el mismo. Tendencia bajista de marzo de 2000 a octubre del 2002, tendencia alcista de octubre de 2002 a diciembre de 2007 , tendencia bajista de diciembre de 2008 a julio de 2012 y tendencia alcista de julio de 2012 hasta junio de 2014.

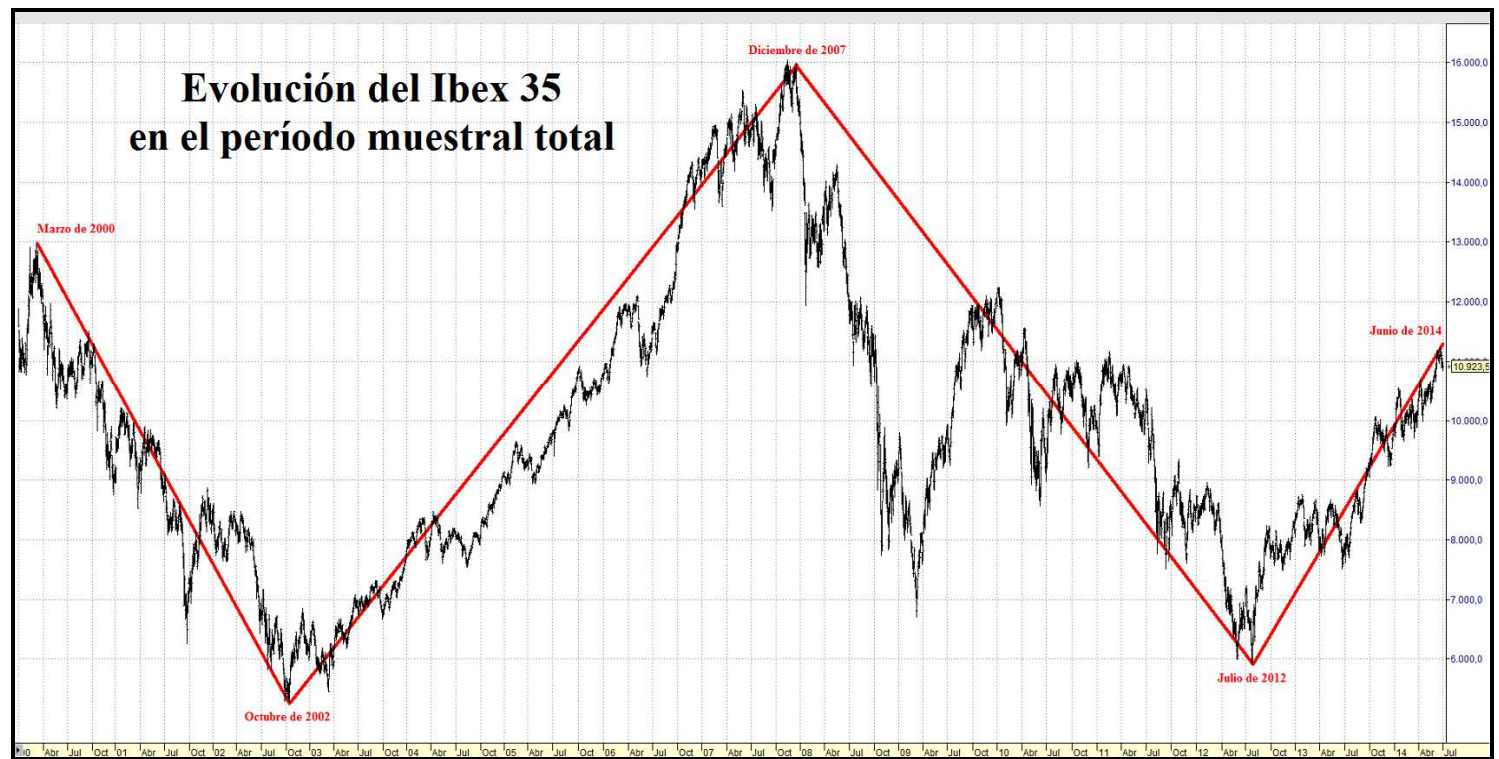

Fuente: Programa VisualChart.

Una vez analizado el gráfico del Ibex 35 se decide estudiar la evolución del dividend puzzle en períodos de expansión y de crisis a través del comportamiento de las dos carteras de inversión en el subperíodo muestral de expansión o alcista de octubre de 2002 a diciembre de 2007 y del subperíodo muestral de crisis o bajista de enero de 2008 a julio de 2012. Recordemos que el Ibex 35 con dividendos no empieza a cotizar hasta julio de 2003, lo que obliga a retrasar el comienzo del subperíodo de expansión de octubre de 2002 hasta julio de 2003.

Los Cuadros 2.15 y 2.16 muestran el comportamiento de las dos carteras de inversión, con y sin dividendos, en subperíodos de expansión y de crisis. Como se puede observar durante el período de expansión la cartera $\mathrm{D}+(35,22 \%)$ obtiene una rentabilidad media anual más del doble que la cartera D- (15,55\%), estando está compuesta en un 79\% vía dividendo y un $21 \%$ vía precio, porcentajes muy similares a los de la D-, $85 \%$ vía dividendo y un $15 \%$ vía precio. En el subperíodo de crisis la rentabilidad de ambas carteras además de reducirse hasta convertirse en negativa, se aproxima, aunque sigue presentando un mejor comportamiento la cartera $\mathrm{D}+$. En este subperíodo la rentabilidad obtenida vía dividendo ayuda a reducir los resultados negativos de la vía precio. 


\section{Cuadro 2.15: Evolución de las carteras de inversión en subperíodos muestrales de expansión y crisis}

Este cuadro muestra el valor liquidativo inicial y final de las carteras D+ y D-, para los subperíodos muestrales de expansión (de julio de 2003 a diciembre de 2007) y de crisis (de enero de 2008 a julio de 2012), la rentabilidad media anual y total de cada una de las carteras y la descomposición de éstas en función de su origen: vía precio o vía dividendo.

Expansión

\begin{tabular}{|c|c|c|c|c|c|c|c|c|}
\hline Cartera & Valor liquidativo inicial & Valor liquidativo final & Rentabilidad media anual & Vía precio & Vía dividendo & Rentabilidad total & Vía precio & Vía dividendo \\
\hline$\overline{\mathrm{D}+}$ & $6.982,98 €$ & $17.852,41 €$ & $35,22 \%$ & $27,88 \%$ & $7,34 \%$ & $155,66 \%$ & $123,11 \%$ & $32,55 \%$ \\
\hline D- & $4.455,76 €$ & $7.518,60 €$ & $15,55 \%$ & $13,21 \%$ & $2,34 \%$ & $68,74 \%$ & $58,39 \%$ & $10,35 \%$ \\
\hline \multicolumn{9}{|l|}{ Crisis } \\
\hline Cartera & Valor liquidativo inicial & Valor liquidativo final & Rentabilidad media anual & Vía precio & Vía dividendo & Rentabilidad total & Vía precio & Vía dividendo \\
\hline $\mathrm{D}+$ & $17.852,41 €$ & $10.470,08 €$ & $-9.03 \%$ & $-12.93 \%$ & $3,90 \%$ & $-41,35 \%$ & $-59,23 \%$ & $17,88 \%$ \\
\hline D- & $7.518,60 €$ & $3.129,44 €$ & $-12,75 \%$ & $-13,84 \%$ & $1,09 \%$ & $-58,38 \%$ & $-63,39 \%$ & $5,01 \%$ \\
\hline
\end{tabular}

Cuadro 2.16: Evolución de las carteras de inversión, sin dividendos, en subperíodos muestrales de expansión y crisis

Este cuadro muestra el valor liquidativo inicial y final de las carteras D+ y D-, excluyendo de su cálculo los dividendos, para los subperíodos muestrales de expansión (de julio de 2003 a diciembre de 2007) y de crisis (de enero de 2008 a julio de 2012), la rentabilidad media anual y total de cada una de las carteras y la descomposición de éstas en función de su origen: vía precio o vía dividendo.

\section{Expansión}

\begin{tabular}{|c|c|c|c|c|c|c|c|c|}
\hline Cartera & Valor liquidativo inicial & Valor liquidativo final & Rentabilidad media anual & Vía precio & Vía dividendo & Rentabilidad total & Vía precio & Vía dividendo \\
\hline $\mathrm{D}+$ & $6.174,46 €$ & $13.775,76 €$ & $27,88 \%$ & $27,88 \%$ & $0,00 \%$ & $123,11 \%$ & $123,11 \%$ & $0,00 \%$ \\
\hline D- & $4.309,52 €$ & $6.825,83 €$ & $13,21 \%$ & $13,21 \%$ & $0,00 \%$ & $58,39 \%$ & $58,39 \%$ & $0,00 \%$ \\
\hline \multicolumn{9}{|l|}{ Crisis } \\
\hline Cartera & Valor liquidativo inicial & Valor liquidativo final & Rentabilidad media anual & Vía precio & Vía dividendo & Rentabilidad total & Vía precio & Vía dividendo \\
\hline $\mathrm{D}+$ & $13.775,76 €$ & $5.615,76 €$ & $-12,93 \%$ & $-12,93 \%$ & $0,00 \%$ & $-41,35 \%$ & $-59,23 \%$ & $0,00 \%$ \\
\hline D- & $6.825,83 €$ & $2.498,94 €$ & $-13,84 \%$ & $-13,84 \%$ & $0,00 \%$ & $-58,38 \%$ & $-63,39 \%$ & $0,00 \%$ \\
\hline
\end{tabular}




\section{Cuadro 2.17: Evolución del Ibex 35 y del Ibex 35 con dividendos en los subperíodos muestrales expansión y crisis}

Este cuadro muestra el valor liquidativo inicial y final del Ibex 35 y el Ibex 35 con dividendos, para los subperíodos muestrales de expansión (de julio de 2003 a diciembre de 2007) y de crisis (de enero de 2008 a julio de 2012), la rentabilidad media anual y total de cada una de las carteras y la descomposición de éstas en función de su origen: vía precio o vía dividendo. Para el Ibex 35 sólo vía precio, ya que excluye de su cálculo los dividendos.

\begin{tabular}{|c|c|c|c|c|c|c|c|c|}
\hline Cartera & Valor liquidativo inicial & Valor liquidativo final & Rentabilidad media anual & Vía precio & Vía dividendo & Rentabilidad total & Vía precio & Vía dividendo \\
\hline Ibex 35 & $7.061,70 €$ & $15.182,30 €$ & $26,02 \%$ & $26,02 \%$ & $0,00 \%$ & $114,99 \%$ & $114,99 \%$ & $0,00 \%$ \\
\hline Ibex $35 \mathrm{D}$ & $9.755,30 €$ & $24.327,50 €$ & $33,80 \%$ & $26,02 \%$ & $7,78 \%$ & $149,38 \%$ & $114,99 \%$ & $34,38 \%$ \\
\hline Ibex 35 & $15.182,30 €$ & $6.738,10 €$ & $-12,14 \%$ & $-12,14 \%$ & $0,00 \%$ & $-55,62 \%$ & $-55,62 \%$ & $0,00 \%$ \\
\hline Ibex $35 \mathrm{D}$ & $24.327,50 €$ & $14.355,00 €$ & $-8,95 \%$ & $-12,14 \%$ & $3,19 \%$ & $-40,99 \%$ & $-55,62 \%$ & $14,63 \%$ \\
\hline
\end{tabular}


El Cuadro 2.17 muestra una comparativa entre las rentabilidades del Ibex $35 \mathrm{y}$ el Ibex 35 con dividendos para subperíodos de expansión y de crisis. Como ocurría con las carteras, aquel activo que obtiene unos mayores cobros de dividendos tiene un mejor comportamiento, el Ibex 35 con dividendos presenta una rentabilidad media anual un $30 \%$ superior en el subperíodo de expansión, y unas menores pérdidas en el subperíodo de crisis, que el Ibex 35, gracias a la vía dividendo.

Los Cuadros 2.18 y 2.19 muestran los resultados para el subperíodo de expansión de julio de 2003 a diciembre de 2007. A diferencia del período muestral total, en el subperíodo de expansión los modelos presentan un mejor ajuste cuando se utiliza como referencia de mercado el Ibex 35, continuando mostrando un mejor ajuste la cartera $\mathrm{D}+$. Las únicas alfas significativas, aunque débilmente, son las de la cartera $\mathrm{D}^{+}$, para el Ibex 35. Todos los factores son significativos excepto el $H M L$ en la cartera D- y el SMB en la $\mathrm{D}+$, con el Ibex 35 y los $S M B$ y $H M L$ en la cartera D+ y el $H M L$ en la D- con el Ibex 35 con dividendos. Además debemos destacar que el modelo de Fama y French, del Cuadro 18, presenta la única diferencia de rentabilidades significativa, aunque débil. La eficiencia de las carteras en ambos cuadros es siempre mejor para la cartera $\mathrm{D}+$ que para la cartera D-. La eficiencia en las dos carteras es menor cuando se utiliza el Ibex 35 con dividendos pero no es significativamente distinta de cero. En resumen, para este subperíodo los resultados son similares a los alcanzados para todo el período muestral.

Los Cuadros 2.20 y 2.21 nuestran los resultados para el subperíodo de crisis de enero de 2008 a julio de 2012. Los modelos presentan un mejor ajuste en el período de crisis cuando se utiliza como referencia de mercado el Ibex 35 con dividendos, igual que en el período muestral total, siendo superior el ajuste del modelo de Fama y French al de Jensen en ambas referencias de mercado y especialmente para la cartera D+ estando su $\mathrm{R}^{2}$ por encima del $90 \%$. La única alfa con una significatividad fuerte es la de la cartera $\mathrm{D}+$ para el modelo de tres factores de Fama y French utilizando como referencia el Ibex 35 , la de la cartera $\mathrm{D}+$ para el alfa de Jensen presenta una significatividad débil. Hay que destacar que con el modelo de 3 factores, la diferencia entre la cartera D+ y D- es mucho menor que anteriormente, así en el Cuadro 2.20 la performance anualizada es $9,66 \%$ y 7,36\% respectivamente para cada cartera. Por otro lado en el Cuadro 2.21 las constantes no son significativas tal como ocurría cuando se utilizaba también el Ibex 35 con dividendos en los cuadros anteriores. 


\section{Cuadro 2.18: Alfa de Jensen y modelo de tres factores de Fama y French, en subperíodo de expansión, siendo la referencia del mercado}

\section{el Ibex 35}

Este cuadro muestra los coeficientes de regresión de los modelos del alfa de Jensen y el modelo de tres factores de Fama y French, para las carteras D+ y D-, y la diferencia entre ambas, en el subperíodo muestral de expansión de julio de 2003 a diciembre de 2007, siendo la referencia de rentabilidad del mercado el Ibex 35 . La ecuación de regresión del modelo del alfa de Jensen se define en (2) y la del modelo de tres factores de Fama y French en (4).

$$
\begin{aligned}
& R_{p t}-R_{f t}=\alpha_{p}+\beta_{p}\left(R_{m t}-R_{f t}\right)+\varepsilon_{p t} \\
& R_{p t}-R_{f t}=\alpha_{p}+\beta_{p, m}\left(R_{m t}-R_{f t}\right)+\beta_{p, s m b} R_{s m b, t}+\beta_{p, h m l} R_{h m l, t}+\varepsilon_{p t}
\end{aligned}
$$

\begin{tabular}{|c|c|c|c|c|c|c|}
\hline & \multicolumn{3}{|c|}{ Alfa de Jensen } & \multicolumn{3}{|c|}{3 Factores de Fama y French } \\
\hline & $\overline{D+}$ & D- & D+ - D- & D+ & D- & D+ - D- \\
\hline Constante anualizada & $\begin{array}{c}4,93 \% \\
{[0,0798]}\end{array}$ & $\begin{array}{c}-3,05 \% \\
{[0,5355]}\end{array}$ & $\begin{array}{c}7,98 \% \\
{[0,1739]}\end{array}$ & $\begin{array}{c}5,03 \% \\
{[0,0677]}\end{array}$ & $\begin{array}{c}-4,46 \% \\
{[0,3426]}\end{array}$ & $\begin{array}{c}9,49 \% \\
{[0,0950]}\end{array}$ \\
\hline$\beta_{\mathrm{p}} / \beta_{\mathrm{p}, \mathrm{m}}$ & $\begin{array}{c}0,9425 \\
{[0,0000]}\end{array}$ & $\begin{array}{c}0,8559 \\
{[0,0000]}\end{array}$ & $\begin{array}{c}0,0866 \\
{[0,5232]}\end{array}$ & $\begin{array}{c}0,9082 \\
{[0,0000]}\end{array}$ & $\begin{array}{c}0,8644 \\
{[0,0000]}\end{array}$ & $\begin{array}{c}0,0438 \\
{[0,7426]}\end{array}$ \\
\hline$\beta_{\mathrm{p}, \mathrm{smb}}$ & - & - & - & $\begin{array}{c}0,0519 \\
{[0,4442]}\end{array}$ & $\begin{array}{c}0,3084 \\
{[0,0107]}\end{array}$ & $\begin{array}{c}-0,2565 \\
{[0,0715]}\end{array}$ \\
\hline$\beta_{\mathrm{p}, \mathrm{hml}}$ & - & - & $\begin{array}{l}- \\
-\end{array}$ & $\begin{array}{c}0,2090 \\
{[0,0310]}\end{array}$ & $\begin{array}{c}-0,1076 \\
{[0,5111]}\end{array}$ & $\begin{array}{c}0,3166 \\
{[0,1105]}\end{array}$ \\
\hline $\mathrm{R}^{2}$ & 0,8085 & 0,5265 & 0,0080 & 0,8270 & 0,5921 & 0,1267 \\
\hline
\end{tabular}

Nota: los valores entre corchetes son la probabilidad crítica ( $p$-values). En negrita, valores significativos para un nivel de significación del 5\%. 
Cuadro 2.19: Alfa de Jensen y modelo de tres factores de Fama y French, en subperíodo de expansión, siendo la referencia del mercado

\section{el Ibex 35 con dividendos}

Este cuadro muestra los coeficientes de regresión de los modelos del alfa de Jensen y el modelo de tres factores de Fama y French, para las carteras D+ y D-, y la diferencia entre ambas, en el subperíodo muestral de expansión de julio de 2003 a diciembre de 2007, siendo la referencia de rentabilidad del mercado el Ibex 35 con dividendos. La ecuación de regresión del modelo del alfa de Jensen se define en (2) y la del modelo de tres factores de Fama y French en (4).

$$
\begin{aligned}
& R_{p t}-R_{f t}=\alpha_{p}+\beta_{p}\left(R_{m t}-R_{f t}\right)+\varepsilon_{p t} \\
& R_{p t}-R_{f t}=\alpha_{p}+\beta_{p, m}\left(R_{m t}-R_{f t}\right)+\beta_{p, s m b} R_{s m b, t}+\beta_{p, h m l} R_{h m l, t}+\varepsilon_{p t}
\end{aligned}
$$

\begin{tabular}{|c|c|c|c|c|c|c|}
\hline & \multicolumn{3}{|c|}{ Alfa de Jensen } & \multicolumn{3}{|c|}{3 Factores de Fama y French } \\
\hline & $\mathbf{D}+$ & D- & D+ - D- & $\mathbf{D}+$ & D- & D+ - D- \\
\hline Constante anualizada & $\begin{array}{c}2,07 \% \\
{[0,4885]}\end{array}$ & $\begin{array}{c}-5,49 \% \\
{[0,2906]}\end{array}$ & $\begin{array}{c}7,56 \% \\
{[0,2099]}\end{array}$ & $\begin{array}{c}2,28 \% \\
{[0,4458]}\end{array}$ & $\begin{array}{c}-7,06 \% \\
{[0,1559]}\end{array}$ & $\begin{array}{c}9,34 \% \\
{[0,1105]}\end{array}$ \\
\hline$\beta_{\mathrm{p}} / \beta_{\mathrm{p}, \mathrm{m}}$ & $\begin{array}{c}0,9234 \\
{[0,0000]}\end{array}$ & $\begin{array}{c}0,8303 \\
{[0,0000]}\end{array}$ & $\begin{array}{c}0,0931 \\
{[0,4882]}\end{array}$ & $\begin{array}{c}0,8921 \\
{[0,0000]}\end{array}$ & $\begin{array}{c}0,8481 \\
{[0,0000]}\end{array}$ & $\begin{array}{c}0,0440 \\
{[0,7415]}\end{array}$ \\
\hline$\beta_{\mathrm{p}, \mathrm{smb}}$ & $\begin{array}{l}- \\
-\end{array}$ & $\begin{array}{l}- \\
-\end{array}$ & $\begin{array}{l}- \\
-\end{array}$ & $\begin{array}{c}0,0502 \\
{[0,4869]}\end{array}$ & $\begin{array}{c}0,3069 \\
{[0,0128]}\end{array}$ & $\begin{array}{c}-0,2566 \\
{[0,0714]}\end{array}$ \\
\hline$\beta_{\mathrm{p}, \mathrm{hml}}$ & $\begin{array}{l}- \\
-\end{array}$ & $\begin{array}{l}- \\
-\end{array}$ & $\begin{array}{l}- \\
-\end{array}$ & $\begin{array}{c}0,1682 \\
{[0,1027]}\end{array}$ & $\begin{array}{c}-0,1460 \\
{[0,3879]}\end{array}$ & $\begin{array}{c}0,3142 \\
{[0,1162]}\end{array}$ \\
\hline $\mathrm{R}^{2}$ & 0,7911 & 0,5051 & 0,0095 & 0,8034 & 0,5741 & 0,1267 \\
\hline
\end{tabular}

Nota: los valores entre corchetes son la probabilidad crítica ( $p$-values). En negrita, valores significativos para un nivel de significación del 5\%. 
Cuadro 2.20: Alfa de Jensen y modelo de tres factores de Fama y French, en subperíodo de crisis, siendo la referencia del mercado el Ibex 35

Este cuadro muestra los coeficientes de regresión de los modelos del alfa de Jensen y el modelo de tres factores de Fama y French, para las carteras D+ y D-, y la diferencia entre ambas, en el subperíodo muestral de crisis de enero de 2008 a julio de 2012, siendo la referencia de rentabilidad del mercado el Ibex 35 . La ecuación de regresión del modelo del alfa de Jensen se define en (2) y la del modelo de tres factores de Fama y French en (4).

$$
\begin{aligned}
& R_{p t}-R_{f t}=\alpha_{p}+\beta_{p}\left(R_{m t}-R_{f t}\right)+\varepsilon_{p t} \\
& R_{p t}-R_{f t}=\alpha_{p}+\beta_{p, m}\left(R_{m t}-R_{f t}\right)+\beta_{p, s m b} R_{s m b, t}+\beta_{p, h m l} R_{h m l, t}+\varepsilon_{p t}
\end{aligned}
$$

\begin{tabular}{|c|c|c|c|c|c|c|}
\hline & \multicolumn{3}{|c|}{ Alfa de Jensen } & \multicolumn{3}{|c|}{3 Factores de Fama y French } \\
\hline & $\mathbf{D +}$ & D- & D+ - D- & $\mathrm{D}+$ & D- & D+ - D- \\
\hline \multirow[t]{2}{*}{ Constante anualizada } & $7,66 \%$ & $0,16 \%$ & $7,50 \%$ & $9,66 \%$ & $7,36 \%$ & $2,30 \%$ \\
\hline & {$[0,0985]$} & {$[0,9853]$} & {$[0,3711]$} & {$[0,0202]$} & {$[0,2949]$} & {$[0,7593]$} \\
\hline \multirow[t]{2}{*}{$\beta_{\mathrm{p}} / \beta_{\mathrm{p}, \mathrm{m}}$} & 1,0598 & $\mathbf{0 , 9 9 9 7}$ & 0,0601 & 0,9676 & 1,1334 & $-0,1658$ \\
\hline & {$[0,0000]$} & {$[0,0000]$} & {$[0,5240]$} & {$[0,0000]$} & {$[0,0000]$} & {$[0,1450]$} \\
\hline \multirow[t]{2}{*}{$\beta_{\mathrm{p}, \mathrm{smb}}$} & - & - & - & 0,1919 & 0,7457 & $-0,5538$ \\
\hline & - & - & - & {$[0,0172]$} & {$[0,0000]$} & {$[0,0004]$} \\
\hline \multirow[t]{2}{*}{$\beta_{\mathrm{p}, \mathrm{hml}}$} & - & - & - & 0,2412 & 0,0630 & 0,1781 \\
\hline & - & - & - & {$[0,0006]$} & {$[0,5804]$} & {$[0,1498]$} \\
\hline $\mathrm{R}^{2}$ & 0,8894 & 0,6730 & 0,0077 & 0,9197 & 0,7966 & 0,2559 \\
\hline
\end{tabular}

Nota: los valores entre corchetes son la probabilidad crítica ( $p$-values). En negrita, valores significativos para un nivel de significación del 5\%. 
Cuadro 2.21: Alfa de Jensen y modelo de tres factores de Fama y French, en subperíodo de crisis, siendo la referencia del mercado el

\section{Ibex 35 con dividendos}

Este cuadro muestra los coeficientes de regresión de los modelos del alfa de Jensen y el modelo de tres factores de Fama y French, para las carteras D+ y D-, y la diferencia entre ambas, en el subperíodo muestral de crisis de enero de 2008 a julio de 2012, siendo la referencia de rentabilidad del mercado el Ibex 35 con dividendos. La ecuación de regresión del modelo del alfa de Jensen se define en (2) y la del modelo de tres factores de Fama y French en (4).

$$
\begin{aligned}
& R_{p t}-R_{f t}=\alpha_{p}+\beta_{p}\left(R_{m t}-R_{f t}\right)+\varepsilon_{p t} \\
& R_{p t}-R_{f t}=\alpha_{p}+\beta_{p, m}\left(R_{m t}-R_{f t}\right)+\beta_{p, s m b} R_{s m b, t}+\beta_{p, h m l} R_{h m l, t}+\varepsilon_{p t}
\end{aligned}
$$

\begin{tabular}{|c|c|c|c|c|c|c|}
\hline & \multicolumn{3}{|c|}{ Alfa de Jensen } & \multicolumn{3}{|c|}{3 Factores de Fama y French } \\
\hline & $\mathbf{D}+$ & D- & D+ - D- & $\mathbf{D}+$ & D- & D+ - D- \\
\hline \multirow[t]{2}{*}{ Constante anualizada } & $0,72 \%$ & $-6,24 \%$ & $6,96 \%$ & $3,39 \%$ & $0,13 \%$ & $3,26 \%$ \\
\hline & {$[0,8737]$} & {$[0,4460]$} & {$[0,4025]$} & {$[0,3907]$} & {$[0,9842]$} & {$[0,6587]$} \\
\hline \multirow[t]{2}{*}{$\beta_{\mathrm{p}} / \beta_{\mathrm{p}, \mathrm{m}}$} & 1,0310 & 0,9885 & 0,0426 & 0,9312 & 1,1130 & $-0,1818$ \\
\hline & {$[0,0000]$} & {$[0,0000]$} & {$[0,6435]$} & {$[0,0000]$} & {$[0,0000]$} & {$[0,0948]$} \\
\hline \multirow[t]{2}{*}{$\beta_{\mathrm{p}, \mathrm{smb}}$} & - & - & - & 0,1862 & 0,7474 & $-0,5611$ \\
\hline & - & - & - & {$[0,0184]$} & {$[0,0000]$} & {$[0,0003]$} \\
\hline \multirow[t]{2}{*}{$\beta_{\mathrm{p}, \mathrm{hml}}$} & - & - & - & 0,2616 & 0,0722 & 0,1894 \\
\hline & - & - & - & {$[0,0001]$} & {$[0,4967]$} & {$[0,1192]$} \\
\hline $\mathrm{R}^{2}$ & 0,8884 & 0,6945 & 0,0041 & 0,9223 & 0,8192 & 0,2656 \\
\hline
\end{tabular}

Nota: los valores entre corchetes son la probabilidad crítica ( $p$-values). En negrita, valores significativos para un nivel de significación del 5\%. 
Como se puede observar en el Cuadro 22, el modelo de tres factores de Fama y French, presenta un mejor ajuste que el alfa de Jensen, para las dos carteras en las dos referencias de rentabilidad del mercado y para todos los períodos. Dentro de ambos modelos la cartera D+ siempre presenta un mejor ajuste que la D-, con mayores valores de $\mathrm{R}^{2}$. Las únicas alfas estadísticamente significativas, de forma fuerte o débil, se encuentran en los modelos que utilizan como referencia de mercado el Ibex 35, y exclusivamente en la cartera $\mathrm{D}+$. Tanto para el modelo del alfa de Jensen como para el de modelo de tres factores de Fama y French, y para ambas referencias del mercado y para todos los períodos analizados el alfa de la cartera $\mathrm{D}+$ es superior al alfa de la cartera D-. Tomando como referencia el Ibex 35, la diferencia en el alfa de Jensen de las dos carteras se sitúa en torno a un 7,98\% (7,5\%) en período expansión (crisis) mientras que con el modelo de FF los respectivos valores son 9,49\% (2,3\%). Siendo la referencia el Ibex 35 con dividendos, las diferencias son respectivamente 7,56\% (6,96\%) con el alfa de Jensen y 9,34\% (3,26\%). Por lo tanto, si bien con el modelo de un factor la diferencia se mantiene en niveles similares en momentos de expansión y crisis, con el modelo de tres factores de FF, la diferencia entre las carteras es aproximadamente un $7 \%$ o $6 \%$ anual mayor en el período de expansión que en el período de crisis, siendo el subeperíodo de expansión con el Ibex 35, el único que presenta una diferencia significativa, aunque débil, entre ambas carteras. Dado que el modelo de FF es más completo en cuanto incluye factores adicionales de riesgo contrastados en la literatura y en este mismo trabajo y en cuanto tiene mayor capacidad explicativa, las conclusiones del trabajo deben apoyarse principalmente en los resultados alcanzados por este modelo. 
Cuadro 2.22: Cuadro resumen del Alfa de Jensen y del modelo de tres factores de Fama y French, para el Ibex 35 y el Ibex 35 con dividendos, para los diferentes períodos muestrales

Este cuadro muestra las constantes anualizadas y los $\mathrm{R}^{2}$ de los modelos del alfa de Jensen y el modelo de tres factores de Fama y French, para las carteras D+ y D-, y la diferencia entre ambas, para el período muestral total de enero de 2000 a junio de 2014, para el subperíodo muestral de expansión de julio de 2003 a diciembre de 2007 y para el subperíodo muestral de crisis de enero de 2008 a julio de 2012, siendo las referencias del mercado el Ibex 35 y el Ibex 35 con dividendos. La ecuación de regresión del modelo del alfa de Jensen se define en (2) y la del modelo de tres factores de Fama y French en (4).

$$
\begin{aligned}
& R_{p t}-R_{f t}=\alpha_{p}+\beta_{p}\left(R_{m t}-R_{f t}\right)+\varepsilon_{p t} \\
& R_{p t}-R_{f t}=\alpha_{p}+\beta_{p, m}\left(R_{m t}-R_{f t}\right)+\beta_{p, s m b} R_{s m b, t}+\beta_{p, h m l} R_{h m l, t}+\varepsilon_{p t}
\end{aligned}
$$

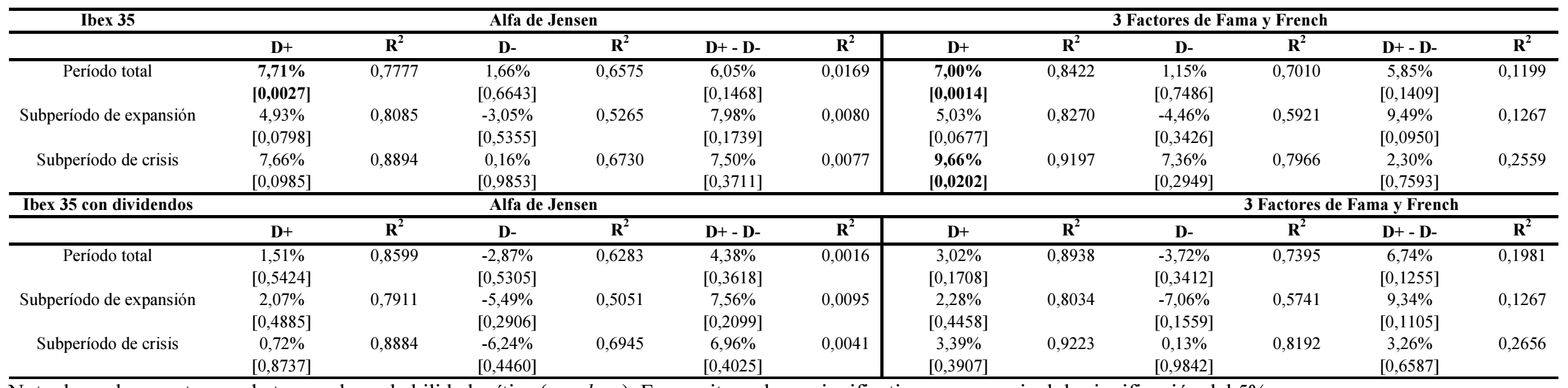

Nota: los valores entre corchetes son la probabilidad crítica (p-values). En negrita, valores significativos para un nivel de significación del 5\%. 


\subsection{Conclusiones}

El principal objetivo de este capítulo es demostrar empíricamente si el dividend puzzle se presenta en un entorno real, específicamente en los mercados financieros españoles. Para ello se considera su índice más representativo, el Ibex 35, incluyéndose adicionalmente el Ibex 35 con dividendos y considerando como período muestral desde enero de 1999 hasta junio de 2014. Para ello se ha utilizado la metodología empleada por Carhart (1997) consistente en la creación de dos carteras de inversión en función de la rentabilidad por dividendo obtenida el año anterior por los activos que forman el índice. La cartera $\mathrm{D}+$ estará compuesta por las 7 empresas que hayan presentado una mayor rentabilidad por dividendo, mientras que las 7 empresas que hayan presentado una menor rentabilidad por dividendo componen la D-.

La cartera $\mathrm{D}+$ presenta un valor liquidativo final y unas rentabilidades superiores a las de la cartera D-, pero estos resultados no se deben exclusivamente a una mayor rentabilidad por dividendo ofrecida por las empresas de la cartera $\mathrm{D}^{+}$, sino también a una mayor demanda de sus acciones por parte de los inversores, consiguiendo éstas un mayor precio de cotización y por lo tanto unas mayores ganancias de capital en el momento de la venta. Durante el período muestral analizado la cartera $\mathrm{D}+$ presentaba una rentabilidad media vía precio casi el triple que la cartera D-. Los resultados confirman la existencia del dividend puzzle en los mercados financieros españoles. Así, las empresas que presentan una mayor rentabilidad por dividendo son recompensadas por los inversores con un mayor valor de sus acciones, por lo tanto, los inversores no son indiferentes ante el cobro o no de dividendos como sostiene la hipótesis de irrelevancia del dividendo de MM (1961).

Pero la eficiencia de una cartera de inversión no puede ser medida únicamente por la rentabilidad obtenida sino también por el riesgo asumido para conseguir dicha rentabilidad, de ahí el denominado binomio rentabilidad-riesgo. Por ello, se han utilizado dos de las medidas de performance más conocidas como son el alfa de Jensen y el modelo de tres factores de Fama y French. Aplicando ambos modelos al período muestral obtenemos que la cartera $\mathrm{D}+$ alcanza un desempeño muy superior a la cartera D-, aunque sólo la cartera $\mathrm{D}+$ presenta unos resultados estadísticamente significativos cuando se usa como referencia de mercado el Ibex 35.

Como se ha comentado en la introducción de la tesis, uno de los objetivos de investigación adicionales del capítulo es el análisis de la robustez del dividend puzzle en diferentes subperíodos muestrales, centrándonos especialmente en la reciente crisis financiera de 2008. Para ello del período muestral total hemos elegido un subperíodo de 
pre-crisis o expansión (de julio de 2003 hasta diciembre de 2007) y un subperíodo de crisis (de enero de 2008 a julio de 2012), concluyendo que cuando se utiliza como referencia del mercado el Ibex 35, el desempeño de las carteras en el subperíodo de crisis en ambas carteras es mejor que el alcanzado en momentos de expansión. Sin embargo, la diferencia entre las dos carteras es mayor en el subperíodo de expansión que de crisis.

Como conclusión del estudio de las medidas de performance se identifica que la cartera $\mathrm{D}+$ siempre presenta una rentabilidad específica, por su composición, superior a la de la cartera D-, por lo tanto, en base al análisis de la performance se confirma que existe el dividend puzzle en los mercados financieros españoles. 


\section{Capítulo 3}

\section{nálisis del efecto \\ disposición en los \\ fondos Socialmente}

\section{Responsables}

\subsection{Introducción}

El efecto disposición se puede definir como la mayor propensión de los inversores a materializar ganancias que a realizar pérdidas. El efecto disposición puede tener graves consecuencias para los inversores cuando éstos no venden las acciones con bajo rendimiento, incluso con pérdidas, ya que su rentabilidad puede verse afectada negativamente y puede llevarles a pagar más impuestos de los necesarios sobre las ganancias de capital. En este contexto, este trabajo tiene como objetivo analizar la existencia de un efecto disposición en los inversores en fondos de inversión de carácter socialmente responsable.

En la literatura financiera se considera al efecto disposición un sesgo dentro del ámbito de las Finanzas del Comportamiento (FC). Así, la teoría prospectiva planteada por Kahneman y Tversky (1979) ha sido probablemente una de las aportaciones teóricas más importantes para dotar de argumentos al efecto disposición. Esta doctrina ha 
representado un cambio de paradigma al exponer que la teoría económica tradicional no puede explicar completamente el comportamiento de los individuos. En este enfoque alternativo se presenta la idea de que los inversores tienen una valoración diferente en función de que sus resultados obtenidos sean ganancias o pérdidas con respecto a un punto de referencia exhibiendo mayoritariamente un comportamiento de aversión al riesgo para las ganancias y de búsqueda de riesgo para las pérdidas. Así, se postula que la desutilidad de un inversor ante una pérdida supera a su satisfacción ante una ganancia de la misma cuantía. En este sentido, la literatura identifica conexiones entre la teoría de la prospección y el efecto disposición de acuerdo a Meng y Weng (2017), Barberis y Xiong (2012), entre otros. En esta línea es destacable señalar a Shefrin y Statman (1985), que en el marco de la teoría prospectiva proponen los siguientes elementos como condicionantes del efecto disposición: la contabilidad mental, aversión al arrepentimiento y el autocontrol. Sin embargo, Barberis y Xiong (2009), Hens y Vlcek (2011), entre otros, cuestionan en cierto modo la universalidad de la teoría prospectiva como elemento explicativo y sostienen que ésta sólo puede explicar la aparición del efecto disposición en algunos casos y no bajo todas las circunstancias. Recientemente, Meng y Weng (2017) sostienen que generalmente la teoría prospectiva puede explicar o predecir el efecto disposición siempre y cuando el punto de referencia sea la riqueza final esperada y bajo el principio de preferencia de equilibrio personal, no siendo así cuando el punto de referencia sea la riqueza inicial. Desde otra perspectiva, Lakonishok y Smidt (1986) cuestionan la explicación psicológica para el efecto disposición y lo atribuyen a consideraciones racionales como el reequilibrio de carteras o los costes de transacción; aunque investigaciones posteriores han demostrado que estas consideraciones racionales no pueden explicarlo plenamente.

Además del enfoque teórico que intenta explicar el efecto disposición, la amplia mayoría de la literatura financiera se ha centrado en analizar empíricamente la existencia del efecto tanto en los mercados financieros, como en un contexto experimental. En este último ámbito, Weber y Camerer (1998) verifican la existencia del efecto disposición en un experimento de laboratorio con 100 participantes a través de 14 rondas de negociación. Otros trabajos han utilizado como datos las decisiones de inversión de inversores y profesionales. Así, Odean (1998) evidencia la existencia del efecto disposición utilizando una muestra de 10.000 inversores individuales durante el período 1987-1993 de un importante agente del mercado. Heath et al. (1998) obtienen resultados similares analizando el comportamiento de más de 50.000 empleados, en siete grandes empresas, en el ejercicio de opciones de compra sobre acciones. Locke y Mann (2000) analizan el comportamiento de los inversores profesionales de futuros encontrando que los inversores con mayor éxito son aquellos que mantienen menos tiempo las pérdidas. También en el ámbito de los mercados financieros, Ranguelova 
(2001) observa que el efecto disposición se concentra principalmente en acciones de gran capitalización, mientras las acciones situadas en el 40\% inferior de la distribución según tamaño, muestran un efecto disposición inverso Kaustia (2010): los inversores mantienen sus ganancias y realizan sus pérdidas, poniendo así en duda que la aversión a las pérdidas sea una posible explicación del efecto disposición. Recientemente, Richards et al. (2017) argumentan que una forma relativamente sencilla de reducir el efecto disposición en el mercado de valores es mediante el uso de órdenes stop loss, ya que éstos pueden automatizar una salida estratégica reduciendo el impulso del inversor. Además, Nolte (2012) encontró que el uso de estrategias de abandonar pérdidas (stop loss) y la realización de ganancias (take gain) invirtió el efecto disposición para los operadores de divisas. A nivel internacional existe un amplio número de trabajos que encuentran evidencia empírica del efecto disposición en sus mercados: Brown et al. (2006) para Australia, Weber y Welfens (2007) para Alemania, Talpsepp (2009) para Estonia, Cheng et al. (2009) para Taiwan, Choe y Eom (2009) para Corea, Cerqueira Leal et al. (2010) para Portugal, Shapira y Venezia (2001) para Israel, Grinblatt y Keloharju (2001) en Finlandia y Feng y Seasholes (2005) en China. A un nivel metodológico, en la literatura se han propuesto básicamente cuatro indicadores diferentes a través de las cuales se puede medir el efecto disposición: i) las rentabilidades alcanzadas: Shefrin y Statman (1985) argumentan que la propensión a materializar las ganancias y a mantener las pérdidas es consistente con la teoría de Kahneman y Tversky (1979); ii) el volumen negociado: Lakonishok y Smidt (1986) y Ferris et al. (1988), entre otros autores, utilizan un modelo de regresión y demuestran que el volumen actual negociado estaba correlacionado negativamente con el volumen de los días previos en los cuales el precio de las acciones había subido, y viceversa; iii) el análisis de las proporción de ganancias realizadas (PGR) y la proporción de pérdidas realizadas (PLR). Bajo esta nomenclatura, Odean (1998) utiliza la diferencia entre PGR y PLR para cada fondo de inversión y para cada mes. La existencia de una diferencia positiva entre PGR y PLR se considera una evidencia del efecto disposición; iv) El coeficiente de disposición abordado por Weber y Camerer (1998) quienes en su estudio aplican una metodología basada en la revalorización media de los precios de las acciones.

Uno de los aspectos de la literatura que creemos relevante, es la relación entre el tipo de inversor y la presencia del efecto disposición. Así, en teoría, el efecto se supone más relevante en los inversores privados con poca educación financiera. Si estos inversores son propensos a la aversión a las pérdidas es inevitable que sufran este efecto y que perjudique sus rentabilidades. Aunque si los inversores fueran conscientes del efecto, así como de otros sesgos existentes, cabe la posibilidad de mejorar su comportamiento de inversión. Sin embargo, Coval y Shumway (2005) también encuentran evidencia de 
este efecto para los inversores institucionales. Frazzini (2006) encuentra el efecto disposición en los gestores de fondos de inversión de Estados Unidos, aunque más débil que en el caso de los inversores individuales. Otros autores se centran en un enfoque puramente experimental, como es el caso de Rau (2015) analizando si existen diferencias del efecto disposición entre inversores individuales o entre colectivos, en concreto, en este último caso refiere a equipos formados por dos inversores y concluye que existen diferencias, siendo el efecto disposición mayormente identificado en el caso de inversores colectivos. Ben-David y Hirshleifer (2012) observan que el efecto disposición ha sido confirmado tanto experimentalmente como en la práctica real para diferentes inversores, países, períodos y horizontes temporales. Otros autores asocian el grado de sofisticación del inversor y su experiencia, como Feng y Seasholes (2005), aunque parece que a priori todos los inversores pueden ser vulnerables a exhibir este patrón, es para el caso del inversor individual en el que se identifica un mayor grado de susceptibilidad ante este sesgo de comportamiento. Da Costa et al. (2013) observan que los inversores experimentados muestran el efecto disposición pero en menor medida que los inversores inexpertos. Algunos trabajos profundizan en las características de los inversores, por ejemplo, Cronqvist y Siegel (2014) proponen las diferencias genéticas de cada inversor, además de considerar sus características individuales, como determinantes de los sesgos de comportamiento. En una línea de investigación similar, Frydman y Rangel (2014) y Frydman y Camerer (2016) abordan el aspecto neurológico subyacente a la toma de decisiones dotando de nuevos argumentos al estudio de este sesgo de comportamiento.

Sin embargo, una menor atención ha recibido la búsqueda de respuestas sobre si los inversores de fondos exhiben un patrón similar de sesgo de comportamiento. En este sentido, Chang et al. (2016) encuentran que el efecto disposición se aplica sólo a activos no delegados como es el caso de acciones individuales; sin embargo, para el caso de los activos delegados, incluyendo entre ellos los fondos de inversión, se identifica un efecto disposición que es inverso y robusto considerando datos de flujos de compra-venta a nivel individual. Este efecto disposición inverso o contrario asociado a los fondos está condicionado por el comportamiento de los inversores siendo más probable que se venda con pérdida como señalan Chang et al. (2016). Los autores usan datos de flujos de compra-venta individuales así como datos experimentales y, en ambos casos, tanto el efecto disposición como el efecto disposición inverso son identificados como respuesta de los inversores ante los sentimientos de disonancia cognitiva que afloran cuando se enfrentan a una pérdida. En esta línea, si las decisiones individuales de inversión de los partícipes en los fondos no son observables, un procedimiento para analizar el efecto disposición en los partícipes es el análisis de los flujos monetarios de entrada y salida en los fondos. 
Existe una amplia literatura que ha analizado los determinantes de los flujos monetarios de los fondos. Entre las primeras referencias en este ámbito podemos destacar los trabajos de Chevalier y Ellison (1997) y Sirri y Tufano (1998) en el que se encuentra una relación positiva entre los flujos monetarios y el desempeño del fondo en el pasado, siendo ésta especialmente relevante para el caso de los mejores fondos. Otro determinante de los flujos de caja puede ser el riesgo, en este sentido, Andreu et al. (2012) señalan que los fondos con mayor riesgo tienden a recibir menores flujos monetarios y soportar menores salidas de flujos. Spiegel y Zhang (2013) apuntan hacia la tendencia de los inversores a no elegir aquéllos fondos más volátiles, siendo los que atraen menores flujos monetarios. Con evidencia empírica dispar, otros trabajos analizan la influencia de las comisiones y gastos como determinantes de los flujos monetarios. Barber et al. (2005) señalan que no existen argumentos suficientes para establecer una relación negativa entre flujos y gastos, si bien se identifica que los inversores buscan evitar las comisiones. Por otro lado, Ivković y Weisbenner (2009) evidencian sensibilidad de los inversores ante las comisiones de suscripción y otros gastos del fondo. Huang et al. (2007) afirman que los costes tienen a ser relevantes para los inversores a la hora de implementar sus decisiones de asignación entre los fondos en medida que los toman en consideración asociándolos a diferentes rangos de nivel de eficiencia del fondo. Así, se identifica que los gastos son determinantes para definir la relación asimétrica existente entre los flujos monetarios y el nivel de eficiencia, concretamente, señalan que los fondos con menores (mayores) costes de participación tienen mayor (menor) sensibilidad en los flujos ante niveles de desempeño medio y menor (mayor) sensibilidad en los flujos para niveles de desempeño elevado. Por citar algunas reseñas recientes, destacan Pleßner (2017) y, Kumar y Goyal (2015) por sus sendas exhaustivas revisiones de literatura.

Dentro del ámbito del análisis de los flujos de caja de los fondos, el presente trabajo tiene como objetivo investigar la existencia del efecto disposición en los inversores de los fondos de inversión socialmente responsables (SR). Esta modalidad de inversión ha experimentado un notable crecimiento en los últimos años y está siendo considerada una alternativa ciertamente popular ya que proporciona cobertura a aspectos éticos compartiendo al mismo tiempo objetivos financieros. La mayoría de los estudios centrados en los fondos SR han tenido como objetivo analizar su eficiencia en términos comparativos con respecto a los fondos convencionales, no encontrando diferencias sustanciales entre ambos tipos de fondos (Statman 2000; Renneboog et al. 2008). Por otro lado, Nofsinger y Varma (2014) postulan que los fondos SR superan a sus homólogos convencionales en etapas de crisis, mientras que en estadios de crecimiento económico reportan un menor rendimiento. Un menor número de trabajos se ha ocupado analizar los determinantes de los flujos monetarios de los fondos SR. Así, 
Bollen (2007) pone de manifiesto que los flujos monetarios de los inversores presentan un menor (mayor) grado de sensibilidad frente a resultados desfavorables (favorables) de los fondos SR, sin embargo, esta tendencia no es identificada en el caso de los fondos convencionales cuando ambos son comparados. Benson y Humphrey (2008) y, Renneboog et al. (2011) sugieren que los flujos de una muestra de fondos SR estadounidense presentan un menor grado de sensibilidad en relación a su eficiencia en comparación a los fondos convencionales. Recientemente, El Ghoul y Karoui (2017) también sugieren que existe una menor sensibilidad de los flujos por parte de los inversores cuando la variable de eficiencia se tiene en consideración, en concreto, para los fondos que tienen un elevado componente de participación en inversión SR parece que existe una mayor reticencia por parte de los inversores para cambiar la estrategia de inversión aún cuando los fondos obtienen una escasa eficiencia.

Finalmente, este estudio ahonda en el impacto de un hito relevante o suceso que afecta al entorno económico-financiero, como es el caso de la reciente crisis financiera global. La mayoría de los estudios sobre el efecto disposición apoyan la existencia del sesgo, sin embargo, todavía en la actualidad este comportamiento presenta cierto grado de ambigüedad cuando se somete a escrutinio ante escenarios en los que los mercados financieros se exponen a situaciones de elevada incertidumbre como pueden ser los períodos de crisis. Así, Lin (2011) mediante el uso del coeficiente de disposición, muestra que efectivamente durante la crisis financiera asiática de 1997 el efecto disposición es significativo en los mercados bursátiles de Taiwán y China. Pero en la crisis financiera global de 2008, sólo se identifica este sesgo para el caso del mercado de valores chino. Contrariamente, Bialkowski y Starks (2016) encuentran que no necesariamente el flujo monetario de los fondos SR de Estados Unidos está relacionado con algún hito con trascendencia de cambio en el mercado financiero o en la industria de inversión, como es la reciente crisis financiera global y sostienen que los fondos SR tienen unos flujos netos positivos mayormente pues reciben un trato preferencial por parte de los inversores en tiempos difíciles.

En consonancia con la literatura anterior, nuestros resultados sugieren la existencia de una relación positiva entre la rentabilidad pasada y los flujos monetarios futuros, a modo de que los inversores de fondos SR son sensibles y tienden a invertir en fondos con mejores resultados pasados. Paradójicamente, se identifica que los fondos SR con peores resultados igualmente captan el dinero de los inversores justificando dicho comportamiento con la esperanza de que los fondos perdedores puedan llegar a ser ganadores en el futuro y encajando con una estrategia de inversión contraria. Para al caso específico de las salidas de dinero, se observa una relación positiva con los resultados anteriores del fondo, lo que puede interpretarse como una evidencia del 
efecto disposición dado que los partícipes del fondo materializan menores (mayores) salidas de dinero en lo fondos con peores (mejores) resultados. Este resultado puede ser asimilado a un sesgo del comportamiento puesto que de forma racional sería esperable que el signo de la relación fuera el opuesto. Con el fin de atribuir al estudio un nivel de robustez adicional en los resultados, se subdivide el período muestral diferenciando entre un estadio de pre-crisis (1999-2007) y otro de post-crisis (2008-2016). Los resultados indican que la relación entre resultados pasados y flujos de caja es mucho más relevante en el segundo período muestral. Es decir, en momentos posteriores al origen de la crisis financiera parece ser que los inversores son más sensibles, en su toma de decisiones de inversión y desinversión, a los resultados pasados de los fondos.

En las secciones siguientes de este capítulo, se abordarán en segundo lugar los datos y la metodología empleada en el análisis. A continuación, se presenta un análisis inicial de los flujos monetarios de los fondos, así como un análisis mediante regresión. La última sección del capítulo recoge las conclusiones más relevantes del trabajo. 


\subsection{Datos y metodología}

En el trabajo se analizan 438 fondos-compartimentos SR de renta variable con inversión en el mercado bursátil de Estados Unidos. Los fondos-compartimentos que comparten la misma cartera de inversión son agregados, resultando 160 fondos. El período muestral analizado abarca desde junio de 1999 a septiembre de 2016. Como estudio de robustez y para apreciar la existencia de diferencias temporales se ha repetido el análisis considerando dos subperíodos muestrales. El primero corresponde a los momentos precrisis y abarca desde 1999 a 2007, el siguiente comprende desde 2008 a 2016 y se enmarca en un contexto post-crisis. Mediante la base de datos Morningstar Direct se ha obtenido la siguiente información de cada fondo: rendimiento neto mensual, entradas de dinero, salidas de dinero, flujo neto de dinero, patrimonio, fecha de inicio, porcentaje de gastos sobre el patrimonio y ratio de rotación de la cartera.

A partir de esta información se elaboran las variables objeto de estudio. En primer lugar, dentro de las variables endógenas, el ratio de entrada de dinero, Intflow $w_{i, t}$, se define como el cociente entre las entradas de dinero del año t y el patrimonio del fondo al final del año anterior. De forma similar se define Outflow $_{i, t}$ para las salidas del dinero y Netflow $_{i, t}$ para los flujos netos de dinero. El objeto fundamental de este trabajo es explicar los flujos monetarios de los fondos. La principal variable explicativa son los resultados pasados de los fondos. Para medir los resultados vamos a utilizar dos variables. La primera está relacionada con la rentabilidad pasada del fondo, aunque rentabilidades pasadas no aseguran rentabilidades futuras, puede ser normal que los inversores, ante la amplia oferta de fondos existente, utilice como criterio de selección de un fondo su rentabilidad pasada. Así, definimos la variable $R_{a n k_{i, t}}$ como el rango percentil del rendimiento del fondo $i$ en el año $t$. El rendimiento anual se computa a partir del rendimiento neto mensual. La segunda variable que mide el resultado de un fondo es la eficiencia o valor añadido del gestor, medido por $\alpha_{i, t}$, la constante o alfa del modelo (1), es decir la diferencia entre el rendimiento obtenido por el fondo $i$ y el esperado según el modelo CAPM. Donde $r_{i, t, h}$ es la rentabilidad del fondo en el mes $h$ en exceso el activo libre de riesgo; $r_{m, t, h}$ la rentabilidad del mercado en el mismo período también en exceso y $\varepsilon_{i, t, h}$ el término de error. La rentabilidad del mercado y la del activo libre de riesgo (Treasury bill rate a un mes) se obtienen de la página web del profesor K.French. ${ }^{5}$

$$
r_{i, t, h}=\alpha_{i, t}+\beta_{i, t} r_{m, t, h}+\varepsilon_{i, t, h}
$$

\footnotetext{
${ }^{5}$ Ver http://mba.tuck.dartmouth.edu/pages/faculty/ken.french/data library.html.
} 
Esta medida de eficiencia o performance fue aplicada originalmente por Jensen (1968) y se ha utilizado ampliamente en la literatura que ha evaluado los fondos de inversión. Ciertamente literatura posterior ha ampliado esta medida, por ejemplo con el desarrollo de modelos multifactoriales. Sin embargo el principal objetivo del trabajo no es evaluar los resultados de los fondos sino analizar la relación entre los flujos monetarios de los inversores y los resultados previos de los fondos. En este sentido, hay que recordar que la rentabilidad es una información más directa, habitual y fácil de interpretar para un inversor medio que los datos sobre eficiencia. Por lo que tampoco hemos querido alargar el desarrollo del trabajo y nos hemos limitado al uso de una de las medidas más conocidas y populares de eficiencia, como es el alfa de Jensen. A partir de este dato, se define la variable Alfarank ${ }_{i, t}$ como el rango percentil de la alfa del fondo $i$ en el año $t$ dentro del conjunto de fondos.

A continuación se definen el resto de variables explicativas que se introducen para controlar por otros factores o características de los fondos. En primer lugar, la variable $R_{i s} k_{i, t}$ es el riesgo del fondo, medido como la desviación típica de sus rendimientos mensuales en el año $t$. La variable Logsize $_{i, t-l}$ es el logaritmo del patrimonio del fondo. La antigüedad del fondo se mide como el logaritmo de los años transcurridos en cada momento desde el inicio de la vida del fondo, $\operatorname{Logage}_{i, t-l}$. La variable $\operatorname{Exp}_{i, t-l}$ es el porcentaje de gastos del fondo sobre el patrimonio. La variable $\operatorname{Logtur}_{i, t-l}$ mide la rotación de la cartera del fondo.

El Panel A del Cuadro 3.1 presenta estadísticos descriptivos de las variables exógenas de los flujos de entrada, salida y neto. Para cada una de ellas se informa de la media, mediana y desviación típica de los valores de la muestra de fondos en cada año. La parte inferior del panel recoge la media de los valores anteriores para cada subperíodo muestral y para el período completo. Para el período 1999-2016, el ratio medio de entrada de dinero sobre el patrimonio ha sido del 1,19\% anual, el de las salidas $0,76 \% \mathrm{y}$ el neto $0,57 \%$. En términos netos esto supone que durante los 17 años de la muestra el patrimonio de los fondos se ha incrementado un 10,14\% en términos netos como consecuencia de los flujos monetarios de los inversores. También podemos destacar que para todos los tipos de flujos, la mediana es inferior a la media lo que indica que la distribución de los flujos está sesgada a la derecha, es decir que la media está conducida por algunos fondos que han acaparado importantes flujos monetarios con relación a su patrimonio. Separando la muestra en los dos subperíodos se alcanzan interesantes conclusiones. La primera es que el movimiento de dinero en la etapa pre-crisis ha sido notablemente superior al habido en los momentos post-crisis. Así, por término medio durante 1999-2007 las entradas han sido del 1,62\% pero en el subperíodo 2008-2016 éstas se han reducido a la mitad, tomando un valor de $0,80 \%$. De forma similar, las 
salidas fueron del 1,11\% para luego disminuir hasta el 0,44\%. En términos netos, se pasó de una media del 0,99\% al 0,19\%. Este comportamiento también se observa, pero con cierta menor intensidad, cuando comparamos las medianas antes y después de la crisis, así incluso la mediana de los flujos netos durante el subperíodo post-crisis llega a tomar valor negativo $(-0,01 \%)$. Si observamos la desviación típica de los flujos entre los fondos, observamos que las entradas presentan una dispersión del 4,75\% en el primer subperíodo, mientras que en el segundo se reduce aproximadamente a la mitad, 2,60\%; para las salidas, la dispersión pasa del $4,08 \%$ al $1,23 \%$ y para el flujo neto del $4,15 \%$ al 0,78\%. En resumen, durante la época de crecimiento económico y bursátil, existió un mayor movimiento del dinero de los inversores, tanto en entradas como salidas. Además esto se produjo de forma desigual entre los fondos, tal como apunta la mayor dispersión de los flujos. Por el contrario, los momentos post-crisis se caracterizan por menores flujos y esta situación es generalizada en el conjunto de fondos a la vista de la menor dispersión. Es decir, durante el segundo subperíodo se produce una situación de enfriamiento para el conjunto de la industria de los fondos SR que finalmente conducen a un reducido ratio de flujo neto, $0,19 \%$ en media, e incluso negativo, $-0,01 \%$, si consideramos a la mediana.

El Panel B del Cuadro 3.1 muestra los estadísticos descriptivos de las principales variables explicativas, es decir el rendimiento y la eficiencia de los fondos. Consideramos más relevante mostrar la información de las variables originales a partir de las cuales se obtienen las variables Ranki,t y Alfarank $_{i, t}$ puesto que al estar estas últimas estandarizadas y tomar valores entre 0 y 1 sus estadísticos no resultan informativos. Las primeras columnas del panel muestran una notable volatilidad de la rentabilidad de los fondos a lo largo del tiempo. La media durante todo el período muestral es del 6,72\% anual. Por subperíodos, en 1999-2007 la media es del 5,44\% mientras que para 2008-2016 es del 8\%. También es destacable señalar que la desviación típica de corte transversal de la rentabilidad anual de los fondos es 10,23\% para el primer subperíodo y casi la mitad para el segundo, concretamente 5,78\%. Especialmente desde 2011 esa dispersión ha sido siempre menor que la precedente en los años anteriores. Este resultado podría interpretarse como una disminución del grado de diferenciación de la gestión activa de los fondos dado que sus resultados guardan más proximidad entre sí que la habida en momentos anteriores. Esta evidencia junto con la encontrada sobre los menores flujos monetarios, nos configuran un segundo período muestral caracterizado por una madurez y enfriamiento, en el que tanto inversores como gestores presentan una menor actividad en lo concerniente a sus inversiones. Por otro lado, las columnas a la derecha del Panel B muestran los estadísticos descriptivos de la estimación de la eficiencia o performance de los fondos mediante el modelo (1), es decir, el alfa de Jensen (1968). Como se observa el valor añadido por los gestores se 
sitúa por término medio en la mayoría de los casos en valores cercanos a cero, siendo el máximo el 1,03\% en el año 2000 y el mínimo -0,34\% en el año 2004, La media desde 1999 a 2016 es el $0,08 \%$, este resultado está en línea con la evidencia generalizada encontrada en la industria de los fondos de inversión: aunque puede haber fondos que batan al mercado y otros que se sitúen por debajo, la media del valor añadido de los gestores desde el punto de los inversores (con rendimientos netos) suele tomar un valor próximo a cero (Sharpe, 1991) porque los fondos en sí mismos constituyen una parte importante de ese mercado. Cabe también destacar que desde 2011 hasta 2016 todos los años la eficiencia toma un valor negativo, de forma que para el primer subperíodo la media es $0,23 \%$ y para el segundo es $-0,07 \%$. Además, en línea con lo comentado antes para la rentabilidad, la dispersión de la eficiencia entre los fondos es casi el doble durante el primer subperíodo, 1,08\% que durante el segundo, $0,55 \%$.

El Panel C del Cuadro 3.1 recoge estadísticos del resto de variables explicativas o variables de control. Lo más destacable de este panel es su menor variabilidad temporal. No obstante, se podría señalar también la disminución de los gastos soportados por los fondos a lo largo del tiempo. Así, durante el primer subperíodo muestral, los gastos fueron por término medio del 1,38\%, mientras que para el segundo son del 1,15\%. Esta evolución podría entenderse como un síntoma de mayor madurez y competencia en el sector. 
Capítulo 3: Análisis del efecto disposición en los fondos SR

Cuadro 3.1: Estadísticos descriptivos

Panel A: variables endógenas

\begin{tabular}{|c|c|c|c|c|c|c|c|c|c|}
\hline & & Intflow $_{i, t}$ & & & Outflow $_{i, t}$ & & & Netflow $_{i, t}$ & \\
\hline & Media & Mediana & D.t. & Media & Mediana & D.t. & Media & Mediana & D.t. \\
\hline 1999 & - & - & - & - & - & - & - & - & - \\
\hline 2000 & $1,20 \%$ & $0,25 \%$ & $3,35 \%$ & $0,35 \%$ & $0,23 \%$ & $0,41 \%$ & $3,77 \%$ & $0,17 \%$ & $20,20 \%$ \\
\hline 2001 & $0,77 \%$ & $0,31 \%$ & $1,04 \%$ & $0,47 \%$ & $0,27 \%$ & $0,66 \%$ & $0,35 \%$ & $0,08 \%$ & $0,59 \%$ \\
\hline 2002 & $0,98 \%$ & $0,37 \%$ & $1,78 \%$ & $0,38 \%$ & $0,22 \%$ & $0,45 \%$ & $0,54 \%$ & $0,11 \%$ & $1,72 \%$ \\
\hline 2003 & $0,75 \%$ & $0,48 \%$ & $1,19 \%$ & $0,41 \%$ & $0,20 \%$ & $0,75 \%$ & $0,30 \%$ & $0,11 \%$ & $0,56 \%$ \\
\hline 2004 & $0,91 \%$ & $0,50 \%$ & $1,45 \%$ & $0,35 \%$ & $0,26 \%$ & $0,33 \%$ & $0,62 \%$ & $0,13 \%$ & $1,42 \%$ \\
\hline 2005 & $0,98 \%$ & $0,16 \%$ & $2,88 \%$ & $0,30 \%$ & $0,19 \%$ & $0,41 \%$ & $0,70 \%$ & $-0,01 \%$ & $2,56 \%$ \\
\hline 2006 & $5,93 \%$ & $0,34 \%$ & $22,39 \%$ & $4,12 \%$ & $0,26 \%$ & $18,12 \%$ & $1,11 \%$ & $0,05 \%$ & $4,47 \%$ \\
\hline 2007 & $1,46 \%$ & $0,31 \%$ & $3,94 \%$ & $2,48 \%$ & $0,28 \%$ & $11,49 \%$ & $0,49 \%$ & $0,05 \%$ & $1,67 \%$ \\
\hline 2008 & $1,34 \%$ & $0,26 \%$ & $3,49 \%$ & $0,72 \%$ & $0,22 \%$ & $2,06 \%$ & $0,20 \%$ & $0,01 \%$ & $0,69 \%$ \\
\hline 2009 & $2,03 \%$ & $0,18 \%$ & $8,49 \%$ & $0,68 \%$ & $0,18 \%$ & $2,54 \%$ & $0,60 \%$ & $0,00 \%$ & $2,23 \%$ \\
\hline 2010 & $1,06 \%$ & $0,26 \%$ & $4,19 \%$ & $0,62 \%$ & $0,28 \%$ & $2,07 \%$ & $0,18 \%$ & $-0,05 \%$ & $0,73 \%$ \\
\hline 2011 & $0,93 \%$ & $0,20 \%$ & $3,41 \%$ & $0,70 \%$ & $0,23 \%$ & $2,58 \%$ & $0,14 \%$ & $-0,03 \%$ & $0,57 \%$ \\
\hline 2012 & $0,45 \%$ & $0,22 \%$ & $0,80 \%$ & $0,34 \%$ & $0,21 \%$ & $0,49 \%$ & $0,09 \%$ & $-0,01 \%$ & $0,38 \%$ \\
\hline 2013 & $0,58 \%$ & $0,25 \%$ & $1,38 \%$ & $0,30 \%$ & $0,22 \%$ & $0,42 \%$ & $0,26 \%$ & $0,00 \%$ & $1,12 \%$ \\
\hline 2014 & $0,44 \%$ & $0,20 \%$ & $0,93 \%$ & $0,28 \%$ & $0,19 \%$ & $0,32 \%$ & $0,19 \%$ & $0,02 \%$ & $0,73 \%$ \\
\hline 2015 & $0,26 \%$ & $0,11 \%$ & $0,50 \%$ & $0,24 \%$ & $0,12 \%$ & $0,41 \%$ & $0,07 \%$ & $0,00 \%$ & $0,42 \%$ \\
\hline 2016 & $0,12 \%$ & $0,06 \%$ & $0,20 \%$ & $0,11 \%$ & $0,06 \%$ & $0,18 \%$ & $0,02 \%$ & $-0,01 \%$ & $0,18 \%$ \\
\hline $1999-2007$ & $1,62 \%$ & $0,34 \%$ & $4,75 \%$ & $1,11 \%$ & $0,24 \%$ & $4,08 \%$ & $0,99 \%$ & $0,09 \%$ & $4,15 \%$ \\
\hline $2008-2016$ & $0,80 \%$ & $0,19 \%$ & $2,60 \%$ & $0,44 \%$ & $0,19 \%$ & $1,23 \%$ & $0,19 \%$ & $-0,01 \%$ & $0,78 \%$ \\
\hline 1999-2016 & $1,19 \%$ & $0,26 \%$ & $3,61 \%$ & $0,76 \%$ & $0,21 \%$ & $2,57 \%$ & $0,57 \%$ & $0,04 \%$ & $2,37 \%$ \\
\hline
\end{tabular}


Capítulo 3: Análisis del efecto disposición en los fondos SR

Cuadro 3.1: Estadísticos descriptivos (continuación)

Panel B: variables explicativas

\begin{tabular}{|c|c|c|c|c|c|c|}
\hline & \multicolumn{3}{|c|}{ Rentabilidad $_{i, t}$} & \multicolumn{3}{|c|}{ Eficiencia $_{i, t}$} \\
\hline & Media & Mediana & D.t. & Media & Mediana & D.t. \\
\hline 1999 & $20,72 \%$ & $15,03 \%$ & $26,14 \%$ & $0,57 \%$ & $0,09 \%$ & $2,28 \%$ \\
\hline 2000 & $-3,28 \%$ & $-5,10 \%$ & $12,41 \%$ & $1,03 \%$ & $0,91 \%$ & $1,09 \%$ \\
\hline 2001 & $-10,59 \%$ & $-12,61 \%$ & $13,53 \%$ & $0,39 \%$ & $0,17 \%$ & $1,38 \%$ \\
\hline 2002 & $-22,33 \%$ & $-22,37 \%$ & $7,78 \%$ & $-0,03 \%$ & $0,10 \%$ & $0,75 \%$ \\
\hline 2003 & $30,60 \%$ & $29,37 \%$ & $9,34 \%$ & $0,04 \%$ & $-0,04 \%$ & $0,52 \%$ \\
\hline 2004 & $11,21 \%$ & $10,35 \%$ & $4,52 \%$ & $-0,34 \%$ & $-0,02 \%$ & $2,05 \%$ \\
\hline 2005 & $5,31 \%$ & $4,57 \%$ & $4,76 \%$ & $0,14 \%$ & $0,13 \%$ & $0,38 \%$ \\
\hline 2006 & $12,08 \%$ & $13,06 \%$ & $5,43 \%$ & $0,00 \%$ & $0,18 \%$ & $0,64 \%$ \\
\hline 2007 & $5,25 \%$ & $3,96 \%$ & $8,15 \%$ & $0,31 \%$ & $0,22 \%$ & $0,62 \%$ \\
\hline 2008 & $-37,55 \%$ & $-37,50 \%$ & $6,53 \%$ & $0,33 \%$ & $0,21 \%$ & $0,80 \%$ \\
\hline 2009 & $31,74 \%$ & $30,25 \%$ & $11,11 \%$ & $0,22 \%$ & $0,20 \%$ & $0,63 \%$ \\
\hline 2010 & $17,86 \%$ & $16,13 \%$ & $6,60 \%$ & $-0,02 \%$ & $-0,12 \%$ & $0,58 \%$ \\
\hline 2011 & $-1,61 \%$ & $-0,71 \%$ & $5,09 \%$ & $-0,17 \%$ & $-0,09 \%$ & $0,44 \%$ \\
\hline 2012 & $14,54 \%$ & $15,06 \%$ & $3,65 \%$ & $-0,15 \%$ & $-0,10 \%$ & $0,37 \%$ \\
\hline 2013 & $33,43 \%$ & $32,75 \%$ & $5,29 \%$ & $-0,17 \%$ & $-0,10 \%$ & $0,51 \%$ \\
\hline 2014 & $8,93 \%$ & $10,26 \%$ & $5,32 \%$ & $-0,28 \%$ & $-0,13 \%$ & $0,54 \%$ \\
\hline 2015 & $-2,46 \%$ & $-2,23 \%$ & $5,10 \%$ & $-0,24 \%$ & $-0,19 \%$ & $0,55 \%$ \\
\hline 2016 & $7,10 \%$ & $7,07 \%$ & $3,31 \%$ & $-0,11 \%$ & $-0,18 \%$ & $0,52 \%$ \\
\hline 1999-2007 & $5,44 \%$ & $4,03 \%$ & $10,23 \%$ & $0,23 \%$ & $0,19 \%$ & $1,08 \%$ \\
\hline $2008-2016$ & $8,00 \%$ & $7,90 \%$ & $5,78 \%$ & $-0,07 \%$ & $-0,06 \%$ & $0,55 \%$ \\
\hline $1999-2016$ & $6,72 \%$ & $5,96 \%$ & $8,00 \%$ & $0,08 \%$ & $0,07 \%$ & $0,81 \%$ \\
\hline
\end{tabular}




\section{Cuadro 3.1: Estadísticos descriptivos (continuación)}

Panel C: variables de control

\begin{tabular}{|c|c|c|c|c|c|c|c|c|c|c|c|c|c|c|c|}
\hline & \multicolumn{3}{|c|}{ Logsize $_{i, t}$} & \multicolumn{3}{|c|}{ Logage $_{i, t}$} & \multicolumn{3}{|c|}{ Risk $_{i, t}$} & \multicolumn{3}{|c|}{$\operatorname{Exp}_{i, t}$} & \multicolumn{3}{|c|}{ Logturnover $_{i, t}$} \\
\hline & Media & Medn. & D.t. & Media & Medn. & D.t. & Media & Medn. & D.t. & Media & Medn. & D.t. & Media & Medn. & D.t. \\
\hline 1999 & 9,89 & 9,81 & 0,98 & 0,51 & 0,63 & 0,71 & $4,59 \%$ & $4,39 \%$ & $1,48 \%$ & $1,60 \%$ & $1,50 \%$ & $0,63 \%$ & 1,72 & 1,83 & 0,39 \\
\hline 2000 & 9,90 & 9,75 & 0,97 & 0,49 & 0,59 & 0,64 & $6,36 \%$ & $5,48 \%$ & $2,45 \%$ & $1,41 \%$ & $1,47 \%$ & $0,54 \%$ & 1,67 & 1,72 & 0,41 \\
\hline 2001 & 9,89 & 9,81 & 0,94 & 0,58 & 0,61 & 0,51 & $6,87 \%$ & $5,92 \%$ & $2,73 \%$ & $1,45 \%$ & $1,49 \%$ & $0,80 \%$ & 1,61 & 1,65 & 0,46 \\
\hline 2002 & 9,89 & 9,74 & 0,88 & 0,73 & 0,71 & 0,39 & $5,95 \%$ & $5,83 \%$ & $1,54 \%$ & $1,52 \%$ & $1,47 \%$ & $1,52 \%$ & 1,55 & 1,57 & 0,49 \\
\hline 2003 & 9,95 & 9,69 & 0,84 & 0,78 & 0,76 & 0,38 & $3,61 \%$ & $3,38 \%$ & $0,77 \%$ & $1,35 \%$ & $1,45 \%$ & $0,54 \%$ & 1,55 & 1,48 & 0,56 \\
\hline 2004 & 9,94 & 9,78 & 0,94 & 0,77 & 0,80 & 0,49 & $2,78 \%$ & $2,48 \%$ & $0,96 \%$ & $1,32 \%$ & $1,45 \%$ & $0,49 \%$ & 1,57 & 1,56 & 0,50 \\
\hline 2005 & 9,93 & 9,81 & 0,95 & 0,79 & 0,82 & 0,45 & $2,88 \%$ & $2,71 \%$ & $0,82 \%$ & $1,28 \%$ & $1,40 \%$ & $0,50 \%$ & 1,62 & 1,62 & 0,46 \\
\hline 2006 & 10,01 & 9,85 & 0,83 & 0,80 & 0,87 & 0,46 & $2,45 \%$ & $2,22 \%$ & $0,97 \%$ & $1,27 \%$ & $1,31 \%$ & $0,44 \%$ & 1,68 & 1,77 & 0,39 \\
\hline 2007 & 9,99 & 9,93 & 0,86 & 0,77 & 0,90 & 0,55 & $2,96 \%$ & $2,97 \%$ & $0,44 \%$ & $1,23 \%$ & $1,25 \%$ & $0,43 \%$ & 1,59 & 1,62 & 0,40 \\
\hline 2008 & 9,87 & 9,90 & 0,92 & 0,84 & 0,93 & 0,44 & $7,02 \%$ & $6,92 \%$ & $1,33 \%$ & $1,20 \%$ & $1,20 \%$ & $0,45 \%$ & 1,68 & 1,71 & 0,40 \\
\hline 2009 & 9,80 & 9,88 & 1,02 & 0,93 & 0,98 & 0,35 & $6,92 \%$ & $6,55 \%$ & $1,75 \%$ & $1,26 \%$ & $1,25 \%$ & $0,46 \%$ & 1,69 & 1,67 & 0,38 \\
\hline 2010 & 9,93 & 9,97 & 0,81 & 0,97 & 1,02 & 0,33 & $5,86 \%$ & $5,76 \%$ & $0,78 \%$ & $1,26 \%$ & $1,28 \%$ & $0,46 \%$ & 1,67 & 1,61 & 0,41 \\
\hline 2011 & 10,01 & 10,06 & 0,79 & 0,98 & 1,06 & 0,39 & $5,40 \%$ & $5,10 \%$ & $1,09 \%$ & $1,22 \%$ & $1,25 \%$ & $0,43 \%$ & 1,62 & 1,62 & 0,41 \\
\hline 2012 & 10,02 & 10,02 & 0,79 & 1,02 & 1,10 & 0,34 & $3,42 \%$ & $3,38 \%$ & $0,71 \%$ & $1,19 \%$ & $1,19 \%$ & $0,44 \%$ & 1,60 & 1,65 & 0,41 \\
\hline 2013 & 10,20 & 10,17 & 0,71 & 1,07 & 1,13 & 0,30 & $2,78 \%$ & $2,65 \%$ & $0,44 \%$ & $1,12 \%$ & $1,11 \%$ & $0,40 \%$ & 1,56 & 1,61 & 0,36 \\
\hline 2014 & 10,35 & 10,32 & 0,66 & 1,11 & 1,16 & 0,27 & $3,00 \%$ & $2,77 \%$ & $0,68 \%$ & $1,09 \%$ & $1,09 \%$ & $0,39 \%$ & 1,55 & 1,56 & 0,34 \\
\hline 2015 & 10,33 & 10,34 & 0,73 & 1,10 & 1,18 & 0,36 & $3,98 \%$ & $3,93 \%$ & $0,53 \%$ & $1,02 \%$ & $1,02 \%$ & $0,38 \%$ & 1,50 & 1,51 & 0,36 \\
\hline 2016 & 10,33 & 10,30 & 0,75 & 1,15 & 1,21 & 0,29 & $3,78 \%$ & $3,58 \%$ & $0,71 \%$ & $0,98 \%$ & $1,00 \%$ & $0,39 \%$ & 1,60 & 1,58 & 0,29 \\
\hline $1999-2007$ & 9,93 & 9,80 & 0,91 & 0,69 & 0,74 & 0,51 & $4,27 \%$ & $3,93 \%$ & $1,35 \%$ & $1,38 \%$ & $1,42 \%$ & $0,66 \%$ & 1,62 & 1,65 & 0,45 \\
\hline $2008-2016$ & 10,09 & 10,11 & 0,80 & 1,02 & 1,09 & 0,34 & $4,68 \%$ & $4,52 \%$ & $0,89 \%$ & $1,15 \%$ & $1,15 \%$ & $0,42 \%$ & 1,61 & 1,61 & 0,37 \\
\hline $1999-2016$ & 10,01 & 9,95 & 0,85 & 0,85 & 0,92 & 0,42 & $4,48 \%$ & $4,22 \%$ & $1,12 \%$ & $1,26 \%$ & $1,29 \%$ & $0,54 \%$ & 1,61 & 1,63 & 0,41 \\
\hline
\end{tabular}




\subsection{Resultados}

\subsubsection{Análisis inicial de los flujos monetarios de los fondos}

\subsubsection{Resultados pasados y flujos monetarios}

Se realiza un análisis previo de la relación entre los flujos de los fondos y algunas de sus características. En primer lugar se examina si los flujos de los inversores están relacionados con los resultados pasados de los fondos. En la práctica cotidiana la información que mayor difusión tiene sobre el desempeño de un fondo es su rentabilidad pasada. A partir de dicho dato se acostumbran a elaborar rankings que pueden ser consultados fácilmente por los inversores. Aunque la advertencia de que "rentabilidades pasadas no garantizan rentabilidades futuras" es habitual en los folletos informativos de los fondos, ciertamente la rentabilidad pasada puede ser una de las variables tenidas en cuenta por el inversor a la hora de elegir un fondo de inversión ante la numerosa oferta existente en la industria de los fondos. Para analizar la relación entre los flujos y la rentabilidad pasada procedemos a agrupar cada año a los fondos en deciles según su desempeño en el año anterior. De esta forma el decil 1 (10) agrupa los fondos con peor (mejor) rentabilidad previa. A continuación se calculan los valores de las variables Intflow $w_{i, t}$, Outflow $w_{i, t}$ y Netflow $w_{i, t}$ para cada fondo $i$ en cada año $t$, es decir en cada caso se computa el flujo monetario en términos relativos sobre el patrimonio del período anterior, $t-1$. Posteriormente se calcula cada año la media de estas variables para cada decil de fondos. Finalmente se estima la media de estas medias a lo largo del período muestral. Con esta información se elabora la Figura 3.1.

\section{Figura 3.1: Relación entre flujos monetarios y rentabilidad pasada}

La figura muestra la relación entre los flujos monetarios y rentabilidad pasada durante el período 19992016. Los fondos se agrupan cada año en deciles según su desempeño en el año anterior. De esta forma el decil 1 (10) agrupa los fondos con peor (mejor) rentabilidad previa. Para cada fondo y año se calcula el ratio de las entradas de dinero sobre el patrimonio del fondo en el período anterior (Intflow $\mathrm{w}_{i, t}$ ) el ratio de las salidas de dinero también sobre el patrimonio en el período anterior (Outflow $i, t$ ) y de la misma forma con referencia al flujo neto de dinero $\left(\operatorname{Netflow~}_{i, t}\right)$. Cada año se calcula la media de estas variables para cada decil de fondos. El eje vertical representa la media de estas medias a lo largo del período muestral. 


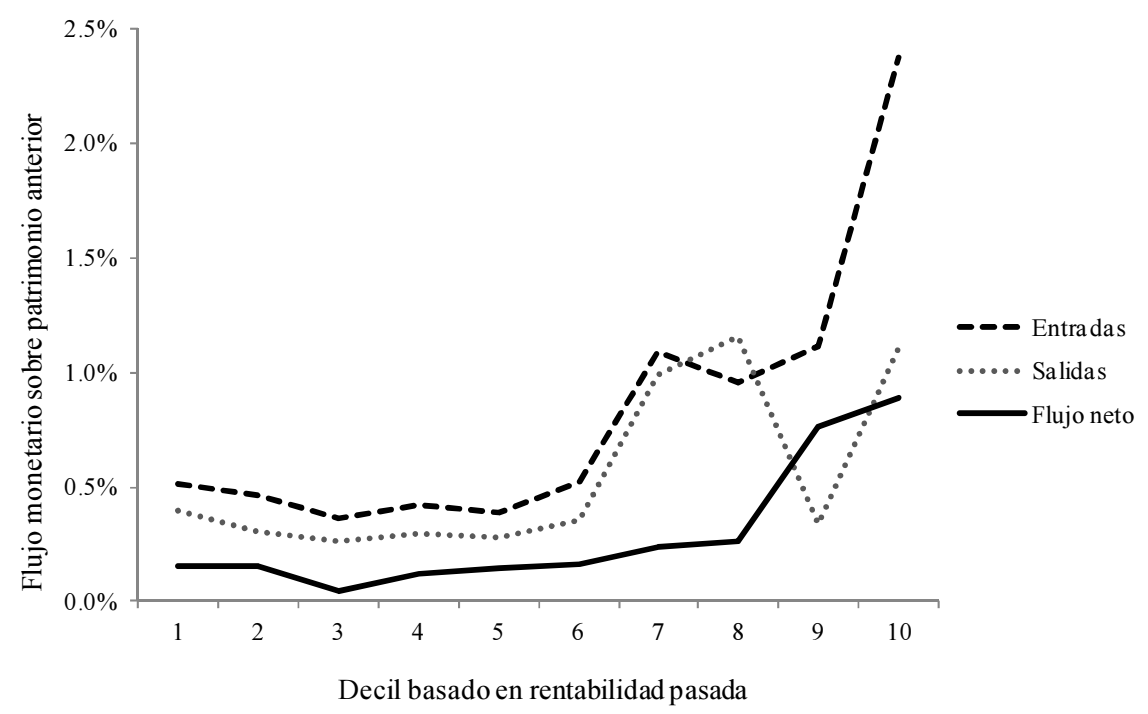

La Figura 3.1 proporciona información relevante sobre la relación entre los flujos de caja y la rentabilidad pasada de los fondos. Con relación al flujo neto, en primer lugar se observa cómo por término medio éste toma valor positivo, lo que significa que en términos generales ha sido mayor la entrada de dinero que la salida, resultado que es consistente con el importante desarrollo experimentado por la industria de los fondos de inversión durante todo el período muestral analizado. En segundo lugar se observa un incremento del flujo monetario conforme nos movemos de los fondos de peor a mejor rentabilidad pasada. Así, las entradas de dinero de los ocho primeros deciles están en torno al $0,16 \%$ del patrimonio, mientras que para el decil 9 es del $0,77 \%$ y para el decil 10 del 0,89\%, es decir aproximadamente 5 veces más. Por lo tanto, cuanto mayor es la rentabilidad anterior del fondo mayor capacidad tiene para atraer, en términos netos y agregados, el dinero de los inversores. No obstante, hay que destacar que el saldo neto para los peores fondos no es negativo, es decir que los inversores no son tan sensibles a la hora de desinvertir o no invertir en los fondos que peores resultados han obtenido. Desde una perspectiva teórica se podría esperar un comportamiento diferenciado de los inversores como respuesta al desempeño del fondo, de forma que se invirtiera en aquellos fondos que mejor lo han hecho y se desinvirtiera en aquellos que peores resultados han alcanzado. Sin embargo no se observa ese comportamiento, si no que se evidencia cierta asimetría, en el sentido de que cuando un fondo lo ha hecho mejor efectivamente sí recibe más dinero, pero si se encuentra entre los peores no experimenta salidas netas de dinero.

El flujo neto es el resultado de las entradas y salidas de dinero de los inversores. La Figura 3.1 también se muestran por separado estos dos componentes. En general las entradas son mayores que las salidas, lo que produce, como ya hemos comentado que el 
flujo neto tenga un saldo positivo en global. Con respecto a las entradas de dinero observamos que éstas son crecientes conforme aumenta el desempeño del fondo. En términos medios, durante los seis primeros deciles la entrada de dinero se sitúa sobre el $0,59 \%$ del patrimonio. A partir del séptimo decil prácticamente se duplica, siendo la media de los deciles 7, 8 y 9 del 1,06\% para luego volver a incrementarse notablemente en el decil 10 y alcanzar un valor del 2,38\%. Por lo tanto, conforme los fondos obtienen mejores resultados mayor es la entrada de dinero que experimentan. Esta sensibilidad es especialmente relevante para el último decil, que corresponde a los mejores fondos. Por otro lado, también hay que destacar que a pesar de sus malos resultados fondos situados en los últimos deciles son capaces de atraer el dinero de inversores. Además se observa cierta convexidad motivada por el hecho de que incluso el peor decil de fondos tiene entradas de dinero ligeramente superiores a las evidenciadas por los deciles de 2 a 5 . Este resultado puede estar conducido por inversores que efectivamente no suponen que rentabilidades pasadas implican rentabilidades futuras (lo que implicaría en cierto modo una distribución aleatoriamente uniforme del dinero entre la amplia oferta de fondos de inversión) o que incluso siguen una estrategia contraria, suponiendo que fondos perdedores pueden ser ganadores en el futuro.

Por último, la Figura 3.1 muestra también el comportamiento de las salidas de dinero en función de los resultados anteriores del fondo. Esta variable nos resulta de mayor interés para el estudio del efecto disposición porque, a diferencia de las entradas de dinero, que las pueden realizar tanto antiguos como nuevos inversores del fondo, las salidas de dinero obviamente sólo las pueden ordenar aquellos que ya son inversores del fondo. Si teóricamente admitiéramos un comportamiento de los inversores dependiente de los rendimientos pasados del fondo, cabría esperar que aquellos fondos con peores (mejores) resultados mostraran mayores (menores) salidas de dinero. Sin embargo la Figura 3.1 muestra un comportamiento contrario al que acabamos de señalar. Concretamente, las salidas de dinero para los deciles 1 a 6 se sitúan sobre el $0,32 \%$ del patrimonio del fondo, siendo mayores para los deciles 7, 8 y 10 con una media del 1,08\%. Estos resultados podrían ser tomados como una evidencia de efecto disposición de los inversores en los fondos. Concretamente, este sesgo supone que un individuo muestra una tendencia a vender (mantener) activos al objeto de realizar (no realizar) las ganancias (pérdidas) derivadas de la inversión en dicho activo. En este sentido, la Figura 3.1 muestra cómo por término medio los mejores (peores) fondos presentan mayores (menores) salidas de dinero, comportamiento consistente con el efecto disposición. Un caso diferente a sus contiguos, es el decil 9, cuyos fondos por término medio experimentan una salida del $0,34 \%$ del patrimonio, similar a la mostrada por los fondos de los deciles inferiores. Los inversores de estos fondos podrían pensar que sus 
fondos con un desempeño positivo podrían tener en el futuro un desempeño similar o mejor.

$\mathrm{Si}$ a partir de estos resultados pudiéramos inferir el comportamiento de los inversores podríamos señalar las siguientes pautas relacionadas con el efecto disposición: a) debido a la tendencia a no realizar pérdidas, la sensibilidad de los inversores de los peores fondos para desinvertir es menor que la existente para invertir en los mejores fondos; $b$ ) debido a la tendencia a realizar ganancias, los inversores de los mejores fondos, en el decil 10, muestran una mayor sensibilidad a desinvertir; c) los inversores de los fondos de los deciles 7 y 8 presentan también una mayor sensibilidad para invertir, quizás debido a que sus fondos no alcanzaron unos resultados mejores de los esperados y d) los inversores del decil 9 no muestran esa mayor sensibilidad por desinvertir quizás a la espera de que el fondo siga persistente con el desempeño previo.

Podría argumentarse que las relaciones observadas entre el rendimiento pasado de los fondos y sus flujos monetarios podrían estar conducidos por alguno de los años objeto de análisis. En este sentido y como prueba de robustez la Figura 3.2 muestra la misma información que la Figura 3.1 pero desagregando para diferentes subperíodos muestrales. Concretamente para un subperíodo pre-crisis, 1999-2007 y otro post-crisis, 2008-2016. Los resultados que muestra el Panel A para el primer subperíodo son consistentes con los comentados anteriormente, es decir: el flujo neto es positivo como consecuencia de mayores entradas que salidas de dinero; los flujos netos y de entrada son crecientes con respecto al rendimiento de los fondos y muestran cierta convexidad; las salidas de dinero también son crecientes con el rendimiento y el decil 9 presenta un elevado nivel de entradas de dinero y unos reembolsos reducidos. Los resultados para el segundo subperíodo son mostrados en el Panel B. Lo más destacable es que la diferencia entre las entradas y las salidas es menor que la mostrada para el período anterior, lo que hace que el flujo neto tome valores muy reducidos, prácticamente para todos los deciles excepto el 10. Este resultado indica que durante todo el período posterior a la crisis los inversores han sido reacios a aumentar las inversiones en estos fondos, a excepción de aquellos situados en el decil de los mejores fondos. Por otro lado, de forma similar a la evidencia encontrada para el primer subperíodo, el decil 9 muestra salidas de dinero menores que las de los deciles contiguos, aunque a diferencia del primer subperíodo su nivel de entradas de dinero también se reduce. 


\section{Figura 3.2: Relación entre flujos monetarios y rentabilidad pasada según subperíodos}

La figura muestra la relación entre los flujos monetarios y rentabilidad pasada. El Panel A presenta los resultados para el subperíodo 1999-2007 y el Panel B para el subperíodo 2008-2016. Los fondos se agrupan cada año en deciles según su desempeño en el año anterior. De esta forma el decil 1 (10) agrupa los fondos con peor (mejor) rentabilidad previa. Para cada fondo y año se calcula el ratio de las entradas de dinero sobre el patrimonio del fondo en el período anterior $\left(\right.$ Intflow $\left._{i, t}\right)$ el ratio de las salidas de dinero también sobre el patrimonio en el período anterior $\left(\right.$ Outflow $\left._{i, t}\right)$ y de la misma forma con referencia al flujo neto de dinero $\left(\right.$ Netflow $\left._{i, t}\right)$. Cada año se calcula la media de estas variables para cada decil de fondos. El eje vertical representa la media de estas medias a lo largo del período muestral.

Panel A. Subperíodo 1999-2007

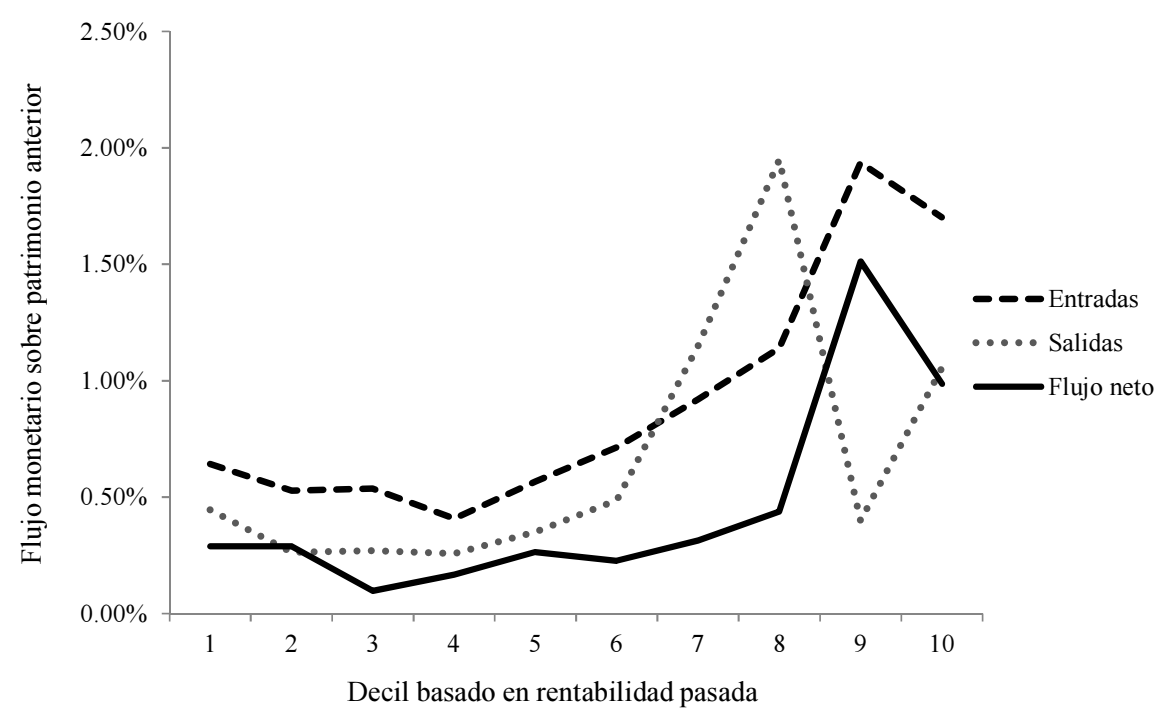

Panel B. Subperíodo 2008-2016

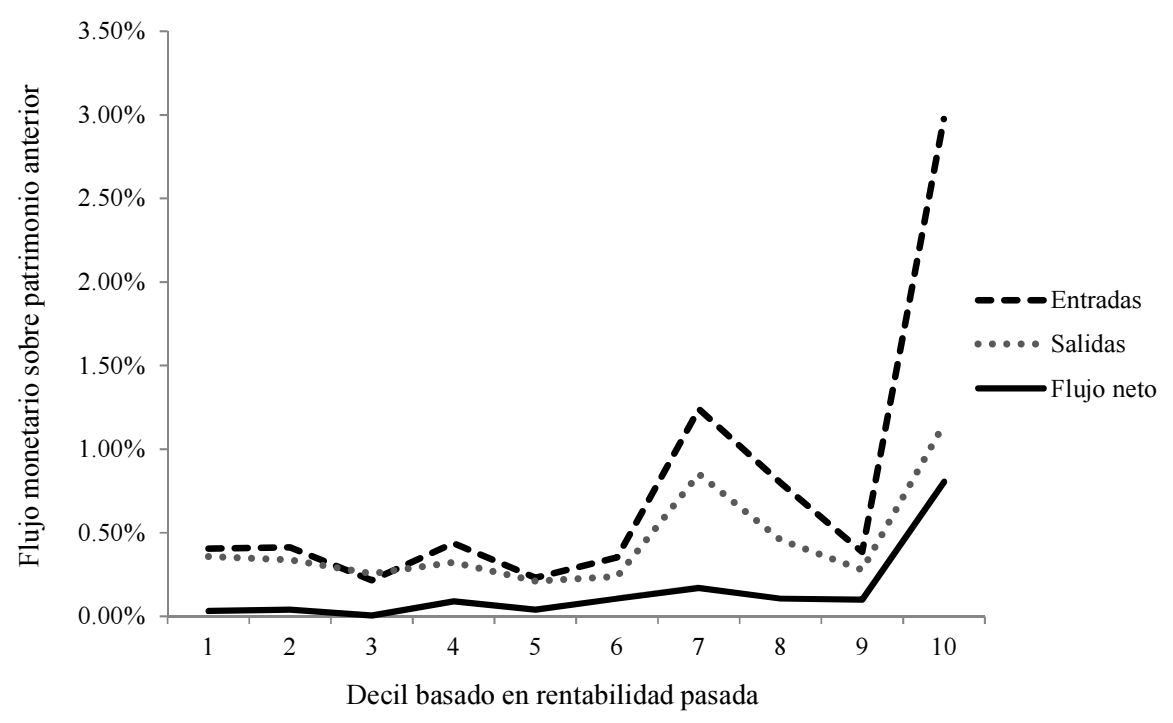

\subsubsection{Eficiencia pasada y flujos monetarios}

Como ya hemos comentado en la sección anterior, uno de los elementos relevantes al objeto de seleccionar los fondos por parte de los inversores puede ser los resultados 
obtenidos por éstos anteriormente. Además de la rentabilidad pasada, cada vez en más medios de información aparece información sobre la performance o eficiencia del fondo. Por lo tanto, éste también puede ser un elemento determinante para la selección de fondos. Para cada fondo se ha estimado la eficiencia anual mediante el modelo (1) a partir de los rendimientos mensuales del fondo, donde la constante o alfa mide el valor añadido del gestor con respecto al rendimiento teórico del fondo según el CAPM. A continuación se han agrupado los fondos en deciles según su eficiencia (alfa) en el año anterior. De esta forma el decil 1 (10) agrupa los fondos con peor (mejor) eficiencia en el período anterior. Seguidamente se calculan los valores de las variables Intflow $w_{i, t}$, Outflow $_{i, t}$ y Netflow $w_{i, t}$ para cada fondo $i$ en cada año $t$, es decir en cada caso se computa el flujo monetario en términos relativos sobre el patrimonio del período anterior, $t-1$. Posteriormente se calcula cada año la media de estas variables para cada decil de fondos. Finalmente se estima la media de estas medias a lo largo del período muestral. Con esta información se elabora la Figura 3.3.

\section{Figura 3.3: Relación entre flujos monetarios y eficiencia pasada}

La figura muestra la relación, durante el período 1999-2016, entre los flujos monetarios y eficiencia pasada. Los fondos se agrupan cada año en deciles según su eficiencia en el año anterior medida a partir de los rendimientos mensuales con el modelo (1). De esta forma el decil 1 (10) agrupa los fondos con peor (mejor) eficiencia previa. Para cada fondo y año se calcula el ratio de las entradas de dinero sobre el patrimonio del fondo en el período anterior ( Intflow $_{i, t}$ ) el ratio de las salidas de dinero también sobre el patrimonio en el período anterior (Outflow $i, t$ ) y de la misma forma con referencia al flujo neto de dinero $\left(\right.$ Netflow $\left._{i, t}\right)$. Cada año se calcula la media de estas variables para cada decil de fondos. El eje vertical representa la media de estas medias a lo largo del período muestral.

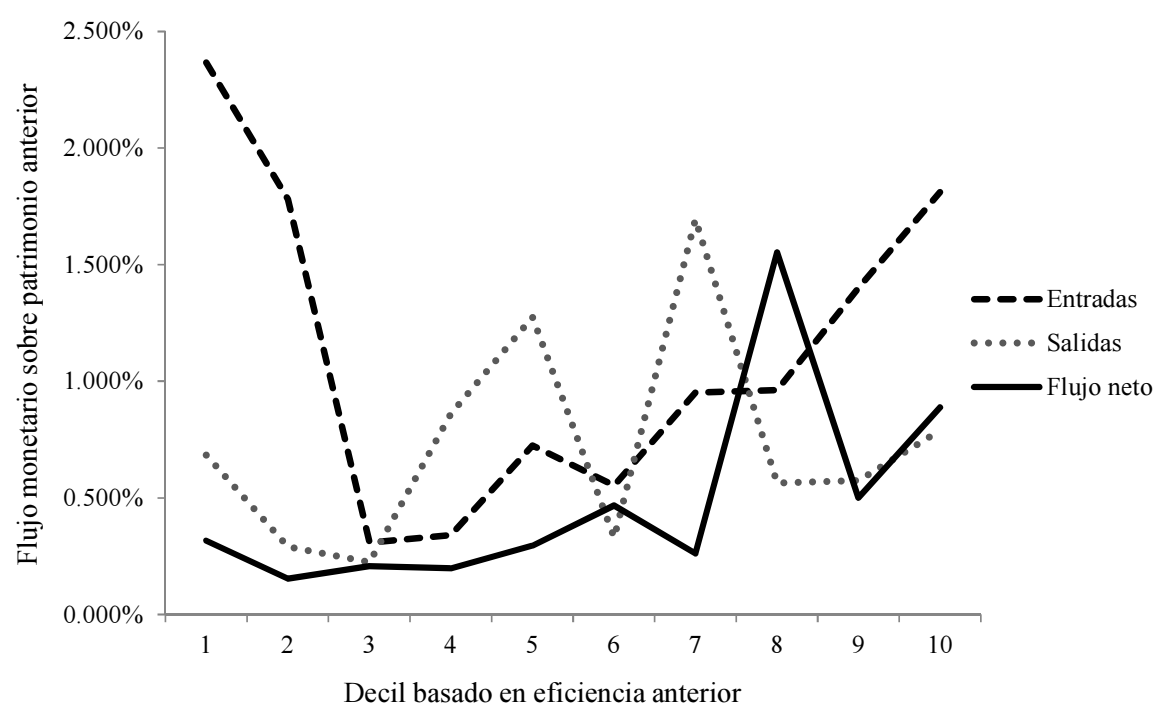

De forma similar al caso de los rendimientos pasados, en la Figura 3.3 se observa en general una relación positiva entre los flujos monetarios y la eficiencia pasada. Sin embargo esa tendencia no se observa con tanta claridad como en la Figura 3.1. Así por ejemplo las mayores salidas de dinero se producen para los deciles 5 y 7 mientras que el 
resto de deciles presentan unos niveles similares entre sí y de este modo no se aprecia una diferencia notable entre el primer y último decil. Con respecto a las entradas de dinero, la relación positiva se observa con más claridad a partir del tercer decil, pero sorprendentemente los deciles 1 y 2 , es decir aquellos fondos con peor eficiencia son los que presentan mayores entradas de dinero, resultado que no parece racional. Como prueba de robustez, la Figura 3.4 muestra el análisis anterior considerando los dos subperíodos muestrales: pre-crisis, 1999-2007 y post-crisis, 2008-2016. Así, observamos que el comportamiento en cierto modo anómalo de las entradas en los primeros deciles y en general la menor relevancia de la relación positiva entre eficiencia y flujos monetarios está conducida fundamentalmente por los datos del primer subperíodo muestral. Sin embargo, el Panel B de la Figura 3.4 para el segundo subperíodo sí muestra con mayor claridad una relación positiva entre flujos de entrada, salida y la eficiencia pasada. En consonancia con lo comentado anteriormente para el caso de la rentabilidad pasada, la relación positiva entre salidas de dinero y eficiencia podría considerarse un indicio del efecto disposición.

\section{Figura 3.4: Relación entre flujos monetarios y eficiencia pasada según subperíodos}

La figura muestra la relación entre los flujos monetarios y eficienca pasada. El Panel A presenta los resultados para el subperíodo 1999-2007 y el Panel B para el subperíodo 2008-2016. Los fondos se agrupan cada año en deciles según su eficiencia en el año anterior medida a partir de los rendimientos mensuales con el modelo (1). De esta forma el decil 1 (10) agrupa los fondos con peor (mejor) rentabilidad previa. Para cada fondo y año se calcula el ratio de las entradas de dinero sobre el patrimonio del fondo en el período anterior ( Intflow $_{i, t}$ ) el ratio de las salidas de dinero también sobre el patrimonio en el período anterior $\left(\right.$ Outflow $\left._{i, t}\right)$ y de la misma forma con referencia al flujo neto de dinero (Netflow $\mathrm{w}_{i, t}$ ). Cada año se calcula la media de estas variables para cada decil de fondos. El eje vertical representa la media de estas medias a lo largo del período muestral.

Panel A. Subperíodo 1999-2007

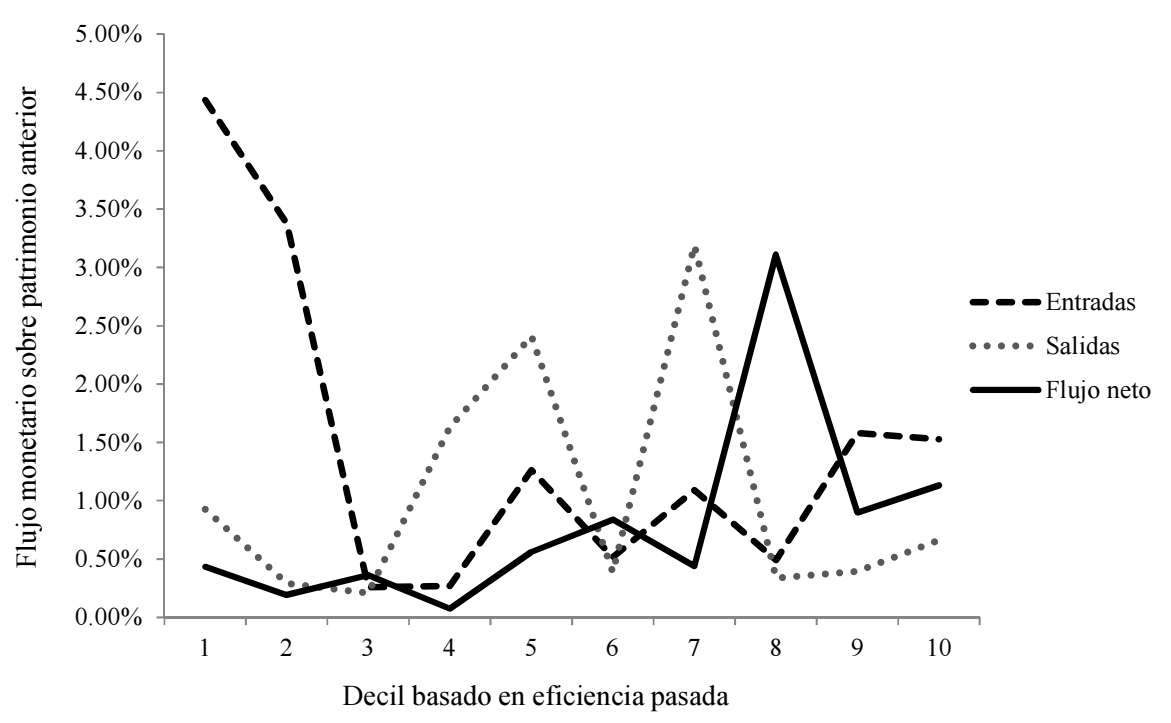


Panel B. Subperíodo 2008-2016

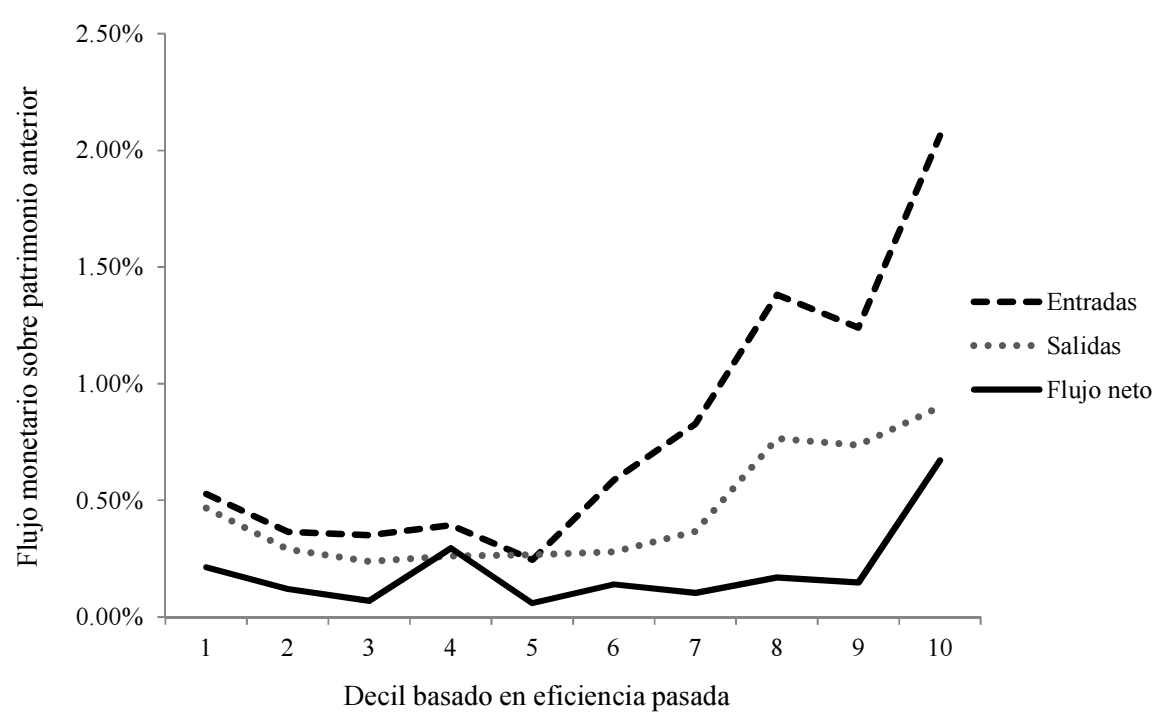

Estos resultados están en línea con la literatura previa, así la relación existente entre flujos netos de caja y eficiencia pasada de los fondos ha sido documentada: Chevalier y Ellison (1997) y Sirri y Tufano (1998). En concreto, Sirri y Tufano (1998) analizan la relación existente entre los flujos monetarios y el desempeño del fondo en el pasado, observando que ambos tienen una relación positiva y significativa, especialmente para los casos en que la eficiencia anterior ha sido más elevada.

\subsubsection{Nivel de riesgo y flujos monetarios}

A continuación se analiza la relación entre el riesgo pasado del fondo y sus flujos monetarios. De forma similar a la sección anterior procedemos a agrupar cada año a los fondos en deciles según su riesgo en el año anterior, medido como la desviación típica de sus rendimientos mensuales. De esta forma el decil 1 (10) agrupa los fondos con menor (mayor) riesgo en el año anterior. A continuación se calculan los valores de las

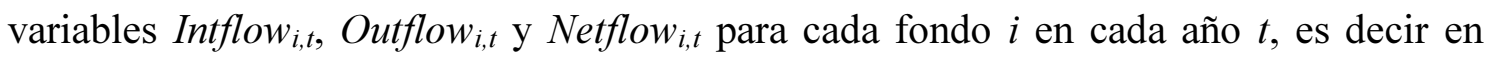
cada caso se computa el flujo monetario en términos relativos sobre el patrimonio del período anterior, $t-1$. Posteriormente se calcula cada año la media de estas variables para cada decil de fondos. Finalmente se estima la media de estas medias a lo largo del período muestral. Con esta información se elabora la Figura 3.5 en la que es difícil apreciar alguna pauta o comportamiento. Sí que se podría señalar que los flujos netos son mayores para los deciles 5 y 6 , es decir, aquellos fondos con niveles intermedios de riesgo. La Figura 3.6 muestra los resultados alcanzados en los subperíodos analizados. Del primer subperíodo, en el Panel A, podemos decir prácticamente lo mismo que lo 
comentado para todo el período muestral en la Figura 3.5. En el Panel B del segundo subperíodo tampoco se aprecia una pauta aunque en este caso los flujos netos no son mayores para los niveles intermedios de gastos, sino que más bien muestran cierta convexidad con mayores flujos para los fondos con más riesgo. En resumen, no se aprecia una relación entre el riesgo anterior de los fondos y sus flujos monetarios.

\section{Figura 3.5: Relación entre flujos monetarios y riesgo anterior}

La figura muestra la relación entre los flujos monetarios y el riesgo anterior de un fondo, durante el período 1999-2016. Los fondos se agrupan cada año en deciles según su riesgo en el año anterior. De esta forma el decil 1 (10) agrupa los fondos con menor (mayor) riesgo anterior. Para cada fondo y año se calcula el ratio de las entradas de dinero sobre el patrimonio del fondo en el período anterior (Intflow $i, t)$ el ratio de las salidas de dinero también sobre el patrimonio en el período anterior (Outflow $i, t$ ) y de la misma forma con referencia al flujo neto de dinero $\left(\right.$ Netflow $\left._{i, t}\right)$. Cada año se calcula la media de estas variables para cada decil de fondos. El eje vertical representa la media de estas medias a lo largo del período muestral.

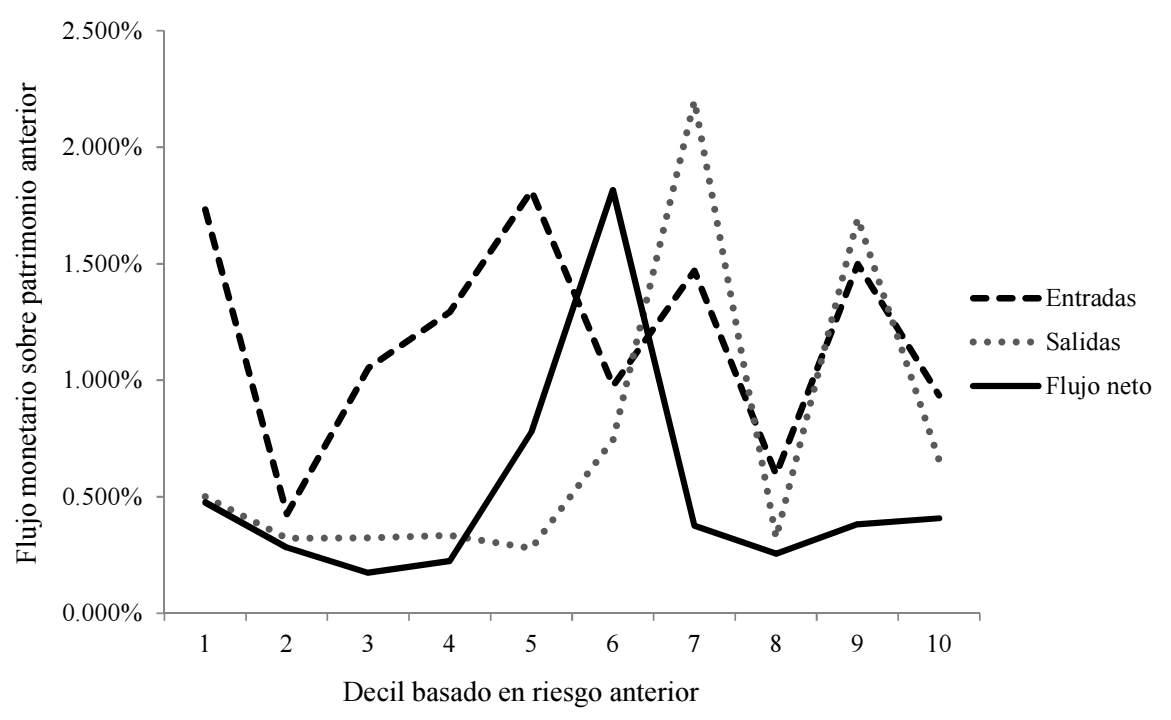

Figura 3.6: Relación entre flujos monetarios y riesgo anterior según subperíodos

La figura muestra la relación entre los flujos monetarios y el riesgo anterior de los fondos. El Panel A presenta los resultados para el subperíodo 1999-2007 y el Panel B para el subperíodo 2008-2016. Los fondos se agrupan cada año en deciles según su riesgo en el año anterior. De esta forma el decil 1 (10) agrupa los fondos con menor (mayor) riesgo anterior. Para cada fondo y año se calcula el ratio de las entradas de dinero sobre el patrimonio del fondo en el período anterior (Intflow $i, t$ ) el ratio de las salidas de dinero también sobre el patrimonio en el período anterior $\left(\mathrm{Outflow}_{i, t}\right)$ y de la misma forma con referencia al flujo neto de dinero $\left(\right.$ Netflow $_{i, t}$ ). Cada año se calcula la media de estas variables para cada decil de fondos. El eje vertical representa la media de estas medias a lo largo del período muestral. 
Panel A. Subperíodo 1999-2007

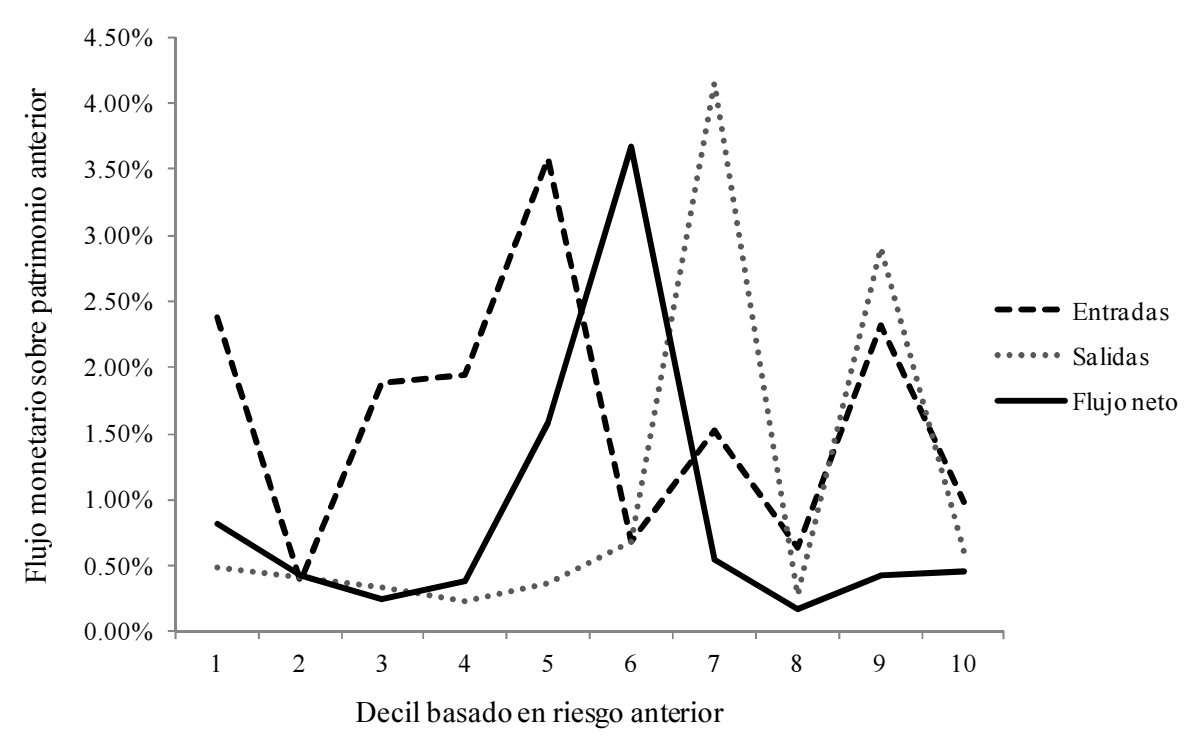

Panel B. Subperíodo 2008-2016

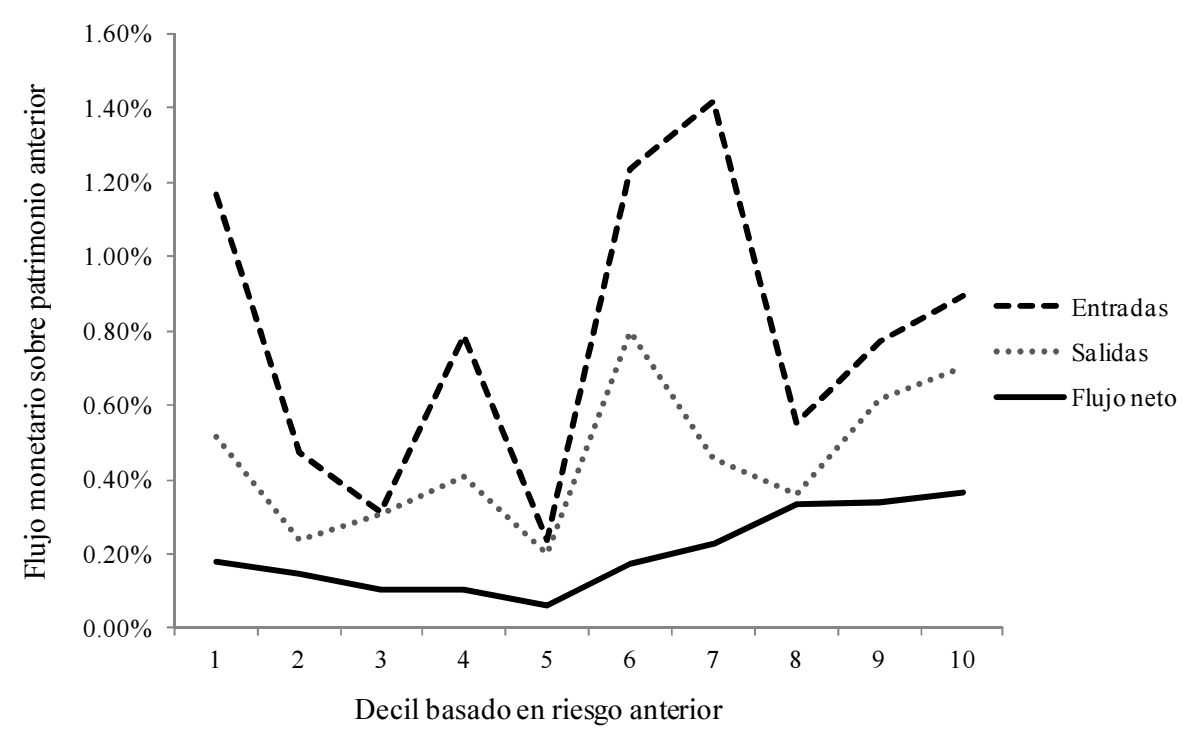

\subsubsection{Nivel de gastos y flujos monetarios}

En línea a Barber et al. (2005) nosotros también vamos a analizar la relación entre el nivel de gastos del fondo y sus flujos monetarios futuros. En este sentido, cabe suponer diferentes hipótesis sobre el comportamiento de los inversores. Por ejemplo, éstos pueden suponer que mayores gastos están asociados a una mayor gestión profesional del fondo por lo que los inversores pueden preferir fondos más caros. Por el contrario, otros inversores pueden suponer que mayores costes no tienen un reflejo en el desempeño del fondo, por lo que pagar unos costes mayores implicará un menor rendimiento y por 
tanto una menor demanda de estos fondos. De forma similar a las secciones anteriores, procedemos a agrupar cada año a los fondos en deciles según su porcentaje de gastos en el año anterior sobre patrimonio. Así el decil 1 (10) agrupa los fondos con menores (mayores) gastos en el año anterior. A continuación se calculan los valores de las

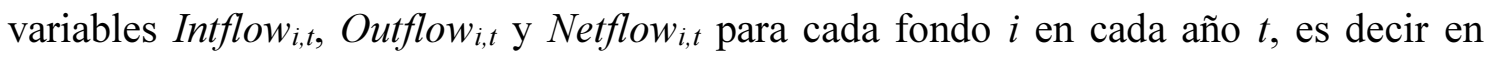
cada caso se computa el flujo monetario en términos relativos sobre el patrimonio del período anterior, $t-1$. Posteriormente se calcula cada año la media de estas variables para cada decil de fondos. Finalmente se estima la media de estas medias a lo largo del período muestral. Con esta información se elabora la Figura 3.7.

\section{Figura 3.7: Relación entre flujos monetarios y gastos soportados por el fondo}

La figura muestra la relación, durante el período 1999-2016, entre los flujos monetarios y el porcentaje de gastos soportados por el fondo en términos relativos sobre el patrimonio gestionado. Los fondos se agrupan cada año en deciles según su nivel de gastos en el año anterior. De esta forma el decil 1 (10) agrupa los fondos con menor (mayor) gastos anteriores. Para cada fondo y año se calcula el ratio de las entradas de dinero sobre el patrimonio del fondo en el período anterior (Intflow ${ }_{i, t}$ ) el ratio de las salidas de dinero también sobre el patrimonio en el período anterior $\left(\mathrm{Outflow}_{i, t}\right)$ y de la misma forma con referencia al flujo neto de dinero $\left(\mathrm{Netflow}_{i, t}\right)$. Cada año se calcula la media de estas variables para cada decil de fondos. El eje vertical representa la media de estas medias a lo largo del período muestral.

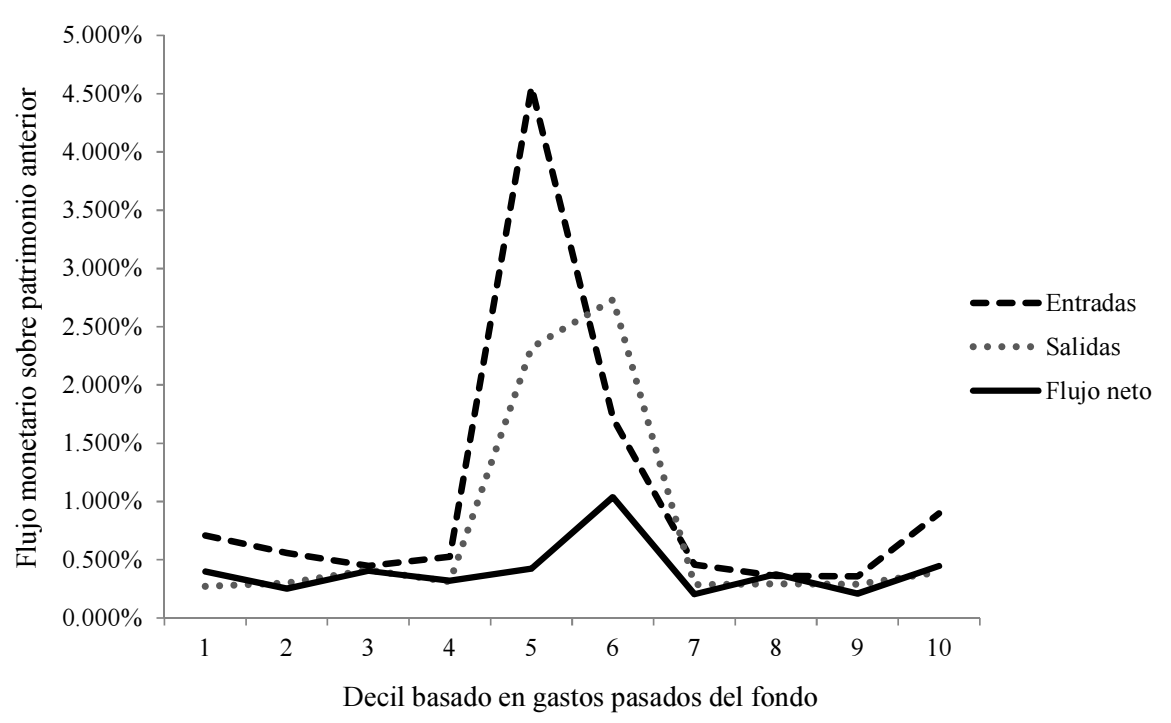

La Figura 3.7 muestra que los mayores niveles de entrada y salida de dinero se alcanzan para los fondos con niveles de gastos intermedios, es decir, ni los fondos más baratos ni los fondos más caros son los que atraen más flujos de dinero de los inversores, sino todo lo contrario. Este resultado se mantiene en los paneles de la Figura 3.8, es decir para los dos subperíodos muestrales contemplados. Sin embargo, este resultado no se aprecia para el caso de los flujos netos. 


\section{Figura 3.8: Relación entre flujos monetarios y gastos soportados por el fondo según subperíodos}

La figura muestra la relación entre los flujos monetarios y el nivel de gastos soportado por el fondo anteriormente. El Panel A presenta los resultados para el subperíodo 1999-2007 y el Panel B para el subperíodo 2008-2016. Los fondos se agrupan cada año en deciles según su nivel de gastos el año anterior. De esta forma el decil 1 (10) agrupa los fondos con menores (mayores) gastos. Para cada fondo y año se calcula el ratio de las entradas de dinero sobre el patrimonio del fondo en el período anterior (Intflow $\mathrm{w}_{i, t}$ ) el ratio de las salidas de dinero también sobre el patrimonio en el período anterior $\left(\right.$ Outflow $\left._{i, t}\right)$ y de la misma forma con referencia al flujo neto de dinero $\left(\operatorname{Netflow~}_{i, t}\right)$. Cada año se calcula la media de estas variables para cada decil de fondos. El eje vertical representa la media de estas medias a lo largo del período muestral.

Panel A. Subperíodo 1999-2007

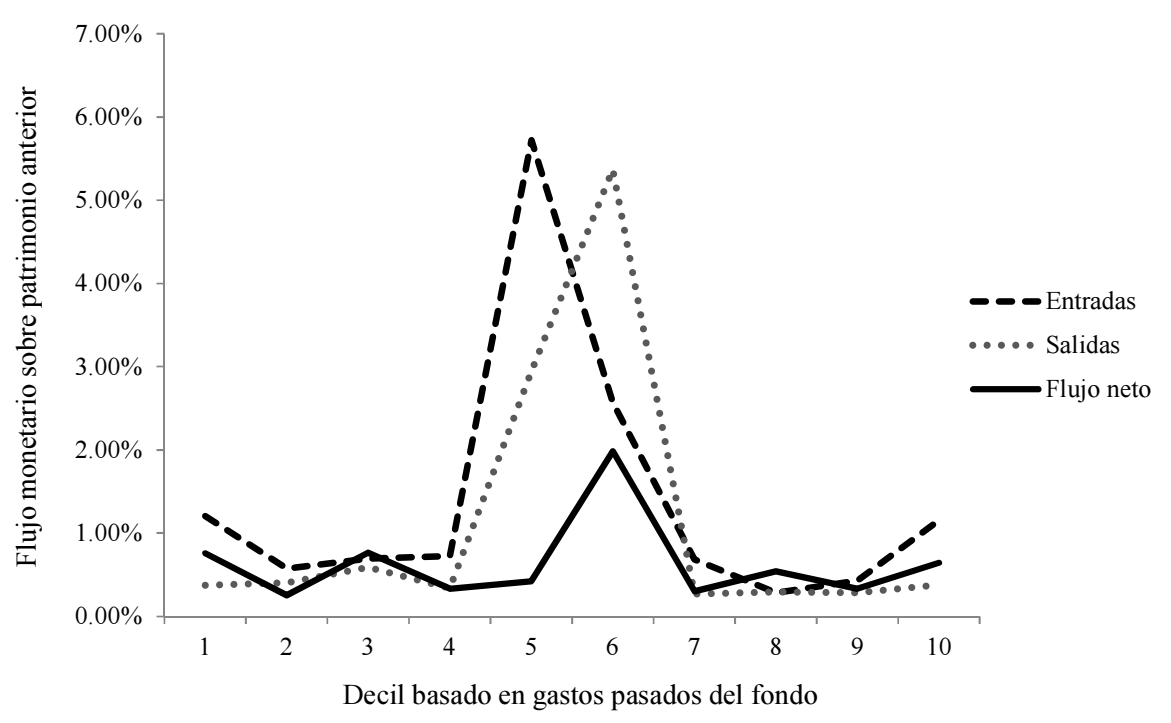

Panel B. Subperíodo 2008-2016

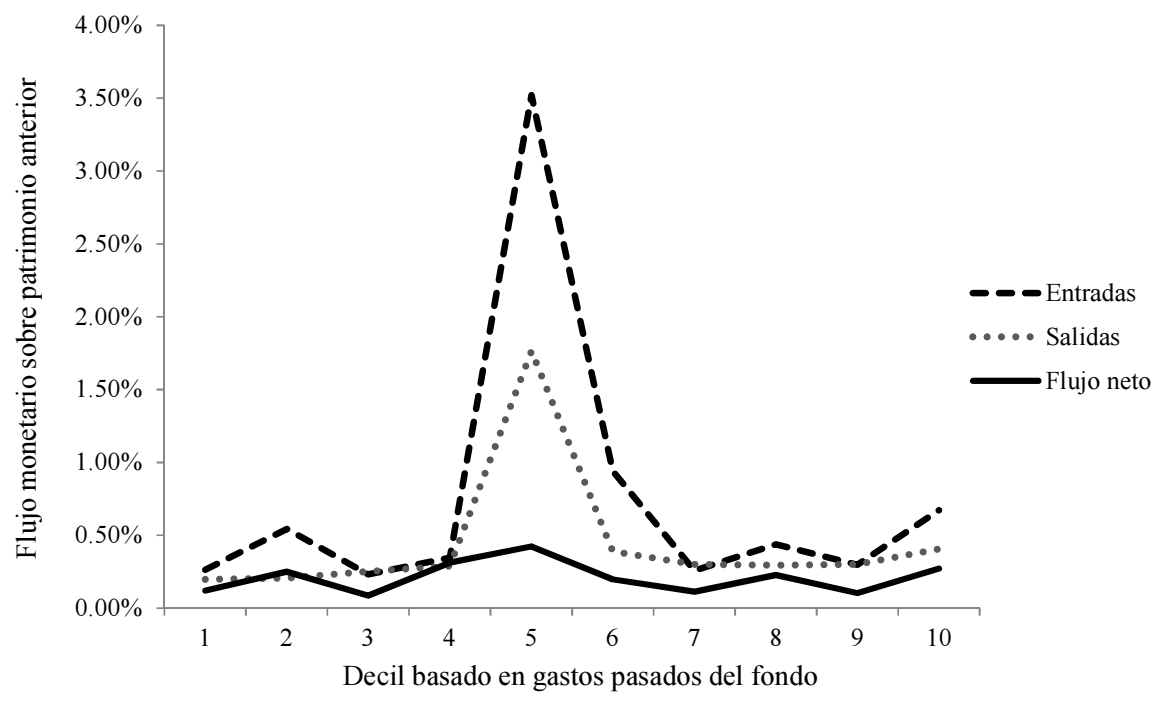

Literatura anterior ha apoyado la conexión existente entre los flujos monetarios y la eficiencia pasada, tomando como referencia los gastos asociados al fondo. Entre otros 
autores, Huang et al. (2007) y, Ivković y Weisbenner (2009) evidencian que los inversores toman en consideración los gastos y que son especialmente sensibles a los flujos en función de los niveles de eficiencia pasada y para fondos convencionales. Nuestro estudio contribuye a perfilar el comportamiento específico para los inversores de FSR observándose una tendencia similar a los convencionales en cuanto a la preferencia por invertir o desinvertir en los fondos que reportan niveles medios de gastos.

\subsubsection{Análisis mediante regresión de los flujos monetarios de los fondos}

\subsubsection{Resultados pasados y flujos monetarios}

A continuación vamos a aplicar un modelo de regresión multifactorial para analizar la relación entre los flujos monetarios y el rendimiento pasado de los fondos. Al igual que en las secciones anteriores, los flujos monetarios estudiados corresponden a las entradas de dinero, Intflow $w_{i, t}$, salidas o reembolsos, Outflow $w_{i, t}$ y el flujo neto, Netflow $w_{i, t}$ para cada fondo $i$ en cada año $t$, computándose en términos relativos como el cociente entre el flujo monetario y el patrimonio del fondo en el período anterior, $t-1$. Como variable explicativas incluiremos el rango de 0 a 1 derivado del rendimiento del fondo en el período anterior, $R_{a n k} k_{i, t-1}$, así como diferentes variables de control, también del período anterior: el logaritmo del patrimonio, Logsize $_{i, t-1}$, el logaritmo de la edad del fondo, $\operatorname{Logage}_{i, t-1}$, el riesgo medido por la desviación típica de los rendimientos mensuales, Risk $_{i, t-1}$, el porcentaje de gastos sobre patrimonio, $\operatorname{Exp}_{i, t-1}$, el logaritmo de la rotación de la cartera, Logtur $_{i, t-1}$, y a la vista de los resultados mostrados mostrado en la Figura 3.7, una variable dummy que toma valor 1 cuando el fondo está situado en los deciles 5 y 6 según su nivel de gastos, D56 $\exp _{i, t-1}$. En corte transversal para cada uno de los años se estiman los coeficientes de esta regresión. Con estos datos, se calcula la media y significatividad de cada coeficiente. Los resultados se muestran en el Cuadro 3.2 en tres paneles según el período muestral analizado.

En primer lugar, el Panel A del Cuadro 3.2 muestra los resultados para el período completo, es decir desde 1999 a 2016. Para las entradas de dinero, Intflow $i$, , la constante es positiva y significativa, lo que pone de manifiesto la entrada generalizada de dinero en la industria de los fondos SR durante estos años. La variable Rank $_{i, t-1}$ toma un valor positivo $(0,016$ y 0,013$)$ y significativamente distinto de cero ( $p$-value $0,012 \mathrm{y}$ $0,014)$ respectivamente en los dos modelos planteados. Es decir, en general aquellos fondos con mejores (peores) resultados reciben mayores (menores) entradas de dinero. 


\section{Cuadro 3.2: Resultados pasados y flujos monetarios}

El cuadro muestra los resultados de la aplicación de un modelo de regresión multifactorial para analizar la relación entre los flujos monetarios y el rendimiento pasado de los fondos. Los flujos monetarios estudiados corresponden a las entradas de dinero, Intflow $i, t$, salidas o reembolsos, Outflow $i, t$ y el flujo neto, Netflow $i, t$ para cada fondo $i$ en cada año $t$, computándose en términos relativos como el cociente entre el flujo monetario y el patrimonio del fondo en el período anterior, $t-1$. Como variables explicativas se consideran, el rango (de 0 a 1) derivado del rendimiento del fondo en el período anterior, Rank $k_{i, t-1}$, así como diferentes variables de control, también del período anterior: el logaritmo del patrimonio, Logsize $e_{i, t-1}$, el logaritmo de la edad del fondo, Logage $e_{i, t-l}$, el riesgo medido por la desviación típica de los rendimientos mensuales, Risk $\mathrm{k}_{i, t-l}$, el porcentaje de gastos sobre patrimonio, Exp $i_{i, t-1}$, el logaritmo de la rotación de la cartera, Logtur $r_{i, t-1}$, y una variable dummy que toma valor 1 cuando el fondo está situado en los deciles 5 y 6 según su nivel de gastos, D56exp $p_{t, t-l}$. En corte transversal para cada uno de los años se estiman los coeficientes de esta regresión. Con estos datos, se calcula la media y significatividad de cada coeficiente. El Panel A presenta los resultados para el período muestral completo, el Panel B para el subperíodo 1999-2007 y el Panel C para el subperíodo 2008-2016

\begin{tabular}{|c|c|c|c|c|c|c|c|c|c|c|c|c|c|c|c|c|c|c|}
\hline \multirow[b]{3}{*}{ Constante } & \multicolumn{6}{|c|}{ Panel A: Período 1999-2016 } & \multicolumn{6}{|c|}{ Panel B: Período 1999-2007 } & \multicolumn{6}{|c|}{ Panel C: Período 2008-2016 } \\
\hline & \multicolumn{2}{|c|}{ Inflow $_{i, t}$} & \multicolumn{2}{|c|}{ Outflow $w_{i, t}$} & \multicolumn{2}{|c|}{ Netflow $_{i, t}$} & \multicolumn{2}{|c|}{ Inflow $_{i, t}$} & \multicolumn{2}{|c|}{ Outflow $w_{i, t}$} & \multicolumn{2}{|c|}{ Netflow $_{i, t}$} & \multicolumn{2}{|c|}{ Inflow $_{i, t}$} & \multicolumn{2}{|c|}{ Outflow $w_{i, t}$} & \multicolumn{2}{|c|}{ Netflow $_{i, t}$} \\
\hline & 0,094 & 0,094 & 0,076 & 0,073 & 0,035 & 0,035 & 0,120 & 0,118 & 0,134 & 0,130 & 0,060 & 0,058 & 0,073 & 0,075 & 0,030 & 0,029 & 0,016 & 0,017 \\
\hline & {$[0,003]$} & {$[0,004]$} & {$[0,110]$} & {$[0,106]$} & {$[0,035]$} & {$[0,030]$} & {$[0,015]$} & {$[0,011]$} & {$[0,225]$} & {$[0,218]$} & {$[0,116]$} & {$[0,104]$} & {$[0,085]$} & {$[0,121]$} & {$[0,095]$} & {$[0,119]$} & {$[0,059]$} & {$[0,078]$} \\
\hline \multirow[t]{2}{*}{$\operatorname{Rank}_{i,-1}$} & 0,016 & 0,013 & 0,006 & 0,004 & $\mathbf{0 , 0 0 8}$ & $\mathbf{0 , 0 0 7}$ & 0,011 & 0,007 & 0,005 & 0,001 & 0,010 & 0,008 & 0,019 & 0,018 & 0,006 & 0,006 & 0,006 & 0,006 \\
\hline & {$[0,012]$} & {$[0,014]$} & {$[0,004]$} & {$[0,054]$} & {$[0,005]$} & {$[0,006]$} & {$[0,065]$} & {$[0,139]$} & {$[0,031]$} & {$[0,674]$} & {$[0,098]$} & {$[0,126]$} & {$[0,063]$} & {$[0,050]$} & {$[0,048]$} & {$[0,038]$} & {$[0,007]$} & {$[0,006]$} \\
\hline \multirow[t]{2}{*}{ Logsize $_{i, t-1}$} & $-0,009$ & $-0,009$ & $-0,008$ & $-0,007$ & $-0,003$ & $-0,003$ & $-0,011$ & $-0,011$ & $-0,013$ & $-0,013$ & $-0,005$ & $-0,005$ & $-0,008$ & $-0,008$ & $-0,003$ & $-0,003$ & $-0,001$ & $-0,001$ \\
\hline & {$[0,007]$} & {$[0,008]$} & {$[0,096]$} & {$[0,093]$} & {$[0,034]$} & {$[0,030]$} & {$[0,015]$} & {$[0,011]$} & {$[0,210]$} & {$[0,200]$} & {$[0,115]$} & {$[0,101]$} & {$[0,137]$} & {$[0,156]$} & {$[0,116]$} & {$[0,130]$} & {$[0,101]$} & {$[0,119]$} \\
\hline \multirow[t]{2}{*}{ Logage $_{i, t-1}$} & $-0,001$ & 0,001 & 0,001 & 0,003 & $-0,004$ & $-0,003$ & 0,000 & 0,004 & 0,003 & 0,007 & $-0,004$ & $-0,002$ & $-0,001$ & $-0,001$ & 0,000 & 0,000 & $-0,004$ & $-0,004$ \\
\hline & {$[0,813]$} & {$[0,788]$} & {$[0,316]$} & {$[0,043]$} & {$[0,216]$} & {$[0,288]$} & {$[0,968]$} & {$[0,652]$} & {$[0,230]$} & {$[0,032]$} & {$[0,628]$} & {$[0,795]$} & {$[0,730]$} & $[0,820]]$ & {$[0,949]$} & {$[0,741]$} & {$[0,008]$} & {$[0,008]$} \\
\hline \multirow[t]{2}{*}{ Risk $_{i, t-1}$} & $-0,019$ & $-0,066$ & 0,077 & 0,047 & $-0,205$ & $-0,210$ & $-0,156$ & $-0,138$ & 0,141 & 0,124 & $-0,408$ & $-0,406$ & 0,088 & $-0,010$ & 0,026 & $-0,012$ & $-0,047$ & $-0,058$ \\
\hline & {$[0,870]$} & {$[0,453]$} & {$[0,107]$} & {$[0,239]$} & {$[0,083]$} & {$[0,064]$} & {$[0,279]$} & {$[0,380]$} & {$[0,040]$} & {$[0,074]$} & {$[0,114]$} & {$[0,100]$} & {$[0,623]$} & {$[0,925]$} & {$[0,695]$} & {$[0,797]$} & {$[0,528]$} & {$[0,430]$} \\
\hline \multirow[t]{2}{*}{$\operatorname{Exp}_{i, t-1}$} & $-0,591$ & $-0,496$ & $-0,615$ & $-0,524$ & 0,008 & 0,028 & $-0,688$ & $-0,652$ & $-1,243$ & $-1,092$ & 0,057 & 0,076 & $-0,516$ & $-0,375$ & $-0,127$ & $-0,081$ & $-0,030$ & $-0,010$ \\
\hline & {$[0,155]$} & {$[0,164]$} & {$[0,158]$} & {$[0,146]$} & {$[0,970]$} & {$[0,893]$} & {$[0,291]$} & {$[0,289]$} & {$[0,216]$} & {$[0,188]$} & {$[0,908]$} & {$[0,873]$} & {$[0,384]$} & {$[0,422]$} & {$[0,484]$} & {$[0,565]$} & {$[0,817]$} & {$[0,931]$} \\
\hline \multirow[t]{2}{*}{ Logtur $_{i, t-1}$} & 0,005 & 0,003 & 0,004 & 0,002 & 0,002 & 0,002 & 0,007 & 0,005 & 0,007 & 0,004 & 0,004 & 0,004 & 0,004 & 0,002 & 0,002 & 0,001 & 0,001 & 0,001 \\
\hline & {$[0,075]$} & {$[0,127]$} & {$[0,237]$} & {$[0,326]$} & {$[0,071]$} & {$[0,069]$} & {$[0,262]$} & {$[0,253]$} & {$[0,388]$} & {$[0,438]$} & {$[0,214]$} & {$[0,190]$} & {$[0,173]$} & {$[0,280]$} & {$[0,077]$} & {$[0,239]$} & {$[0,031]$} & {$[0,066]$} \\
\hline \multirow[t]{2}{*}{ D56exp $\exp _{i,-1}$} & & 0,012 & & 0,009 & & 0,002 & & 0,005 & & 0,010 & & 0,002 & & 0,018 & & 0,009 & & 0,001 \\
\hline & & {$[0,045]$} & & {$[0,057]$} & & {$[0,284]$} & & {$[0,529]$} & & {$[0,366]$} & & {$[0,514]$} & & {$[0,055]$} & & {$[0,017]$} & & {$[0,298]$} \\
\hline
\end{tabular}

Nota: los valores entre corchetes son la probabilidad crítica ( $p$-values). En negrita, valores significativos para un nivel de significación del 5\%. 
Estos resultados son similares a los alcanzados por Sirri y Tufano (1998) para el caso de los fondos convencionales. Aunque en los folletos de los fondos se advierte que rentabilidades pasadas no implican rentabilidades futuras, es lógico suponer que ante la variada oferta de fondos existentes los inversores necesiten algún criterio para elegir en que fondo invertir, y parece ser que la rentabilidad pasada es un criterio relevante para los inversores. Este resultado está en consonancia con la evidencia mostrada en la Figura 3.1. La otra variable que resulta significativa en ambos modelos es la relacionada con el tamaño del fondo $\operatorname{Logsize}_{i, t-1}$. El signo negativo de esta variable señala que el ratio de entrada de dinero es inversamente proporcional al tamaño del fondo. Este resultado es en cierto modo lógico por la propia construcción de la variable ya que ésta es el porcentaje de entrada de dinero sobre el patrimonio anterior del fondo. Ante una misma cuantía de dinero invertida en el fondo este ratio es mayor (menor) para el fondo de menor (mayor) tamaño. Por lo tanto, es lógico que este signo tome valor negativo a no ser que los flujos monetarios de entrada sean proporcionales al tamaño del fondo, cuestión que por la propia dinámica de la industria no tiene porqué producirse. Las siguientes variables no son significativas, aunque en algunos casos su signo tienen cierto sentido económico, así si suponemos que la mayoría de los inversores no tendrán una capacidad elevada para soportar riesgos, sería esperable una relación inversa entre el riesgo anterior del fondo, Risk $_{i, t-1}$, y la entrada de dinero. De la misma forma el signo negativo con respecto a los gastos, $\operatorname{Exp}_{i, t-1}$, implicaría que en cierto modo los inversores tienen menor preferencia por invertir en fondos con mayores gastos. En el primer modelo a izquierda la rotación de la cartera toma valor positivo y débilmente significativo ( $p$-value 0,075 ) dada la persistencia encontrada en la rotación de la cartera (De Mingo y Matallín, 2017) es plausible inferir que mayores entradas de dinero suponen mayores niveles de rotación de la cartera. Sin embargo, esta variable deja de ser significativa en el segundo modelo, es decir cuando se incorpora la variable binaria que toma valor 1 para los fondos con niveles intermedios de gastos, D56exp $p_{i, t-l}$ y cero en otro caso. Esta variable toma un valor positivo y significativo, recogiendo así el efecto de la entrada de dinero asociada a los fondos con un nivel de gastos dentro los deciles quinto y sexto, tal como se evidenciaba en la Figura 3.7.

Las siguientes columnas a la derecha muestran los resultados para las salidas de dinero o reembolsos de los fondos, Outflow $w_{i, t}$. Como se observa, la constante del modelo y la variable tamaño mantienen los mismos signos que para el caso de las entradas de dinero, pero ahora la significatividad es menor. La variable que mantiene cierta significatividad sigue siendo el rango de la rentabilidad pasada del fondo, $\operatorname{Rank}_{i, t-1}$, que también toma signo positivo, de forma que menor (mayor) rentabilidad pasada suponen menores (mayores) reembolsos de los inversores. Como ya hemos comentado si en cierto modo es esperable una relación positiva entre rentabilidad pasada y entradas de dinero, 
también sería de esperar una relación negativa en el caso de las salidas. Es decir, sería esperado que aquellos fondos con peores (mejores) resultados experimentaran mayores (menores) salidas de dinero. Sin embargo, el signo positivo observado en el Cuadro 3.2 indica en todo caso lo contrario; lo que se podría interpretar como una consecuencia del efecto disposición aplicado a la inversión en fondos de inversión, es decir la propensión a desinvertir en los mejores fondos y no desinvertir en los peores. No obstante, también hay que señalar que comparando el valor del coeficiente de $\operatorname{Rank}_{i, t-1}$ para el caso de las entradas de dinero ( 0,016 en el primer modelo y 0,013 en el segundo) éste es entre 2 y 3 veces superior a la sensibilidad de las salidas ante el nivel de rendimiento pasado $(0,006$ y 0,004 respectivamente). Es decir, que la sensibilidad del inversor a la hora de invertir en un fondo con relación a su rendimiento pasado es mayor que la existente en el efecto disposición. Por otro lado y con respecto al resto de variables que explican las salidas de dinero, también es significativa en el segundo modelo la variable $\operatorname{Logage}_{i, t-I}$ tomando un valor positivo de 0,003 lo que señala que en cierta medida hay mayores salidas de dinero en aquellos fondos más antiguos. En este segundo modelo, también la variable D56 $\exp _{i, t-l}$ toma valor positivo aunque con significatividad débil, lo que implica que los fondos con niveles de gastos intermedios experimentan mayores salidas de dinero. Este resultado valorado conjuntamente con el alcanzado para las entradas, supone que un nivel intermedio de gastos es una característica que favorece tanto la demanda como posterior desinversión en el fondo, es decir la rotación de dinero en el fondo. El resto de variables no son significativamente relevantes, aunque hay que señalar que el signo de esas variables es el mismo que el alcanzado para las entradas excepto para el riesgo, que toma valor positivo, de forma que más riesgo supone más salida de dinero.

En tercer lugar, las siguientes dos columnas hacia la derecha muestran los resultados para los flujos netos, Netflow $w_{i, t}$. Cuando se agregan entradas y salidas los resultados son similares, en cuanto a signo y significatividad a los alcanzados para las entradas. Es decir, constante positiva y significativa, sensibilidad positiva al nivel del rendimiento pasado del fondo, $\operatorname{Rank}_{i, t-l}$ y coeficiente negativo y significativo para el factor ligado al tamaño del fondo, $\operatorname{Logsize}_{i, t-l}$. Con significatividad débil (p value $<0,10$ ) también resultan relevantes el riesgo y la rotación de la cartera. Así, la variable Riskit-l toma valor negativo en ambos modelos $(-0,205$ y $-0,210)$ lo que señala una menor demanda de fondos con mayor riesgo. El valor 0,002 en ambos modelos para la variable Logtur $_{i, t}$ ${ }_{l}$ indica una relación positiva entre flujos netos de dinero y la rotación de la cartera.

Los paneles B y C del Cuadro 3.2, muestran respectivamente los resultados para el período pre-crisis 1999-2007 y post-crisis 2008-2016. En primer lugar, cabe señalar que los signos que toman las variables en ambos paneles son muy similares a los alcanzados en el Panel A para todo el período muestral. Es decir, una relación positiva entre los 
flujos (entradas, salidas y saldo neto) y el nivel de rentabilidad pasada, la rotación de la cartera, y la dummy para los niveles intermedios de gastos, mientras que se evidencia una relación generalmente negativa para el caso del tamaño y los gastos. Con respecto a la antigüedad del fondo, en general se presenta una relación positiva para las salidas de dinero pero negativa para los flujos netos. En consecuencia a mayor antigüedad el saldo de los flujos es negativo. En relación al riesgo, en general toma signo positivo para las salidas y negativo para el flujo neto, por lo que como resultado a mayor riesgo el saldo de los flujos es negativo. En resumen, no hay diferencias notables en los resultados alcanzados entre los dos subperíodos con respecto al signo de las variables que explican los flujos. Sí que hay diferencias en cuanto a su significatividad, de forma que en el segundo subperíodo, 2008-2016 resulta en general especialmente significativo el nivel de rentabilidad pasada, Rank $_{i, t-I}$ tanto para las entradas, como las salidas y el flujo neto, siendo también significativo pero negativa la relación entre el flujo neto y la edad del fondo. Sin embargo, para el primer período, 1999-2007 la variable Ranki,t-l en general no es significativa, excepto para el primer modelo y las salidas de dinero, mientras que sí lo son otros coeficientes como la constante, el efecto negativo del tamaño para las entradas, así como el efecto positivo de la edad y el riesgo, según modelo, para las salidas. En resumen estos resultados indican que en el subperíodo pre-crisis, era notable la entrada y salida de dinero, seguramente debido a la buena coyuntura económica y en los mercados financieros. Así la constante en este subperíodo según modelo es 0,12 y 0,118 para las entradas, 0,134 y 0,130 para las salidas y 0,06 y 0,058 para el flujo neto; mientras que en el segundo subperíodo los valores respectivamente son, 0,073 y 0,075 para las entradas, 0,030 y 0,029 para las salidas y 0,016 y 0,017 para el neto. Es decir estamos hablando que en el primer subperíodo la tasa de entrada y salida era casi el doble que la existente en el segundo subperíodo y que en términos netos era más del triple. Estos resultados están en línea con los estadísticos descriptivos de los flujos monetarios mostrados en el Panel A del Cuadro 3.1 en la sección de Datos y Metodología. Por lo tanto, el subperíodo pre-crisis se caracteriza por un mayor movimiento de dinero alentado por una situación económica boyante en el que el rendimiento pasado no es tan relevante. Sin embargo, en los momentos post-crisis el movimiento de dinero es menor y resulta más relevante la rentabilidad pasada del fondo para explicar la distribución de los flujos monetarios de los inversores entre los fondos SR.

\subsubsection{Eficiencia pasada y flujos monetarios}

De forma similar al apartado anterior, el Cuadro 3.3 muestra los resultados del análisis de la relación entre la eficiencia pasada Alfarank $_{i, t-1}$ y los flujos monetarios. Esta 
variable es el rango entre 0 y 1 que mide la posición relativa del fondo en función de su eficiencia en el período anterior. La efíciencia anual es estimada mediante el modelo (1) a partir de los rendimientos mensuales del fondo, es decir, la constante o alfa que mide el valor añadido del gestor con respecto al rendimiento teórico del fondo según el CAPM. En Panel A muestra los resultados para el período muestral completo y los paneles $\mathrm{B}$ y $\mathrm{C}$ los resultados correspondientes a los subperíodos pre-crisis y post-crisis respectivamente. La primera observación a realizar al comparar el Panel A del Cuadro 3.3 con el Cuadro 3.2, donde en lugar de la eficiencia se utilizaba la rentabilidad pasada, es que la variable Alfarank $_{i, t-l}$, al contrario que la evidencia del Cuadro 3.2, toma signo negativo y no es significativa cuando se analizan por separado las entradas y salidas. Para el caso de los flujos netos sí que toma un valor positivo $(0,007$ y 0,006 según modelo) y significativo, en consonancia con la evidencia mostrada anteriormente en el Cuadro 3.2. Por lo tanto, cuando se analizan de forma separada las entradas y las salidas, la eficiencia no resulta relevante, pero sí lo es en términos agregados sobre el flujo neto. La variable tamaño, sigue tomando signo negativo pero sólo es significativa para el caso de los flujos netos. El resto de variables no son significativas, aunque el signo de sus coeficientes en términos generales coincide con el de sus respectivos del Cuadro 3.2.

Cuando se realiza el análisis por subperíodos, hay que destacar la ausencia de significatividad de los parámetros en el Panel B para el primer subperíodo 1999-2007. Por el contrario en el Panel C, para el segundo subperíodo, la eficiencia pasada tiene una relación positiva y significativa tanto para las entradas, como para las salidas y los flujos netos. Este resultado está en línea con el alcanzado en el Cuadro 3.2 de forma que en el superíodo pre-crisis es tal el movimiento de dinero que no resulta relevante la eficiencia pasada mientras que los momentos post-crisis los inversores parecen poner más atención al desempeño del fondo en el pasado tanto a la hora de invertir como para desinvertir. Hay que tener en cuenta que la correlación entre las variables Alfarank $_{i, t-1}$ y Rank $_{i, t-l}$ es de 0,85 por lo tanto los resultados de utilizar una u otra variable no tienen que distar mucho. Sin embargo, los resultados utilizando la variable Rank $_{i, t-1}$, es decir que la rentabilidad pasada del fondo, parece que tienen mayor capacidad para explicar los flujos de caja de los inversores en los fondos. Este resultado tiene su lógica porque al fin y al cabo la rentabilidad es una información más directa, habitual y fácil de interpretar para un inversor medio, que lo es la información sobre eficiencia. 


\section{Cuadro 3.3: Eficiencia pasada y flujos monetarios}

El cuadro muestra los resultados de la aplicación de un modelo de regresión multifactorial para analizar la relación entre los flujos monetarios y la eficiencia pasada del fondo medida como la constante del modelo (1). Los flujos monetarios estudiados corresponden a las entradas de dinero, Intflow $i, t$, salidas o reembolsos, Outflow $i, t$ y el flujo neto, Netflow $_{i, t}$ para cada fondo $i$ en cada año $t$, computándose en términos relativos como el cociente entre el flujo monetario y el patrimonio del fondo en el período anterior, $t$ - 1 . Como variables explicativas se consideran el rango (de 0 a 1 ) derivado de la eficiencia del fondo en el período anterior, Alfarank $k_{i, t-l}$, así como diferentes variables de control, también del período anterior: el logaritmo del patrimonio, Logsize $e_{i, t-l}$, el logaritmo de la edad del fondo, Logage $e_{i, t-l}$, el riesgo medido por la desviación típica de los rendimientos mensuales, Risk $_{i, t-1}$, el porcentaje de gastos sobre patrimonio, Exp $p_{i, t-1}$, el logaritmo de la rotación de la cartera, Logtur ${ }_{i, t-l}$, y una variable dummy que toma valor 1

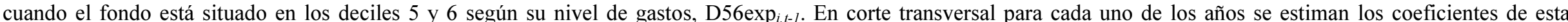
regresión. Con estos datos, se calcula la media y significatividad de cada coeficiente. El Panel A presenta los resultados para el período muestral completo, el Panel B para el subperíodo 1999-2007 y el Panel C para el subperíodo 2008-2016.

\begin{tabular}{|c|c|c|c|c|c|c|c|c|c|c|c|c|c|c|c|c|c|c|}
\hline \multirow[b]{3}{*}{ Constante } & \multicolumn{6}{|c|}{ Panel A: Período 1999-2016 } & \multicolumn{6}{|c|}{ Panel B: Período 1999-2007 } & \multicolumn{6}{|c|}{ Panel C: Período 2008-2016 } \\
\hline & \multicolumn{2}{|c|}{ Inflow $_{i, t}$} & \multicolumn{2}{|c|}{ Outflow $w_{i, t}$} & \multicolumn{2}{|c|}{ Netflow $w_{i, t}$} & \multicolumn{2}{|c|}{ Inflow $_{i, t}$} & \multicolumn{2}{|c|}{ Outflow $_{i, t}$} & \multicolumn{2}{|c|}{ Netflow $w_{i, t}$} & \multicolumn{2}{|c|}{ Inflow $_{i, t}$} & \multicolumn{2}{|c|}{ Outflow $w_{i, t}$} & \multicolumn{2}{|c|}{ Netflow $w_{i, t}$} \\
\hline & 0,196 & 0,180 & 0,158 & 0,144 & 0,034 & $\mathbf{0 , 0 3 3}$ & 0,347 & 0,312 & 0,323 & 0,293 & 0,060 & 0,056 & 0,077 & 0,076 & 0,030 & 0,028 & 0,014 & 0,015 \\
\hline & {$[0,110]$} & {$[0,091]$} & {$[0,105]$} & {$[0,096]$} & {$[0,056]$} & {$[0,049]$} & {$[0,222]$} & {$[0,198]$} & {$[0,156]$} & {$[0,144]$} & {$[0,133]$} & {$[0,123]$} & {$[0,147]$} & {$[0,184]$} & {$[0,111]$} & {$[0,149]$} & {$[0,197]$} & {$[0,211]$} \\
\hline \multirow[t]{2}{*}{ Alfarank $_{i, t-1}$} & $-0,001$ & $-0,004$ & $-0,006$ & $-0,010$ & $\mathbf{0 , 0 0 7}$ & 0,006 & $-0,023$ & $-0,029$ & $-0,022$ & $-0,029$ & 0,009 & 0,006 & $\mathbf{0 , 0 1 7}$ & 0,015 & 0,006 & 0,005 & 0,006 & 0,006 \\
\hline & {$[0,969]$} & {$[0,774]$} & {$[0,631]$} & {$[0,471]$} & {$[0,007]$} & {$[0,010]$} & {$[0,457]$} & {$[0,372]$} & {$[0,478]$} & {$[0,364]$} & {$[0,128]$} & {$[0,190]$} & {$[\mathbf{0 , 0 2 4}]$} & {$[0,022]$} & {$[0,027]$} & {$[0,025]$} & {$[0,010]$} & {$[0,010]$} \\
\hline \multirow[t]{2}{*}{$\operatorname{Logsize}_{i, t-1}$} & $-0,018$ & $-0,016$ & $-0,014$ & $-0,013$ & $-0,003$ & $-0,003$ & $-0,030$ & $-0,027$ & $-0,029$ & $-0,026$ & $-0,005$ & $-0,005$ & $-0,008$ & $-0,008$ & $-0,003$ & $-0,003$ & $-0,001$ & $-0,001$ \\
\hline & {$[0,084]$} & {$[0,069]$} & {$[0,086]$} & {$[0,079]$} & {$[0,050]$} & {$[0,047]$} & {$[0,199]$} & {$[0,173]$} & {$[0,136]$} & {$[0,126]$} & {$[0,138]$} & {$[0,133]$} & {$[0,145]$} & {$[0,161]$} & {$[0,118]$} & {$[0,136]$} & {$[0,125]$} & {$[0,131]$} \\
\hline \multirow[t]{2}{*}{ Logage $_{i, t-1}$} & 0,001 & 0,003 & 0,003 & 0,005 & $-0,002$ & $-0,002$ & 0,001 & 0,005 & 0,005 & 0,009 & 0,000 & 0,001 & 0,001 & 0,001 & 0,001 & 0,001 & $-0,004$ & $-0,004$ \\
\hline & {$[0,799]$} & {$[0,477]$} & {$[0,240]$} & {$[0,146]$} & {$[0,276]$} & {$[0,452]$} & {$[0,846]$} & {$[0,466]$} & {$[0,335]$} & {$[0,222]$} & {$[0,952]$} & {$[0,836]$} & {$[0,883]$} & {$[0,849]$} & {$[0,558]$} & {$[0,421]$} & {$[0,010]$} & {$[0,008]$} \\
\hline \multirow[t]{2}{*}{ Risk $_{i, t-1}$} & $-0,032$ & $-0,116$ & 0,022 & $-0,050$ & $-0,061$ & $-0,072$ & $-0,206$ & $-0,283$ & $-0,002$ & $-0,120$ & $-0,212$ & $-0,224$ & 0,103 & 0,014 & 0,042 & 0,005 & 0,057 & 0,047 \\
\hline & {$[0,784]$} & {$[0,428]$} & {$[0,757]$} & {$[0,542]$} & {$[0,418]$} & {$[0,320]$} & {$[0,393]$} & {$[0,354]$} & {$[0,987]$} & {$[0,523]$} & {$[0,187]$} & {$[0,133]$} & {$[0,333]$} & {$[0,914]$} & {$[0,469]$} & {$[0,918]$} & {$[0,225]$} & {$[0,359]$} \\
\hline \multirow[t]{2}{*}{$\operatorname{Exp}_{i, t-1}$} & $-1,380$ & $-1,212$ & $-1,172$ & $-1,050$ & $-0,019$ & $-0,002$ & $-2,469$ & $-2,305$ & $-2,482$ & $-2,290$ & 0,006 & 0,021 & $-0,533$ & $-0,362$ & $-0,154$ & $-0,086$ & $-0,038$ & $-0,020$ \\
\hline & {$[0,174]$} & {$[0,187]$} & {$[0,133]$} & {$[0,141]$} & {$[0,930]$} & {$[0,991]$} & {$[0,292]$} & {$[0,281]$} & {$[0,172]$} & {$[0,168]$} & {$[0,991]$} & {$[0,967]$} & {$[0,316]$} & {$[0,369]$} & {$[0,365]$} & {$[0,504]$} & {$[0,757]$} & {$[0,856]$} \\
\hline \multirow[t]{2}{*}{$\operatorname{Logtur}_{i, t-1}$} & 0,007 & 0,006 & 0,005 & 0,004 & 0,002 & 0,002 & 0,011 & 0,012 & 0,010 & 0,009 & 0,003 & 0,003 & 0,004 & 0,002 & 0,002 & 0,001 & 0,001 & 0,001 \\
\hline & {$[0,068]$} & {$[0,119]$} & {$[0,107]$} & {$[0,154]$} & {$[0,105]$} & {$[0,088]$} & {$[0,179]$} & {$[0,196]$} & {$[0,191]$} & {$[0,209]$} & {$[0,292]$} & {$[0,220]$} & {$[0,258]$} & {$[0,312]$} & {$[0,157]$} & {$[0,207]$} & {$[0,074]$} & {$[0,092]$} \\
\hline \multirow[t]{2}{*}{ D56exp ${ }_{i, t-1}$} & & 0,017 & & 0,014 & & 0,002 & & 0,016 & & 0,020 & & 0,002 & & 0,017 & & 0,008 & & 0,001 \\
\hline & & {$[0,057]$} & & {$[0,041]$} & & {$[0,433]$} & & {$[0,367]$} & & {$[0,183]$} & & {$[0,693]$} & & {$[0,058]$} & & {$[0,017]$} & & {$[0,282]$} \\
\hline
\end{tabular}

Nota: los valores entre corchetes son la probabilidad crítica ( $p$-values). En negrita, valores significativos para un nivel de significación del 5\%. 


\subsection{Conclusiones}

En este capítulo de la tesis se analiza el patrón de comportamiento que experimentan los inversores de fondos socialmente responsables en el mercado de Estados Unidos. En concreto, este estudio ahonda en el análisis del sesgo o la tendencia existente entre los inversores a mantener (vender) sus inversiones en situación de pérdidas (ganancias), o en otras palabras, la cuestión de investigación es si existe fundamento empírico sobre la existencia del efecto disposición para esta tipología de fondos que difiere de los convencionales. Para ello se toma como referencia la información histórica de los flujos monetarios definiéndose ésta como la variable clave y convenientemente se establece como variable explicativa la medición de los resultados del fondo y se toman dos indicadores, por un lado, la rentabilidad pasada del fondo y, por otro lado, la eficiencia o valora añadido del gestor.

El presente estudio proporciona evidencias de que las rentabilidades pasadas tienen un impacto sobre los flujos monetarios futuros, es decir, se identifica una clara sensibilidad de los inversores hacia los fondos que han obtenido mejores resultados en el pasado, concluyéndose que a mayor rentabilidad pasada del fondo mayor capacidad de atraer dinero de los inversores. Anecdóticamente, se constata además que los fondos con peores resultados siguen atrayendo el dinero de los inversores pudiendo dar cabida a comportamientos en base a una estrategia contraria que se apoyaría en el precepto de que los fondos perdedores pueden ser ganadores en el futuro. Para dotar de robustez al estudio, el período muestral se disecciona en dos subperíodos coincidiendo con etapa de pre-crisis (1999-2007) y post-crisis (2008-2016). Los resultados indican que la relación entre resultados pasados y flujos de caja es mucho más relevante en el segundo período muestral. Es decir, en momentos posteriores al origen de la crisis financiera parece ser que los inversores son más sensibles, en su toma de decisiones de inversión y desinversión, a los resultados pasados de los fondos.

Para la determinación de la existencia del efecto disposición, el estudio de los outflows o de las salidas de dinero resulta de especial importancia ya que contrariamente a lo esperado, los fondos con una menor (mayor) rentabilidad pasada son los que experimentan unas menores (mayores) salidas de dinero. Así, este estudio evidencia la existencia del efecto disposición ya que los inversores de fondos socialmente responsables presentan una propensión a ser menos sensibles a la hora de desinvertir o dejar de invertir en los fondos que peores resultados han reportado. Paralelamente, el enfoque de análisis que incluye la relación entre flujos monetarios y eficiencia parece ser menos evidente, aunque nuevamente atribuye una relación positiva entre las salidas de dinero y el grado de eficiencia; ésta puede considerarse indicativa de un sesgo de 
comportamiento, mostrándose un grado de sensibilidad mayor de los inversores especialmente en la etapa post-crisis tras un hito de innegable impacto económicosocial como ha sido el caso de la reciente crisis financiera global.

No existe unanimidad en la actualidad sobre la implicación que tienen los sesgos de comportamiento de los inversores en general y el efecto disposición en particular. Algunos autores postulan que los sesgos pueden orientar exitosas estrategias de inversión, mientras que otros defienden que una tendencia continuada puede conducir a decisiones desastrosas. Mientras que los sesgos de comportamiento pueden tener un carácter temporal o permanente y si la consideración de períodos se centra con perspectiva de medio-corto plazo versus largo plazo, distintos eventos acontecidos en el tiempo pueden conducir a distintas conclusiones. Se identifica que, en base a la hipótesis de existencia del sesgo de comportamiento, puede existir un impacto en los precios, pero también en el propio comportamiento del mercado como respuesta a la dinámica seguida por los inversores. Así, este análisis podría ser considerado como una posible extensión a futuras líneas de investigación. Además, un análisis combinado del efecto disposición con otros sesgos, por ejemplo, el herding tomando en consideración diferentes países, podría ser interesante. 


\section{Capítulo 4}

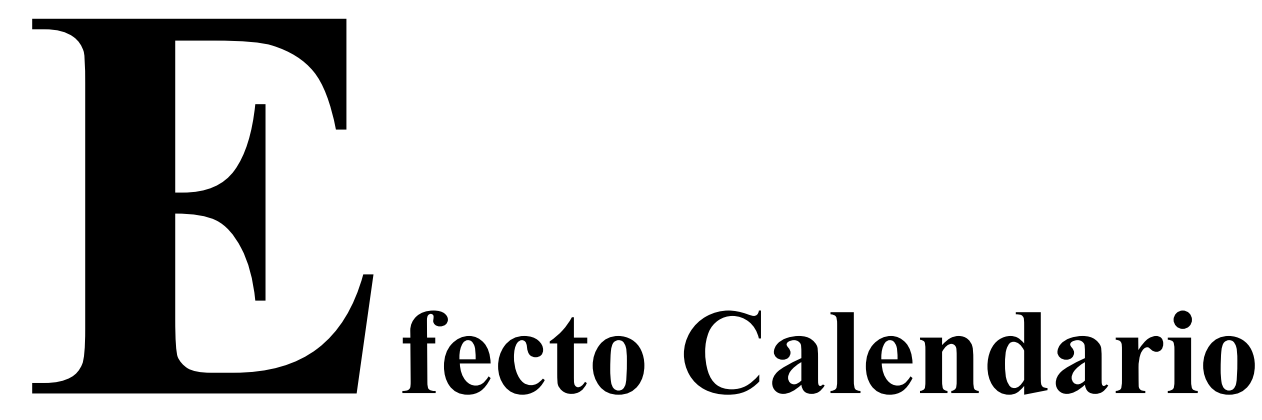

\subsection{Introducción}

Durante las últimas décadas, numerosos estudios han demostrado empíricamente la existencia de patrones de comportamiento regulares en las rentabilidades de las acciones y de los índices bursátiles. Así, en la mayoría de economías, se identifica la existencia de rendimientos sistemáticamente superiores o inferiores en función del día de la semana, el día del mes, el mes del año o incluso eventos estacionales. Estas anomalías que van ligadas a un determinado comportamiento de los mercados bursátiles y que están relacionadas con el calendario han sido denominadas "efecto calendario". Entre ellas podemos destacar: el efecto enero, el efecto fin de semana, el efecto cambio de mes y el efecto vacaciones.

Tradicionalmente, ha habido un gran interés tanto por parte de los inversores como por parte de los académicos en el estudio de los datos bursátiles, existiendo trabajos que abordan el efecto calendario que se remontan a las décadas de los años 30 y 40, como es el caso de los estudios de Fields $(1931,1934)$ o Wachtel (1942). Pero a pesar del tiempo transcurrido este tema sigue centrando la atención en la actualidad, tal es así que índices bursátiles como el Dow Jones Industrial Average (DJIA) o el Standard \& Poor's (S\&P) 500 Index se encuentran entre los conjuntos de datos más estudiados en el campo de las ciencias sociales.

En este contexto, varias de estas anomalías del calendario están bien documentadas y, en ocasiones, ya están consideradas como hechos fehacientes que acontecen en los 
mercados financieros. Por ejemplo: Cross (1973) sobre el efecto fin de semana, Ariel (1987) sobre el efecto vacaciones, Thaler (1987a, b) los efectos: enero, fin de semana, vacaciones, cambio de mes e intradía; Lakonishok y Smidt (1988) sobre el efecto cambio de mes, Bouman y Jacobsen (2002) y Jacobsen y Visaltanachoti (2009) proporcionan evidencias empíricas sobre el efecto Halloween, además Bouman y Jacobsen (2002) también observan la existencia de un fuerte efecto estacional basado en el popular dicho del mercado: "Vende en mayo y desaparece". Los autores encontraron que esta afirmación se corroboraba en 36 de los 37 mercados estudiados. Singleton y Wingender (2003) y Chandra (2006) investigan sobre el efecto día de la semana y Haug y Hirschey (2006), Moller y Zilca (2008), entre otros, reexaminaron el efecto enero. Por otro lado, Zhang y Li (2006) analizaron la rentabilidad de las acciones de China, uno de los líderes mundiales de los mercados de valores emergentes, estudiaron datos desde 1991 hasta 2004 en busca de algún patrón estacional. En su análisis demostraron la existencia de tres efectos calendario: el efecto mes del año, cambio de mes, y día de la semana, pero sólo son identificados hasta 1997 momento a partir del cual desaparecen. Estos resultados apoyan la hipótesis de Schwert (2002), según la cual a medida que los estudios confirman la existencia de los diversos efectos calendario, los inversores responden en consecuencia eliminándose así la anomalía y contribuyendo a hacer los mercados más eficientes.

Recientemente y para el caso español, el elevado número de trabajos publicados es un indicador de la relevancia del tema: Aragó y Fernández (2003) investigan la existencia de rentabilidades anormales dependiendo del mes del año, mientras que Meneu y Pardo (2004) analizan el efecto vacaciones. Cáceres et al. (2006) y Maroto et al. (2007) investigan el efecto día de la semana, el primero de los más importantes en los mercados europeos. García (2008) hace hincapié en las grandes diferencias entre las empresas de pequeña y mediana capitalización frente a los blue chips y confirma la existencia de efectos calendario en los mercados bursátiles españoles tanto para el Ibex 35 como para el Ibex Small Cap (aunque en el segundo son significativamente más importantes). Además, observa que el Ibex 35 presenta un importante efecto cambio de mes así como un elevado grado de autocorrelación en los rendimientos diarios de los lunes y que el Ibex Small Cap tiene rendimientos anormalmente elevados los viernes y el primer día de negociación después de períodos vacacionales, y a diferencia del Ibex 35 un importante efecto enero.

En general, los efectos calendario son estudiados aisladamente en la literatura, si bien es reseñable que algunos efectos pueden estar relacionados, por ejemplo, pudiéndose dar el caso de que algunos compartan días de cotización y consiguientemente pudiéndose identificar un efecto conjunto. Éste es aún un tema de investigación que ha recibido 
limitadas aportaciones, siendo destacable el estudio de Swinkels y Van Vliet (2012) quienes presentan un análisis exhaustivo centrado en la interacción entre los diferentes efectos calendario. Los autores identifican que los efectos Halloween y cambio de mes son los más relevantes, y que específicamente su coincidencia con el efecto vacaciones y fin de semana conjuntamente tiene un impacto notable. Este resultado es fruto de una regresión lineal multivariante que omite las interacciones no lineales. Recientemente, Olson et al. (2015) postulan que las anomalías pueden resurgir después de su desaparición inicial, presentando un comportamiento errante y que con el tiempo éstas desaparecerán considerando una perspectiva de largo plazo. La desaparición progresiva de los efectos calendario es un precepto anunciado en la hipótesis de los mercados eficientes o $E M H$, la cual establece que una anomalía tiende a desaparecer poco después de ser identificada.

Así, entre las posibles causas que justifican la existencia del efecto calendario se identifican las siguientes: el calendario impositivo (Van den Bergh y Wessels, 1985; Poterba y Weisbenner, 2001), los efectos de microestructura, tales como el cierre de mercados (Pettengill, 1989), la variación temporal de los diferenciales entre los precios (Keim, 1989), el riesgo macroeconómico (Chen y Chan, 1997), los sesgos en el comportamiento de los inversores (Kamstra et al., 2003; Doeswijk, 2008) y las ventas a corto (Christophe et al., 2009). En cambio, tomando en consideración la teoría económica tradicional, los precios de las acciones no deberían seguir pautas sistemáticas, por lo que excluye a priori los componentes estacionales a menos que éstos pueden estar ligados a las variaciones sistemáticas de las primas de riesgo (Samuelson, 1965; Leroy, 1973; Lucas, 1978). Por otro lado, existe una clara contradicción entre las anomalías del efecto calendario y la hipótesis de los mercados eficientes, según la cual toda la información debe estar reflejada en los precios de las acciones $\mathrm{y}$, por lo tanto, estas anomalías no deberían persistir en el tiempo (Fama, 1965).

Siguiendo la misma línea de criticismo, otros estudios más recientes también son escépticos ante la aceptación de la existencia de los efectos calendario y asocian los resultados en mayor grado al sesgo de selección de los datos en el ámbito de la investigación, "data snooping" (Sullivan et al., 2001; Baker et al., 2008; Cho et al., 2007). Lucey y Whelan (2001) proponen dos posibles soluciones ante este problema: en primer lugar, esperar a que el transcurso del tiempo proporcione nuevos datos, o alternativamente, encontrar una base de datos nueva que sea razonablemente independiente y que no haya sido investigada (o poco) previamente, como por ejemplo el Ibex Small Cap. Para Borges (2009) los efectos calendario pueden ser sólo una "quimera" desarrollada por el data mining, ya que los resultados son específicos para cada país y no siempre presentan una estabilidad en el tiempo. 
El principal objetivo de investigación de este capítulo es contrastar empíricamente la existencia de los diferentes efectos calendario estudiados en los mercados bursátiles españoles, y en caso de verificarse su existencia: i) determinar la relación entre éstos y las empresas de diferentes tamaños y ii) analizar su evolución y robustez en diferentes subperíodos muestrales, centrando específicamente el esfuerzo investigador en la reciente crisis financiera de 2008. 


\subsection{Datos y metodología}

Para analizar el efecto calendario en los mercados bursátiles españoles se utilizará la información histórica de las rentabilidades diarias de los cinco índices más representativos de las bolsas españolas: el Índice General de la Bolsa de Madrid (IGBM), el Ibex 35, el Ibex Medium Cap, el Ibex Small Cap y el Ibex Top Dividendo. La fuente utilizada es NetStation de Infobolsa, a excepción de la serie histórica del IGBM, la cual hemos obtenido a través de la base de datos de Morningstar. La utilización de estos cinco índices bursátiles, compuestos por empresas de diferente capitalización además de facilitar el contraste empírico sobre la existencia de los diferentes efectos, permitirá determinar una posible relación entre el tamaño de la empresa y la presencia de los efectos. Pero además, la utilización de índices de reciente creación y poco investigados, como el Ibex Small Cap (2005) y el Ibex Top Dividendo (2007), también nos aporta una posible solución, según Lucey y Whelan (2001), frente al peligro de exposición al efecto data snooping o data mining.

\section{Cuadro 4.1: Períodos muestrales}

Este cuadro muestra los períodos muestrales a estudiar para cada uno de los índices bursátiles.

\begin{tabular}{lcc} 
& Inicio del período muestral & Fin del período muestral \\
\hline IGBM & 2 de enero de 1986 & 31 de diciembre de 2015 \\
Ibex 35 & 2 de enero de 1992 & 31 de diciembre de 2015 \\
Ibex Medium Cap & 1 de julio de 1998 & 31 de diciembre de 2015 \\
Ibex Small Cap & 1 de julio de 2005 & 31 de diciembre de 2015 \\
Ibex Top Dividendo & 9 de mayo de 2007 & 31 de diciembre de 2015 \\
\hline
\end{tabular}

A continuación, se presenta una concisa descripción de los índices objeto de análisis. El IGBM es el Índice General de la Bolsa de Madrid, es el más longevo de los índices españoles ya que su origen se remonta a finales de 1940. Hasta 2002 tenía consideración de índice de precios formado por un conjunto de valores variables del mercado continuo y el mercado de corros de Madrid, calculado a partir del día 31 de diciembre de 1985 como una serie histórica continua con base 100. Pero es en el año 2002 cuando se producen una serie de transformaciones profundas aunque este "nuevo índice" va ligado a la misma base que el anterior Índice General (1985). Además, sigue estando igualmente formado por un número variable de empresas, normalmente superior a cien, cumple una serie de requisitos, que son: que coticen en la Bolsa de Madrid, que se revisen en reuniones ordinarias (semestrales) o extraordinarias para ser incluidas o excluidas en función del cumplimiento de en los siguientes criterios de liquidez, referidos al semestre anterior: i) Volumen de contratación sea superior a tres millones de euros en el semestre; ii) Rotación superior al 10\% de su capitalización en base anual, 
teniendo en cuenta para ello tan solo el capital flotante; iii) Frecuencia de contratación superior al 50\% de las sesiones hábiles. La ponderación de cada valor en el índice se calcula en función de la capitalización bursátil ajustada según capital flotante y teniendo en consideración las ponderaciones relativas de los sectores y subsectores en el Índice General. Este índice no se ajusta por dividendos, pero si por ampliaciones de capital, por fusiones y absorciones de empresas, existiesen desdoblamientos de acciones o splits y agrupamientos de acciones o contra-splits.

El Ibex 35 es el principal índice de referencia en los mercados financieros españoles, usado como referente nacional e internacional. Está elaborado por Bolsas y Mercados Españoles (BME) y compuesto por los 35 valores más líquidos cotizados en el Sistema de Interconexión Bursátil de las cuatro Bolsas Españolas (Madrid, Barcelona, Bilbao y Valencia).

El Ibex Medium Cap y el Ibex Small Cap son los índices de los valores de mediana y pequeña capitalización bursátil cotizados en el Sistema de Interconexión Bursátil de las cuatro Bolsas Españolas. Nacen con la vocación de mejorar la visibilidad y seguimiento de estos valores, convertirse en referente nacional e internacional de la evolución bursátil de las compañías españolas de mediana y pequeña capitalización y ser referencia para productos de inversión y ahorro. Técnicamente son índices de precios, ponderados por capitalización y ajustados por el capital flotante de cada compañía integrante del índice. El capital flotante hace referencia al número de títulos efectivamente en circulación en el mercado, es decir, que no pertenecen a una participación directa considerada de control (capital cautivo y, por tanto, no circulante en el mercado). Para que los valores puedan llegar a integrase en los índices Ibex Medium Cap e Ibex Small Cap dichos valores no pueden formar parte del índice Ibex 35 , además como requisitos se destaca que: ser contratados en el mercado principal, deben tener un porcentaje de capital flotante superior al 15\% y una rotación anualizada sobre el capital flotante real superior al 15\%. Los valores que cumplan estos criterios, se ordenarán por la capitalización bursátil del capital flotante y se establece un ranking de manera que los primeros 20 valores entran a formar parte de Ibex Medium Cap y los siguientes 30 valores entran a formar parte de Ibex Small Cap.

El Índice Ibex Top Dividendo es un índice que pondera la rentabilidad por dividendo. Se compone de los 25 valores cotizados en el Segmento de Contratación General del Sistema de Interconexión Bursátil de las cuatro Bolsas Españolas que, pertenecientes a los índices Ibex 35, Ibex Medium Cap o Ibex Small Cap tras la revisión, presenten una mayor rentabilidad por dividendo ajustado por el capital flotante de la compañía y con un coeficiente de liquidez. Para incorporar un valor en el índice Ibex Top Dividendo se 
requiere el pago de dividendos ordinarios de al menos los dos años anteriores a la fecha de la revisión.

\section{Cuadro 4.2: Estadísticos descriptivos de los cinco índices}

Este cuadro muestra los principales estadísticos descriptivos de las rentabilidades medias diarias de los cinco índices para sus respectivos períodos muestrales.

\begin{tabular}{lccccc}
\hline & IGBM & Ibex 35 & Ibex Medium Cap & Ibex Small Cap & Ibex Top Dividendo \\
\hline Media & 0,0004 & 0,0003 & 0,0002 & $-0,0002$ & $-0,0001$ \\
Mediana & 0,0005 & 0,0007 & 0,0009 & 0,0006 & 0,0006 \\
Desviación estándar & 0,0137 & 0,0143 & 0,0107 & 0,0114 & 0,0149 \\
Varianza de la muestra & 0,0002 & 0,0002 & 0,0001 & 0,0001 & 0,0002 \\
Curtosis & 9,2945 & 5,1708 & 3,6220 & $-9,9322$ & 3,2842 \\
Coeficiente de asimetría & 0,1076 & 0,1212 & $-0,3457$ & $-0,4022$ & 0,1110 \\
Rango & 0,2870 & 0,2358 & 0,1371 & -1346 & $-0,1700$ \\
Mínimo & $-0,1341$ & $-0,0914$ & $-0,0654$ & 0,0738 & 0,0689 \\
Máximo & 0,1529 & 0,1443 & 0,0717 & 2678 & 2206 \\
Observaciones & 7532 & 6067 & 5431 & $54,21 \%$ & $51,90 \%$ \\
\hline \% Observaciones positivas & $52,04 \%$ & $52,91 \%$ & $54,37 \%$ & & \\
\hline
\end{tabular}

Como se puede observar en el Cuadro 4.2, tanto el IGBM, el Ibex 35 y el Ibex Medium Cap presentan rentabilidades medias diarias positivas, a diferencia del Ibex Small Cap y el Ibex Top Dividendo que las presentan negativas. Una de las principales causas que podemos identificar para estas rentabilidades negativas es que ambos índices han cotizado coincidiendo con el período de crisis financiera de 2008. De los tres índices que presentan rentabilidades positivas el IGBM es el que obtiene una mayor rentabilidad media diaria con un $0,04 \%$, seguido por el Ibex $35(0,03 \%)$ y el Ibex Medium Cap (0,02\%). Los cinco índices tienen curtosis positiva lo que indica que los datos están muy concentrados o cercanos al promedio y la distribución será muy estrecha. El coeficiente de asimetría es positivo para el IGBM, el Ibex 35 y el Ibex Top Dividendo, teniendo por lo tanto más valores por encima de la media que por debajo (la cola de la distribución se alarga para valores superiores a la media) al contrario que el Ibex Medium Cap y el Ibex Small Cap que lo presentan negativo. El mayor rango lo tiene el IGBM que es el que presenta una mayor diferencia entre su rentabilidad máxima y su rentabilidad mínima.

En la Figura 4.1 se observa la evolución de los cinco índices, lo más notable es la caída pronunciada que se produce en diciembre de 2007, momento en el que todos los índices tocan máximos históricos. El detonante de esta caída es el comienzo de la crisis financiera global de 2008. 
Figura 4.1: Evolución índices bursátiles mercado español

Gráfico de la evolución de los cinco índices bursátiles (con base 100) desde el inicio de su cotización hasta el 31 de diciembre de 2015.

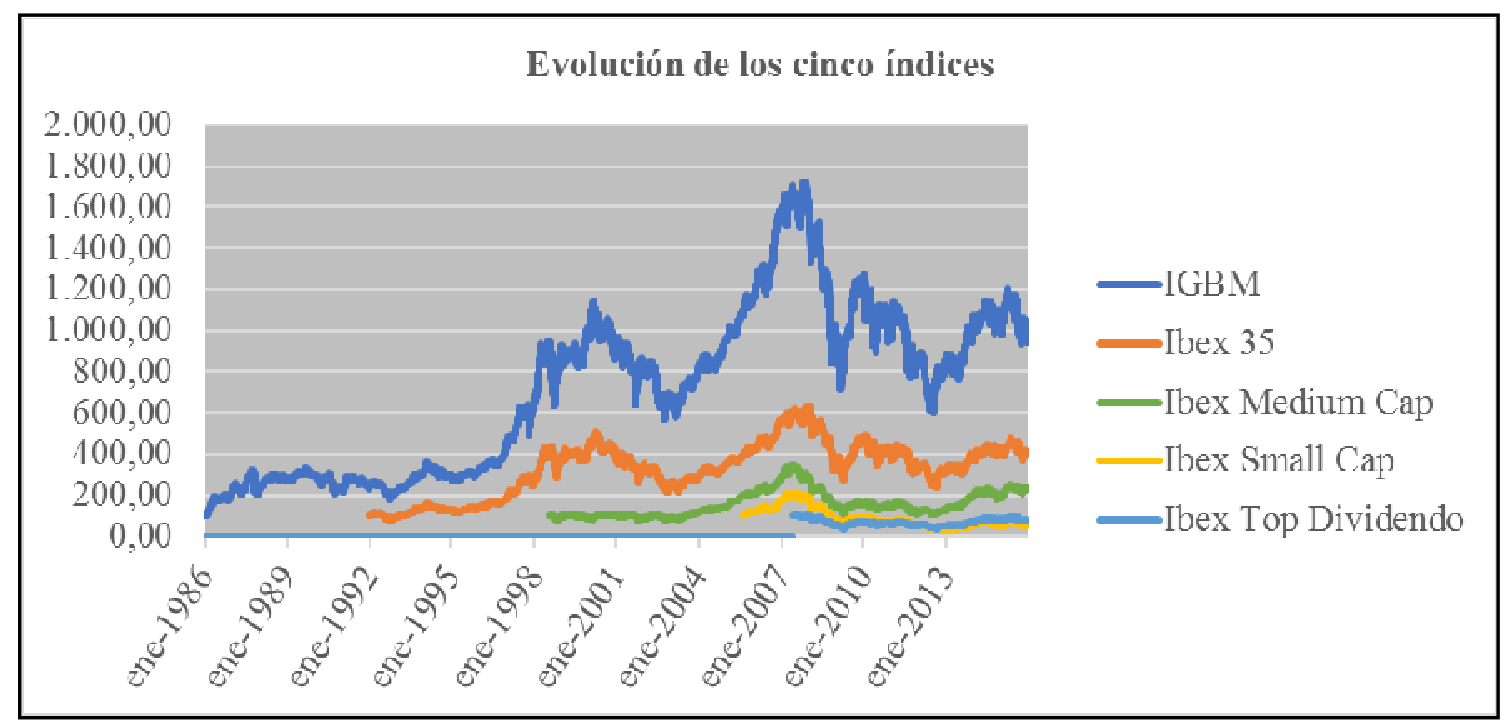

Las primeras investigaciones sobre el efecto calendario (French, 1980; Gibbons y Hess, 1981; Jaffe y Westerfield, 1985) empleaban el modelo de regresión por mínimos cuadrados ordinarios (MCO), el cual se basa en que los datos se distribuyen normalmente, no hay correlación en la serie y la varianza es constante. Sin embargo, Connolly $(1989,1991)$ identifica los problemas subyacentes a la utilización de MCO sobre índices bursátiles mayormente porque los residuos no siguen una distribución normal, las rentabilidades del índice posiblemente estén autocorrelacionadas o que la varianza de los residuos puede no ser constante. Engle (1982) propone el uso del modelo de heteroscedasticidad condicional autorregresiva (ARCH), que supone que la varianza condicional depende del pasado con estructura autorregresiva, con el objeto de corregir la variabilidad en la varianza de los residuos. Los modelos ARCH suponen que la varianza condicionada a la información pasada no es constante. Bollerslev (1986) evoluciona la metodología ARCH y propone los modelos $\mathrm{GARCH}$, en los que la varianza de los residuos se expresa como la suma de una media móvil polinómica de orden q de los residuos pasados $(\mathrm{ARCH})$, además de un polinomio autorregresivo de orden $\mathrm{p}$, sobre las variaciones pasadas (el término GARCH). La especificación GARCH se define como un modelo ARCH de orden infinito (Bollerslev, 1986). La expresión del modelo es:

$$
\begin{gathered}
h_{t}=\alpha_{0}+\sum_{i=1}^{q} \alpha_{i} \varepsilon_{t-i}^{2}+\sum_{j=1}^{p} \beta_{j} h_{t-i} \\
\text { donde } \varepsilon_{t} \rightarrow N\left(0, h_{t}\right) \quad \varepsilon_{t}=\sqrt{h_{t}} v_{t} \quad v_{t} \sim \operatorname{iidN}(0,1)
\end{gathered}
$$


El modelo más sencillo es el GARCH $(1,1)$, que se calcula mediante máxima verosimilitud y sólo incluye un retardo tanto en el término $\mathrm{ARCH}$ (último período de volatilidad) como en el término GARCH (último período de la varianza). En los últimos años se han venido desarrollando diferentes propuestas del modelo GARCH aplicándolas al estudio del efecto calendario, como en el caso de Choudhry (2000) quien aplica el modelo GARCH a una investigación sobre el efecto día de la semana en siete países de Asia Oriental.

En los mercados bursátiles se ha observado empíricamente que las noticias negativas tienen un efecto más significativo en la volatilidad que las noticias positivas; esta asimetría existente en la relación entre rendimientos positivos (negativos) y una futura menor (mayor) volatilidad es conocida como leverage effect (efecto apalancamiento) (Enders, 2004). Este efecto no está recogido por los modelos GARCH, ya que la varianza condicional depende de las varianzas condicionales pasadas y los cuadrados de las innovaciones y esto hace que el signo de los rendimientos no afecte la volatilidad (Knight y Satchell, 2007), por lo tanto en este contexto se plantea la utilización del modelo asimétrico EGARCH o GARCH exponencial de Nelson (1991) que en contraposición a los modelos GARCH permite recoger respuestas asimétricas de la varianza condicional a las innovaciones pasadas, dado que su forma logarítmica garantiza su posivitividad. Aunque en discrepancia a ésto, Hansen y Lunde (2005) tras analizar 330 modelos $\mathrm{ARCH}$ no encuentran pruebas empíricas que ninguno supere al GARCH $(1,1)$. Así, el modelo exponencial EGARCH se presenta como sigue:

$$
\ln \mathrm{h}_{\mathrm{t}}=\alpha_{0}+\sum_{\mathrm{i}=1}^{\mathrm{q}} \alpha_{\mathrm{i}}\left[\frac{\varepsilon_{\mathrm{t}-\mathrm{i}}}{\sqrt{\mathrm{h}_{\mathrm{t}-\mathrm{i}}}}\right]+\sum_{\mathrm{i}=1}^{\mathrm{q}} \alpha_{\mathrm{i}}^{*}\left[\left|\frac{\mathrm{e}_{\mathrm{t}-\mathrm{i}}}{\sqrt{\mathrm{h}_{\mathrm{t}-\mathrm{i}}}}\right|-\mu\right]+\sum_{\mathrm{j}=1}^{\rho} \beta_{\mathrm{j}} \ln \left(\mathrm{h}_{\mathrm{t}-\mathrm{j}}\right)
$$

La metodología utilizada para determinar la existencia de efectos estacionales será la siguiente: En primer lugar, se realizará un análisis estadístico de las rentabilidades diarias $^{6}$ de los cinco índices, durante sus diferentes períodos muestrales, en base a los precios de cierre diarios.

$$
R_{t}=\left(P_{t}-P_{t-1}\right) / P_{t-1}
$$

Donde:

${ }^{6} \mathrm{El}$ análisis de todos los efectos se hará en función de las rentabilidades diarias a excepción del efecto enero, que se realizará en función de las rentabilidades mensuales. 
$R_{t}=$ Rentabilidad en el período t.

$P_{t}=$ Precio de cierre en el período t.

$P_{t-1}=$ Precio de cierre en el período $\mathrm{t}-1$.

Una vez se haya realizado el análisis de los principales estadísticos descriptivos se procederá a realizar un contraste de medias a través de una prueba $t$ para dos muestras suponiendo varianzas desiguales, para determinar si las medias son significativamente distintas y, por lo tanto, determinar la existencia o no del efecto calendario analizado.

En segundo lugar, se utilizarán modelos econométricos uniecuacionales con variables dummy, dado que es un enfoque común el uso de estos cuando se utilizan índices bursátiles. La metodología a seguir será la siguiente: i) Se procederá a estimar la ecuación con variables dummy por MCO. ii) Se estudiará si la ecuación estimada presenta efecto $\mathrm{ARCH}$; para determinar si presenta el efecto $\mathrm{ARCH}$ se realizará el test ARCH-LM de EViews. iii) Si no se dan efectos ARCH, la ecuación estimada es consistente para determinar si está presente el efecto calendario o no. iv) Si se da el efecto $\mathrm{ARCH}$, se realiza la estimación a través de los modelos $\mathrm{GARCH}(1,1)$ y EGARCH $(1,1)$ y se evalúa si bajo estas nuevas especificaciones, las cuales se consideran más consistentes, el efecto calendario está presente o no.

En este apartado, igual que en el anterior, se realizará el análisis de las rentabilidades de los índices en base a los precios de cierre diarios, utilizando la misma fórmula, pero aplicando logaritmos naturales.

$$
R_{t}=\ln \left(P_{t} / P_{t-1}\right)
$$

El desarrollo de los modelos econométricos y su posterior estudio, se ha realizado mediante el programa econométrico: Econometric Views (EViews). Como hemos comentado en la introducción del capítulo uno de los objetivos del mismo es estudiar la evolución y robustez de los diferentes efectos calendario a lo largo del tiempo, para ello hemos dividido el período muestral total del IGBM en tres subperíodos muestrales: i) de 1986 a 1997, ii) de 1998 a 2007 y iii) de 2008 a 2015, y el del Ibex 35 en dos subperíodos muestrales: i) de 1992 a 2007 y ii) de 2008 a 2015. Centrando especialmente el esfuerzo investigador en el punto de inflexión coincidente con los períodos pre-crisis y crisis financiera global de 2008. Para ello aplicaremos toda la metodología desarrollada anteriormente para los períodos muestrales totales a cada uno de los subperíodos. 


\subsection{EI efecto enero}

\subsubsection{Revisión bibliográfica}

El efecto enero es una de las anomalías del efecto calendario más conocidas, ésta se identifica cuando las rentabilidades en enero son sistemáticamente más elevadas que en el resto de meses del año. El término efecto enero fue acuñado por primera vez por Wachtel (1942), quien se percató de que, a través del estudio de los movimientos estacionales en el mercado bursátil estadounidense, desde 1925 las empresas de pequeña capitalización habían superado ampliamente el mercado en ese mes, produciéndose la mayor disparidad en la primera mitad del mismo. Desde el trabajo pionero de Wachtel existe una amplía literatura que demuestra la existencia de este efecto, a continuación se presenta una relación en base cronológica y para diferentes países.

Branch (1977) observa que las empresas con mayor disminución de su cotización en diciembre, eran posteriormente las que mayores rentabilidades reportaban en el mes de enero del año siguiente, batiendo ampliamente al mercado. Gultekin y Gultekin (1983) además de los mercados bursátiles de Estado Unidos, analizaron los mercados bursátiles de dieciséis países, encontrando el efecto enero de forma generalizada en todos los países objeto de estudio. Aggarwal y Rivoli (1989) examinan los mercados financieros de Hong Kong, Malasia, Filipinas y Singapur, confirmando sus resultados la existencia del efecto enero en todos los países, excepto en Filipinas. Fama (1991) encuentra evidencias de la existencia del efecto enero al estudiar el índice S\&P 500. Lakonishok y Smidt (1988) llegaron a la misma conclusión centrando su atención en el Dow Jones, pero sólo encontraron evidencias leves para las rentabilidades más elevadas en la primera mitad de mes. Mills y Coutts (1995) estudian el el período de enero de 1986 hasta octubre de 1992, encontrando rendimientos diarios positivos y significativos para los meses de enero y febrero en el FTSE 100 y para enero en el Mid 250. Riepe (1998) señala que en las décadas de los años 80 y 90 aumenta el conocimiento general sobre el efecto enero y con la aparición de los contratos de futuros su aplicación se presenta como una alternativa de bajo coste para los inversores siendo partícipes de los beneficios que reporta este efecto.

Entre los estudios más recientes destaca Borges (2009) quien examina el efecto mes del año para un grupo de 17 índices bursátiles de Europa Occidental y Central, identificándolo en Islandia (exceso de rentabilidad positiva en agosto y negativa en octubre), Austria (exceso de rentabilidad positiva en febrero y negativa en septiembre), Portugal (exceso de rentabilidad positiva en enero y negativa en mayo), y Grecia (exceso de rentabilidad negativa en junio). Darrat et al. (2011) analizan un amplio conjunto de datos de 34 países y descubren el efecto enero en todos excepto en 
Dinamarca, Irlanda y Jordania. Guler (2013) encuentra el efecto enero en las rentabilidades de China, Argentina y Turquía. Sin embargo, no lo logra evidenciar en los mercados de valores de Brasil e India. Hashmi (2014) investiga el índice KSE-100 en busca del efecto enero en el período 2004-2009, llegando a la conclusión de su presencia, pero en este caso las rentabilidades obtenidas no eran lo suficientemente altas para compensar los costes de transacción. Friday y Hoang (2015) examinan la bolsa de Vietnam encontrando rentabilidades significativamente positivas en abril y significativamente negativas en julio. Hui y Chan (2015) investigan entre otros efectos calendario el efecto enero en índices de ocho economías, siendo la única en el que es significativo la de Hong-Kong. Heitmann (2016) estudia la existencia del efecto enero en los tres principales índices de Alemania (SDAX, MDAX y DAX), concluyendo que el único índice que presentaba un efecto enero significativo era el SDAX (el de las empresas de pequeña capitalización) pero este efecto presentaba una tendencia a la baja. Si bien el efecto enero ha sido ampliamente abordado en los mercados bursátiles, este fenómeno también se ha identificado en los mercados de bonos (Starks et al. (2006)) y en los mercados de futuros (Rendon y Ziemba (2007)).

Para el caso específico del mercado financiero español, son numerosos los trabajos que han centrado su atención en explorar el impacto de esta anomalía y que también han encontrado evidencias sobre su existencia. Entre ellos, se destaca Santesmases (1986), Fernández e Yzaguirre (1995) y Marhuenda (1998). Aunque estos estudios discrepan respecto a las causas de la anomalía, debatiéndose entre si los impuestos o los inversores institucionales pueden ser determinantes. Además y como se ha comentado anteriormente, el estudio del efecto enero no sólo se ha venido centrando en los mercados bursátiles, precisamente De Andrés Sánchez (2007) estudia los efectos "enero" y "cambio de año" en los mercados españoles de renta fija a medio y largo plazo no encontrando prácticamente indicios del efecto enero, pero sí identifica claros indicios del efecto cambio de año. Así, con el efecto de cambio de año también se consolida una creencia generalizada entre los gestores o inversores profesionales, consistente en que los mercados tienden a experimentar un repunte de los precios a medida que se acerca el final del año, este efecto es conocido como rally de diciembre o navideño. En este sentido, García (2008) no encuentra pruebas del rally de diciembre ni para el Ibex Small Cap, ni para el Ibex 35, pero sí que observa un efecto enero para el Ibex Small Cap, no siendo así para el Ibex 35. Se concluye que si el efecto enero está causado por la recompra de las acciones vendidas en diciembre por motivos fiscales, por esa misma razón se tendrían que esperar rentabilidades inferiores alrededor de los últimos días del año. 
En este contexto, la relación existente entre el efecto enero y las empresas de pequeña capitalización es una de las más estudiadas, existiendo amplia literatura que la analiza. Entre otros autores, Rozeff y Kinney (1976) se centran en la bolsa de Nueva York (NYSE) para el período 1904 a 1974 y observan rentabilidades anormalmente altas en los primeros días del año (la rentabilidad media de enero fue del 3,48\% en comparación con el $0,42 \%$ del resto de meses) especialmente para empresas de pequeña capitalización. Este fenómeno lo atribuyeron al aumento de las primas de riesgo (las pequeñas empresas presentan una mayor prima de riesgo en el precio) aunque otros autores, como Haugen y Lakonishok (1988) consideran que el fin de año sirve como escaparate para los gestores profesionales de carteras, siendo ésta la principal causa. Keim (1983) también estudio la NYSE desde 1963 a 1979 encontrando que casi el 50\% de la prima de riesgo anual de las pequeñas empresas en comparación con las grandes empresas se debía a las rentabilidades de enero, especialmente para la primera semana de negociación que es donde se producía el 50\% de la rentabilidad del mes. Roll (1983) y Reinganum (1983) apoyan estos resultados para las pequeñas empresas y, en particular, para aquéllas cuyas las acciones se asocian con precios bajos. Kato y Schallheim (1985) examinaron las altas rentabilidades en el mes de enero de la bolsa de Tokio. Llegando a la conclusión de que existe una fuerte relación entre la rentabilidad y el tamaño de la empresa. Las empresas pequeñas presentaban una rentabilidad del $8 \%$ y las grandes del 7\%. Sin embargo, Kohers y Kohli (1991) proporcionan evidencias de que el efecto no se relaciona con las pequeñas empresas. Pero en un índice que se compone solamente de grandes empresas, como el Dow Jones, no se da. Rogalski y Tinic (1986) sugieren que el efecto enero en las pequeñas empresas podría atribuirse a un mayor riesgo de éstas en la composición de las carteras, en particular en el mes de enero. Además, Sias y Starks (1997) postulan que las acciones que tienen la propiedad distribuida entre pequeños accionistas superan a las que la propiedad esta concentrada en inversores institucionales. Beyer et al. (2013) han estudiado la rentabilidad mensual desde junio de 1963 a diciembre de 2010 mostrando que una cartera compuesta por pequeñas empresas superó a la media del mercado en 45 de los 47 meses de enero analizados.

Como se ha podido constatar hasta ahora ha habido un gran número de evidencias empíricas a favor del efecto enero, pero investigaciones más recientes han argumentado que la magnitud de la anomalía ha disminuido a lo largo del tiempo, incluso llegando a desaparecer. Así, Mehdian y Perry (2002) sugieren que el efecto enero ha desaparecido en los Estados Unidos, su estudio sobre el DJIA, NYSE y S\&P 500 arroja como resultado que desde 1964 hasta 1987 el efecto enero es significativo para los tres índices, pero a partir de 1987, aunque en enero es positivo, ya no es significativamente positivo, lo que indica que la anomalía ha desaparecido. Gu (2003) compara las rentabilidades de 
enero con las rentabilidades medias del año y los resultados muestran que el efecto enero ha disminuido tanto para las grandes como para las pequeñas empresas desde 1988 y desaparecido para el índice Russell. Esta tendencia a la baja también es evidente en el Dow 30 desde 1930. Sin embargo, Rathinasamy y Mantripragada (1996) demostraron que el efecto enero aún existía para las pequeñas empresas, incluso aplicando los ratios de Treynor y Sharpe como medida de riesgo. Marquering et al. (2006) siguen con esa misma línea de investigación y afirman que no sólo ha disminuido, sino que tiende a desaparecer a principios del siglo XXI. Al contrario, Haug y Hirschey (2006) reafirman la presencia del efecto enero para períodos más recientes. Moosa (2007) observa, para el período 1970-2005, una disminución sistemática del efecto enero y la aparición de un nuevo efecto, el efecto julio con la aparición de rentabilidades significativamente superiores a la media ese mes. Esto último también fue observado por Brown et al. (1983), para el caso australiano, donde la mayor parte de los beneficios se producían en los meses de enero y julio, respectivamente. Moller y Zilca (2008) al examinar los datos diarios del NYSE, AMEX y NASDAQ, desde 1927 a 2004, al contrario que los estudios anteriores, concluyen que la dimensión del efecto enero no ha disminuido. Sin embargo, encuentran mayores rentabilidades anormales en la primera parte del mes de enero y menores en la segunda, en la submuestra 1995-2004.

Dando continuidad al debate, Jacobsen y Zhang (2013) estudian más de 300 años de rentabilidad bursátil en el Reino Unido y encuentran que el efecto enero surge en torno a 1830, coincidiendo con el momento en que la Navidad se convierte en una festividad pública, pero deja de ser significativo desde 1951 a 2009. Patel (2016) estudia el efecto enero en la rentabilidad de acciones internacionales durante el período 1997-2014, obteniendo pruebas concluyentes de que la fuerza del efecto enero había desaparecido durante los últimos años y, especialmente, en el período 2008-2009 siendo el momento en el cual el mercado de valores se desplomó a nivel internacional como consecuencia de la crisis. Sin embargo, Beyer et al. (2013) llegan a la conclusión de que no existen pruebas concluyentes que indiquen que el efecto enero haya disminuido desde su gran auge en la década de 1980.

Desde una perspectiva teórica, Dyl (1977) explica este fenómeno como respuesta de los inversores individuales quienes tienen una alta sensibilidad a los impuestos, y que la razón de las ventas a finales de año es por motivos fiscales pudiendo desgravarse las pérdidas de capital para después volver a reinvertir a comienzos de año. Esta teoría es apoyada por Reinganum (1983), D’Mello et al. (2003), Chen y Singal (2004), Starks et al. (2006), entre otros autores, coincidiendo en que ésta es la explicación más probable para este efecto. Sin embargo, un estudio de Jones et al. (1987) sobre el período 18211917, en Estados Unidos, anterior a la existencia del impuesto sobre beneficios, 
presenta claras evidencias empíricas sobre el efecto enero. Junto a esta teoría, existe otra aún más aceptada para atribuir justificación al efecto enero, consistente en que los inversores institucionales (especialmente los fondos de inversión) reestructuran sus carteras de inversión a principios de año. Entre los autores que apoyan este precepto, destacan Porter et al. (1997) quienes encuentran evidencias consistentes de ello. Además, Poterba y Weisbenner (2001) comparan directamente las dos hipótesis y determinan que resulta determinante la venta a finales de año para desgravarse las pérdidas fiscales. Easterday y Sen (2016) encuentran que el efecto enero es experimentado por relativamente pocas empresas de la muestra total, pero en un porcentaje sustancial de éstas se identifica como posible causa del efecto las motivaciones fiscales.

Pero teorías alternativas dirigen la atención hacia la publicación de informes positivos de las empresas o a un exceso de cash-flow (regalos, gratificaciones, bonus, etc.) de los inversores particulares que deciden invertirlo en la compra de activos financieros. En esta línea Ritter (1988) sostiene que los hábitos de inversión de los pequeños inversores explicarían el 46\% del efecto enero. Gottschalk et al. (2006) llegarían a la misma conclusión, en su estudio sobre los mercados polaco y húngaro, entre 1994 y 2004. Ciccone (2011) propone una explicación alternativa para el efecto enero, relacionada con la psicología, señalan que enero es un mes de renovado optimismo, al empezar el año, y que existe una motivación derivada que incita a los inversores a presentar una propensión a comprar en los mercados.

\subsubsection{Resultados}

\subsubsection{Análisis totalidad período muestral}

En primer lugar, se han calculado diferentes estadísticos descriptivos para los cinco índices, mostrándose los resultados en los siguientes cuadros. Para el IGBM el Cuadro 4.3 presenta una evidencia preliminar a favor de la presencia del efecto enero, con una rentabilidad media mensual del $2,56 \%$ y el porcentaje de observaciones positivas más elevado con el $70 \%$, seguido por el mes de febrero con una rentabilidad media de $2,12 \%$. También se puede ver un efecto negativo en septiembre, siendo el mes con una menor rentabilidad media, -1,15\%. En el Cuadro 4.4. se observa que el Ibex 35 no presentaría un efecto enero, pero si un efecto octubre con una rentabilidad media del 2,37\% seguido de noviembre con el 2,06\%, enero presentaría una rentabilidad media del 1,38\%. El mes con un mayor porcentaje de observaciones positivas sería diciembre, igual que en el IGBM, se pude observar un efecto septiembre negativo con una rentabilidad media de $0,84 \%$. 


\section{Cuadro 4.3: Estadísticos descriptivos del IGBM para el efecto enero}

Este cuadro muestra los principales estadísticos descriptivos de las rentabilidades medías mensuales del IGBM durante el período muestral de enero de 1986 a diciembre de 2015.

\begin{tabular}{|c|c|c|c|c|c|c|c|c|c|c|c|c|}
\hline & Enero & Febrero & Marzo & Abril & Mayo & Junio & Julio & Agosto & Septiembre & Octubre & Noviembre & Diciembre \\
\hline Media & 0,0256 & 0,0212 & 0,0051 & 0,0178 & 0,0089 & $-0,0013$ & 0,0062 & $-0,0004$ & $-0,0115$ & 0,0049 & 0,0097 & 0,0138 \\
\hline Mediana & 0,0304 & 0,0150 & $-0,0006$ & 0,0130 & 0,0081 & 0,0026 & $-0,0044$ & $-0,0016$ & $-0,0008$ & 0,0222 & 0,0121 & 0,0187 \\
\hline Desviación estándar & 0,0653 & 0,0632 & 0,0649 & 0,0519 & 0,0537 & 0,0618 & 0,0626 & 0,0686 & 0,0669 & 0,0873 & 0,0582 & 0,0474 \\
\hline Varianza de la muestra & 0,0043 & 0,0040 & 0,0042 & 0,0027 & 0,0029 & 0,0038 & 0,0039 & 0,0047 & 0,0045 & 0,0076 & 0,0034 & 0,0022 \\
\hline Curtosis & 0,3485 & 0,8796 & 2,6636 & 1,6461 & 1,5140 & 0,6412 & 0,4240 & 1,2725 & 0,7366 & 3,0805 & 0,5189 & $-0,1287$ \\
\hline Coeficiente de asimetría & $-0,1303$ & 0,7232 & 1,1289 & 0,0464 & $-0,4229$ & 0,3248 & 0,6315 & $-0,5645$ & $-0,4800$ & $-1,4417$ & $-0,5624$ & $-0,1943$ \\
\hline Rango & 0,3025 & 0,2841 & 0,3158 & 0,2767 & 0,2702 & 0,2767 & 0,2559 & 0,3164 & 0,2987 & 0,4066 & 0,2501 & 0,1878 \\
\hline Mínimo & $-0,1259$ & $-0,1048$ & $-0,1074$ & $-0,1238$ & $-0,1276$ & $-0,1126$ & $-0,0930$ & $-0,1936$ & $-0,1876$ & $-0,2845$ & $-0,1497$ & $-0,0860$ \\
\hline Máximo & 0,1766 & 0,1793 & 0,2083 & 0,1529 & 0,1426 & 0,1641 & 0,1629 & 0,1228 & 0,1110 & 0,1221 & 0,1004 & 0,1018 \\
\hline Observaciones & 30 & 30 & 30 & 30 & 30 & 30 & 30 & 30 & 30 & 30 & 30 & 30 \\
\hline$\%$ Observaciones positivas & $70,00 \%$ & $63,33 \%$ & $50,00 \%$ & $60,00 \%$ & $63,33 \%$ & $50,00 \%$ & $46,67 \%$ & $50,00 \%$ & $50,00 \%$ & $60,00 \%$ & $60,00 \%$ & $63,33 \%$ \\
\hline
\end{tabular}

\section{Cuadro 4.4: Estadísticos descriptivos del Ibex 35 para el efecto enero}

Este cuadro muestra los principales estadísticos descriptivos de las rentabilidades medías mensuales del Ibex 35 durante el período muestral de enero de 1992 a diciembre de 2015.

\begin{tabular}{|c|c|c|c|c|c|c|c|c|c|c|c|c|}
\hline & Enero & Febrero & Marzo & Abril & Mayo & Junio & Julio & Agosto & Septiembre & Octubre & Noviembre & Diciembre \\
\hline Media & 0,0138 & 0,0133 & $-0,0018$ & 0,0168 & $-0,0038$ & $-0,0061$ & 0,0018 & $-0,0069$ & $-0,0084$ & 0,0237 & 0,0206 & 0,0152 \\
\hline Mediana & 0,0198 & 0,0096 & $-0,0145$ & 0,0109 & $-0,0021$ & 0,0046 & $-0,0054$ & $-0,0072$ & $-0,0052$ & 0,0335 & 0,0187 & 0,0206 \\
\hline Desviación estándar & 0,0632 & 0,0564 & 0,0449 & 0,0566 & 0,0509 & 0,0666 & 0,0628 & 0,0662 & 0,0679 & 0,0735 & 0,0668 & 0,0514 \\
\hline Varianza de la muestra & 0,0040 & 0,0032 & 0,0020 & 0,0032 & 0,0026 & 0,0044 & 0,0039 & 0,0044 & 0,0046 & 0,0054 & 0,0045 & 0,0026 \\
\hline Curtosis & $-0,1905$ & 1,3500 & 4,0573 & 1,5734 & 0,6504 & 0,9056 & $-0,4429$ & 3,5091 & $-0,2339$ & 1,1302 & 0,4421 & 0,1197 \\
\hline Coeficiente de asimetría & $-0,4029$ & 0,6113 & 1,5031 & 0,1692 & $-0,8076$ & 0,2777 & 0,1769 & $-0,9522$ & $-0,1163$ & $-0,8740$ & $-0,6600$ & $-0,4646$ \\
\hline Rango & 0,2391 & 0,2597 & 0,2141 & 0,2810 & 0,1978 & 0,2967 & 0,2368 & 0,3396 & 0,2689 & 0,3167 & 0,2678 & 0,2014 \\
\hline Mínimo & $-0,1287$ & $-0,0982$ & $-0,0670$ & $-0,1245$ & $-0,1314$ & $-0,1304$ & $-0,1034$ & $-0,2124$ & $-0,1560$ & $-0,1703$ & $-0,1429$ & $-0,0970$ \\
\hline Máximo & 0,1105 & 0,1616 & 0,1471 & 0,1565 & 0,0664 & 0,1662 & 0,1335 & 0,1271 & 0,1129 & 0,1464 & 0,1249 & 0,1043 \\
\hline Observaciones & 24 & 24 & 24 & 24 & 24 & 24 & 24 & 24 & 24 & 24 & 24 & 24 \\
\hline$\%$ Observaciones positivas & $66,67 \%$ & $58,33 \%$ & $45,83 \%$ & $62,50 \%$ & $45,83 \%$ & $50,00 \%$ & $45,83 \%$ & $45,83 \%$ & $50,00 \%$ & $70,83 \%$ & $70,83 \%$ & $75,00 \%$ \\
\hline
\end{tabular}


Cuadro 4.5: Estadísticos descriptivos del Ibex Medium Cap para el efecto enero

Este cuadro muestra los principales estadísticos descriptivos de las rentabilidades medías mensuales del Ibex Medium Cap durante el período muestral de enero de 1999 a diciembre de 2015

\begin{tabular}{|c|c|c|c|c|c|c|c|c|c|c|c|c|}
\hline & Enero & Febrero & Marzo & Abril & Mayo & Junio & Julio & Agosto & Septiembre & Octubre & Noviembre & Diciembre \\
\hline Media & 0,0309 & 0,0188 & 0,0084 & 0,0152 & $-0,0041$ & $-0,0094$ & 0,0018 & $-0,0028$ & $-0,0076$ & 0,0100 & $-0,0024$ & 0,0029 \\
\hline Mediana & 0,0499 & 0,0131 & 0,0091 & 0,0104 & 0,0024 & $-0,0087$ & 0,0089 & $-0,0031$ & 0,0022 & 0,0369 & 0,0134 & 0,0051 \\
\hline Desviación estándar & 0,0541 & 0,0510 & 0,0352 & 0,0510 & 0,0551 & 0,0542 & 0,0491 & 0,0363 & 0,0698 & 0,0585 & 0,0442 & 0,0403 \\
\hline Varianza de la muestra & 0,0029 & 0,0026 & 0,0012 & 0,0026 & 0,0030 & 0,0029 & 0,0024 & 0,0013 & 0,0049 & 0,0034 & 0,0019 & 0,0016 \\
\hline Curtosis & 2,9612 & 1,9308 & $-0,4237$ & 5,9036 & 0,2518 & 0,7152 & $-0,3736$ & 0,1498 & $-0,2057$ & 0,6567 & $-0,2543$ & $-0,4857$ \\
\hline Coeficiente de asimetría & $-1,5466$ & 0,1412 & 0,0896 & 2,0111 & $-0,7451$ & $-0,6047$ & 0,1363 & $-0,8382$ & $-0,3105$ & $-1,1545$ & $-0,6859$ & $-0,1533$ \\
\hline Rango & 0,2236 & 0,2329 & 0,1294 & 0,2286 & 0,1999 & 0,2076 & 0,1680 & 0,1241 & 0,2704 & 0,2058 & 0,1594 & 0,1479 \\
\hline Mínimo & $-0,1221$ & $-0,0966$ & $-0,0509$ & $-0,0522$ & $-0,1200$ & $-0,1410$ & $-0,0754$ & $-0,0874$ & $-0,1534$ & $-0,1341$ & $-0,0919$ & $-0,0784$ \\
\hline Máximo & 0,1015 & 0,1363 & 0,0785 & 0,1764 & 0,0798 & 0,0666 & 0,0926 & 0,0367 & 0,1170 & 0,0717 & 0,0675 & 0,0694 \\
\hline Observaciones & 17 & 17 & 17 & 17 & 17 & 17 & 17 & 17 & 17 & 17 & 17 & 17 \\
\hline$\%$ Observaciones positivas & $76,47 \%$ & $76,47 \%$ & $64,71 \%$ & $58,82 \%$ & $52,94 \%$ & $47,06 \%$ & $52,94 \%$ & $47,06 \%$ & $52,94 \%$ & $64,71 \%$ & $58,82 \%$ & $58,82 \%$ \\
\hline
\end{tabular}

\section{Cuadro 4.6: Estadísticos descriptivos del Ibex Small Cap para el efecto enero}

Este cuadro muestra los principales estadísticos descriptivos de las rentabilidades medías mensuales del Ibex Small Cap durante el período muestral de enero de 2006 a diciembre de 2015.

\begin{tabular}{|c|c|c|c|c|c|c|c|c|c|c|c|c|}
\hline & Enero & Febrero & Marzo & Abril & Mayo & Junio & Julio & Agosto & Septiembre & Octubre & Noviembre & Diciembre \\
\hline Media & 0,0458 & 0,0206 & 0,0088 & 0,0015 & $-0,0311$ & $-0,0285$ & $-0,0211$ & 0,0021 & 0,0016 & $-0,0010$ & $-0,0315$ & $-0,0158$ \\
\hline Mediana & 0,0692 & 0,0220 & 0,0143 & $-0,0029$ & $-0,0160$ & $-0,0280$ & 0,0005 & 0,0099 & 0,0134 & 0,0059 & $-0,0422$ & $-0,0205$ \\
\hline Desviación estándar & 0,0768 & 0,0782 & 0,0370 & 0,0585 & 0,0789 & 0,0426 & 0,0601 & 0,0697 & 0,0919 & 0,0977 & 0,0528 & 0,0514 \\
\hline Varianza de la muestra & 0,0059 & 0,0061 & 0,0014 & 0,0034 & 0,0062 & 0,0018 & 0,0036 & 0,0049 & 0,0084 & 0,0096 & 0,0028 & 0,0026 \\
\hline Curtosis & 4,4011 & $-0,8119$ & $-1,0778$ & 2,7269 & $-0,3691$ & 0,8040 & $-0,6859$ & $-0,8226$ & $-1,2904$ & $-0,9218$ & $-0,0124$ & 0,1529 \\
\hline Coeficiente de asimetría & $-1,8705$ & 0,1619 & $-0,1915$ & 0,8468 & $-0,6991$ & 0,2521 & $-0,7358$ & $-0,2729$ & $-0,2721$ & $-0,2894$ & 0,2085 & 0,1064 \\
\hline Rango & 0,2751 & 0,2422 & 0,1091 & 0,2266 & 0,2304 & 0,1536 & 0,1730 & 0,2091 & 0,2744 & 0,3020 & 0,1827 & 0,1771 \\
\hline Mínimo & $-0,1450$ & $-0,0863$ & $-0,0447$ & $-0,0954$ & $-0,1650$ & $-0,1000$ & $-0,1191$ & $-0,1038$ & $-0,1461$ & $-0,1685$ & $-0,1199$ & $-0,1010$ \\
\hline Máximo & 0,1301 & 0,1559 & 0,0644 & 0,1312 & 0,0654 & 0,0537 & 0,0540 & 0,1054 & 0,1283 & 0,1335 & 0,0628 & 0,0762 \\
\hline Observaciones & 10 & 10 & 10 & 10 & 10 & 10 & 10 & 10 & 10 & 10 & 10 & 10 \\
\hline$\%$ Observaciones positivas & $90,00 \%$ & $60,00 \%$ & $60,00 \%$ & $50,00 \%$ & $30,00 \%$ & $20,00 \%$ & $50,00 \%$ & $50,00 \%$ & $50,00 \%$ & $60,00 \%$ & $30,00 \%$ & $30,00 \%$ \\
\hline
\end{tabular}




\section{Cuadro 4.7: Estadísticos descriptivos del Ibex Top Dividendo para el efecto enero}

Este cuadro muestra los principales estadísticos descriptivos de las rentabilidades medías mensuales del Ibex Small Cap durante el período muestral de enero de 2008 a diciembre de 2015

\begin{tabular}{|c|c|c|c|c|c|c|c|c|c|c|c|c|}
\hline & Enero & Febrero & Marzo & Abril & Mayo & Junio & Julio & Agosto & Septiembre & Octubre & Noviembre & Diciembre \\
\hline Media & 0,0049 & $-0,0129$ & 0,0054 & 0,0220 & $-0,0257$ & $-0,0147$ & 0,0196 & $-0,0030$ & $-0,0024$ & 0,0046 & $-0,0208$ & 0,0073 \\
\hline Mediana & 0,0210 & 0,0016 & 0,0176 & 0,0095 & $-0,0271$ & $-0,0189$ & $-0,0087$ & $-0,0052$ & 0,0084 & 0,0212 & $-0,0147$ & 0,0218 \\
\hline Desviación estándar & 0,0733 & 0,0666 & 0,0455 & 0,0986 & 0,0731 & 0,0778 & 0,0777 & 0,0633 & 0,0627 & 0,0798 & 0,0416 & 0,0501 \\
\hline Varianza de la muestra & 0,0054 & 0,0044 & 0,0021 & 0,0097 & 0,0053 & 0,0060 & 0,0060 & 0,0040 & 0,0039 & 0,0064 & 0,0017 & 0,0025 \\
\hline Curtosis & $-1,0484$ & 1,5831 & $-0,6749$ & 2,9431 & $-0,4197$ & 2,0103 & $-2,0058$ & $-0,3481$ & $-0,4186$ & $-0,6977$ & 3,0160 & 0,0986 \\
\hline Coeficiente de asimetría & $-0,3414$ & $-1,1769$ & $-0,4391$ & 1,1346 & 0,0351 & 0,3945 & 0,4482 & 0,1948 & $-0,1147$ & $-0,4316$ & $-1,5867$ & $-0,9841$ \\
\hline Rango & 0,2145 & 0,2151 & 0,1334 & 0,3453 & 0,2152 & 0,2748 & 0,1875 & 0,1939 & 0,1913 & 0,2333 & 0,1325 & 0,1403 \\
\hline Mínimo & $-0,1110$ & $-0,1455$ & $-0,0637$ & $-0,1185$ & $-0,1234$ & $-0,1435$ & $-0,0608$ & $-0,0968$ & $-0,0953$ & $-0,1228$ & $-0,1103$ & $-0,0861$ \\
\hline Máximo & 0,1035 & 0,0696 & 0,0697 & 0,2268 & 0,0918 & 0,1313 & 0,1267 & 0,0971 & 0,0959 & 0,1105 & 0,0222 & 0,0542 \\
\hline Observaciones & 8 & 8 & 8 & 8 & 8 & 8 & 8 & 8 & 8 & 8 & 8 & 8 \\
\hline$\%$ Observaciones positivas & $50,00 \%$ & $50,00 \%$ & $62,50 \%$ & $62,50 \%$ & $37,50 \%$ & $37,50 \%$ & $50,00 \%$ & $50,00 \%$ & $50,00 \%$ & $62,50 \%$ & $37,50 \%$ & $62,50 \%$ \\
\hline
\end{tabular}


Tanto el Ibex Medium Cap como el Ibex Small Cap (cuadros 4.5 y 4.6 respectivamente) presentarían el efecto enero con unas rentabilidades medias del 3,09\% y del 4,58\%, respectivamente, además de presentar ambos el mayor número de observaciones positivas llegando el Ibex Small Cap al 90\%. En el Ibex Medium Cap junio sería el mes que tendría una menor rentabilidad con una rentabilidad media del $-0,94 \%$, seguido por septiembre con el -0,76\%. El Ibex Small Cap presenta rentabilidades negativas notables los meses de mayo y noviembre por debajo del $-3 \%$ en términos medios. El Ibex Top Dividendo no presentaría efecto enero, siendo abril (mayo) el mes con una mayor (menor) rentabilidad media del 2,20\% (-2,57\%).

\section{Cuadro 4.8: Contraste de significatividad de medias para el efecto enero}

Este cuadro muestra el contraste de significatividad entre la rentabilidad media del mes de enero frente a la rentabilidad media del resto de meses para cada uno de los índices, para el período muestral total.

\begin{tabular}{lccccc}
\hline & IGBM & Ibex 35 & Ibex Medium Cap & Ibex Small Cap & Ibex Top Dividendo \\
\hline Enero & $\mathbf{0 , 0 2 5 6}$ & 0,0138 & $\mathbf{0 , 0 3 0 9}$ & 0,0458 & 0,0049 \\
& {$[\mathbf{0 , 0 4 0 2}]$} & {$[0,2964]$} & {$[\mathbf{0 , 0 3 1 7 ]}$} & {$[0,0919]$} & {$[0,8541]$} \\
Resto de meses & 0,0068 & 0,0059 & 0,0028 & $-0,0086$ & $-0,0019$ \\
\multirow{2}{*}{ Diferencia } & {$[0,0515]$} & {$[0,1191]$} & {$[0,4408]$} & {$[0,1822]$} & {$[0,7928]$} \\
& 0,0188 & 0,0079 & 0,0281 & 0,0544 & 0,0068 \\
& {$[0,1384]$} & {$[0,5602]$} & {$[0,0533]$} & {$[0,0556]$} & {$[0,8062]$} \\
\hline
\end{tabular}

Nota: los valores entre corchetes son la probabilidad crítica ( $p$-values). En negrita, valores significativos para un nivel de significación del 5\%.

El contraste de significatividad de medias, entre la rentabilidad media del mes de enero y el resto de meses para cada uno de los índices descartaría la existencia del efecto enero para los cinco, ya que ninguna de las diferencias de medias es estadísticamente significativa, aunque el Ibex Medium Cap y el Ibex Small Cap presentarían una significatividad débil. Lo que en línea con la evidencia de la literatura anterior indica que en todo caso el efecto enero se concentra en las empresas de menor tamaño.

Alternativamente, para probar la existencia del efecto enero vamos a proceder a desarrollar un modelo econométrico a través del uso de variables dummy, dado que es un enfoque común el uso de éstas cuando se utilizan índices bursátiles. Desarrollamos el siguiente modelo, a través de la creación de 11 variables dummy estacionales, una para cada mes, excepto el mes de enero:

$$
\mathrm{r}_{\mathrm{t}}=\mathrm{c}+\beta_{2} \mathrm{M}_{2 \mathrm{t}}+\beta_{3} \mathrm{M}_{3 \mathrm{t}}+\beta_{4} \mathrm{M}_{4 \mathrm{t}}+\beta_{5} \mathrm{M}_{5 \mathrm{t}}+\beta_{6} \mathrm{M}_{6 \mathrm{t}}+\beta_{7} \mathrm{M}_{7 \mathrm{t}}+\beta_{8} \mathrm{M}_{8 \mathrm{t}}+\beta_{9} \mathrm{M}_{9 \mathrm{t}}+\beta_{10} \mathrm{M}_{10 \mathrm{t}}+\beta_{11} \mathrm{M}_{11 \mathrm{t}}+\beta_{12} \mathrm{M}_{12 \mathrm{t}}+\varepsilon_{\mathrm{t}}
$$

Donde:

$r_{t}=$ Es la rentabilidad del índice en el período $t$.

$\mathrm{c}=$ Es la rentabilidad media en el mes de enero.

$\beta_{i}=$ Es la diferencia entre la rentabilidad de enero y el mes i-ésimo. 
$M_{i t}=$ Son las variables dummy estacionales, que tomaran los siguientes valores:

$M_{i t}= \begin{cases}1 & \text { Si el rendimiento en el tiempo t corresponde al mes i } \\ 0 & \text { de otra forma }\end{cases}$

$\varepsilon_{t}=$ Es un término de error, idéntica e independientemente distribuido.

La hipótesis nula a ser probada, bajo este modelo, es que los coeficientes de las variables dummy o $\beta_{i}$ sean iguales a cero. Adicionalmente, valores negativos de los coeficientes dummy deben ser considerados como una prueba de la presencia del efecto enero. De esta manera, la estimación de los coeficientes en la ecuación revela qué meses tienen rendimientos diferentes a los obtenidos en enero.

Como se puede ver en el Cuadro 4.9 las estimaciones de la ecuación desarrollada para determinar la presencia del efecto enero a través de MCO es válido ya que ninguna presenta efectos $\mathrm{ARCH}$, por lo tanto, la elaboración de los Cuadros 4.10 y 4.11 no sería necesaria, aunque se ha optado por su elaboración para contrastar los diferentes resultados. La no aparición de efectos $\mathrm{ARCH}$ en el efecto enero era previsible dado que el efecto $\mathrm{ARCH}$ se relaciona habitualmente con series financieras de datos diarios y no con series financieras de datos mensuales.

Como se observa en el Cuadro 4.9, ningún índice presentaría un efecto enero estadísticamente significativo. La rentabilidad media de enero del IGBM es positiva $(2,33 \%)$ y significativamente distinta de cero, y el resto de betas negativas, pero sólo la de septiembre es significativa. Por lo tanto, no se puede afirmar la existencia del efecto enero, ya que para confirmar su existencia el resto de betas, además de presentar una diferencia negativa, está tendría que ser estadísticamente relevante, pero sí que se podría confirmar la existencia de un efecto enero débil, situación que se repetiría para el Ibex Medium Cap y para el Ibex Small Cap. El Ibex Medium Cap presentaría, una rentabilidad media positiva y significativa para el mes de enero, y una diferencia negativa y significativa de junio y septiembre, pero no para el resto de meses. El Ibex Small Cap presentaría una significatividad débil para enero y unos valores negativos significativos para mayo, junio, julio y noviembre. 


\section{Cuadro 4.9: Resultados para la estimación del efecto enero con MCO}

Este cuadro muestra los resultados de la estimación de la ecuación: $\mathrm{r}_{\mathrm{t}}=\mathrm{c}+\beta_{2} \mathrm{M}_{2 \mathrm{t}}+\beta_{3} \mathrm{M}_{3 \mathrm{t}}+\beta_{4} \mathrm{M}_{4 \mathrm{t}}+\beta_{5} \mathrm{M}_{5 \mathrm{t}}+\beta_{6} \mathrm{M}_{6 \mathrm{t}}+\beta_{7} \mathrm{M}_{7 \mathrm{t}}+\beta_{8} \mathrm{M}_{8 \mathrm{t}}+\beta_{9} \mathrm{M}_{9 \mathrm{t}}+\beta_{10} \mathrm{M}_{10 \mathrm{t}}+\beta_{11} \mathrm{M}_{11 \mathrm{t}}+\beta_{12} \mathrm{M}_{12 \mathrm{t}}+\varepsilon_{\mathrm{t}}$, con MCO, para los cinco índices y para el período muestral total.

\begin{tabular}{|c|c|c|c|c|c|}
\hline & IGBM & Ibex 35 & Ibex Medium Cap & Ibex Small Cap & Ibex Top Dividendo \\
\hline \multirow[t]{2}{*}{$\mathrm{C}$} & $\mathbf{0 , 0 2 3 3}$ & 0,0118 & $\mathbf{0 , 0 2 9 0}$ & 0,0422 & 0,0026 \\
\hline & {$[0,0468]$} & {$[0,3487]$} & {$[0,0203]$} & {$[0,0593]$} & {$[0,9170]$} \\
\hline \multirow[t]{2}{*}{$\beta_{2}$} & $-0,0042$ & 0,0000 & $-0,0116$ & $-0,0244$ & $-0,0176$ \\
\hline & {$[0,8011]$} & {$[0,9987]$} & {$[0,5111]$} & {$[0,4373]$} & {$[0,6134]$} \\
\hline \multirow[t]{2}{*}{$\beta_{3}$} & $-0,0201$ & $-0,0145$ & $-0,0212$ & $-0,0340$ & 0,0020 \\
\hline & {$[0,2243]$} & {$[0,4149]$} & {$[0,2277]$} & {$[0,2791]$} & {$[0,9551]$} \\
\hline \multirow[t]{2}{*}{$\beta_{4}$} & $-0,0069$ & 0,0034 & $-0,0151$ & $-0,0421$ & 0,0153 \\
\hline & {$[0,6779]$} & {$[0,8487]$} & {$[0,3899]$} & {$[0,1809]$} & {$[0,6594]$} \\
\hline \multirow[t]{2}{*}{$\beta_{5}$} & $-0,0158$ & $-0,0169$ & $-0,0346$ & $-0,0768$ & $-0,0310$ \\
\hline & {$[0,3387]$} & {$[0,3434]$} & {$[0,0502]$} & {$[0,0157]$} & {$[0,3732]$} \\
\hline \multirow[t]{2}{*}{$\beta_{6}$} & $-0,0265$ & $-0,0200$ & $-0,0399$ & $-0,0720$ & $-0,0201$ \\
\hline & {$[0,1100]$} & {$[0,2601]$} & {$[0,0242]$} & {$[0,0234]$} & {$[0,5631]$} \\
\hline \multirow[t]{2}{*}{$\beta_{7}$} & $-0,0189$ & $-0,0119$ & $-0,0283$ & $-0,0653$ & 0,0143 \\
\hline & {$[0,2522]$} & {$[0,5041]$} & {$[0,1081]$} & {$[0,0393]$} & {$[0,6808]$} \\
\hline \multirow[t]{2}{*}{$\beta_{8}$} & $-0,0261$ & $-0,0209$ & $-0,0324$ & $-0,0422$ & $-0,0073$ \\
\hline & {$[0,1152]$} & {$[0,2398]$} & {$[0,0661]$} & {$[0,1797]$} & {$[0,8331]$} \\
\hline \multirow[t]{2}{*}{$\beta_{9}$} & $-0,0372$ & $-0,0225$ & $-0,0391$ & $-0,0444$ & $-0,0068$ \\
\hline & {$[0,0250]$} & {$[0,2069]$} & {$[\mathbf{0 , 0 2 7 2 ]}$} & {$[0,1588]$} & {$[0,8461]$} \\
\hline \multirow[t]{2}{*}{$\beta_{10}$} & $-0,0224$ & 0,0090 & $-0,0207$ & $-0,0476$ & $-0,0008$ \\
\hline & {$[0,1757]$} & {$[0,6112]$} & {$[0,2396]$} & {$[0,1310]$} & {$[0,9823]$} \\
\hline \multirow[t]{2}{*}{$\beta_{11}$} & $-0,0153$ & 0,0065 & $-0,0324$ & $-0,0755$ & $-0,0244$ \\
\hline & {$[0,3557]$} & {$[0,7159]$} & {$[0,0665]$} & {$[0,0175]$} & {$[0,4840]$} \\
\hline \multirow[t]{2}{*}{$\beta_{12}$} & $-0,0106$ & 0,0020 & $-0,0269$ & $-0,0593$ & 0,0036 \\
\hline & {$[0,5200]$} & {$[0,9100]$} & {$[0,1267]$} & {$[0,0605]$} & {$[0,9186]$} \\
\hline $\mathrm{R}^{2}$ & 0,0251 & 0,0334 & 0,0505 & 0,0976 & 0,0451 \\
\hline \multirow[t]{2}{*}{$\mathrm{F}$} & 0,8156 & 0,8679 & 0,9276 & 1,0623 & 0,3609 \\
\hline & {$[0,6245]$} & {$[0,5724]$} & {$[0,5150]$} & {$[0,3985]$} & {$[0,9674]$} \\
\hline Observaciones & 360 & 288 & 204 & 120 & 96 \\
\hline $\operatorname{Arch}(1)$ & 0,1404 & 0,1155 & 0,3181 & 0,1468 & 0,2998 \\
\hline
\end{tabular}

Nota: los valores entre corchetes son la probabilidad crítica (p-values). En negrita, valores significativos para un nivel de significación del 5\%. 


\section{Cuadro 4.10: Resultados para la estimación del efecto enero con el modelo GARCH $(1,1)$}

Este cuadro muestra los resultados de la estimación de la ecuación: $r_{t}=c+\beta_{2} \mathrm{M}_{2 t}+\beta_{3} \mathrm{M}_{3 \mathrm{t}}+\beta_{4} \mathrm{M}_{4 \mathrm{t}}+\beta_{5} \mathrm{M}_{5 \mathrm{t}}+\beta_{6} \mathrm{M}_{6 \mathrm{t}}+\beta_{7} \mathrm{M}_{7 \mathrm{t}}+\beta_{8} \mathrm{M}_{8 \mathrm{t}}+\beta_{9} \mathrm{M}_{9 \mathrm{t}}+\beta_{10} \mathrm{M}_{10 \mathrm{t}}+\beta_{11} \mathrm{M}_{11 \mathrm{t}}+\beta_{12} \mathrm{M}_{12 \mathrm{t}}+\varepsilon_{\mathrm{t}}$, con el modelo GARCH $(1,1)$, para los cinco índices y para el período muestral total.

\begin{tabular}{|c|c|c|c|c|c|}
\hline & IGBM & Ibex 35 & Ibex Medium Cap & Ibex Small Cap & Ibex Top Dividendo \\
\hline \multirow[t]{2}{*}{$\mathrm{C}$} & 0,0182 & 0,0130 & $\mathbf{0 , 0 4 0 5}$ & $\mathbf{0 , 0 5 1 6}$ & 0,0377 \\
\hline & {$[0,0811]$} & {$[0,2765]$} & {$[0,0005]$} & {$[0,0447]$} & {$[0,0790]$} \\
\hline \multirow[t]{2}{*}{$\beta_{2}$} & 0,0021 & 0,0064 & $-0,0120$ & $-0,0261$ & $-0,0231$ \\
\hline & {$[0,8956]$} & {$[0,7382]$} & {$[0,4980]$} & {$[0,4356]$} & {$[0,4193]$} \\
\hline \multirow[t]{2}{*}{$\beta_{3}$} & $-0,0196$ & $-0,0186$ & $-0,0391$ & $-0,0399$ & $-0,0308$ \\
\hline & {$[0,1973]$} & {$[0,3668]$} & {$[0,0245]$} & {$[0,3838]$} & {$[0,2847]$} \\
\hline \multirow[t]{2}{*}{$\beta_{4}$} & $-0,0029$ & 0,0016 & $-0,0267$ & $-0,0465$ & $-0,0297$ \\
\hline & {$[0,8440]$} & {$[0,9192]$} & {$[0,1266]$} & {$[0,1860]$} & {$[0,3277]$} \\
\hline \multirow[t]{2}{*}{$\beta_{5}$} & $-0,0076$ & $-0,0098$ & $-0,0468$ & $-0,0891$ & $-0,0570$ \\
\hline & {$[0,6198]$} & {$[0,5712]$} & {$[0,0007]$} & {$[0,0039]$} & {$[0,0683]$} \\
\hline \multirow[t]{2}{*}{$\beta_{6}$} & $-0,0259$ & $-0,0185$ & $-0,0415$ & $-0,0808$ & $-0,0536$ \\
\hline & {$[0,0504]$} & {$[0,2226]$} & {$[0,0100]$} & {$[0,0633]$} & {$[0,0715]$} \\
\hline \multirow[t]{2}{*}{$\beta_{7}$} & $-0,0249$ & $-0,0134$ & $-0,0337$ & $-0,0733$ & $-0,0315$ \\
\hline & {$[0,0776]$} & {$[0,4129]$} & {$[0,0312]$} & {$[0,0314]$} & {$[0,2481]$} \\
\hline \multirow[t]{2}{*}{$\beta_{8}$} & $-0,0215$ & $-0,0183$ & $-0,0346$ & $-0,0487$ & $-0,0629$ \\
\hline & {$[0,1202]$} & {$[0,2665]$} & {$[0,0457]$} & {$[0,1337]$} & {$[0,0353]$} \\
\hline \multirow[t]{2}{*}{$\beta_{9}$} & $-0,0217$ & $-0,0100$ & $-0,0405$ & $-0,0508$ & $-0,0406$ \\
\hline & {$[0,1232]$} & {$[0,5323]$} & {$[0,0047]$} & {$[0,0964]$} & {$[0,1869]$} \\
\hline \multirow[t]{2}{*}{$\beta_{10}$} & $-0,0146$ & 0,0052 & $-0,0317$ & $-0,0538$ & $-0,0276$ \\
\hline & {$[0,3027]$} & {$[0,7354]$} & {$[0,0452]$} & {$[0,0986]$} & {$[0,3493]$} \\
\hline \multirow[t]{2}{*}{$\beta_{11}$} & $-0,0080$ & 0,0069 & $-0,0365$ & $-0,0821$ & $-0,0632$ \\
\hline & {$[0,5670]$} & {$[0,6602]$} & {$[0,0282]$} & {$[0,0357]$} & {$[0,0562]$} \\
\hline \multirow[t]{2}{*}{$\beta_{12}$} & $-0,0064$ & 0,0025 & $-0,0280$ & $-0,0689$ & $-0,0336$ \\
\hline & {$[0,6447]$} & {$[0,8688]$} & {$[0,1020]$} & {$[0,0652]$} & {$[0,3181]$} \\
\hline \multirow[t]{2}{*}{$\mathrm{C}$} & 0,0003 & 0,0002 & 0,0003 & 0,0004 & 0,0004 \\
\hline & {$[0,0370]$} & {$[0,1481]$} & {$[0,1110]$} & {$[0,5315]$} & {$[0,3806]$} \\
\hline \multirow[t]{2}{*}{ ARCH(1) } & 0,2022 & 0,1510 & 0,1963 & $-0,0027$ & 0,2281 \\
\hline & {$[0,0015]$} & {$[0,0143]$} & {$[0,0443]$} & {$[0,9531]$} & {$[0,1252]$} \\
\hline \multirow[t]{2}{*}{ GARCH(1) } & 0,7346 & 0,8091 & 0,7109 & 0,9119 & 0,6771 \\
\hline & {$[0,0000]$} & {$[0,0000]$} & {$[0,0000]$} & {$[0,0000]$} & {$[0,0002]$} \\
\hline Observaciones & 360 & 288 & 204 & 120 & 96 \\
\hline
\end{tabular}

Nota: los valores entre corchetes son la probabilidad crítica ( $p$-values). En negrita, valores significativos para un nivel de significación del 5\%. 


\section{Cuadro 4.11: Resultados para la estimación del efecto enero con el modelo EGARCH $(1,1)$}

Este cuadro muestra los resultados de la estimación de la ecuación: $r_{t}=c+\beta_{2} M_{2 t}+\beta_{3} M_{3 t}+\beta_{4} M_{4 t}+\beta_{5} M_{5 t}+\beta_{6} M_{6 t}+\beta_{7} M_{7 t}+\beta_{8} M_{8 t}+\beta_{9} M_{9 t}+\beta_{10} M_{10 t}+\beta_{11} M_{11 t}+\beta_{12} M_{12 t}+\varepsilon_{t}$, con el modelo EGARCH $(1,1)$, para los cinco índices y para el período muestral total.

\begin{tabular}{|c|c|c|c|c|c|}
\hline & IGBM & Ibex 35 & Ibex Medium Cap & Ibex Small Cap & Ibex Top Dividendo \\
\hline \multirow[t]{2}{*}{$\mathrm{C}$} & 0,0179 & 0,0107 & 0,0342 & 0,0605 & 0,0316 \\
\hline & {$[0,1019]$} & {$[0,3809]$} & {$[0,0028]$} & {$[0,0251]$} & {$[0,0497]$} \\
\hline \multirow[t]{2}{*}{$\beta_{2}$} & 0,0031 & 0,0082 & $-0,0129$ & $-0,0358$ & $-0,0219$ \\
\hline & {$[0,8529]$} & {$[0,6730]$} & {$[0,4825]$} & {$[0,1942]$} & {$[0,3450]$} \\
\hline \multirow[t]{2}{*}{$\beta_{3}$} & $-0,0221$ & $-0,0189$ & $-0,0273$ & $-0,0471$ & $-0,0113$ \\
\hline & {$[0,1686]$} & {$[0,3542]$} & {$[0,1298]$} & {$[0,3123]$} & {$[0,6529]$} \\
\hline \multirow[t]{2}{*}{$\beta_{4}$} & $-0,0032$ & 0,0024 & $-0,0262$ & $-0,0503$ & $-0,0312$ \\
\hline & {$[0,8363]$} & {$[0,8872]$} & {$[0,1904]$} & {$[0,1606]$} & {$[0,2911]$} \\
\hline \multirow[t]{2}{*}{$\beta_{5}$} & $-0,0063$ & $-0,0061$ & $-0,0292$ & $-0,0934$ & $-0,0348$ \\
\hline & {$[0,6797]$} & {$[0,7238]$} & {$[0,0431]$} & {$[0,0049]$} & {$[0,1434]$} \\
\hline \multirow[t]{2}{*}{$\beta_{6}$} & $-0,0262$ & $-0,0176$ & $-0,0395$ & $-0,1003$ & $-0,0324$ \\
\hline & {$[0,0559]$} & {$[0,2547]$} & {$[0,0054]$} & {$[0,0166]$} & {$[0,1658]$} \\
\hline \multirow[t]{2}{*}{$\beta_{7}$} & $-0,0283$ & $-0,0131$ & $-0,0275$ & $-0,0804$ & $-0,0333$ \\
\hline & {$[0,0504]$} & {$[0,4173]$} & {$[0,0789]$} & {$[0,0152]$} & {$[0,1284]$} \\
\hline \multirow[t]{2}{*}{$\beta_{8}$} & $-0,0186$ & $-0,0146$ & $-0,0303$ & $-0,0633$ & $-0,0394$ \\
\hline & {$[0,1791]$} & {$[0,3654]$} & {$[0,0877]$} & {$[0,0452]$} & {$[0,1487]$} \\
\hline \multirow[t]{2}{*}{$\beta_{9}$} & $-0,0262$ & $-0,0102$ & $-0,0216$ & $-0,0510$ & $-0,0274$ \\
\hline & {$[0,0750]$} & {$[0,5346]$} & {$[0,1159]$} & {$[0,1168]$} & {$[0,2687]$} \\
\hline \multirow[t]{2}{*}{$\beta_{10}$} & $-0,0175$ & 0,0030 & $-0,0263$ & $-0,0684$ & $-0,0184$ \\
\hline & {$[0,2172]$} & {$[0,8488]$} & {$[0,0471]$} & {$[0,0371]$} & {$[0,3968]$} \\
\hline \multirow[t]{2}{*}{$\beta_{11}$} & $-0,0073$ & 0,0054 & $-0,0340$ & $-0,1005$ & $-0,0403$ \\
\hline & {$[0,6097]$} & {$[0,7321]$} & {$[0,0325]$} & {$[0,0047]$} & {$[0,1098]$} \\
\hline \multirow[t]{2}{*}{$\beta_{12}$} & $-0,0075$ & 0,0044 & $-0,0216$ & $-0,0719$ & $-0,0350$ \\
\hline & {$[0,6048]$} & {$[0,7866]$} & {$[0,1860]$} & {$[0,0260]$} & {$[0,1669]$} \\
\hline \multirow[t]{2}{*}{$\bar{C}$} & $-0,7514$ & $-0,7376$ & $-1,0744$ & $-4,6235$ & $-0,2624$ \\
\hline & {$[0,0093]$} & {$[0,0184]$} & {$[0,0032]$} & {$[0,0369]$} & {$[0,0940]$} \\
\hline \multirow[t]{2}{*}{ |RES/SQR[GARCH](1) } & 0,3445 & 0,2818 & $-0,0775$ & 0,4091 & $-0,3435$ \\
\hline & {$[0,0006]$} & {$[0,0082]$} & {$[0,4435]$} & {$[0,1230]$} & {$[0,0900]$} \\
\hline \multirow[t]{2}{*}{ RES/SQR[GARCH](1) } & $-0,0214$ & $-0,0689$ & $-0,2336$ & $-0,2154$ & $-0,1918$ \\
\hline & {$[0,5489]$} & {$[0,0656]$} & {$[0,0001]$} & {$[0,2171]$} & {$[0,0728]$} \\
\hline \multirow[t]{2}{*}{ EGARCH(1) } & 0,9142 & 0,9083 & 0,8167 & 0,2153 & 0,9085 \\
\hline & {$[0,0000]$} & {$[0,0000]$} & {$[0,0000]$} & {$[0,6032]$} & {$[0,0000]$} \\
\hline Observaciones & 360 & 288 & 204 & 120 & 96 \\
\hline
\end{tabular}

Nota: los valores entre corchetes son la probabilidad crítica (p-values). En negrita, valores significativos para un nivel de significación del 5\%. 
En los Cuadros 4.10 y 4.11 podemos ver que muchos de los términos de la ecuación de la varianza no son significativos, por lo tanto, desestima el uso de los modelos GARCH $(1,1)$ y EGARCH $(1,1)$. La única estimación que ofrece los términos significativos es la del IGBM para el modelo GARCH $(1,1)$.

\subsubsection{Análisis robustez subperíodos muestrales}

Como se observa en el Cuadro 4.12, el efecto enero sólo está presenta en el IGBM en el subperíodo 1986-1997. En el subperíodo 1998-2007, el efecto enero no se evidencia y es octubre el mes que presenta una mayor rentabilidad media mensual $(4,80 \%)$ para pasar en el tercer subperíodo a invertirse el efecto enero, es decir, enero pasa a ser uno de los meses con una menor rentabilidad media mensual con un $-1,87 \%$, únicamente superado por noviembre con el $-2,35 \%$. El Ibex 35 al contrario no presenta en ningún subperíodo el efecto enero, sólo presenta un efecto noviembre en el subperíodo 19922007 y un efecto julio en el subperíodo 2008-2015. En el subperíodo 1992-2007 el mes que presenta una menor rentabilidad media mensual es septiembre y en el subperíodo 2008-2015, es mayo, aunque con valores próximos a los de enero.

El Cuadro 4.14 corrobora lo expuesto anteriormente el efecto enero sólo está presente en en el IGBM para el subperíodo muestral 1986-1997.

En los Cuadros del 4.15 al 4.17, no se observa la presencia significativa del efecto enero en ninguno de los subperíodos analizados, pero si débil para el subperíodo 1986-1997 del IGBM. 


\section{Cuadro 4.12: Estadísticos descriptivos del IGBM, para el efecto enero, en diferentes subperíodos muestrales}

Este cuadro muestra los principales estadísticos descriptivos de las rentabilidades medías mensuales del IGBM durante los subperíodos muestrales de 1986 a 1997 , de 1998 a 2007 y de 2008 a 2015 .

\begin{tabular}{|c|c|c|c|c|c|c|c|c|c|c|c|c|}
\hline Subperíodo 1986-1997 & Enero & Febrero & Marzo & Abril & Mayo & Junio & Julio & Agosto & Septiembre & Octubre & Noviembre & Diciembre \\
\hline Media & 0,0555 & 0,0312 & 0,0078 & 0,0348 & 0,0371 & 0,0040 & 0,0058 & 0,0155 & $-0,0167$ & $-0,0287$ & 0,0124 & 0,0242 \\
\hline Mediana & 0,0437 & 0,0179 & 0,0028 & 0,0335 & 0,0391 & 0,0032 & $-0,0044$ & 0,0179 & $-0,0054$ & $-0,0177$ & 0,0029 & 0,0162 \\
\hline Desviación estándar & 0,0612 & 0,0676 & 0,0883 & 0,0538 & 0,0192 & 0,0607 & 0,0652 & 0,0737 & 0,0706 & 0,1024 & 0,0524 & 0,0532 \\
\hline Varianza de la muestra & 0,0038 & 0,0046 & 0,0078 & 0,0029 & 0,0004 & 0,0037 & 0,0043 & 0,0054 & 0,0050 & 0,0105 & 0,0027 & 0,0028 \\
\hline Curtosis & 0,8085 & 1,2490 & 1,1809 & 0,6592 & $-0,5924$ & $-0,9768$ & 2,4677 & $-0,2902$ & 3,0765 & 2,8953 & $-1,6012$ & $-1,2318$ \\
\hline Coeficiente de asimetría & 0,0935 & 1,1431 & 0,8277 & 0,7471 & $-0,3681$ & $-0,0895$ & 0,9992 & $-0,1472$ & $-0,9025$ & $-1,3555$ & 0,0264 & 0,2467 \\
\hline Rango & 0,2369 & 0,2319 & 0,3158 & 0,1888 & 0,0628 & 0,1843 & 0,2552 & 0,2467 & 0,2963 & 0,3932 & 0,1446 & 0,1567 \\
\hline Mínimo & $-0,0602$ & $-0,0526$ & $-0,1074$ & $-0,0359$ & 0,0055 & $-0,0871$ & $-0,0923$ & $-0,1239$ & $-0,1876$ & $-0,2845$ & $-0,0658$ & $-0,0549$ \\
\hline Máximo & 0,1766 & 0,1793 & 0,2083 & 0,1529 & 0,0683 & 0,0972 & 0,1629 & 0,1228 & 0,1087 & 0,1087 & 0,0788 & 0,1018 \\
\hline Observaciones & 12 & 12 & 12 & 12 & 12 & 12 & 12 & 12 & 12 & 12 & 12 & 12 \\
\hline$\%$ Observaciones positivas & $83,33 \%$ & $66,67 \%$ & $50,00 \%$ & $66,67 \%$ & $100,00 \%$ & $50,00 \%$ & $41,67 \%$ & $58,33 \%$ & $41,67 \%$ & $41,67 \%$ & $50,00 \%$ & $58,33 \%$ \\
\hline $\begin{array}{l}\text { Subperíodo 1998-2007 } \\
\end{array}$ & Enero & Febrero & Marzo & Abril & Mayo & Junio & Julio & Agosto & Septiembre & Octubre & Noviembre & Diciembre \\
\hline Media & 0,0252 & 0,0346 & 0,0056 & 0,0111 & $-0,0036$ & $-0,0063$ & $-0,0094$ & $-0,0112$ & $-0,0212$ & 0,0480 & 0,0331 & 0,0079 \\
\hline Mediana & 0,0266 & 0,0202 & $-0,0151$ & 0,0025 & $-0,0058$ & 0,0113 & $-0,0014$ & 0,0025 & $-0,0113$ & 0,0577 & 0,0253 & 0,0188 \\
\hline Desviación estándar & 0,0454 & 0,0615 & 0,0543 & 0,0423 & 0,0383 & 0,0495 & 0,0449 & 0,0684 & 0,0711 & 0,0551 & 0,0577 & 0,0439 \\
\hline Varianza de la muestra & 0,0021 & 0,0038 & 0,0030 & 0,0018 & 0,0015 & 0,0024 & 0,0020 & 0,0047 & 0,0051 & 0,0030 & 0,0033 & 0,0019 \\
\hline Curtosis & $-0,5432$ & 0,4938 & 5,8650 & 0,8931 & $-0,3303$ & 1,3790 & $-0,4298$ & 6,8826 & $-0,7023$ & $-0,4251$ & 0,5690 & 1,0838 \\
\hline Coeficiente de asimetría & 0,4693 & 0,7099 & 2,2837 & 1,2101 & 0,3404 & $-1,1179$ & $-0,8159$ & $-2,4632$ & $-0,2261$ & $-0,4606$ & $-0,7565$ & $-1,1446$ \\
\hline Rango & 0,1334 & 0,2103 & 0,1824 & 0,1335 & 0,1196 & 0,1716 & 0,1276 & 0,2377 & 0,2191 & 0,1664 & 0,1862 & 0,1391 \\
\hline Mínimo & $-0,0336$ & $-0,0574$ & $-0,0354$ & $-0,0342$ & $-0,0605$ & $-0,1126$ & $-0,0930$ & $-0,1936$ & $-0,1396$ & $-0,0443$ & $-0,0858$ & $-0,0860$ \\
\hline Máximo & 0,0998 & 0,1530 & 0,1470 & 0,0993 & 0,0591 & 0,0590 & 0,0346 & 0,0442 & 0,0796 & 0,1221 & 0,1004 & 0,0532 \\
\hline Observaciones & 10 & 10 & 10 & 10 & 10 & 10 & 10 & 10 & 10 & 10 & 10 & 10 \\
\hline$\%$ Observaciones positivas & $70,00 \%$ & $80,00 \%$ & $40,00 \%$ & $50,00 \%$ & $50,00 \%$ & $60,00 \%$ & $50,00 \%$ & $50,00 \%$ & $50,00 \%$ & $80,00 \%$ & $80,00 \%$ & $60,00 \%$ \\
\hline \begin{tabular}{|l|} 
Subperíodo 2008-2015 \\
\end{tabular} & Enero & Febrero & Marzo & Abril & Mayo & Junio & Julio & Agosto & Septiembre & Octubre & Noviembre & Diciembre \\
\hline $\mathrm{Me}$ & $-0,0187$ & & & & $-0,0$ & $-0,00$ & 0,0 & $-0,0109$ & & 0,0016 & $-0,0235$ & 0,0056 \\
\hline Mediana & $-0,0010$ & $-0,0048$ & 0,0150 & 0,02 & $-0,0$ & $-0,0108$ & 0,0105 & $-0,0149$ & 0199 & 0,0205 & $-0,0018$ & 0,0179 \\
\hline Desviación estándar & 0,0729 & 0,0538 & 0,0367 & 0,0587 & 0,0841 & 0,0824 & 0,0785 & 0,0647 & 0,0598 & 0,0814 & 0,0582 & 0,0455 \\
\hline Varianza de la muestra & 0,0053 & 0,0029 & 0,0013 & 0,0034 & 0,0071 & 0,0068 & 0,0062 & 0,0042 & 0,0036 & 0,0066 & 0,0034 & 0,0021 \\
\hline Curtosis & $-0,3652$ & 1,0107 & $-1,5911$ & 2,6539 & 1,1832 & 2,1098 & $-1,7821$ & 0,0234 & $-0,0423$ & 2,1944 & 3,0606 & 0,6673 \\
\hline Coeficiente de asimetría & 0,0794 & $-0,2661$ & $-0,4472$ & $-1,5323$ & 0,6812 & 1,0781 & 0,1843 & 0,4800 & 0,2063 & $-1,3594$ & $-1,7409$ & $-1,0520$ \\
\hline Rango & 0,2271 & 0,1819 & 0,0983 & 0,1865 & 0,2702 & 0,2756 & 0,2059 & 0,1963 & 0,1816 & 0,2490 & 0,1765 & 0,1416 \\
\hline Mínimo & $-0,1259$ & $-0,1048$ & $-0,0528$ & $-0,1238$ & $-0,1276$ & $-0,1115$ & $-0,0728$ & $-0,0944$ & $-0,0706$ & $-0,1676$ & $-0,1497$ & $-0,0793$ \\
\hline & 0,1012 & 0,0771 & 0,0455 & 0,0627 & 0,1426 & 0,1641 & 0,1330 & 0,1018 & 0,1110 & 0,0814 & 0,0268 & 0,0622 \\
\hline Observaciones & 8 & 8 & 8 & 8 & 8 & 8 & 8 & 8 & 8 & 8 & 8 & 8 \\
\hline \% Observaciones positivas & $50,00 \%$ & $37,50 \%$ & $62,50 \%$ & $62,50 \%$ & $25,00 \%$ & $37,50 \%$ & $50,00 \%$ & $37,50 \%$ & $62,50 \%$ & $62,50 \%$ & $50,00 \%$ & $75,00 \%$ \\
\hline
\end{tabular}


Cuadro 4.13: Estadísticos descriptivos del Ibex 35, para el efecto enero, en diferentes subperíodos muestrales

Este cuadro muestra los principales estadísticos descriptivos de las rentabilidades medías mensuales del Ibex 35 durante los subperíodos muestrales de 1992 a 2007 y de 2008 a 2015.

\begin{tabular}{|c|c|c|c|c|c|c|c|c|c|c|c|c|}
\hline Subperíodo 1992-2007 & Enero & Febrero & Marzo & Abril & Mayo & Junio & Julio & Agosto & Septiembre & Octubre & Noviembre & Diciembre \\
\hline Media & 0,0311 & 0,0251 & $-0,0040$ & 0,0172 & 0,0095 & $-0,0075$ & $-0,0106$ & $-0,0048$ & $-0,0171$ & 0,0340 & 0,0413 & 0,0199 \\
\hline Mediana & 0,0287 & 0,0151 & $-0,0182$ & 0,0097 & 0,0050 & 0,0142 & $-0,0054$ & 0,0004 & $-0,0225$ & 0,0436 & 0,0518 & 0,0206 \\
\hline Desviación estándar & 0,0522 & 0,0568 & 0,0493 & 0,0430 & 0,0407 & 0,0596 & 0,0531 & 0,0693 & 0,0724 & 0,0692 & 0,0632 & 0,0544 \\
\hline Varianza de la muestra & 0,0027 & 0,0032 & 0,0024 & 0,0019 & 0,0017 & 0,0036 & 0,0028 & 0,0048 & 0,0052 & 0,0048 & 0,0040 & 0,0030 \\
\hline Curtosis & $-0,5965$ & 1,3312 & 5,5373 & $-0,3734$ & $-0,8571$ & $-0,0707$ & $-1,0720$ & 5,7178 & $-0,2816$ & 0,4424 & 0,7074 & 0,2251 \\
\hline Coeficiente de asimetría & $-0,1347$ & 0,8770 & 1,9692 & 0,7244 & $-0,1932$ & $-0,6229$ & $-0,5651$ & $-1,5069$ & $-0,0316$ & $-0,5367$ & $-0,9261$ & $-0,4575$ \\
\hline Rango & 0,1797 & 0,2221 & 0,2141 & 0,1446 & 0,1344 & 0,2231 & 0,1544 & 0,3396 & 0,2689 & 0,2687 & 0,2357 & 0,2014 \\
\hline Mínimo & $-0,0693$ & $-0,0605$ & $-0,0670$ & $-0,0391$ & $-0,0680$ & $-0,1304$ & $-0,1034$ & $-0,2124$ & $-0,1560$ & $-0,1223$ & $-0,1108$ & $-0,0970$ \\
\hline Máximo & 0,1105 & 0,1616 & 0,1471 & 0,1054 & 0,0664 & 0,0926 & 0,0511 & 0,1271 & 0,1129 & 0,1464 & 0,1249 & 0,1043 \\
\hline Observaciones & 16 & 16 & 16 & 16 & 16 & 16 & 16 & 16 & 16 & 16 & 16 & 16 \\
\hline$\%$ Observaciones positivas & $75,00 \%$ & $68,75 \%$ & $37,50 \%$ & $62,50 \%$ & $56,25 \%$ & $56,25 \%$ & $43,75 \%$ & $50,00 \%$ & $43,75 \%$ & $75,00 \%$ & $81,25 \%$ & $75,00 \%$ \\
\hline Subperíodo 2008-2015 & Enero & Febrero & Marzo & Abril & Mayo & Junio & Julio & Agosto & Septiembre & Octubre & Noviembre & Diciembre \\
\hline Media & $-0,0209$ & $-0,0102$ & 0,0026 & 0,0160 & $-0,0302$ & $-0,0033$ & 0,0265 & $-0,0110$ & 0,0091 & 0,0031 & $-0,0208$ & 0,0057 \\
\hline Mediana & $-0,0032$ & $-0,0048$ & 0,0149 & 0,0200 & $-0,0145$ & $-0,0107$ & 0,0122 & $-0,0158$ & 0,0206 & 0,0229 & $-0,0023$ & 0,0196 \\
\hline Desviación estándar & 0,0722 & 0,0510 & 0,0374 & 0,0809 & 0,0614 & 0,0833 & 0,0767 & 0,0640 & 0,0581 & 0,0823 & 0,0561 & 0,0467 \\
\hline Varianza de la muestra & 0,0052 & 0,0026 & 0,0014 & 0,0065 & 0,0038 & 0,0069 & 0,0059 & 0,0041 & 0,0034 & 0,0068 & 0,0031 & 0,0022 \\
\hline Curtosis & $-0,4233$ & 1,0148 & $-1,2855$ & 1,4418 & $-0,4398$ & 2,2207 & $-1,7075$ & 0,1268 & $-0,1323$ & 2,4727 & 3,1933 & 0,5939 \\
\hline Coeficiente de asimetría & 0,0139 & $-0,2038$ & $-0,3906$ & $-0,0139$ & $-0,7030$ & 1,0784 & 0,1941 & 0,4781 & 0,1789 & $-1,4442$ & $-1,7594$ & $-1,0361$ \\
\hline Rango & 0,2247 & 0,1727 & 0,1061 & 0,2810 & 0,1741 & 0,2806 & 0,2039 & 0,1960 & 0,1762 & 0,2541 & 0,1709 & 0,1450 \\
\hline Mínimo & $-0,1287$ & $-0,0982$ & $-0,0541$ & $-0,1245$ & $-0,1314$ & $-0,1143$ & $-0,0704$ & $-0,0947$ & $-0,0681$ & $-0,1703$ & $-0,1429$ & $-0,0811$ \\
\hline Máximo & 0,0960 & 0,0745 & 0,0520 & 0,1565 & 0,0427 & 0,1662 & 0,1335 & 0,1013 & 0,1080 & 0,0838 & 0,0280 & 0,0639 \\
\hline Observaciones & 8 & 8 & 8 & 8 & 8 & 8 & 8 & 8 & 8 & 8 & 8 & 8 \\
\hline$\%$ Observaciones positivas & $50,00 \%$ & $37,50 \%$ & $62,50 \%$ & $62,50 \%$ & $25,00 \%$ & $37,50 \%$ & $50,00 \%$ & $37,50 \%$ & $62,50 \%$ & $62,50 \%$ & $50,00 \%$ & $75,00 \%$ \\
\hline
\end{tabular}




\section{Cuadro 4.14: Contraste de significatividad de medias, para el efecto enero, en diferentes subperíodos muestrales}

Este cuadro muestra el contraste de significatividad entre la rentabilidad media del mes de enero frente a la rentabilidad media del resto de meses para el IGBM y para el Ibex 35 en diferentes subperíodos muestrales.

\begin{tabular}{lccccc} 
& IGBM & IGBM & IGBM & Ibex 35 & Ibex 35 \\
\cline { 2 - 6 } & Subperíodo 1986-1997 & Subperíodo 1998-2007 & Subperíodo 2008-2015 & Subperíodo 1992-2007 & Subperíodo 2008-2015 \\
\hline Enero & $\mathbf{0 , 0 5 5 5}$ & 0,0252 & $-0,0187$ & $\mathbf{0 , 0 3 1 1}$ & $-0,0209$ \\
& {$[\mathbf{0 , 0 0 9 5}]$} & {$[0,1130]$} & {$[0,4911]$} & {$[\mathbf{0 , 0 3 0 8}]$} & {$[0,4401]$} \\
Resto de meses & 0,0116 & 0,0081 & $-0,0021$ & $\mathbf{0 , 0 0 9 4}$ & $-0,0011$ \\
& {$[0,0518]$} & {$[0,1327]$} & {$[0,7567]$} & {$[\mathbf{0 , 0 3 8 5}]$} & {$[0,8665]$} \\
Diferencia & $\mathbf{0 , 0 4 3 9}$ & 0,0171 & $-0,0166$ & 0,0218 & $-0,0198$ \\
& {$[\mathbf{0 , 0 3 3 7 ]}$} & {$[0,2850]$} & {$[0,5498]$} & {$[0,1315]$} & {$[0,4757]$} \\
\hline Nota: los valores entre corchetes son la probabilidad crítica $($ p-values $)$. En negrita, valores significativos para un nivel de significación del $5 \%$.
\end{tabular}

Nota: los valores entre corchetes son la probabilidad crítica ( $p$-values). En negrita, valores significativos para un nivel de significación del 5\%. 


\section{Cuadro 4.15: Resultados para la estimación del efecto enero con MCO, para diferentes subperíodos muestrales}

Este cuadro muestra los resultados de la estimación de la ecuación: $\mathrm{r}_{\mathrm{t}}=\mathrm{c}+\beta_{2} \mathrm{M}_{2 \mathrm{t}}+\beta_{3} \mathrm{M}_{3 \mathrm{t}}+\beta_{4} \mathrm{M}_{4 \mathrm{t}}+\beta_{5} \mathrm{M}_{5 \mathrm{t}}+\beta_{6} \mathrm{M}_{6 \mathrm{t}}+\beta_{7} \mathrm{M}_{7 \mathrm{t}}+\beta_{8} \mathrm{M}_{8 \mathrm{t}}+\beta_{9} \mathrm{M}_{9 \mathrm{t}}+\beta_{10} \mathrm{M}_{10 \mathrm{t}}+\beta_{11} \mathrm{M}_{11 \mathrm{t}}+\beta_{12} \mathrm{M}_{12 \mathrm{t}}+\varepsilon_{\mathrm{t}}$, con MCO, para el IGBM y el Ibex 35, en diferentes subperíodos muestrales.

\begin{tabular}{|c|c|c|c|c|c|}
\hline & IGBM & IGBM & IGBM & Ibex 35 & Ibex 35 \\
\hline & 1986-1997 & 1998-2007 & $2008-2015$ & 1992-2007 & $2008-2015$ \\
\hline \multirow[t]{2}{*}{$\mathrm{C}$} & $\mathbf{0 , 0 5 2 4}$ & 0,0240 & $-0,0213$ & 0,0294 & $-0,0235$ \\
\hline & {$[0,0081]$} & {$[0,1620]$} & {$[0,3710]$} & {$[0,0438]$} & {$[0,3201]$} \\
\hline \multirow{2}{*}{$\beta_{2}$} & $-0,0236$ & 0,0085 & 0,0091 & $-0,0061$ & 0,0121 \\
\hline & {$[0,3946]$} & {$[0,7259]$} & {$[0,7865]$} & {$[0,7663]$} & {$[0,7164]$} \\
\hline \multirow[t]{2}{*}{$\beta_{3}$} & $-0,0480$ & $-0,0197$ & 0,0213 & $-0,0345$ & 0,0255 \\
\hline & {$[0,0838]$} & {$[0,4169]$} & {$[0,5277]$} & {$[0,0941]$} & {$[0,4449]$} \\
\hline \multirow[t]{2}{*}{$\beta_{4}$} & $-0,0194$ & $-0,0138$ & 0,0206 & $-0,0132$ & 0,0366 \\
\hline & {$[0,4824]$} & {$[0,5694]$} & {$[0,5407]$} & {$[0,5199]$} & {$[0,2738]$} \\
\hline \multirow[t]{2}{*}{$\beta_{5}$} & $-0,0162$ & $-0,0283$ & 0,0003 & $-0,0208$ & $-0,0090$ \\
\hline & {$[0,5583]$} & {$[0,2437]$} & {$[0,9927]$} & {$[0,3120]$} & {$[0,7875]$} \\
\hline \multirow[t]{2}{*}{$\beta_{6}$} & $-0,0502$ & $-0,0314$ & 0,0154 & $-0,0387$ & 0,0173 \\
\hline & {$[0,0712]$} & {$[0,1953]$} & {$[0,6483]$} & {$[0,0607]$} & {$[0,6047]$} \\
\hline \multirow[t]{2}{*}{$\beta_{7}$} & $-0,0485$ & $-0,0344$ & 0,0447 & $-0,0414$ & 0,0472 \\
\hline & {$[0,0809]$} & {$[0,1571]$} & {$[0,1861]$} & {$[0,0448]$} & {$[0,1591]$} \\
\hline \multirow[t]{2}{*}{$\beta_{8}$} & $-0,0395$ & $-0,0377$ & 0,0085 & $-0,0367$ & 0,0106 \\
\hline & {$[0,1549]$} & {$[0,1215]$} & {$[0,8010]$} & {$[0,0753]$} & {$[0,7504]$} \\
\hline \multirow[t]{2}{*}{$\beta_{9}$} & $-0,0718$ & $-0,0478$ & 0,0280 & $-0,0493$ & 0,0312 \\
\hline & {$[0,0103]$} & {$[0,0500]$} & {$[0,4063]$} & {$[0,0173]$} & {$[0,3514]$} \\
\hline \multirow[t]{2}{*}{$\beta_{10}$} & $-0,0872$ & 0,0216 & 0,0198 & 0,0019 & 0,0234 \\
\hline & {$[0,0019]$} & {$[0,3731]$} & {$[0,5558]$} & {$[0,9280]$} & {$[0,4833]$} \\
\hline \multirow[t]{2}{*}{$\beta_{11}$} & $-0,0413$ & 0,0071 & $-0,0041$ & 0,0092 & 0,0009 \\
\hline & {$[0,1361]$} & {$[0,7689]$} & {$[0,9027]$} & {$[0,6529]$} & {$[0,9776]$} \\
\hline \multirow[t]{2}{*}{$\beta_{12}$} & $-0,0297$ & $-0,0170$ & 0,0260 & $-0,0111$ & 0,0282 \\
\hline & {$[0,2828]$} & {$[0,4818]$} & {$[0,4401]$} & {$[0,5888]$} & {$[0,3980]$} \\
\hline $\mathrm{R}^{2}$ & 0,1138 & 0,1379 & 0,0434 & 0,1000 & 0,0606 \\
\hline \multirow[t]{2}{*}{$\mathrm{F}$} & 1,5412 & 1,5708 & 0,3464 & 1,8190 & 0,4923 \\
\hline & {$[0,1241]$} & {$[0,1177]$} & {$[0,9721]$} & {$[0,0536]$} & {$[0,9032]$} \\
\hline Observaciones & 144 & 120 & 96 & 192 & 96 \\
\hline $\operatorname{Arch}(1)$ & 0,1984 & 0,4896 & 0,4674 & 0,1094 & 0,3662 \\
\hline
\end{tabular}

Nota: los valores entre corchetes son la probabilidad crítica (p-values). En negrita, valores significativos para un nivel de significación del 5\%. 
Cuadro 4.16: Resultados para la estimación del efecto enero con el modelo GARCH $(1,1)$, para diferentes subperíodos muestrales Este cuadro muestra los resultados de la estimación de la ecuación: $r_{t}=c+\beta_{2} \mathrm{M}_{2 t}+\beta_{3} \mathrm{M}_{3 \mathrm{t}}+\beta_{4} \mathrm{M}_{4 \mathrm{t}}+\beta_{5} \mathrm{M}_{5 \mathrm{t}}+\beta_{6} \mathrm{M}_{6 \mathrm{t}}+\beta_{7} \mathrm{M}_{7 \mathrm{t}}+\beta_{8} \mathrm{M}_{8 \mathrm{t}}+\beta_{9} \mathrm{M}_{9 \mathrm{t}}+\beta_{10} \mathrm{M}_{10 \mathrm{t}}+\beta_{11} \mathrm{M}_{11 \mathrm{t}}+\beta_{12} \mathrm{M}_{12 \mathrm{t}}+\varepsilon_{\mathrm{t}}$, con el modelo GARCH $(1,1)$, para el IGBM y el Ibex 35 , en diferentes períodos muestrales.

\begin{tabular}{|c|c|c|c|c|c|}
\hline & IGBM & IGBM & IGBM & \begin{tabular}{|l|l|} 
Ibex 35 \\
\end{tabular} & Ibex 35 \\
\hline & 1986-1997 & 1998-2007 & $2008-2015$ & $1992-2007$ & $2008-2015$ \\
\hline \multirow[t]{2}{*}{$\mathrm{C}$} & $\mathbf{0 , 0 3 5 0}$ & 0,0236 & $-0,0100$ & 0,0256 & $-0,0139$ \\
\hline & {$[0,0304]$} & {$[0,2914]$} & {$[0,6022]$} & {$[0,1269]$} & {$[0,4948]$} \\
\hline \multirow[t]{2}{*}{$\beta_{2}$} & $-0,0192$ & 0,0026 & 0,0101 & $-0,0039$ & 0,0175 \\
\hline & {$[0,4381]$} & {$[0,9292]$} & {$[0,7237]$} & {$[0,8767]$} & {$[0,5410]$} \\
\hline \multirow[t]{2}{*}{$\beta_{3}$} & $-0,0359$ & $-0,0291$ & 0,0147 & $-0,0374$ & 0,0144 \\
\hline & {$[0,0976]$} & {$[0,3693]$} & {$[0,6191]$} & {$[0,1209]$} & {$[0,6146]$} \\
\hline \multirow[t]{2}{*}{$\beta_{4}$} & $-0,0041$ & $-0,0155$ & 0,0158 & $-0,0085$ & 0,0406 \\
\hline & {$[0,8733]$} & {$[0,5741]$} & {$[0,5867]$} & {$[0,6764]$} & {$[0,1855]$} \\
\hline \multirow[t]{2}{*}{$\beta_{5}$} & $-0,0017$ & $-0,0189$ & 0,0040 & $-0,0155$ & $-0,0039$ \\
\hline & {$[0,9623]$} & {$[0,4527]$} & {$[0,8861]$} & {$[0,4729]$} & {$[0,9038]$} \\
\hline \multirow[t]{2}{*}{$\beta_{6}$} & $-0,0453$ & $-0,0246$ & $-0,0416$ & $-0,0313$ & $-0,0358$ \\
\hline & {$[0,0210]$} & {$[0,3189]$} & {$[0,1296]$} & {$[0,1101]$} & {$[0,1663]$} \\
\hline \multirow[t]{2}{*}{$\beta_{7}$} & $-0,0481$ & $-0,0274$ & $\mathbf{0 , 0 4 9 7}$ & $-0,0364$ & 0,0499 \\
\hline & {$[0,0171]$} & {$[0,3307]$} & {$[0,0480]$} & {$[0,0723]$} & {$[0,0591]$} \\
\hline \multirow[t]{2}{*}{$\beta_{8}$} & $-0,0231$ & $-0,0320$ & 0,0011 & $-0,0260$ & $-0,0011$ \\
\hline & {$[0,2567]$} & {$[0,3116]$} & {$[0,9690]$} & {$[0,2070]$} & {$[0,9700]$} \\
\hline \multirow[t]{2}{*}{$\beta_{9}$} & $-0,0476$ & $-0,0210$ & 0,0337 & $-0,0277$ & 0,0379 \\
\hline & {$[0,0525]$} & {$[0,4119]$} & {$[0,1798]$} & {$[0,1580]$} & {$[0,1313]$} \\
\hline \multirow[t]{2}{*}{$\beta_{10}$} & $-0,0592$ & 0,0177 & 0,0038 & 0,0068 & 0,0028 \\
\hline & {$[0,0147]$} & {$[0,4926]$} & {$[0,8951]$} & {$[0,7349]$} & {$[0,9184]$} \\
\hline \multirow[t]{2}{*}{$\beta_{11}$} & $-0,0224$ & $-0,0025$ & $-0,0194$ & 0,0057 & $-0,0057$ \\
\hline & {$[0,2832]$} & {$[0,9242]$} & {$[0,4660]$} & {$[0,7871]$} & {$[0,8416]$} \\
\hline \multirow[t]{2}{*}{$\beta_{12}$} & $-0,0212$ & $-0,0097$ & 0,0084 & $-0,0032$ & 0,0071 \\
\hline & {$[0,2824]$} & {$[0,7204]$} & {$[0,7371]$} & {$[0,8819]$} & {$[0,8356]$} \\
\hline \multirow[t]{2}{*}{$\mathrm{C}$} & 0,0004 & 0,0001 & 0,0025 & 0,0001 & 0,0017 \\
\hline & {$[0,2180]$} & {$[0,3543]$} & {$[0,0176]$} & {$[0,3303]$} & {$[0,0965]$} \\
\hline \multirow[t]{2}{*}{$\mathrm{ARCH}(1)$} & 0,2718 & 0,1214 & 0,6004 & 0,1865 & 0,6286 \\
\hline & {$[0,0435]$} & {$[0,1006]$} & {$[0,0408]$} & {$[0,0172]$} & {$[0,0388]$} \\
\hline \multirow[t]{2}{*}{ GARCH(1) } & 0,6638 & $\mathbf{0 , 8 3 4 4}$ & $-0,0875$ & 0,7943 & 0,0694 \\
\hline & {$[0,0000]$} & {$[0,0000]$} & {$[0,6639]$} & {$[0,0000]$} & {$[0,7698]$} \\
\hline Observaciones & 144 & 120 & 96 & 192 & 96 \\
\hline
\end{tabular}

Nota: los valores entre corchetes son la probabilidad crítica (p-values). En negrita, valores significativos para un nivel de significación del 5\%. 
Cuadro 4.17: Resultados para la estimación del efecto enero con el modelo EGARCH (1,1), para diferentes subperíodos muestrales Este cuadro muestra los resultados de la estimación de la ecuación: $r_{t}=c+\beta_{2} M_{2 t}+\beta_{3} M_{3 t}+\beta_{4} M_{4 t}+\beta_{5} M_{5 t}+\beta_{6} M_{6 t}+\beta_{7} M_{7 t}+\beta_{8} M_{8 t}+\beta_{9} M_{9 t}+\beta_{10} M_{10 t}+\beta_{11} M_{11 t}+\beta_{12} \mathrm{M}_{12 t}+\varepsilon_{t}$, con el modelo EGARCH $(1,1)$, para el IGBM y el Ibex 35 , en diferentes subperíodos muestrales.

\begin{tabular}{|c|c|c|c|c|c|}
\hline & IGBM & IGBM & IGBM & Ibex 35 & Ibex 35 \\
\hline & 1986-1997 & 1998-2007 & 2008-2015 & $1992-2007$ & $2008-2015$ \\
\hline \multirow[t]{2}{*}{$\mathrm{C}$} & 0,0365 & 0,0258 & $-0,0314$ & $\mathbf{0 , 0 2 9 7}$ & $-0,0365$ \\
\hline & {$[0,0363]$} & {$[0,1807]$} & {$[0,0330]$} & {$[0,0242]$} & {$[0,0137]$} \\
\hline \multirow[t]{2}{*}{$\beta_{2}$} & $-0,0154$ & 0,0010 & 0,0197 & $-0,0107$ & 0,0287 \\
\hline & {$[0,5038]$} & {$[0,9721]$} & {$[0,3302]$} & {$[0,6133]$} & {$[0,1452]$} \\
\hline \multirow[t]{2}{*}{$\beta_{3}$} & $-0,0385$ & $-0,0253$ & 0,0367 & $-0,0339$ & 0,0497 \\
\hline & {$[0,0699]$} & {$[0,3688]$} & {$[0,0467]$} & {$[0,1538]$} & {$[0,0085]$} \\
\hline \multirow[t]{2}{*}{$\beta_{4}$} & $-0,0026$ & $-0,0047$ & 0,0376 & $-0,0062$ & 0,0415 \\
\hline & {$[0,9167]$} & {$[0,8405]$} & {$[0,0671]$} & {$[0,7444]$} & {$[0,0558]$} \\
\hline \multirow[t]{2}{*}{$\beta_{5}$} & $-0,0042$ & $-0,0211$ & 0,0232 & $-0,0181$ & 0,0273 \\
\hline & {$[0,8905]$} & {$[0,3835]$} & {$[0,3147]$} & {$[0,3593]$} & {$[0,2109]$} \\
\hline \multirow[t]{2}{*}{$\beta_{6}$} & $-0,0476$ & $-0,0326$ & 0,0335 & $-0,0345$ & 0,0356 \\
\hline & {$[0,0167]$} & {$[0,1809]$} & {$[0,1136]$} & {$[0,0506]$} & {$[0,0921]$} \\
\hline \multirow[t]{2}{*}{$\beta_{7}$} & $-0,0345$ & $-0,0495$ & 0,0427 & $-0,0504$ & 0,0488 \\
\hline & {$[0,1008]$} & {$[0,0368]$} & {$[0,0302]$} & {$[0,0037]$} & {$[0,0199]$} \\
\hline \multirow[t]{2}{*}{$\beta_{8}$} & $-0,0224$ & $-0,0330$ & 0,0201 & $-0,0344$ & 0,0236 \\
\hline & {$[0,2741]$} & {$[0,1845]$} & {$[0,3863]$} & {$[0,0593]$} & {$[0,2770]$} \\
\hline \multirow[t]{2}{*}{$\beta_{9}$} & $-0,0622$ & $-0,0434$ & 0,0615 & $-0,0474$ & 0,0655 \\
\hline & {$[0,0096]$} & {$[0,0451]$} & {$[0,0006]$} & {$[0,0025]$} & {$[0,0005]$} \\
\hline \multirow[t]{2}{*}{$\beta_{10}$} & $-0,0510$ & 0,0264 & 0,0301 & 0,0129 & 0,0383 \\
\hline & {$[0,0484]$} & {$[0,3173]$} & {$[0,1450]$} & {$[0,4850]$} & {$[0,0641]$} \\
\hline \multirow[t]{2}{*}{$\beta_{11}$} & $-0,0119$ & 0,0064 & 0,0189 & 0,0136 & 0,0259 \\
\hline & {$[0,5897]$} & {$[0,8044]$} & {$[0,3958]$} & {$[0,4640]$} & {$[0,3078]$} \\
\hline \multirow[t]{2}{*}{$\beta_{12}$} & $-0,0200$ & $-0,0040$ & 0,0383 & $-0,0085$ & 0,0397 \\
\hline & {$[0,3594]$} & {$[0,8773]$} & {$[0,1091]$} & {$[0,6529]$} & {$[0,1305]$} \\
\hline \multirow[t]{2}{*}{$\mathrm{C}$} & $-0,9381$ & $\begin{array}{l}-3,8499 \\
\end{array}$ & $\begin{array}{l}-0,7884 \\
\end{array}$ & $\begin{array}{l}-5,5300 \\
\end{array}$ & $\begin{array}{l}-0,6532 \\
\end{array}$ \\
\hline & {$[0,1165]$} & {$[0,0262]$} & {$[0,0000]$} & {$[0,0043]$} & {$[0,0000]$} \\
\hline \multirow[t]{2}{*}{ |RES|/SQR[GARCH](1) } & 0,4517 & 0,7322 & $-0,5934$ & 0,6574 & $-0,4939$ \\
\hline & {$[0,0122]$} & {$[0,0093]$} & {$[0,0000]$} & {$[0,0028]$} & {$[0,0000]$} \\
\hline \multirow[t]{2}{*}{$\mathrm{RES} / \mathrm{SQR}[\mathrm{GARCH}](1)$} & 0,1293 & 0,1874 & $-0,4077$ & 0,1272 & $-0,3914$ \\
\hline & {$[0,2146]$} & {$[0,2959]$} & {$[0,0002]$} & {$[0,3340]$} & {$[0,0003]$} \\
\hline \multirow[t]{2}{*}{ EGARCH(1) } & 0,8961 & 0,4544 & 0,7814 & 0,1393 & $\mathbf{0 , 8 1 9 7}$ \\
\hline & {$[0,0000]$} & {$[0,1195]$} & {$[0,0000]$} & {$[0,6775]$} & {$[0,0000]$} \\
\hline Observaciones & 144 & 120 & 96 & 192 & 96 \\
\hline
\end{tabular}

Nota: los valores entre corchetes son la probabilidad crítica (p-values). En negrita, valores significativos para un nivel de significación del 5\%. 


\subsubsection{Resumen resultados análisis efecto enero}

Este estudio evidencia que el efecto enero no está presente claramente en ninguno de los cinco índices analizados aunque encontramos una presencia débil en el IGBM, el Ibex Medium Cap y en el Ibex Small Cap. Para el caso del Ibex 35 y el Ibex Top Dividendo no encontramos ningún indicio que constate su presencia, coincidiendo con García (2008), quien tampoco identifica el sesgo para el Ibex 35 y sólo encuentra un patrón de comportamiento para el caso del Ibex Small Cap. Es resaltable que estos resultados están en consonancia con los estudios de Rozeff y Kinney (1976), Keim (1983), Roll (1983), Reinganum (1983) o, más recientemente, el de Beyer et al. (2013) en los cuales se expone que el efecto enero está relacionado directamente con el efecto tamaño asociado a las compañías de pequeña capitalización. Esto explicaría porque el Ibex Top Dividendo no lo presenta, ya que como se puede ver en el Cuadro 4.18 de las 25 compañías que componen el Ibex Top Dividendo a principios de 2015, el 84\% eran compañías de gran capitalización que forman parte del Ibex 35 habitualmente, a excepción de D. Felguera, Ence, Faes y Europac. Ésto también descarta una relación positiva entre el pago de dividendos y el efecto enero.

Cuadro 4.18: Empresas que componen el Ibex Top Dividendo a principios de 2015 Este cuadro contiene las veinticinco empresas que componen el Ibex Top Dividendo a principios de 2015.

\begin{tabular}{ccccc}
\hline SANTANDER & REPSOL & MAPFRE & INDRA "A" & ZARDOYA OTIS \\
D. FELGUERA & ABENGOA B & ENAGAS & FERROVIAL & OBR.H.LAIN \\
IBERDROLA & FAES & CAIXABANK & ABERTIS INFR & EBRO FOODS \\
ENCE & BBVA & GAS NATURAL & ACS CONST. & ACERINOX \\
TELEFONICA & BOLSAS Y MER & EUROPAC & TEC.REUNIDAS & RED ELE.CORP \\
\hline
\end{tabular}

En cuanto al análisis de la robustez del efecto enero en los diferentes subperíodos muestrales del IGBM, podemos observar que el efecto enero sólo está presente débilmente en el subperíodo 1986-1997, desapareciendo en el subperíodo 1998-2007 y volviéndose negativa la rentabilidad media de enero en el subperíodo 2008-2015. En cambio, de una forma más generalizada, el Ibex 35 no presenta el efecto enero en ninguno de los subperíodos muestrales analizados, pero pasa de presentar una rentabilidad media positiva y significativa para los meses de enero en el subperíodo 1992-2007 a negativa, aunque no significativa en el subperíodo de crisis 2008-2015. En sintonía con los resultados presentados por Patel (2016) quien evidencia que el efecto enero ha desaparecido durante los últimos años y especialmente en el período 20082009, coincidiendo con el comienzo de la crisis financiera global.

Finalmente, además de encontrar un efecto enero débil para el IGBM, el Ibex Medium Cap y el Ibex Small Cap, también podemos resaltar la existencia de unas rentabilidades 
medias negativas y significativas en el mes de septiembre para el IGBM, en junio y septiembre para el Ibex Medium Cap y mayo, junio, julio y noviembre para el Ibex Small Cap. 


\subsection{El efecto día de la semana}

\subsubsection{Revisión bibliográfica}

El efecto lunes o efecto día de la semana coincide en denotar que las rentabilidades observadas de los lunes, en término medio, son significativamente menores que las del resto de días de la semana y que las rentabilidades netas son negativas. Son muchos los autores que han centrado su atención en el estudio de este fenómeno, como es el caso de Keim y Stambaugh (1984), Junkus (1986), Thaler (1987b), Rystrom y Benson (1989), Abraham e Ikenberry (1994), Arsad y Coutts (1997), Keef y Roush (2005), Cho et al. (2007), entre otros, pero además es reseñable que el efecto lunes no sólo ha sido estudiado en los mercados de valores sino que también ha sido identificado en los de tipos de cambio, destacando las aportaciones de McFarland et al. (1982) y Hsieh (1988); para las commodities destaca Chiang y Tapley (1983), Gay y Kim (1987) y, Crain y Lee (1996), y para el caso de los metales preciosos las aportaciones de Ball et al. (1982) y Ma (1986), entre otros autores. La literatura también ha encontrado paralelismo con el efecto viernes pues supone la misma anomalía, pero de signo contrario, definiéndose como la existencia de rentabilidades anormalmente altas, en promedio, para los viernes. La combinación de ambos efectos da lugar al denominado "efecto fin de semana", según el cual, las rentabilidades negativas de los lunes se concentran en gran parte de los casos, entre el cierre del viernes y la apertura del lunes, es decir, en el fin de semana. Todo ello pone de manifiesto la importancia del fin de semana en el proceso de búsqueda y generación de rentabilidades.

El efecto día de la semana fue formalemente descrito en el estudio de Fields (1931) en el que al analizar el índice Dow Jones con datos diarios en el período 1915-1930 se encuentra una significativa diferencia entre la rentabilidad media de los lunes y la de los viernes, coincidiendo en evidenciar la baja (o negativa) rentabilidad de los lunes. Posteriormente, Fama (1965) considera que la diferencia de rendimientos de las acciones de Estados Unidos el lunes es mayor que la de otros días. En contraposición a ésto, Merril (1966) describe que entre 1952 y 1965 el índice Dow Jones sube en un 43\% el lunes y más de un 50\% sobre el resto de días de la semana. El primer documento académico del efecto lunes fue desarrollado por Cross (1973) quien estudia el S\&P 500 desde 1953 a 1970. Durante este período, el índice se situó en positivo un 62\% de los viernes frente a un $39,50 \%$ de los lunes con una rentabilidad media del $0,12 \%$ los viernes frente a $-0,18 \%$ de los lunes. Además, Cross (1973) también identifica una clara relación entre la rentabilidad del lunes con la del viernes anterior. Chow et al. (1997) también evidencia una correlación entre el viernes y el lunes analizando el S\&P 500 en el período de 1970 a 1973 . Pero la correlación positiva entre el viernes y el lunes no se limita sólo a los mercados de Estados Unidos. Por ejemplo, Jaffe et al. (1989) 
encontraron correlaciones positivas en los de Australia, Canadá, Japón y Reino Unido, pero sólo cuando se producía una noticia negativa el viernes. Keim y Stambaugh (1984) y Brusa et al. (2005) postulan que la autocorrelación de rentabilidades es especialmente importante entre los lunes y los viernes.

La literatura centra su atención en los índices bursátiles más relevantes del mundo como es el caso del S\&P 500. Así, French (1980) examina la evolución de la rentabilidad bursátil de este índice, entre 1953 y 1977, encontrando indicios de la existencia del efecto lunes. Argumenta que los inversores podrían obtener una rentabilidad promedio anual de 13,4\% entre 1953 y 1977 sólo explotando el efecto lunes (comprar una cartera compuesta por valores del Standard and Poor's cada lunes por la tarde y venderla el viernes por la tarde). Este resultado fue muy inesperado, porque si las rentabilidades se generan durante un tiempo físico, las rentabilidades de los lunes deberían ser tres veces mayores que las de los otros días de la semana. Gibbons y Hess (1981) llegan a resultados similares estudiando también el S\&P 500. Jaffe y Westerfield (1985) investigan la presencia del efecto fin se semana en Australia, Canadá, Japón, y Reino Unido, encontrando pruebas de su existencia en todos los países. Hindmarch et al. (1984) en los mercados canadienses, Theobald y Price (1984) en la bolsa de Londres, Barone (1990) en la de Milán. Lakonishok y Smidt (1988) ampliaron el tamaño de la muestra a 90 años (1897-1986) sobre el Dow Jones, su resultado fue de rentabilidades negativas los lunes para el conjunto de la muestra. Connolly (1989) encuentra que las rentabilidades de los lunes fueron significativamente diferentes al resto de los días de la semana antes de 1974, pero estas no fueron significativamente diferentes después, aunque siguen siendo negativas. Estos resultados fueron confirmados por Chang et al. (1993).

Dando continuidad al enfoque de evidencias de la literatura internacional destaca la aportación de Agrawal y Tandon (1994) para un grupo dieciocho países, encuentran que las rentabilidades medias negativas se producen los martes. Pero el efecto fin de semana sólo en nueve de los dieciocho países. Estas rentabilidades medias negativas los martes también fueron observadas por Solnik y Bousquet (1990) examinando el CAC (Índice de Bolsa de París), en el período 1978-1987. Dubois y Louvet (1996) reexaminan el efecto día de la semana en la bolsa de París junto a las de Estados Unidos, Reino Unido, Alemania, Japón, Australia y Suiza, durante el período 1969-1992, utilizando enfoques estadísticos y medias móviles, concluyendo que el miércoles era el día de la semana que mayores rentabilidades presentaba, al contrario de lo esperado, y el lunes continuaba siendo el que más bajas las obtenía, a excepción de Japón y Australia. Wang et al. (1997) descubrieron que el efecto lunes existe sólo en los dos últimos lunes del mes, mientras que los lunes de la primera mitad del mes no son significativamente distintos 
de cero. Siegel (1998) estudió el efecto lunes durante el período 1885 a 1997, afirmando que: "si la rentabilidad de los lunes hubiera sido igual a la media del resto de días de la semana en el mismo período, el DJIA estaría a casi al doble de su nivel a finales de 1997". Tong (2000) encuentra el efecto lunes en 23 mercados de valores de Asia, Europa y América del Norte. Berument y Kiymaz (2001) estudiaron el efecto día de la semana en rentabilidad y volatilidad para el S\&P 500, encontrando evidencias de bajas rentabilidades los lunes y altas volatilidades los viernes. Borges (2009) examina el efecto día de la semana para un grupo de 17 índices bursátiles de Europa Occidental y Central, detectándolo en Islandia (rentabilidades negativas los lunes y positivas los viernes) y Grecia (rentabilidades negativas los lunes y martes; y positivas los viernes). Charles (2010) estudio el efecto día de la semana en seis mercados bursátiles europeos, encontrando pruebas del efecto en rentabilidad y volatilidad en: Atenas, Dublín y París, y sólo en volatilidad para Helsinki, Milán y Zúrich.

Interesantemente se ha identificado que hay evidencias del efecto lunes también en los mercados emergentes. Así, el efecto fin de semana fue encontrado por Aggarwal y Rivoli (1989) en cuatro mercados emergentes. Yalcin y Yucel (2003) analizaron 24 mercados emergentes y encontraron el efecto día de la semana en las rentabilidades de 11 países. Yunita y Martain (2012) emplean el modelo EGARCH para estudiar el efecto día de la semana en las bolsas de Indonesia, Singapur y Malasia. Su resultado muestra que hay rentabilidades anormalmente positivas los viernes en las bolsas de Indonesia y Malasia, pero no así en la de Singapur. El estudio también concluye que no hay rentabilidades anormalmente negativas en ninguno de los tres países. Compton et al. (2013) se centran en Rusia, más concretamente en las rentabilidades diarias del índice MICEX descubriendo varias anomalías entre ellas el efecto día de la semana, enero y cambio de mes. El efecto fin de semana en el mercado de valores de Hong Kong fue descubierto por Gao et al. (2015). También se encuentra en el mercado de valores de Taiwán (Basher y Sadorsky (2006) y Jones (2008)). Lu y Gao (2016) estudian el efecto día de la semana utilizando los nueve índices bursátiles más representativos de China, desde el período anterior a la crisis financiera hasta seis años después, encontrando que el efecto ha sido muy significativo en las bolsas de valores de China desde el año 2004. Sin embargo, a diferencia del caso anteriormente observado en los Estados Unidos (efecto negativo el lunes y efecto positivo el viernes), el mercado de valores chino muestra resultados positivos, los lunes y negativos los martes. Siendo el efecto negativo de los martes significativo sólo después del inicio de la crisis financiera, lo que sugiere una propagación del efecto lunes de la bolsa de valores de Estados Unidos. Esto está en consonancia con los estudios de Agrawal y Tandon (1994) o Davidson y Faff (1999) sobre la bolsa australiana, en la cual el efecto lunes pasa al martes, Jaffe y Westerfield 
(1985) proponen una relación entre los martes en la región de Asia y el Pacífico y el efecto lunes en los Estados Unidos.

En los mercados bursátiles españoles que centran la atención de este capítulo, la evidencia empírica muestra resultados contradictorios en función del período investigado, mientras que Santesmases (1986), Peña (1995) o, más recientemente, Gardeazabal y Regulez (2004) no encuentran evidencias del efecto día de la semana, en contraposición Viñolas (1995), Corredor y Santamaría (1996), Camino (1997) y García (2007) sí que detectan rentabilidades anormalmente superiores los viernes. Gimenez (1994) estudia el período 1985-1993, encontrando un fuerte efecto lunes positivo, hasta noviembre de 1991 que cambió el procedimiento de liquidación, atribuyendo las compras en lunes al antiguo sistema de liquidación ya que las incentivaba. Serna et al. (2000) contrastan el efecto día de la semana, tomando datos de noviembre de 1985 a noviembre de 1995 y encontrando en todos los análisis realizados el efecto lunes y el efecto viernes. García $(2007,2008)$ observa que la autocorrelación entre las rentabilidades es especialmente intensa en los días separados por intervalos de ausencia de negociación, como es el caso del viernes y del lunes, destacando la importancia de la noche entre los períodos de no negociación. Apolinario et al. (2006) estudian el efecto día de la semana en diferentes países, además del mercado español, para los mercados de Alemania, Austria, Bélgica, Dinamarca, Francia, Los Países Bajos, Italia, Portugal, Reino Unido, República Checa, Suecia y Suiza, evidenciando el efecto en todos excepto en Portugal y la República Checa, lo hace aplicando un modelo simétrico y, en Francia y la República Checa, utiliza un modelo asimétrico T-ARCH. Aksoy et al. (2012) demuestran la presencia del efecto día de la semana para el período 2006-2011 para España, Portugal, Irlanda, Grecia e Italia, siendo las rentabilidades significativas para España y Grecia sólo los lunes y los martes.

Igualmente, como sucedía con el efecto enero, el efecto lunes y el efecto viernes no sólo se dan en los mercados bursátiles pudiéndose observar, por ejemplo, para el mercado español de Bonos y Obligaciones del Estado. Así, autores como Andrés y Fernández (2004) y, Heras y Nave (2004), entre otros, documentan el efecto viernes. Concretamente, Heras y Nave (2004) observan un efecto lunes positivo en las operaciones realizadas con Letras del Tesoro.

Entre otras extensiones del efecto fin de semana en el contexto internacional, destaca Kamara (1997) quien observa que el efecto lunes ha disminuido considerablemente desde la introducción del S\&P 500 en los contratos de futuros en el año 1982. También sostiene que el efecto lunes ha desaparecido a causa de la creciente preponderancia de los inversores institucionales. El autor afirma que desde que han comenzado a disminuir 
los costes de transacción, el efecto lunes también ha comenzado a desaparecer. Sin embargo, Brusa et al. (2000) han observado un cambio total de las rentabilidades en los mercados estadounidenses, descubriendo que el lunes tiene las rentabilidades más positivas que cualquier otro día de la semana durante la década de los 90. Mehdian y Perry (2001) confirman este cambio en las rentabilidades desde noviembre de 1987 hasta agosto de 1998, a pesar de que encuentran una persistente rentabilidad negativa los lunes en las acciones pequeñas. Marquering et al. (2006) estudiaron el DJIA desde 1960 hasta 2003 encontrando evidencias que el efecto lunes ha disminuido en los últimos años. Alt et al. (2011) examinan el efecto lunes en los mercados bursátiles de Estados Unidos, el Reino Unido y Alemania, aunque parece que han desaparecido en los tres mercados en los 90 y 2000. Steeley (2001) obtuvo los mismos resultados para Reino Unido en la década de los 90 identificando que el efecto ha ido desapareciendo. Kohers, et al. (2004) constatan la disminución de la intensidad del efecto en los mercados financieros más desarrollados en los últimos años.

La explicación generalmente aceptada para justificar el origen de este efecto es la planteada por Fisher (1966), la cual consiste en la no sincronización de la operatoria, es decir, en el retraso del tiempo de reacción de los precios de los activos menos líquidos del índice. Osborne (1962) y Lakonishok y Maberly (1990) sostienen que, dado que los inversores individuales tienen más tiempo para tomar decisiones financieras los fines de semana, son más activos en los mercados financieros los lunes. Sin embargo, los inversores institucionales son menos activos los lunes debido a que éste tiende a ser un día de planificación estratégica. Abraham e Ikenberry (1994) respaldan las conclusiones de Lakonishok y Maberly (1990) mediante el estudio de datos en Estados Unidos entre 1963 y 1991 y encontrando que cuando el viernes presenta rentabilidades negativas (por ejemplo, por proximidad de malas noticias), el lunes también reporta en negativo casi en el $80 \%$ de las veces. Los investigadores sugieren que el efecto lunes es probablemente la respuesta de los inversores individuales a las malas noticias del viernes. Por lo tanto, se asocia una mayor presión vendedora de los inversores particulares los lunes, si hay coincidencia con malas noticias dadas el viernes anterior. Sias y Starks (1995) están en desacuerdo con las conclusiones de Lakonishok y Marbely (1990) y, Abraham e Ikenberry (1994) ponen en duda el argumento de que el efecto lunes este impulsado por inversores individuales, encontrando que las acciones que son principalmente propiedad de inversores institucionales tienen mayor importancia los lunes que aquellas que son principalmente propiedad de inversores individuales. Sobre esta base, sugieren que el efecto lunes está impulsado por los inversores institucionales. Brusa et al. (2003) también contradicen los hallazgos de Lakonishok y Maberly (1990) y, Abraham e Ikenberry (1994) quienes argumentan que 
la correlación significativa sólo se produce si las rentabilidades son negativas, no siendo así cuando sean positivas.

Por otro lado, esta anomalía también se suele atribuir a factores relacionados con la microestructura de los mercados financieros, tales como el pago de dividendos, que en su mayoría se lleva a cabo los lunes, o la difusión de malas noticias sobre las empresas que tienden a ocurrir durante el fin de semana (Patell y Wolfson, 1982). Posteriormente, varios estudios han intentado explicar el efecto lunes mediante el análisis del estado de ánimo de los inversores. Jacobs y Levi (1988), Rystrom y Benson (1989), y Markese (1989) entre otros señalan que las personas son más pesimistas los lunes en comparación a los otros días de la semana; ésto implica que los inversores están más predispuestos a vender que a comprar coincidiendo con el día lunes. Este ánimo pesimista de los inversores se denomina la teoría del lunes azul. En este sentido, Pettengill (1993) hizo un estudio experimental centrado en la hipótesis del lunes azul y encontró que los participantes tomaban menos riesgos en sus inversiones los lunes que los viernes. Singleton y Wingender (2003) sugieren que los factores de comportamiento, -como el sentimiento de los inversores- o económicos -como los tipos de interés- están asociados a las rentabilidades negativas de los lunes y a las diferencias que se producen entre los diferentes mercados.

Alternativemente, Chen y Singal (2003), sostienen que la imposibilidad para negociar durante el fin de semana tiende a hacer que los vendedores a corto cierren sus posiciones especulativas los viernes y vuelvan a abrirlas los lunes, ello da fuerza a otro argumento para identificar el efecto fin de semana, observándose que los precios de las acciones suben los viernes (ya que los vendedores a corto cubren sus posiciones) y a que caigan los lunes (ya que los vendedores a corto restablecen nuevas posiciones cortas). Su hipótesis sugiere las ventas a corto plazo como una alternativa para explicar el efecto fin de semana. Recientemente, Christophe et al. (2009) examinan diariamente las ventas a corto de acciones del Nasdaq, su principal conclusión es que la venta a corto especulativa no explica de forma significativa el efecto fin de semana, contradiciendo así la hipótesis de Chen y Singal (2003). Para Moshirian et al. (2008) otros factores como las leyes, la transparencia del mercado, el desarrollo financiero o la protección de los inversores tienen relevancia para explicar las diferencias en el plano internacional del efecto lunes. 


\subsubsection{Resultados}

\subsubsection{Análisis totalidad período muestral}

Como puede observarse en el Cuadro 4.19, el IGBM, presenta un efecto viernes con la mayor rentabilidad media de la semana, un $0,09 \%$, pero no un efecto lunes, el efecto lunes ha sido sustituido por un efecto miércoles, siendo el miércoles el día de la semana con una menor rentabilidad media, un $0 \%$. En contraste, observando el Cuadro 4.20 para el Ibex 35 sí que se encuentra evidencia preliminar sobre el efecto fin de semana, dado que hay una rentabilidad media del $-0,07 \%$ para los lunes y del $0,09 \%$ para los viernes; igual que el Ibex Medium Cap, representado en el Cuadro 4.21, con una rentabilidad positiva los viernes del $0,05 \%$ y negativa los lunes del $-0,04 \%$. El Ibex Small Cap que muestra el Cuadro 4.22, presenta un efecto viernes en lunes, es decir, el lunes obtiene la rentabilidad media más elevada, y el efecto lunes pasa al jueves con una rentabilidad media del $-0,06 \%$. Por último, en el Cuadro 4.23 de estadísticos descriptivos para el Ibex Top Dividendo sí que muestra el efecto lunes, pero no el efecto viernes, ya que el día que tiene una mayor rentabilidad media es el martes con un $0,06 \%$.

\section{Cuadro 4.19: Estadísticos descriptivos del IGBM para el efecto fin de semana}

Este cuadro muestra los principales estadísticos descriptivos de las rentabilidades medías diarias del IGBM durante el período muestral de enero de 1986 a diciembre de 2015.

\begin{tabular}{lccccc}
\hline & Lunes & Martes & Miércoles & Jueves & Viernes \\
\hline & & & & & \\
Media & 0,0003 & 0,0005 & 0,0000 & 0,0003 & 0,0009 \\
Mediana & 0,0004 & 0,0007 & 0,0000 & 0,0004 & 0,0010 \\
Desviación estándar & 0,0154 & 0,0132 & 0,0133 & 0,0134 & 0,0130 \\
Varianza de la muestra & 0,0002 & 0,0002 & 0,0002 & 0,0002 & 0,0002 \\
Curtosis & 10,3284 & 8,6933 & 15,3842 & 4,8566 & 5,1445 \\
Coeficiente de asimetría & 0,7195 & $-0,7149$ & 0,8754 & $-0,4673$ & $-0,2291$ \\
Rango & 0,2298 & 0,1874 & 0,2312 & 0,1579 & 0,1783 \\
Mínimo & $-0,0825$ & $-0,1341$ & $-0,0783$ & $-0,0928$ & $-0,0923$ \\
Máximo & 0,1473 & 0,0533 & 0,1529 & 0,0651 & 0,0860 \\
Observaciones & 1490 & 1529 & 1521 & 1505 & 1487 \\
\hline \% Observaciones positivas & $51,54 \%$ & $52,84 \%$ & $49,84 \%$ & $51,56 \%$ & $54,47 \%$ \\
\hline
\end{tabular}


Cuadro 4.20: Estadísticos descriptivos del Ibex 35 para el efecto fin de semana

Este cuadro muestra los principales estadísticos descriptivos de las rentabilidades medías diarias del Ibex 35 durante el período muestral de enero de 1992 a diciembre de 2015.

\begin{tabular}{lccccc}
\hline & Lunes & Martes & Miércoles & Jueves & Viernes \\
\hline Media & $-0,0007$ & 0,0008 & 0,0000 & 0,0006 & 0,0009 \\
Mediana & 0,0000 & 0,0010 & 0,0004 & 0,0008 & 0,0014 \\
Desviación estándar & 0,0155 & 0,0136 & 0,0140 & 0,0144 & 0,0141 \\
Varianza de la muestra & 0,0002 & 0,0002 & 0,0002 & 0,0002 & 0,0002 \\
Curtosis & 10,0806 & 1,6937 & 4,1745 & 3,0255 & 4,5679 \\
Coeficiente de asimetría & 0,8508 & $-0,0365$ & 0,0243 & $-0,1926$ & $-0,2290$ \\
Rango & 0,2197 & 0,1134 & 0,1758 & 0,1403 & 0,1785 \\
Mínimo & $-0,0754$ & $-0,0545$ & $-0,0816$ & $-0,0708$ & $-0,0914$ \\
Máximo & 0,1443 & 0,0589 & 0,0942 & 0,0695 & 0,0871 \\
Observaciones & 1203 & 1229 & 1223 & 1216 & 1196 \\
\hline \% Observaciones positivas & $50,04 \%$ & $54,43 \%$ & $51,35 \%$ & $52,80 \%$ & $55,94 \%$ \\
\hline
\end{tabular}

\section{Cuadro 4.21: Estadísticos descriptivos del Ibex Medium Cap para el efecto fin de semana}

Este cuadro muestra los principales estadísticos descriptivos de las rentabilidades medías diarias del Ibex Medium Cap durante el período muestral de julio de 1998 a diciembre de 2015.

\begin{tabular}{lccccc}
\hline & Lunes & Martes & Miércoles & Jueves & Viernes \\
\hline & & & & & \\
Media & $-0,0004$ & 0,0003 & 0,0004 & 0,0002 & 0,0005 \\
Mediana & 0,0007 & 0,0009 & 0,0008 & 0,0009 & 0,0011 \\
Desviación estándar & 0,0116 & 0,0106 & 0,0101 & 0,0108 & 0,0104 \\
Varianza de la muestra & 0,0001 & 0,0001 & 0,0001 & 0,0001 & 0,0001 \\
Curtosis & 4,0544 & 3,7647 & 1,9328 & 2,8739 & 5,4455 \\
Coeficiente de asimetría & $-0,1253$ & $-0,5975$ & $-0,3184$ & $-0,4548$ & $-0,3407$ \\
Rango & 0,1248 & 0,1065 & 0,0887 & 0,0979 & 0,1240 \\
Mínimo & $-0,0531$ & $-0,0654$ & $-0,0486$ & $-0,0530$ & $-0,0579$ \\
Máximo & 0,0717 & 0,0411 & 0,0401 & 0,0449 & 0,0661 \\
Observaciones & 875 & 896 & 893 & 893 & 874 \\
\hline \% Observaciones positivas & $53,03 \%$ & $53,91 \%$ & $53,30 \%$ & $55,43 \%$ & $56,06 \%$ \\
\hline
\end{tabular}


Cuadro 4.22: Estadísticos descriptivos del Ibex Small Cap para el efecto fin de semana

Este cuadro muestra los principales estadísticos descriptivos de las rentabilidades medías diarias del Ibex Small Cap durante el período muestral de julio de 2005 a diciembre de 2015.

\begin{tabular}{lccccc}
\hline & Lunes & Martes & Miércoles & Jueves & Viernes \\
\hline & & & & & \\
Media & 0,0001 & $-0,0002$ & 0,0000 & $-0,0006$ & $-0,0002$ \\
Mediana & 0,0007 & 0,0008 & 0,0012 & 0,0002 & 0,0006 \\
Desviación estándar & 0,0133 & 0,0116 & 0,0108 & 0,0110 & 0,0100 \\
Varianza de la muestra & 0,0002 & 0,0001 & 0,0001 & 0,0001 & 0,0001 \\
Curtosis & 4,3969 & 2,2940 & 1,2056 & 1,3189 & 2,7005 \\
Coeficiente de asimetría & $-0,2388$ & $-0,4382$ & $-0,5157$ & $-0,3439$ & $-0,6693$ \\
Rango & 0,1346 & 0,0960 & 0,0808 & 0,0924 & 0,0889 \\
Mínimo & $-0,0607$ & $-0,0519$ & $-0,0415$ & $-0,0480$ & $-0,0541$ \\
Máximo & 0,0738 & 0,0441 & 0,0394 & 0,0444 & 0,0348 \\
Observaciones & 531 & 541 & 540 & 539 & 527 \\
\hline \% Observaciones positivas & $52,35 \%$ & $53,79 \%$ & $55,74 \%$ & $51,02 \%$ & $53,13 \%$ \\
\hline
\end{tabular}

\section{Cuadro 4.23: Estadísticos descriptivos del Ibex Top Dividendo para el efecto fin de semana}

Este cuadro muestra los principales estadísticos descriptivos de las rentabilidades medías diarias del Ibex Top Dividendo durante el período muestral de mayo de 2007 a diciembre de 2015.

\begin{tabular}{lccccc}
\hline & Lunes & Martes & Miércoles & Jueves & Viernes \\
\hline Media & $-0,0014$ & 0,0006 & 0,0004 & $-0,0002$ & 0,0003 \\
Mediana & $-0,0010$ & 0,0010 & 0,0008 & 0,0001 & 0,0014 \\
Desviación estándar & 0,0162 & 0,0143 & 0,0143 & 0,0150 & 0,0147 \\
Varianza de la muestra & 0,0003 & 0,0002 & 0,0002 & 0,0002 & 0,0002 \\
Curtosis & 6,2319 & 1,2482 & 1,9555 & 2,1220 & 3,5073 \\
Coeficiente de asimetría & 0,5975 & $-0,1381$ & $-0,0772$ & 0,1521 & $-0,1068$ \\
Rango & 0,1634 & 0,1012 & 0,1266 & 0,1152 & 0,1463 \\
Mínimo & $-0,0623$ & $-0,0517$ & $-0,0583$ & $-0,0579$ & $-0,0689$ \\
Máximo & 0,1011 & 0,0495 & 0,0683 & 0,0573 & 0,0774 \\
Observaciones & 440 & 446 & 443 & 443 & 434 \\
\hline \% Observaciones positivas & $46,59 \%$ & $53,81 \%$ & $53,72 \%$ & $50,34 \%$ & $55,07 \%$ \\
\hline
\end{tabular}

El contraste de significatividad de medias para el efecto fin de semana para cada uno de los índices, nos da únicamente como diferencia de medias significativas el efecto lunes para el Ibex 35 y para el Ibex Top Dividendo, aunque el Ibex Medium Cap también presenta una significatividad débil para el efecto lunes. En general, ningún índice presenta significatividad para el efecto viernes. 
Cuadro 4.24: Contraste de significatividad de medias para el efecto fin de semana Este cuadro muestra el contraste de significatividad entre la rentabilidad media del lunes frente a la rentabilidad media del resto de días de la semana y la rentabilidad media del viernes frente a la rentabilidad media del resto de días de la semana para cada uno de los índices, para el período muestral total.

\begin{tabular}{|c|c|c|c|c|c|}
\hline & IGBM & Ibex 35 & Ibex Medium Cap & Ibex Small Cap & Ibex Top Dividendo \\
\hline \multirow[t]{2}{*}{ Lunes } & 0,0003 & $-0,0007$ & $-0,0004$ & 0,0001 & $-0,0014$ \\
\hline & {$[0,4779]$} & {$[0,1393]$} & {$[0,3518]$} & {$[0,8766]$} & {$[0,0649]$} \\
\hline \multirow[t]{2}{*}{ Resto de días } & 0,0004 & 0,0006 & 0,0004 & $-0,0002$ & 0,0003 \\
\hline & {$[0,0130]$} & {$[0,0048]$} & {$[0,0317]$} & {$[0,3093]$} & {$[0,4133]$} \\
\hline \multirow[t]{3}{*}{ Diferencia } & $-0,0001$ & $-0,0012$ & $-0,0007$ & 0,0003 & $-0,0017$ \\
\hline & {$[0,7506]$} & {$[0,0124]$} & {$[0,0840]$} & {$[0,5982]$} & {$[0,0435]$} \\
\hline & IGBM & Ibex 35 & Ibex Medium Cap & Ibex Small Cap & Ibex Top Dividendo \\
\hline \multirow[t]{2}{*}{ Viernes } & 0,0009 & 0,0009 & 0,0005 & $-0,0002$ & 0,0003 \\
\hline & {$[0,0114]$} & {$[0,0240]$} & {$[0,1525]$} & {$[0,7062]$} & {$[0,7102]$} \\
\hline \multirow[t]{2}{*}{ Resto de días } & 0,0003 & 0,0002 & 0,0002 & $-0,0002$ & $-0,0001$ \\
\hline & {$[0,1130]$} & {$[0,3921]$} & {$[0,3642]$} & {$[0,4862]$} & {$[0,6991]$} \\
\hline \multirow[t]{2}{*}{ Diferencia } & 0,0006 & 0,0007 & 0,0003 & 0,0000 & 0,0004 \\
\hline & {$[0,1347]$} & {$[0,1035]$} & {$[0,3914]$} & {$[0,9822]$} & {$[0,6131]$} \\
\hline
\end{tabular}

Nota: los valores entre corchetes son la probabilidad crítica ( $p$-values). En negrita, valores significativos para un nivel de significación del 5\%.

Como se ha comentado en la revisión bibliográfica, en un gran número de trabajos se ha encontrado una correlación positiva entre las rentabilidades de los viernes y las de los lunes. Entre los que podemos destacar los de Chow et al. (1997), Brusa et al. (2003) o García $(2007,2008)$ para los mercados españoles. Por ello se va a proceder a calcular el coeficiente de correlación entre las rentabilidades de los viernes con respecto a la de los lunes, para los cinco índices objeto de estudio, aplicando la siguiente expresión:

$$
\rho_{i, j}=\frac{\sigma\left(r_{i}, r_{j}\right)}{\sigma\left(r_{i}\right) \sigma\left(r_{j}\right)}
$$

Como podemos ver en el Cuadro 4.25 el Ibex Small Cap, el Ibex Medium Cap y el IGBM presentan una correlación positiva pero muy baja al situarse por debajo de 0,20, a diferencia de éstos el Ibex 35 y Ibex Top Dividendo la presentan prácticamente nula, es decir, tomando valores cercanos a cero.

\section{Cuadro 4.25: Coeficiente de correlación para el efecto fin de semana}

Este cuadro muestra el coeficiente de correlación entre las rentabilidades de los viernes y las de los lunes para cada uno de los índices y para el período muestral total.

\begin{tabular}{lc} 
& Coeficiente de correlación \\
\hline IGBM & 0,1010 \\
Ibex 35 & 0,0290 \\
Ibex Medium Cap & 0,1219 \\
Ibex Small Cap & 0,1470 \\
Ibex Top Dividendo & 0,0121 \\
\hline
\end{tabular}

Para demostrar empíricamente la existencia del efecto fin de semana vamos a crear dos modelos econométricos con 4 variables dummy (cada uno) para para cada día de la 
semana, excepto el día objeto de análisis. Obtenemos así el modelo (7) para el efecto lunes y el (8) para el efecto viernes.

$$
\begin{aligned}
& \mathrm{r}_{\mathrm{t}}=\mathrm{c}+\beta_{2} \mathrm{D}_{2 \mathrm{t}}+\beta_{3} \mathrm{D}_{3 \mathrm{t}}+\beta_{4} \mathrm{D}_{4 \mathrm{t}}+\beta_{5} \mathrm{D}_{5 \mathrm{t}}+\varepsilon_{t} \\
& \mathrm{r}_{\mathrm{t}}=\beta_{1} \mathrm{D}_{1 \mathrm{t}}+\beta_{2} \mathrm{D}_{2 \mathrm{t}}+\beta_{3} \mathrm{D}_{3 \mathrm{t}}+\beta_{4} \mathrm{D}_{4 \mathrm{t}}+\mathrm{c}+\varepsilon_{t}
\end{aligned}
$$

Donde:

$r_{t}=$ Es la rentabilidad del índice en el período $\mathrm{t}$.

$\mathrm{c}=$ Es la rentabilidad media los lunes/viernes.

$\beta_{\mathrm{i}}=$ Es la diferencia entre la rentabilidad del lunes/vienes y el día i-ésimo.

$D_{i t}=$ Son las variables dummy, que tomarán los siguientes valores:

$\mathrm{D}_{\text {it }}= \begin{cases}1 & \text { Si el rendimiento en el tiempo t corresponde al día } \mathrm{i} \\ 0 & \text { de otra forma }\end{cases}$

$\varepsilon_{t}=$ Es un término de error, idéntica e independientemente distribuido.

La hipótesis nula a ser probada, bajo estas especificaciones, es que el resto de los coeficientes de las variables dummy o $\beta_{i}$ son iguales a cero. Adicionalmente, valores positivos de los coeficientes dummy deben ser considerados como una prueba de la presencia del efecto lunes, así como valores negativos de los coeficientes dummy deben ser considerados como una prueba de la presencia del efecto viernes. De esta manera, la estimación de los coeficientes en la ecuación revela aquellos días que tienen rendimientos mayores o menores a los obtenidos en lunes y viernes.

Como observamos en los Cuadros 4.26 y 4.29 las estimaciones de los modelos econométricos realizadas a través de MCO no son lo suficientemente consistentes para determinar la presencia de los efectos lunes y viernes en los índices bursátiles, ya que todas las estimaciones presentan efectos $\mathrm{ARCH}$, por lo tanto, debemos estimar las ecuaciones con los modelos GARCH $(1,1)$ y EGARCH $(1,1)$.

Como se observa, en los Cuadros 4.27 y 4.28, ningún índice presenta un efecto lunes significativo, pero si de una forma débil el Ibex 35 y el Ibex Top Dividendo, el lunes es el día que presenta una menor rentabilidad media, pero algunas de las diferencias positivas del resto de días sobre el lunes no son positivas. El efecto viernes tampoco lo presenta ningún índice de forma significativa, pero si de forma débil, el IGBM, el Ibex 
35 y el Ibex Medium Cap. Los tres índices presentan rentabilidades positivas superiores al resto de días, pero algunas de esas diferencias de rentabilidad no son significativas. 
Cuadro 4.26: Resultados para la estimación del efecto lunes con MCO

Este cuadro muestra los resultados de la estimación de la ecuación: $r_{t}=c+\beta_{2} D_{2 t}+\beta_{3} D_{3 t}+\beta_{4} D_{4 t}+\beta_{5} D_{5 t}+\varepsilon_{t}$ con MCO, para los cinco índices y para el período muestral total.

\begin{tabular}{|c|c|c|c|c|c|}
\hline & IGBM & Ibex 35 & Ibex Medium Cap & Ibex Small Cap & Ibex Top Dividendo \\
\hline \multirow[t]{2}{*}{$\mathrm{C}$} & 0,0002 & $-0,0008$ & $-0,0004$ & 0,0000 & $-0,0016$ \\
\hline & {$[0,6402]$} & {$[0,0584]$} & {$[0,2324]$} & {$[0,9982]$} & {$[0,0279]$} \\
\hline \multirow[t]{2}{*}{$\beta_{2}$} & 0,0003 & 0,0015 & 0,0007 & $-0,0002$ & 0,0021 \\
\hline & {$[0,5790]$} & {$[0,0104]$} & {$[0,1668]$} & {$[0,7265]$} & {$[0,0408]$} \\
\hline \multirow[t]{2}{*}{$\beta_{3}$} & $-0,0003$ & 0,0006 & 0,0008 & $-0,0001$ & 0,0019 \\
\hline & {$[0,5890]$} & {$[0,2679]$} & {$[0,1035]$} & {$[0,9295]$} & {$[0,0595]$} \\
\hline \multirow[t]{2}{*}{$\beta_{4}$} & 0,0001 & 0,0013 & 0,0006 & $-0,0007$ & 0,0013 \\
\hline & {$[0,8799]$} & {$[0,0290]$} & {$[0,2325]$} & {$[0,3352]$} & {$[0,1946]$} \\
\hline \multirow[t]{2}{*}{$\beta_{5}$} & 0,0006 & 0,0016 & 0,0010 & $-0,0002$ & 0,0017 \\
\hline & {$[0,2302]$} & {$[0,0062]$} & {$[0,0631]$} & {$[0,7586]$} & {$[0,0886]$} \\
\hline $\mathrm{R}^{2}$ & 0,0005 & 0,0017 & 0,0009 & 0,0004 & 0,0025 \\
\hline \multirow[t]{2}{*}{$\mathrm{F}$} & 0,8493 & 2,6494 & 1,0429 & 0,2859 & 1,3569 \\
\hline & {$[0,4937]$} & {$[0,0316]$} & {$[0,3834]$} & {$[0,8873]$} & {$[0,2466]$} \\
\hline Observaciones & 7532 & 6067 & 4431 & 2678 & 2206 \\
\hline $\operatorname{Arch}(1)$ & 0,0000 & 0,0000 & 0,0000 & 0,0000 & $\mathbf{0 , 0 0 0 0}$ \\
\hline
\end{tabular}

Nota: los valores entre corchetes son la probabilidad crítica ( $p$-values). En negrita, valores significativos para un nivel de significación del 5\%. 
Cuadro 4.27: Resultados para la estimación del efecto lunes con el modelo GARCH $(1,1)$

Este cuadro muestra los resultados de la estimación de la ecuación: $r_{t}=c+\beta_{2} D_{2 t}+\beta_{3} D_{3 t}+\beta_{4} D_{4 t}+\beta_{5} D_{5 t}+\varepsilon_{t}$, con el modelo GARCH $(1,1)$, para los cinco índices y para el período muestral total.

\begin{tabular}{|c|c|c|c|c|c|}
\hline & IGBM & Ibex 35 & Ibex Medium Cap & Ibex Small Cap & Ibex Top Dividendo \\
\hline \multirow[t]{2}{*}{$\mathrm{C}$} & 0,0006 & 0,0000 & 0,0004 & 0,0007 & $-0,0009$ \\
\hline & {$[0,0092]$} & {$[0,9725]$} & {$[0,0548]$} & {$[0,0652]$} & {$[0,1151]$} \\
\hline \multirow[t]{2}{*}{$\beta_{2}$} & $-0,0002$ & 0,0007 & $-0,0001$ & $-0,0005$ & 0,0016 \\
\hline & {$[0,5290]$} & {$[0,1244]$} & {$[0,6891]$} & {$[0,3875]$} & {$[0,0387]$} \\
\hline \multirow[t]{2}{*}{$\beta_{3}$} & $-0,0003$ & 0,0006 & 0,0002 & 0,0001 & 0,0018 \\
\hline & {$[0,4961]$} & {$[0,1637]$} & {$[0,6499]$} & {$[0,9178]$} & {$[0,026]$} \\
\hline \multirow[t]{2}{*}{$\beta_{4}$} & 0,0003 & 0,0011 & $\mathbf{0 , 0 0 0 7}$ & $-0,0008$ & 0,0011 \\
\hline & {$[0,3536]$} & {$[0,0106]$} & {$[0,0338]$} & {$[0,1257]$} & {$[0,1763]$} \\
\hline \multirow[t]{2}{*}{$\beta_{5}$} & 0,0005 & $\mathbf{0 , 0 0 1 2}$ & $\mathbf{0 , 0 0 0 7}$ & 0,0000 & 0,0015 \\
\hline & {$[0,1716]$} & {$[0,0034]$} & {$[0,0426]$} & {$[0,9935]$} & {$[0,0647]$} \\
\hline \multirow[t]{2}{*}{$\mathrm{C}$} & 0,0000 & 0,0000 & 0,0000 & 0,0000 & 0,0000 \\
\hline & {$[0,0000]$} & {$[0,0000]$} & {$[0,0000]$} & {$[0,0000]$} & {$[0,0000]$} \\
\hline \multirow[t]{2}{*}{$\mathrm{ARCH}(1)$} & 0,1189 & 0,0937 & 0,1384 & 0,1654 & $\mathbf{0 , 0 8 5 9}$ \\
\hline & {$[0,0000]$} & {$[0,0000]$} & {$[0,0000]$} & {$[0,0000]$} & {$[0,0000]$} \\
\hline \multirow[t]{2}{*}{ GARCH(1) } & 0,8568 & 0,8943 & $\mathbf{0 , 8 5 6 7}$ & 0,7823 & 0,8953 \\
\hline & {$[0,0000]$} & {$[0,0000]$} & {$[0,0000]$} & {$[0,0000]$} & {$[0,0000]$} \\
\hline Observaciones & 7532 & 6067 & 4431 & 2678 & 2206 \\
\hline
\end{tabular}

Nota: los valores entre corchetes son la probabilidad crítica ( $p$-values). En negrita, valores significativos para un nivel de significación del 5\%. 
Cuadro 4.28: Resultados para la estimación del efecto lunes con el modelo EGARCH $(1,1)$

Este cuadro muestra los resultados de la estimación de la ecuación: $r_{t}=c+\beta_{2} D_{2 t}+\beta_{3} D_{3 t}+\beta_{4} D_{4 t}+\beta_{5} D_{5 t}+\varepsilon_{t}$, con el modelo EGARCH (1,1), para los cinco índices y para el período muestral total.

\begin{tabular}{|c|c|c|c|c|c|}
\hline & IGBM & Ibex 35 & Ibex Medium Cap & Ibex Small Cap & Ibex Top Dividendo \\
\hline \multirow[t]{2}{*}{$\mathrm{C}$} & 0,0005 & $-0,0001$ & 0,0003 & 0,0006 & $-0,0011$ \\
\hline & {$[0,0382]$} & {$[0,6853]$} & {$[0,1489]$} & {$[0,0928]$} & {$[0,0625]$} \\
\hline \multirow[t]{2}{*}{$\beta_{2}$} & $-0,0003$ & 0,0003 & $-0,0003$ & $-0,0005$ & 0,0013 \\
\hline & {$[0,3543]$} & {$[0,5013]$} & {$[0,4527]$} & {$[0,3604]$} & {$[0,1060]$} \\
\hline \multirow[t]{2}{*}{$\beta_{3}$} & $-0,0004$ & 0,0004 & 0,0001 & 0,0000 & 0,0012 \\
\hline & {$[0,2818]$} & {$[0,3873]$} & {$[0,7911]$} & {$[0,9411]$} & {$[0,1029]$} \\
\hline \multirow[t]{2}{*}{$\beta_{4}$} & 0,0003 & 0,0009 & 0,0004 & $-0,0009$ & 0,0009 \\
\hline & {$[0,4371]$} & {$[\mathbf{0 , 0 3 8 9 ]}$} & {$[0,1851]$} & {$[0,1072]$} & {$[0,2433]$} \\
\hline \multirow[t]{2}{*}{$\beta_{5}$} & 0,0006 & 0,0010 & 0,0005 & $-0,0001$ & 0,0014 \\
\hline & {$[0,0518]$} & {$[0,0163]$} & {$[0,1504]$} & {$[0,9185]$} & {$[0,0928]$} \\
\hline \multirow[t]{2}{*}{$\mathrm{C}$} & $-0,4276$ & $-0,2995$ & $-0,4472$ & $-0,9680$ & $-0,2841$ \\
\hline & {$[0,0000]$} & {$[0,0000]$} & {$[0,0000]$} & {$[0,0000]$} & {$[0,0000]$} \\
\hline \multirow[t]{2}{*}{ |RES|/SQR[GARCH](1) } & $\mathbf{0 , 1 7 8 2}$ & 0,1452 & 0,2181 & $\mathbf{0 , 2 8 5 5}$ & 0,1150 \\
\hline & {$[0,0000]$} & {$[0,0000]$} & {$[0,0000]$} & {$[0,0000]$} & {$[0,0000]$} \\
\hline \multirow[t]{2}{*}{ RES/SQR[GARCH](1) } & $-0,0773$ & $-0,0780$ & $-0,0748$ & $-0,0581$ & $-0,0901$ \\
\hline & {$[0,0000]$} & {$[0,0000]$} & {$[0,0000]$} & {$[0,0000]$} & {$[0,0000]$} \\
\hline \multirow[t]{2}{*}{ EGARCH(1) } & 0,9671 & 0,9788 & 0,9702 & 0,9178 & 0,9773 \\
\hline & {$[0,0000]$} & {$[0,0000]$} & {$[0,0000]$} & {$[0,0000]$} & {$[0,0000]$} \\
\hline Observaciones & 7532 & 6067 & 4431 & 2678 & 2206 \\
\hline
\end{tabular}

Nota: los valores entre corchetes son la probabilidad crítica ( $p$-values). En negrita, valores significativos para un nivel de significación del 5\%. 
Cuadro 4.29: Resultados para la estimación del efecto viernes con MCO

Este cuadro muestra los resultados de la estimación de la ecuación: $r_{t}=\beta_{1} D_{1 t}+\beta_{2} D_{2 t}+\beta_{3} D_{3 t}+\beta_{4} D_{4 t}+c+\varepsilon_{t}$, con MCO, para los cinco índices y para el período muestral total.

\begin{tabular}{|c|c|c|c|c|c|}
\hline & IGBM & Ibex 35 & Ibex Medium Cap & Ibex Small Cap & Ibex Top Dividendo \\
\hline \multirow[t]{2}{*}{$\beta_{1}$} & $-0,0006$ & $-0,0016$ & $-0,0010$ & 0,0002 & $-0,0017$ \\
\hline & {$[0,2302]$} & {$[0,0062]$} & {$[0,0631]$} & {$[0,7586]$} & {$[0,0886]$} \\
\hline \multirow[t]{2}{*}{$\beta_{2}$} & $-0,0003$ & $-0,0001$ & $-0,0002$ & 0,0000 & 0,0003 \\
\hline & {$[0,5137]$} & {$[0,8450]$} & {$[0,6257]$} & {$[0,9679]$} & {$[0,7413]$} \\
\hline \multirow[t]{2}{*}{$\beta_{3}$} & $-0,0009$ & $-0,0010$ & $-0,0001$ & 0,0002 & 0,0002 \\
\hline & {$[0,0808]$} & {$[0,1002]$} & {$[0,8101]$} & {$[0,8256]$} & {$[0,8631]$} \\
\hline \multirow[t]{2}{*}{$\beta_{4}$} & $-0,0005$ & $-0,0003$ & $-0,0003$ & $-0,0005$ & $-0,0004$ \\
\hline & {$[0,2928]$} & {$[0,5714]$} & {$[0,4999]$} & {$[0,5135]$} & {$[0,6792]$} \\
\hline \multirow[t]{2}{*}{$\mathrm{C}$} & $\mathbf{0 , 0 0 0 8}$ & 0,0008 & 0,0005 & $-0,0002$ & 0,0002 \\
\hline & {$[0,0306]$} & {$[0,0477]$} & {$[0,1515]$} & {$[0,6660]$} & {$[0,8292]$} \\
\hline $\mathrm{R}^{2}$ & 0,0005 & 0,0017 & 0,0009 & 0,0004 & 0,0025 \\
\hline \multirow[t]{2}{*}{$\mathrm{F}$} & 0,8493 & 2,6494 & 1,0429 & 0,2859 & 1,3569 \\
\hline & {$[0,4937]$} & {$[0,0316]$} & {$[0,3834]$} & {$[0,8873]$} & {$[0,2466]$} \\
\hline Observaciones & 7532 & 6067 & 4431 & 2678 & 2206 \\
\hline $\operatorname{Arch}(1)$ & 0,0000 & 0,0000 & 0,0000 & 0,0000 & 0,0000 \\
\hline
\end{tabular}

Nota: los valores entre corchetes son la probabilidad crítica ( $p$-values). En negrita, valores significativos para un nivel de significación del $5 \%$. 
Cuadro 4.30: Resultados para la estimación del efecto viernes con el modelo GARCH $(1,1)$

Este cuadro muestra los resultados de la estimación de la ecuación: $r_{t}=\beta_{1} D_{1 t}+\beta_{2} D_{2 t}+\beta_{3} D_{3 t}+\beta_{4} D_{4 t}+c+\varepsilon_{t}$, con el modelo GARCH $(1,1)$, para los cinco índices y para el período muestral total.

\begin{tabular}{|c|c|c|c|c|c|}
\hline & IGBM & Ibex 35 & Ibex Medium Cap & Ibex Small Cap & Ibex Top Dividendo \\
\hline \multirow[t]{2}{*}{$\beta_{1}$} & $-0,0005$ & $-0,0012$ & $\mathbf{- 0 , 0 0 0 7}$ & 0,0000 & $-0,0015$ \\
\hline & {$[0,1722]$} & {$[0,0034]$} & {$[0,0426]$} & {$[0,9923]$} & {$[0,0647]$} \\
\hline \multirow[t]{2}{*}{$\beta_{2}$} & $-0,0007$ & $-0,0006$ & $-0,0008$ & $-0,0005$ & 0,0001 \\
\hline & {$[0,0637]$} & {$[0,2030]$} & {$[0,0213]$} & {$[0,4357]$} & {$[0,8801]$} \\
\hline \multirow[t]{2}{*}{$\beta_{3}$} & $-0,0007$ & $-0,0006$ & $-0,0006$ & 0,0000 & 0,0003 \\
\hline & {$[0,0590]$} & {$[0,1390]$} & {$[0,1283]$} & {$[0,9332]$} & {$[0,7517]$} \\
\hline \multirow[t]{2}{*}{$\beta_{4}$} & $-0,0001$ & $-0,0001$ & 0,0000 & $-0,0008$ & $-0,0004$ \\
\hline & {$[0,7388]$} & {$[0,7599]$} & {$[0,9671]$} & {$[0,1732]$} & {$[0,6071]$} \\
\hline \multirow[t]{2}{*}{$\mathrm{C}$} & 0,0011 & 0,0012 & $\mathbf{0 , 0 0 1 2}$ & 0,0007 & 0,0006 \\
\hline & {$[0,0000]$} & {$[0,0001]$} & {$[0,0000]$} & {$[0,1418]$} & {$[0,3174]$} \\
\hline \multirow[t]{2}{*}{$\mathrm{C}$} & 0,0000 & 0,0000 & 0,0000 & $\mathbf{0 , 0 0 0 0}$ & $\mathbf{0 , 0 0 0 0}$ \\
\hline & {$[0,0000]$} & {$[0,0000]$} & {$[0,0000]$} & {$[0,0000]$} & {$[0,0000]$} \\
\hline \multirow[t]{2}{*}{$\mathrm{ARCH}(1)$} & 0,1190 & $\mathbf{0 , 0 9 3 7}$ & $\mathbf{0 , 1 3 8 4}$ & 0,1654 & 0.085924 \\
\hline & {$[0,0000]$} & {$[0,0000]$} & {$[0,0000]$} & {$[0,0000]$} & {$[0,0000]$} \\
\hline \multirow[t]{2}{*}{ GARCH(1) } & $\mathbf{0 , 8 5 6 8}$ & $\mathbf{0 , 8 9 4 3}$ & $\mathbf{0 , 8 5 6 7}$ & 0,7823 & 0.895265 \\
\hline & {$[0,0000]$} & {$[0,0000]$} & {$[0,0000]$} & {$[0,0000]$} & {$[0,0000]$} \\
\hline Observaciones & 7532 & 6067 & 4431 & 2678 & 2206 \\
\hline
\end{tabular}

Nota: los valores entre corchetes son la probabilidad crítica ( $p$-values). En negrita, valores significativos para un nivel de significación del 5\%. 
Cuadro 4.31: Resultados para la estimación del efecto viernes con el modelo EGARCH $(1,1)$

Este cuadro muestra los resultados de la estimación de la ecuación: $r_{t}=\beta_{1} D_{1 t}+\beta_{2} D_{2 t}+\beta_{3} D_{3 t}+\beta_{4} D_{4 t}+c+\varepsilon_{t}$, con el modelo EGARCH $(1,1)$, para los cinco índices y para el período muestral total.

\begin{tabular}{|c|c|c|c|c|c|}
\hline & IGBM & Ibex 35 & Ibex Medium Cap & Ibex Small Cap & Ibex Top Dividendo \\
\hline \multirow[t]{2}{*}{$\beta_{1}$} & $-0,0006$ & $-0,0010$ & $-0,0005$ & 0,0001 & $-0,0014$ \\
\hline & {$[0,0524]$} & {$[0,0163]$} & {$[0,1508]$} & {$[0,9129]$} & {$[0,0929]$} \\
\hline \multirow[t]{2}{*}{$\beta_{2}$} & $-0,0010$ & $-0,0007$ & $-0,0008$ & $-0,0004$ & $-0,0001$ \\
\hline & {$[0,0055]$} & {$[0,0993]$} & {$[0,0374]$} & {$[0,4638]$} & {$[0,9328]$} \\
\hline \multirow[t]{2}{*}{$\beta_{3}$} & $-0,0010$ & $-0,0006$ & $-0,0004$ & 0,0001 & $-0,0001$ \\
\hline & {$[0,0030]$} & {$[0,1207]$} & {$[0,2525]$} & {$[0,8701]$} & {$[0,8973]$} \\
\hline \multirow[t]{2}{*}{$\beta_{4}$} & $-0,0004$ & $-0,0001$ & 0,0000 & $-0,0008$ & $-0,0004$ \\
\hline & {$[0,2753]$} & {$[0,7599]$} & {$[0,8987]$} & {$[0,1600]$} & {$[0,5770]$} \\
\hline \multirow[t]{2}{*}{$\mathrm{C}$} & 0,0011 & 0,0009 & 0,0009 & 0,0005 & 0,0003 \\
\hline & {$[0,0000]$} & {$[0,0030]$} & {$[0,0018]$} & {$[0,2171]$} & {$[0,6291]$} \\
\hline \multirow[t]{2}{*}{$\mathrm{C}$} & $-0,4273$ & $-0,2995$ & $-0,4462$ & $-0,9686$ & $-0,2840$ \\
\hline & {$[0,0000]$} & {$[0,0000]$} & {$[0,0000]$} & {$[0,0000]$} & {$[0,0000]$} \\
\hline \multirow[t]{2}{*}{ |RES|/SQR[GARCH](1) } & 0,1782 & 0,1453 & 0,2179 & $\mathbf{0 , 2 8 5 7}$ & 0,1150 \\
\hline & {$[0,0000]$} & {$[0,0000]$} & {$[0,0000]$} & {$[0,0000]$} & {$[0,0000]$} \\
\hline \multirow[t]{2}{*}{ RES/SQR[GARCH](1) } & $-0,0772$ & $-0,0780$ & $-0,0746$ & $-0,0581$ & $-0,0901$ \\
\hline & {$[0,0000]$} & {$[0,0000]$} & {$[0,0000]$} & {$[0,0000]$} & {$[0,0000]$} \\
\hline \multirow[t]{2}{*}{ EGARCH(1) } & 0,9671 & 0,9788 & 0,9703 & $\mathbf{0 , 9 1 7 7}$ & $\mathbf{0 , 9 7 7 3}$ \\
\hline & {$[0,0000]$} & {$[0,0000]$} & {$[0,0000]$} & {$[0,0000]$} & {$[0,0000]$} \\
\hline Observaciones & 7532 & 6067 & 4431 & 2678 & 2206 \\
\hline
\end{tabular}

Nota: los valores entre corchetes son la probabilidad crítica ( $p$-values). En negrita, valores significativos para un nivel de significación del 5\%. 


\subsubsection{Análisis robustez subperíodos muestrales}

\section{Cuadro 4.32: Estadísticos descriptivos del IGBM, para el efecto fin de semana, en} diferentes subperíodos muestrales

Este cuadro muestra los principales estadísticos descriptivos de las rentabilidades medías diarias del IGBM durante los subperíodos muestrales de 1986 a 1997, de 1998 a 2007 y de 2008 a 2015.

\begin{tabular}{|c|c|c|c|c|c|}
\hline Subperíodo 1986-1997 & Lunes & Martes & Miércoles & Jueves & Viernes \\
\hline Media & 0,0015 & 0,0004 & 0,0001 & 0,0004 & 0,0011 \\
\hline Mediana & 0,0011 & 0,0001 & $-0,0005$ & 0,0000 & 0,0008 \\
\hline Desviación estándar & 0,0139 & 0,0123 & 0,0119 & 0,0109 & 0,0104 \\
\hline Varianza de la muestra & 0,0002 & 0,0002 & 0,0001 & 0,0001 & 0,0001 \\
\hline Curtosis & 5,7784 & 25,1908 & 47,9345 & 10,9362 & 2,3486 \\
\hline Coeficiente de asimetría & $-0,5234$ & $-2,0520$ & 3,2093 & $-0,9768$ & $-0,0932$ \\
\hline Rango & 0,1544 & 0,1874 & 0,2265 & 0,1400 & 0,0899 \\
\hline Mínimo & $-0,0825$ & $-0,1341$ & $-0,0736$ & $-0,0928$ & $-0,0412$ \\
\hline Máximo & 0,0719 & 0,0533 & 0,1529 & 0,0473 & 0,0486 \\
\hline Observaciones & 590 & 608 & 601 & 588 & 588 \\
\hline$\%$ Observaciones positivas & $54,07 \%$ & $50,33 \%$ & $45,09 \%$ & $49,49 \%$ & $54,08 \%$ \\
\hline Subperíodo 1998-2007 & Lunes & Martes & Miércoles & Jueves & Viernes \\
\hline Media & 0,0003 & 0,0005 & $-0,0001$ & 0,0005 & 0,0011 \\
\hline Mediana & 0,0008 & 0,0011 & 0,0007 & 0,0013 & 0,0017 \\
\hline Desviación estándar & 0,0129 & 0,0118 & 0,0122 & 0,0129 & 0,0119 \\
\hline Varianza de la muestra & 0,0002 & 0,0001 & 0,0001 & 0,0002 & 0,0001 \\
\hline Curtosis & 2,3807 & 1,9150 & 2,6806 & 3,3538 & 2,1828 \\
\hline Coeficiente de asimetría & 0,0585 & 0,1208 & $-0,1992$ & $-0,6028$ & $-0,2406$ \\
\hline Rango & 0,1099 & 0,0948 & 0,1189 & 0,1061 & 0,0989 \\
\hline Mínimo & $-0,0510$ & $-0,0464$ & $-0,0650$ & $-0,0628$ & $-0,0500$ \\
\hline Máximo & 0,0589 & 0,0485 & 0,0540 & 0,0433 & 0,0489 \\
\hline Observaciones & 492 & 507 & 508 & 508 & 499 \\
\hline$\%$ Observaciones positivas & $53,66 \%$ & $54,44 \%$ & $53,35 \%$ & $54,92 \%$ & $56,11 \%$ \\
\hline Subperíodo 2008-2015 & Lunes & Martes & Miércoles & Jueves & Viernes \\
\hline Media & $-0,0015$ & 0,0007 & 0,0000 & 0,0000 & 0,0002 \\
\hline Mediana & $-0,0013$ & 0,0012 & 0,0006 & 0,0002 & 0,0006 \\
\hline Desviación estándar & 0,0196 & 0,0157 & 0,0162 & 0,0169 & 0,0170 \\
\hline Varianza de la muestra & 0,0004 & 0,0002 & 0,0003 & 0,0003 & 0,0003 \\
\hline Curtosis & 12,0328 & 0,8969 & 4,1731 & 2,4196 & 4,6426 \\
\hline Coeficiente de asimetría & 1,6746 & $-0,1846$ & 0,0505 & $-0,1267$ & $-0,1750$ \\
\hline Rango & 0,2186 & 0,1079 & 0,1712 & 0,1383 & 0,1783 \\
\hline Mínimo & $-0,0713$ & $-0,0548$ & $-0,0783$ & $-0,0732$ & $-0,0923$ \\
\hline Máximo & 0,1473 & 0,0531 & 0,0928 & 0,0651 & 0,0860 \\
\hline Observaciones & 408 & 414 & 412 & 409 & 400 \\
\hline$\%$ Observaciones positivas & $45,34 \%$ & $54,59 \%$ & $52,43 \%$ & $50,37 \%$ & $53,00 \%$ \\
\hline
\end{tabular}


Cuadro 4.33: Estadísticos descriptivos del Ibex 35, para el efecto fin de semana, en diferentes subperíodos muestrales

Este cuadro muestra los principales estadísticos descriptivos de las rentabilidades medías diarias del Ibex 35 durante los subperíodos muestrales de 1992 a 2007 y de 2008 a 2015.

\begin{tabular}{lccccc}
\hline Subperíodo 1992-2007 & Lunes & Martes & Miércoles & Jueves & Viernes \\
\hline Media & $-0,0002$ & 0,0008 & $-0,0001$ & 0,0008 & 0,0013 \\
Mediana & 0,0003 & 0,0009 & 0,0002 & 0,0009 & 0,0018 \\
Desviación estándar & 0,0133 & 0,0123 & 0,0127 & 0,0131 & 0,0123 \\
Varianza de la muestra & 0,0002 & 0,0002 & 0,0002 & 0,0002 & 0,0002 \\
Curtosis & 2,5873 & 2,1180 & 2,8597 & 3,5751 & 2,5765 \\
Coeficiente de asimetría & $-0,0273$ & 0,1211 & 0,0473 & $-0,3996$ & $-0,2421$ \\
Rango & 0,1168 & 0,1096 & 0,1341 & 0,1217 & 0,1168 \\
Mínimo & $-0,0547$ & $-0,0507$ & $-0,0688$ & $-0,0708$ & $-0,0582$ \\
Máximo & 0,0621 & 0,0589 & 0,0653 & 0,0509 & 0,0586 \\
Observaciones & 795 & 815 & 811 & 807 & 796 \\
\hline \% Observaciones positivas & $52,08 \%$ & $54,60 \%$ & $50,80 \%$ & $53,90 \%$ & $57,54 \%$ \\
\hline & & & & & \\
\hline Subperíodo 2008-2015 & Lunes & Martes & Miércoles & Jueves & Viernes \\
\hline & & & & & \\
Media & $-0,0016$ & 0,0007 & 0,0000 & 0,0003 & 0,0002 \\
Mediana & $-0,0013$ & 0,0011 & 0,0006 & 0,0004 & 0,0009 \\
Desviación estándar & 0,0191 & 0,0159 & 0,0163 & 0,0166 & 0,0170 \\
Varianza de la muestra & 0,0004 & 0,0003 & 0,0003 & 0,0003 & 0,0003 \\
Curtosis & 11,5667 & 0,9060 & 4,4450 & 2,0914 & 4,5588 \\
Coeficiente de asimetría & 1,4366 & $-0,1723$ & $-0,0020$ & 0,0388 & $-0,1413$ \\
Rango & 0,2197 & 0,1081 & 0,1758 & 0,1322 & 0,1785 \\
Mínimo & $-0,0754$ & $-0,0545$ & $-0,0816$ & $-0,0627$ & $-0,0914$ \\
Máximo & 0,1443 & 0,0536 & 0,0942 & 0,0695 & 0,0871 \\
Observaciones & 408 & 414 & 412 & 409 & 400 \\
\hline \% Observaciones positivas & $46,08 \%$ & $54,11 \%$ & $52,43 \%$ & $50,61 \%$ & $52,75 \%$ \\
\hline
\end{tabular}

Ninguno de los tres subperíodos muestrales analizados presenta el efecto fin de semana para el IGBM, el subperíodo muestral 1986-1997, no presenta ni efecto lunes ni efecto viernes y, contrariamente a lo esperado, el lunes es el día con una mayor rentabilidad media (0,15\%). El subperíodo 1998-2007, sí que presenta efecto viernes, pero no efecto lunes, siendo el día que presenta la menor rentabilidad el miércoles con el -0,01\%. El subperíodo 2008-2015 presenta efecto lunes, pero no efecto viernes, siendo el martes el día que presenta una mayor rentabilidad media. El Ibex 35 presenta el efecto fin de semana, es decir, el viernes presenta la rentabilidad media más elevada $(0,13 \%)$ y el lunes la más baja con el (-0,02\%), en el subperíodo 2008-2015 sucede igual que en IGBM pues el Cuadro 4.33 en la parte inferior presenta un efecto lunes con una rentabilidad media del $-0,16 \%$ y el martes es el día que obtiene una mayor rentabilidad. 
Cuadro 4.34: Contraste de significatividad de medias, para el efecto fin de semana, en diferentes subperíodos muestrales

Este cuadro muestra el contraste de significatividad entre la rentabilidad media del lunes frente a la rentabilidad media del resto de días de la semana, y la rentabilidad media del viernes frente a la rentabilidad media del resto de días de la semana para el IGBM y para el Ibex 35 en diferentes subperíodos muestrales.

\begin{tabular}{|c|c|c|c|c|c|}
\hline & IGBM & IGBM & IGBM & Ibex 35 & Ibex 35 \\
\hline & Subperíodo 1986-1997 & Subperíodo 1998-2007 & Subperíodo 2008-2015 & Subperíodo 1992-2007 & Subperíodo 2008-2015 \\
\hline \multirow[t]{2}{*}{ Lunes } & 0,0015 & 0,0003 & $-0,0015$ & $-0,0002$ & $-0,0016$ \\
\hline & {$[0,0106]$} & {$[0,5958]$} & {$[0,1326]$} & {$[0,6859]$} & {$[0,0961]$} \\
\hline \multirow[t]{2}{*}{ Resto de días } & 0,0005 & 0,0005 & 0,0002 & 0,0007 & 0,0003 \\
\hline & {$[0,0325]$} & {$[0,0702]$} & {$[0,5846]$} & {$[0,0015]$} & {$[0,4745]$} \\
\hline \multirow[t]{3}{*}{ Diferencia } & 0,0010 & $-0,0002$ & $-0,0017$ & $-0,0009$ & $-0,0019$ \\
\hline & {$[0,1173]$} & {$[0,7760]$} & {$[0,1099]$} & {$[0,0852]$} & {$[0,0701]$} \\
\hline & Subperíodo 1986-1997 & Subperíodo 1998-2007 & Subperíodo 2008-2015 & Subperíodo 1992-2007 & Subperíodo 2008-2015 \\
\hline \multirow[t]{2}{*}{ Viernes } & 0,0011 & 0,0011 & 0,0002 & 0,0013 & 0,0002 \\
\hline & {$[0,0089]$} & {$[0,0452]$} & {$[0,8369]$} & {$[0,0030]$} & {$[0,8480]$} \\
\hline \multirow[t]{2}{*}{ Resto de días } & 0,0006 & 0,0003 & $-0,0002$ & 0,0003 & $-0,0001$ \\
\hline & {$[0,0201]$} & {$[0,2744]$} & {$[0,6639]$} & {$[0,1339]$} & {$[0,7345]$} \\
\hline \multirow[t]{2}{*}{ Diferencia } & 0,0005 & 0,0008 & 0,0004 & 0,0010 & 0,0003 \\
\hline & {$[0,2796]$} & {$[0,2009]$} & {$[0,7053]$} & {$[0,0508]$} & {$[0,7475]$} \\
\hline
\end{tabular}

Nota: los valores entre corchetes son la probabilidad crítica (p-values). En negrita, valores significativos para un nivel de significación del 5\%.

En el contraste de significatividad de medias que muestra el Cuadro 4.34 podemos observar que el IGBM y el Ibex 35, no presentan un efecto lunes ni viernes significativo para ningún subperíodo, aunque el Ibex 35 sí que presenta significatividad débil para el efecto lunes en ambos subperíodos, y para el efecto viernes para el subperíodo 19922007.

Como se observa en el Cuadro 4.35 el coeficiente de correlación presenta una evolución negativa a través del tiempo, pasando el coeficiente de correlación del IGBM de positivo bajo a muy bajo en los dos primeros subperíodos hasta llegar a negativo muy bajo en el tercero. El Ibex 35 presenta un comportamiento similar siendo en subperídodo 1992-2007 positivo muy bajo y en el período 2008-2015 negativo muy bajo.

\section{Cuadro 4.35: Coeficiente de correlación, para el efecto fin de semana, en diferentes subperíodos muestrales}

Este cuadro muestra el coeficiente de correlación entre las rentabilidades de los viernes y las de los lunes para el IGBM y para el Ibex 35 en diferentes subperíodos muestrales.

\begin{tabular}{lc}
\cline { 2 - 2 } Coeficiente de correlación \\
\hline IGBM & 0,3523 \\
Subperíodo 1986-1997 & 0,0972 \\
Subperíodo 1998-2007 & $-0,0597$ \\
Subperíodo 2008-2015 & \\
Ibex 35 & 0,1280 \\
Subperíodo 1992-2007 & $-0,0668$ \\
Subperíodo 2008-2015 & \\
\hline
\end{tabular}


Como ocurría en el período muestral total, en el Cuadro 4.36 se observa que ninguna de las estimaciones realizadas por MCO es consistente para su estudio, ya que todas presentan efectos $\mathrm{ARCH}$, por lo tanto, se deberán estimar las ecuaciones con los modelos GARCH $(1,1)$ y EGARCH $(1,1)$.

Tomando en consideración los valores que aparecen desde el Cuadro 4.37 al Cuadro 4.41 , ninguno de los subperíodos analizados para cada uno de los índices presenta el efecto lunes ni el efecto viernes claramente. Pero observamos que aparece un efecto lunes débil, en los Cuadros 4.37 y 4.38 para ambos índices en el subperíodo de crisis 2008-2015. Para el efecto viernes, viendo los Cuadros 4.39 a 4.41, parece ocurrir lo contrario, se encuentra que aparece en los períodos anteriores a la crisis de forma débil para los dos índices, pero desaparece el efecto en la etapa de crisis. 
Cuadro 4.36: Resultados para la estimación del efecto lunes con MCO, para diferentes subperíodos muestrales

Este cuadro muestra los resultados de la estimación de la ecuación: $r_{t}=c+\beta_{2} D_{2 t}+\beta_{3} D_{3 t}+\beta_{4} D_{4 t}+\beta_{5} D_{5 t}+\varepsilon_{t}$ con MCO, para el IGBM y el Ibex 35, en diferentes subperíodos muestrales.

\begin{tabular}{|c|c|c|c|c|c|}
\hline & IGBM & IGBM & IGBM & Ibex 35 & Ibex 35 \\
\hline & 1986-1997 & 1998-2007 & $2008-2015$ & $1992-2007$ & 2008-2015 \\
\hline \multirow[t]{2}{*}{$\mathrm{C}$} & 0,0014 & 0,0002 & $-0,0017$ & $-0,0003$ & $-0,0018$ \\
\hline & {$[0,0054]$} & {$[0,6853]$} & {$[0,0513]$} & {$[0,5379]$} & {$[0,0365]$} \\
\hline \multirow[t]{2}{*}{$\beta_{2}$} & $-0,0010$ & 0,0002 & 0,0022 & 0,0010 & 0,0024 \\
\hline & {$[0,1478]$} & {$[0,7908]$} & {$[0,0644]$} & {$[0,1018]$} & {$[0,0467]$} \\
\hline \multirow[t]{2}{*}{$\beta_{3}$} & $-0,0014$ & $-0,0004$ & 0,0015 & 0,0001 & 0,0016 \\
\hline & {$[0,0455]$} & {$[0,5922]$} & {$[0,2008]$} & {$[0,8359]$} & {$[0,1666]$} \\
\hline \multirow[t]{2}{*}{$\beta_{4}$} & $-0,0010$ & 0,0002 & 0,0015 & 0,0010 & 0,0019 \\
\hline & {$[0,1332]$} & {$[0,7880]$} & {$[0,2012]$} & {$[0,1329]$} & {$[0,1143]$} \\
\hline \multirow[t]{2}{*}{$\beta_{5}$} & $-0,0003$ & 0,0008 & 0,0017 & 0,0015 & 0,0018 \\
\hline & {$[0,6633]$} & {$[0,3229]$} & {$[0,1623]$} & {$[0,0188]$} & {$[0,1369]$} \\
\hline $\mathrm{R}^{2}$ & 0,0018 & 0,0010 & 0,0019 & 0,0020 & 0,0022 \\
\hline \multirow[t]{2}{*}{$\mathrm{F}$} & 1,3680 & 0,6133 & 0,9530 & 2,0125 & 1,1423 \\
\hline & {$[0,2425]$} & {$[0,6531]$} & {$[0,4323]$} & {$[0,0900]$} & {$[0,3348]$} \\
\hline Observaciones & 2975 & 2514 & 2043 & 4024 & 2043 \\
\hline $\operatorname{Arch}(1)$ & $\overline{0,0000}$ & 0,0000 & 0,0000 & $\mathbf{0 , 0 0 0 0}$ & 0,0000 \\
\hline
\end{tabular}

Nota: los valores entre corchetes son la probabilidad crítica (p-values). En negrita, valores significativos para un nivel de significación del $5 \%$. 
Cuadro 4.37: Resultados para la estimación del efecto lunes con el modelo GARCH $(1,1)$, para diferentes subperíodos muestrales

Este cuadro muestra los resultados de la estimación de la ecuación: $r_{t}=c+\beta_{2} D_{2 t}+\beta_{3} D_{3 t}+\beta_{4} D_{4 t}+\beta_{5} D_{5 t}+\varepsilon_{t}$, con el modelo GARCH (1,1), para el IGBM y el Ibex 35, en diferentes subperíodos muestrales.

\begin{tabular}{|c|c|c|c|c|c|}
\hline & IGBM & IGBM & IGBM & Ibex 35 & Ibex 35 \\
\hline & 1986-1997 & 1998-2007 & $2008-2015$ & $1992-2007$ & $2008-2015$ \\
\hline \multirow[t]{2}{*}{$\mathrm{C}$} & 0,0013 & 0,0006 & $-0,0010$ & 0,0003 & $-0,0010$ \\
\hline & {$[0,0002]$} & {$[0,1433]$} & {$[0,1141]$} & {$[0,4318]$} & {$[0,1005]$} \\
\hline \multirow[t]{2}{*}{$\beta_{2}$} & $-0,0009$ & $-0,0004$ & $\mathbf{0 , 0 0 1 7}$ & 0,0003 & 0,0018 \\
\hline & {$[0,1025]$} & {$[0,5174]$} & {$[0,0480]$} & {$[0,4940]$} & {$[0,0373]$} \\
\hline \multirow[t]{2}{*}{$\beta_{3}$} & $-0,0015$ & 0,0001 & $\mathbf{0 , 0 0 2 0}$ & 0,0002 & 0,0021 \\
\hline & {$[0,0102]$} & {$[0,8355]$} & {$[0,0276]$} & {$[0,6982]$} & {$[0,0224]$} \\
\hline \multirow[t]{2}{*}{$\beta_{4}$} & $-0,0006$ & 0,0005 & 0,0016 & 0,0009 & 0,0018 \\
\hline & {$[0,2918]$} & {$[0,4099]$} & {$[0,0657]$} & {$[0,0684]$} & {$[0,0468]$} \\
\hline \multirow[t]{2}{*}{$\beta_{5}$} & $-0,0002$ & 0,0007 & 0,0012 & $\mathbf{0 , 0 0 1 2}$ & 0,0013 \\
\hline & {$[0,6781]$} & {$[0,1702]$} & {$[0,1918]$} & {$[0,0112]$} & {$[0,1584]$} \\
\hline \multirow[t]{2}{*}{$\mathrm{C}$} & $\mathbf{0 , 0 0 0 0}$ & $\mathbf{0 , 0 0 0 0}$ & $\mathbf{0 , 0 0 0 0}$ & $\mathbf{0 , 0 0 0 0}$ & $\mathbf{0 , 0 0 0 0}$ \\
\hline & {$[0,0000]$} & {$[0,0000]$} & {$[0,0000]$} & {$[0,0000]$} & {$[0,0000]$} \\
\hline \multirow[t]{2}{*}{$\mathrm{ARCH}(1)$} & 0,1610 & 0,0959 & 0,1035 & 0,0903 & 0,0946 \\
\hline & {$[0,0000]$} & {$[0,0000]$} & {$[0,0000]$} & {$[0,0000]$} & {$[0,0000]$} \\
\hline \multirow[t]{2}{*}{ GARCH(1) } & 0,7559 & $\mathbf{0 , 8 9 2 1}$ & $\mathbf{0 , 8 7 4 2}$ & $\mathbf{0 , 8 9 3 0}$ & $\mathbf{0 , 8 8 3 9}$ \\
\hline & {$[0,0000]$} & {$[0,0000]$} & {$[0,0000]$} & {$[0,0000]$} & {$[0,0000]$} \\
\hline Observaciones & 2975 & 2514 & 2043 & 4024 & 2043 \\
\hline
\end{tabular}

Nota: los valores entre corchetes son la probabilidad crítica ( $p$-values). En negrita, valores significativos para un nivel de significación del 5\%. 
Cuadro 4.38: Resultados para la estimación del efecto lunes con el modelo EGARCH $(1,1)$, para diferentes subperíodos muestrales Este cuadro muestra los resultados de la estimación de la ecuación: $r_{t}=c+\beta_{2} D_{2 t}+\beta_{3} D_{3 t}+\beta_{4} D_{4 t}+\beta_{5} D_{5 t}+\varepsilon_{t}$, con el modelo EGARCH $(1,1)$, para el IGBM y el Ibex 35, en diferentes subperíodos muestrales.

\begin{tabular}{|c|c|c|c|c|c|}
\hline & IGBM & IGBM & IGBM & Ibex 35 & Ibex 35 \\
\hline & 1986-1997 & 1998-2007 & $2008-2015$ & $1992-2007$ & 2008-2015 \\
\hline \multirow[t]{2}{*}{$\mathrm{C}$} & 0,0016 & 0,0005 & $-0,0017$ & 0,0003 & $-0,0017$ \\
\hline & {$[0,0000]$} & {$[0,1842]$} & {$[0,0066]$} & {$[0,3961]$} & {$[0,0086]$} \\
\hline \multirow[t]{2}{*}{$\beta_{2}$} & $-0,0013$ & $-0,0007$ & 0,0015 & 0,0000 & 0,0015 \\
\hline & {$[0,0144]$} & {$[0,2432]$} & {$[0,0917]$} & {$[0,9308]$} & {$[0,1033]$} \\
\hline \multirow[t]{2}{*}{$\beta_{3}$} & $-0,0023$ & $-0,0001$ & 0,0016 & 0,0000 & 0,0015 \\
\hline & {$[0,0000]$} & {$[0,8590]$} & {$[0,0773]$} & {$[0,9944]$} & {$[0,0882]$} \\
\hline \multirow[t]{2}{*}{$\beta_{4}$} & $-0,0009$ & 0,0004 & 0,0016 & 0,0007 & 0,0018 \\
\hline & {$[0,1021]$} & {$[0,4980]$} & {$[0,0578]$} & {$[0,1734]$} & {$[0,0373]$} \\
\hline \multirow[t]{2}{*}{$\beta_{5}$} & 0,0001 & 0,0005 & 0,0014 & 0,0010 & 0,0014 \\
\hline & {$[0,7680]$} & {$[0,3834]$} & {$[0,1274]$} & {$[0,0234]$} & {$[0,1242]$} \\
\hline \multirow[t]{2}{*}{$\mathrm{C}$} & $-0,8921$ & $-0,3352$ & $-0,3452$ & $-\mathbf{0 , 3 0 5 7}$ & $-0,2888$ \\
\hline & {$[0,0000]$} & {$[0,0000]$} & {$[0,0000]$} & {$[0,0000]$} & {$[0,0000]$} \\
\hline \multirow[t]{2}{*}{ |RES|/SQR[GARCH](1) } & 0,2481 & 0,1664 & 0,1265 & 0,1512 & 0,1034 \\
\hline & {$[0,0000]$} & {$[0,0000]$} & {$[0,0000]$} & {$[0,0000]$} & {$[0,0000]$} \\
\hline \multirow[t]{2}{*}{ RES/SQR[GARCH](1) } & $-0,0592$ & $-0,0741$ & $-0,1396$ & $-0,0523$ & $-0,1349$ \\
\hline & {$[0,0000]$} & {$[0,0000]$} & {$[0,0000]$} & {$[0,0000]$} & {$[0,0000]$} \\
\hline \multirow[t]{2}{*}{ EGARCH(1) } & 0,9218 & 0,9775 & 0,9704 & 0,9792 & 0,9751 \\
\hline & {$[0,0000]$} & {$[0,0000]$} & {$[0,0000]$} & {$[0,0000]$} & {$[0,0000]$} \\
\hline Observaciones & 2975 & 2514 & 2043 & 4024 & 2043 \\
\hline
\end{tabular}

Nota: los valores entre corchetes son la probabilidad crítica ( $p$-values). En negrita, valores significativos para un nivel de significación del 5\%. 
Cuadro 4.39: Resultados para la estimación del efecto viernes con MCO, para diferentes subperíodos muestrales

Este cuadro muestra los resultados de la estimación de la ecuación: $r_{t}=\beta_{1} D_{1 t}+\beta_{2} D_{2 t}+\beta_{3} D_{3 t}+\beta_{4} D_{4 t}+c+\varepsilon_{t}$, con MCO, para el IGBM y el Ibex 35, en diferentes subperíodos muestrales.

\begin{tabular}{|c|c|c|c|c|c|}
\hline & IGBM & IGBM & IGBM & Ibex 35 & Ibex 35 \\
\hline & 1986-1997 & 1998-2007 & $2008-2015$ & $1992-2007$ & $2008-2015$ \\
\hline \multirow[t]{2}{*}{$\beta_{1}$} & 0,0003 & $-0,0008$ & $-0,0017$ & $-0,0015$ & $-0,0018$ \\
\hline & {$[0,6633]$} & {$[0,3229]$} & {$[0,1623]$} & {$[0,0188]$} & {$[0,1369]$} \\
\hline \multirow[t]{2}{*}{$\beta_{2}$} & $-0,0007$ & $-0,0006$ & 0,0005 & $-0,0005$ & 0,0006 \\
\hline & {$[0,3136]$} & {$[0,4655]$} & {$[0,6613]$} & {$[0,4670]$} & {$[0,6263]$} \\
\hline \multirow[t]{2}{*}{$\beta_{3}$} & $-0,0011$ & $-0,0012$ & $-0,0002$ & $-0,0014$ & $-0,0001$ \\
\hline & {$[0,1185]$} & {$[0,1251]$} & {$[0,8983]$} & {$[0,0313]$} & {$[0,9086]$} \\
\hline \multirow[t]{2}{*}{$\beta_{4}$} & $-0,0007$ & $-0,0006$ & $-0,0002$ & $-0,0005$ & 0,0001 \\
\hline & {$[0,2866]$} & {$[0,4674]$} & {$[0,8995]$} & {$[0,3925]$} & {$[0,9336]$} \\
\hline \multirow[t]{2}{*}{$\mathrm{C}$} & $\mathbf{0 , 0 0 1 1}$ & 0,0010 & 0,0000 & $\mathbf{0 , 0 0 1 2}$ & 0,0000 \\
\hline & {$[0,0304]$} & {$[0,0702]$} & {$[0,9714]$} & {$[0,0068]$} & {$[0,9829]$} \\
\hline $\mathrm{R}^{2}$ & 0,0018 & 0,0010 & 0,0019 & 0,0020 & 0,0022 \\
\hline \multirow[t]{2}{*}{$\mathrm{F}$} & 1,3680 & 0,6133 & 0,9530 & 2,0125 & 1,1423 \\
\hline & {$[0,2425]$} & {$[0,6531]$} & {$[0,4323]$} & {$[0,0900]$} & {$[0,3348]$} \\
\hline Observaciones & 2975 & 2514 & 2043 & 4024 & 2043 \\
\hline $\operatorname{Arch}(1)$ & 0,0000 & 0,0000 & 0,0000 & 0,0000 & 0,0000 \\
\hline
\end{tabular}

Nota: los valores entre corchetes son la probabilidad crítica ( $p$-values). En negrita, valores significativos para un nivel de significación del 5\%. 
Cuadro 4.40: Resultados para la estimación del efecto viernes con el modelo GARCH (1,1), para diferentes subperíodos muestrales

Este cuadro muestra los resultados de la estimación de la ecuación: $r_{t}=\beta_{1} D_{1 t}+\beta_{2} D_{2 t}+\beta_{3} D_{3 t}+\beta_{4} D_{4 t}+c+\varepsilon_{t}$, con el modelo GARCH $(1,1)$, para el IGBM y el Ibex 35, en diferentes subperíodos muestrales.

\begin{tabular}{|c|c|c|c|c|c|}
\hline & IGBM & IGBM & IGBM & Ibex 35 & Ibex 35 \\
\hline & 1986-1997 & 1998-2007 & $2008-2015$ & 1992-2007 & 2008-2015 \\
\hline \multirow[t]{2}{*}{$\beta_{1}$} & 0,0002 & $-0,0007$ & $-0,0012$ & $-0,0012$ & $-0,0013$ \\
\hline & {$[0,6780]$} & {$[0,1701]$} & {$[0,1919]$} & {$[0,0112]$} & {$[0,1584]$} \\
\hline \multirow[t]{2}{*}{$\beta_{2}$} & $-0,0007$ & $-0,0011$ & 0,0005 & $-0,0008$ & 0,0005 \\
\hline & {$[0,2122]$} & {$[0,0507]$} & {$[0,5874]$} & {$[0,0880]$} & {$[0,5956]$} \\
\hline \multirow[t]{2}{*}{$\beta_{3}$} & $-0,0013$ & $-0,0006$ & 0,0008 & $-0,0010$ & 0,0008 \\
\hline & {$[0,0247]$} & {$[0,2670]$} & {$[0,4366]$} & {$[0,0296]$} & {$[0,4457]$} \\
\hline \multirow[t]{2}{*}{$\beta_{4}$} & $-0,0004$ & $-0,0003$ & 0,0004 & $-0,0003$ & 0,0005 \\
\hline & {$[0,4674]$} & {$[0,6187]$} & {$[0,6685]$} & {$[0,5446]$} & {$[0,6336]$} \\
\hline \multirow[t]{2}{*}{$\mathrm{C}$} & 0,0011 & 0,0013 & 0,0002 & 0,0015 & 0,0003 \\
\hline & {$[0,0023]$} & {$[0,0006]$} & {$[0,7607]$} & {$[0,0000]$} & {$[0,7010]$} \\
\hline \multirow[t]{2}{*}{$\mathrm{C}$} & 0,0000 & 0,0000 & 0,0000 & 0,0000 & 0,0000 \\
\hline & {$[0,0000]$} & {$[0,0000]$} & {$[0,0000]$} & {$[0,0000]$} & {$[0,0000]$} \\
\hline \multirow[t]{2}{*}{ ARCH(1) } & 0,1610 & $\mathbf{0 , 0 9 5 9}$ & $\mathbf{0 , 1 0 3 5}$ & $\mathbf{0 , 0 9 0 3}$ & 0,0946 \\
\hline & {$[0,0000]$} & {$[0,0000]$} & {$[0,0000]$} & {$[0,0000]$} & {$[0,0000]$} \\
\hline \multirow[t]{2}{*}{ GARCH(1) } & 0,7559 & $\mathbf{0 , 8 9 2 1}$ & $\mathbf{0 , 8 7 4 2}$ & $\mathbf{0 , 8 9 3 0}$ & $\mathbf{0 , 8 8 3 9}$ \\
\hline & {$[0,0000]$} & {$[0,0000]$} & {$[0,0000]$} & {$[0,0000]$} & {$[0,0000]$} \\
\hline Observaciones & 2975 & 2514 & 2043 & 4024 & 2043 \\
\hline
\end{tabular}

Nota: los valores entre corchetes son la probabilidad crítica ( $p$-values). En negrita, valores significativos para un nivel de significación del 5\%. 
Cuadro 4.41: Resultados para la estimación del efecto viernes con el modelo EGARCH $(1,1)$, para diferentes subperíodos muestrales Este cuadro muestra los resultados de la estimación de la ecuación: $\mathrm{r}_{\mathrm{t}}=\beta_{1} \mathrm{D}_{1 \mathrm{t}}+\beta_{2} \mathrm{D}_{2 \mathrm{t}}+\beta_{3} \mathrm{D}_{3 \mathrm{t}}+\beta_{4} \mathrm{D}_{4 \mathrm{t}}+\mathrm{c}+\varepsilon_{\mathrm{t}}$, con el modelo EGARCH $(1,1)$, para el IGBM y el Ibex 35, en diferentes subperíodos muestrales.

\begin{tabular}{|c|c|c|c|c|c|}
\hline & & & & & \\
\hline & IGBM & IGBM & IGBM & Ibex 35 & Ibex 35 \\
\hline & 1986-1997 & 1998-2007 & $2008-2015$ & 1992-2007 & $2008-2015$ \\
\hline \multirow[t]{2}{*}{$\beta_{1}$} & $-0,0001$ & $-0,0005$ & $-0,0014$ & $-0,0010$ & $-0,0014$ \\
\hline & {$[0,7661]$} & {$[0,3833]$} & {$[0,1284]$} & {$[0,0264]$} & {$[0,1202]$} \\
\hline \multirow[t]{2}{*}{$\beta_{2}$} & $-0,0014$ & $-0,0011$ & 0,0001 & $-0,0010$ & 0,0001 \\
\hline & {$[0,0025]$} & {$[0,0466]$} & {$[0,8750]$} & {$[0,0359]$} & {$[0,9489]$} \\
\hline \multirow[t]{2}{*}{$\beta_{3}$} & $-0,0024$ & $-0,0006$ & 0,0002 & $-0,0010$ & 0,0001 \\
\hline & {$[0,0000]$} & {$[0,2988]$} & {$[0,8545]$} & {$[0,0184]$} & {$[0,9022]$} \\
\hline \multirow[t]{2}{*}{$\beta_{4}$} & $-0,0010$ & $-0,0001$ & 0,0002 & $-0,0004$ & 0,0004 \\
\hline & {$[0,0440]$} & {$[0,8568]$} & {$[0,7973]$} & {$[0,3989]$} & {$[0,6663]$} \\
\hline \multirow[t]{2}{*}{$\mathrm{C}$} & 0,0017 & 0,0010 & $-0,0003$ & 0,0013 & $-0,0003$ \\
\hline & {$[0,0000]$} & {$[0,0110]$} & {$[0,6025]$} & {$[0,0000]$} & {$[0,6918]$} \\
\hline \multirow[t]{2}{*}{$\mathrm{C}$} & $-0,8930$ & $-0,3352$ & $-0,3465$ & $-0,3059$ & $-0,2917$ \\
\hline & {$[0,0000]$} & {$[0,0000]$} & {$[0,0000]$} & {$[0,0000]$} & {$[0,0000]$} \\
\hline \multirow[t]{2}{*}{$|\mathrm{RES}| / \mathrm{SQR}[\mathrm{GARCH}](1)$} & 0,2481 & 0,1664 & 0,1267 & 0,1513 & 0,1040 \\
\hline & {$[0,0000]$} & {$[0,0000]$} & {$[0,0000]$} & {$[0,0000]$} & {$[0,0000]$} \\
\hline \multirow[t]{2}{*}{ RES/SQR[GARCH](1) } & $-0,0593$ & $-0,0741$ & $-0,1399$ & $-0,0522$ & $-\mathbf{0 , 1 3 5 7}$ \\
\hline & {$[0,0000]$} & {$[0,0000]$} & {$[0,0000]$} & {$[0,0000]$} & {$[0,0000]$} \\
\hline \multirow[t]{2}{*}{ EGARCH(1) } & 0,9217 & 0,9775 & 0,9703 & 0,9791 & 0,9748 \\
\hline & {$[0,0000]$} & {$[0,0000]$} & {$[0,0000]$} & {$[0,0000]$} & {$[0,0000]$} \\
\hline Observaciones & 2975 & 2514 & 2043 & 4024 & 2043 \\
\hline
\end{tabular}

Nota: los valores entre corchetes son la probabilidad crítica ( $p$-values). En negrita, valores significativos para un nivel de significación del 5\%. 


\subsubsection{Resumen de los resultados del efecto lunes y viernes}

Este estudio aborda el análisis de los efectos lunes y viernes para los índices representativos del mercado español. Los resultados de este estudio indican que no se han encontrado evidencias significativas ni del efecto lunes, ni efecto viernes para ninguno de los índices, aunque se identifica un efecto lunes débil para el Ibex 35, el Ibex Medium Cap y el Ibex Top Dividendo y un efecto viernes débil para el IGBM, EL Ibex 35 y el Ibex Medium Cap. Por lo tanto, el Ibex 35 y el Ibex Medium Cap, presentarían un efecto fin de semana débil. La literatura muestra resultados contradictorios en función de los períodos analizados, mientras Gardeazabal y Regulez (2004) no encuentran evidencias del efecto día de la semana, García (2007) sí que detecta rentabilidades anormalmente superiores los viernes y los lunes coincidiendo en identificar el efecto fin de semana.

Los resultados del coeficiente de correlación muestran una correlación muy baja entre las rentabilidades de los lunes y las de los viernes para el IGBM, el Ibex Medium Cap y el Ibex Small Cap, y casi nula para el Ibex 35 y el Ibex Top Dividendo, observándose una relación positiva entre el tamaño de la empresa y la correlación. Así puede establecerse que a menor tamaño de las empresas que componen el índice existe una mayor correlación entre las rentabilidades de los lunes y de los viernes. Estas correlaciones muy bajas o casi nulas entre ambas rentabilidades se contradicen con lo observado por Chow et al. (1997), Brusa et al. (2005) o García (2007, 2008), para el caso español, quienes observan una importante autocorrelación entre las rentabilidades de los lunes y de los viernes.

En cuanto al análisis de la robustez en los diferentes subperíodos muestrales no encontramos evidencias de un efecto lunes o viernes significativo para ninguno de los subperíodos analizados del IGBM y del Ibex 35, pero sí aparece una significatividad débil para el efecto lunes en el período de crisis 2008-2015, para ambos índices, y ocurre lo contrario para el efecto viernes, existe una significatividad débil para ambos índices antes del subperíodo de crisis que desaparece en el subperíodo de crisis. En cuanto al análisis del coeficiente de correlación, ambos índices presentan una evolución negativa a lo largo del tiempo presentando una correlación negativa, aunque muy baja. 


\subsection{EI efecto cambio de mes (TOTM)}

\subsubsection{Revisión bibliográfica}

En el contexto de efectos asociados al efecto calendario, la literatura ha estudiado la existencia de rentabilidades anormalmente altas durante los primeros días del mes, el así denominado efecto cambio de mes (Turn-Of-The-Month). Existe un amplio número de estudios que centran su atención en evidenciar su existencia, entre otros autores, Ariel (1987), Mills et al. (2000), Holden et al. (2005). Precisamente, Ariel (1987) fue el estudio pionero en identificar el efecto cambio de mes en las rentabilidades del mercado bursátil estadounidense. Mediante un estudio de los valores y rentabilidades diarios de la bolsa de Nueva York, durante el período de 1963 a 1981, encontró que las rentabilidades diarias de las acciones son positivas en el comienzo del mes y continuando así hasta la primera mitad de éste, para posteriormente una vez pasado ese punto pasar a convertirse en predominantemente negativas. Lakonishok y Smidt (1988) investigaron el DJIA desde 1897 hasta 1986, descubriendo que las rentabilidades eran especialmente altas el último día de negociación del mes y los tres primeros de cotización del mes siguiente. Posteriormente, McConnel y Xu (2008) confirman los resultados de Lakonishok y Smidt (1988), prolongando su estudio para el período 18972005 y muestran que el efecto persiste en ese período. En un análisis profundo de la literatura, se observa que la mayoría de estudios utilizan generalmente las definiciones propuestas por Ariel (1987) y Lakonishok y Smidt (1988) para determinar el espacio de tiempo que comprende el período cambio de mes: (i) para Ariel (1987), el período cambio de mes abarca desde el último día de negociación del mes anterior hasta los cuatro primeros días del mes en curso (de $t-1$ a $t+4$ ); (ii) para Lakonishok y Smidt (1988) comprende desde el último día de negociación del mes anterior hasta los tres primeros días del mes en curso (de $t-1$ a $t+3$ ). Los trabajos de Pettengill y Jordan, (1988) y Agrawal y Tandon, (1994) nos muestran que entre el 55\% y 70\% de la rentabilidad total mensual se produce en una corta ventana de tiempo entre los días $t-1$ y $t+4$ de cada mes.

De entre las evidencias de estudios internacionales hay amplitud de propuestas y son distintos los países que han sido objeto de análisis. Así, Kunkel et al. (2003) examinan 19 mercados bursátiles en 15 países diferentes, encontrando el efecto cambio de mes en todos ellos, representando en promedio el $87 \%$ de los rendimientos mensuales. Cadsby y Ratner (1992) estudian las rentabilidades diarias de los índices de diez países, de 1962 a 1989, demostrando que el efecto cambio de mes es significativo en seis países de la muestra. Bildik (2004) confirma la existencia del efecto cambio de mes en la bolsa de Estambul. Khaled y Keef (2012) examinan el efecto en 50 índices bursátiles internacionales durante el período 1994-2006, encontrando evidencias de su existencia. 
Sharma y Narayan (2014) estudian el efecto cambio de mes en 560 empresas incluidas en la bolsa de Nueva York, concluyendo que el efecto tiene un impacto heterogéneo en la rentabilidad y volatilidad de cada empresa, en función del sector y el tamaño de la misma. Recientemente, Rodríguez y Yáñez (2015) también investigan el efecto cambio de mes, tanto para la rentabilidad como para la volatilidad en seis mercados de valores de América Latina: Brasil, México, Chile, Colombia, Perú y Argentina durante el período de 1993-2011. Los resultados de esta investigación demuestran la existencia de rentabilidades anormalmente positivas y volatilidades anormales en los días asociados al cambio de mes para la mayoría de los países. Kayaçetin y Lekpek (2016) analizan el efecto cambio de mes en la rentabilidad de las acciones turcas. Demostrando que el efecto es altamente significativo en el índice BIST100 durante el intervalo 1988-2014, en particular, la rentabilidad media del índice es del $0,46 \%$ en el período de tres días que comprende el último día hábil de cada mes y los dos primeros días hábiles del mes siguiente, y del 0,09\% en los días restantes.

De entre los estudios centrados en el mercado financiero español destaca García (2008) quien centra su análisis en los índices españoles e identifica un fuerte efecto cambio de mes tanto en el Ibex 35 como en el Ibex Small Cap.

De forma similar a los distintos efectos que se van analizando en el presente capítulo, se han encontrado argumentos a favor de la debilidad del impacto de los efectos en el tiempo. En esa línea, Marquering et al. (2006) encuentran que el efecto cambio de mes se va debilitando en el tiempo, tomando como referencia el año 1987 y según la información reportada por el índice DJIA. Esto no quiere decir que la anomalía haya necesariamente desaparecido, sino que los autores sugieren que los costes de transacción son demasiado altos para aprovecharla. Atanasova y Hudson (2010), partiendo de Lakonishok y Smidt (1988) llegan a una conclusión contraria ya que identifican que el efecto no ha disminuido sino que ha aumentado en intensidad, aumentando así las rentabilidades.

Ahondando en la justificación de la existencia de este efecto, Thaler (1987c) establece tres posibles explicaciones para este efecto: i) "Liquid funds hypothesis", se refiere a cómo la regularidad en los días de pago influye en las corrientes de fondos dentro y fuera del mercado bursátil. Esta hipótesis fue desarrollada por Ogden (1990) quien sostiene que la regularidad en las fechas de pago de salarios e intereses/dividendos crea un suministro de "fondos líquidos" a finales de mes en el mercado de acciones. Esta inyección de capital empujara al alza el precio de las acciones, obteniendo unas rentabilidades superiores a la media en el período cambio de mes; ii) "Window dressing hypothesis", sugiere que los gestores de fondos ajustan sus carteras para cerrar las 
posiciones difíciles, anticipándose a las fechas de presentación de informes, para luego regresar a sus composiciones previas, ésto puede dar lugar a un patrón estacional que se caracteriza por una alta rentabilidad en torno a las fechas de información, se respalda por Haugen y Lakonishok (1988) y, Ritter (1988); iii) "News clustering hypothesis", identifica patrones sistemáticos en la difusión de buenas y malas noticias. Entre otros autores, Penman (1987) atribuye los altos rendimientos positivos en el cambio de mes y la primera mitad de éste a los anuncios sobre ganancias. McNichols (1988) muestra que las empresas tienden a difundir las buenas noticias voluntariamente en los primeros días del mes y a suspender las malas hasta los plazos de notificación, lo cual puede explicar las altas rentabilidades de las acciones acumuladas al final del mes.

Siguiendo otras líneas de argumentos para evidenciar el efecto de cambio de mes, Lakonishok y Smidt (1988) y, Ogden (1990) proponen los patrones de compra de los fondos de pensiones. Jacobs y Levy (1988) sostienen que tales anomalías se producen en los puntos de inflexión del tiempo (como el cambio de mes o el cambio de año), generándose patrones particulares de comportamiento a pesar de tener poca importancia económica estos puntos de inflexión. También es plausible suponer que los inversores se enfrentan a una mayor información sobre los riesgos en el período de cambio de mes debido a un aumento en la frecuencia en la llegada de la información macroeconómica, argumento apoyado por Ross (1989) quien identifica que los principales anuncios macroeconómicos ocurren sistemáticamente en la primera mitad del mes. Tres estudios sostienen esta afirmación, Gerlach (2007) y Nikkinen et al. (2007a, b) y en todos ellos los resultados apoyan que las rentabilidades positivas encontradas en el efecto cambio de mes y en la primera mitad del mes están generadas en los días en los que se anuncian noticias macroeconómicas importantes.

\subsubsection{Resultados}

Para el análisis del efecto cambio de mes partimos de las siguientes dos premisas: i) se utilizará la definición propuesta por Ariel (1987) en la cual se define el período cambio de mes como el último día de negociación del mes anterior y los cuatro primeros del mes en curso $(t-1$ a $t+4)$ y ii) para simplificar la operatoria, se considerará el período cambio de mes, de cada mes, como los cuatro primeros días de cotización y el último del mismo. 


\subsubsection{Análisis totalidad período muestral}

\section{Cuadro 4.42: Estadísticos descriptivos del IGBM para el efecto cambio de mes}

Este cuadro muestra los principales estadísticos descriptivos de las rentabilidades medías de los días cambio de mes y del resto de días del IGBM durante el período muestral de enero de 1986 a diciembre de 2015.

\begin{tabular}{lcc}
\hline & Días cambio de mes & Resto de días \\
\hline Media & 0,0010 & \\
Mediana & 0,0013 & 0,0002 \\
Desviación estándar & 0,0138 & 0,0003 \\
Varianza de la muestra & 0,0002 & 0,0136 \\
Curtosis & 4,6116 & 0,0002 \\
Coeficiente de asimetría & 0,0124 & 10,8712 \\
Rango & 0,1728 & 0,1376 \\
Mínimo & $-0,0732$ & 0,2870 \\
Máximo & 0,0997 & $-0,1341$ \\
Observaciones & 1799 & 0,1529 \\
\% Observaciones positivas & $54,53 \%$ & 5732 \\
\hline
\end{tabular}

\section{Cuadro 4.43: Estadísticos descriptivos del Ibex 35 para el efecto cambio de mes}

Este cuadro muestra los principales estadísticos descriptivos de las rentabilidades medías de los días cambio de mes y del resto de días del Ibex 35 durante el período muestral de enero de 1992 a diciembre de 2015 .

\begin{tabular}{lcc}
\hline & Días cambio de mes & Resto de días \\
\hline Media & 0,0009 & \\
Mediana & 0,0011 & 0,0001 \\
Desviación estándar & 0,0145 & 0,0006 \\
Varianza de la muestra & 0,0002 & 0,0143 \\
Curtosis & 2,5391 & 0,0002 \\
Coeficiente de asimetría & $-0,1898$ & 6,0660 \\
Rango & 0,1329 & 0,2210 \\
Mínimo & $-0,0708$ & 0,2358 \\
Máximo & 0,0621 & $-0,0914$ \\
Observaciones & 1440 & 0,1443 \\
\hline \% Observaciones positivas & $55,07 \%$ & 4627 \\
\hline
\end{tabular}


Cuadro 4.44: Estadísticos descriptivos del Ibex Medium Cap para el efecto cambio de mes

Este cuadro muestra los principales estadísticos descriptivos de las rentabilidades medías de los días cambio de mes y del resto de días del Ibex Medium Cap durante el período muestral de julio de 1998 a diciembre de 2015.

\begin{tabular}{lcc}
\hline & Días cambio de mes & Resto de días \\
\hline Media & 0,0011 & \\
Mediana & 0,0016 & 0,0000 \\
Desviación estándar & 0,0109 & 0,0006 \\
Varianza de la muestra & 0,0001 & 0,0106 \\
Curtosis & 3,2544 & 0,0001 \\
Coeficiente de asimetría & $-0,4869$ & 3,7924 \\
Rango & 0,1017 & $-0,3039$ \\
Mínimo & $-0,0531$ & 0,1371 \\
Máximo & 0,0487 & $-0,0654$ \\
Observaciones & 1050 & 0,0717 \\
\hline \% Observaciones positivas & $59,33 \%$ & 3381 \\
\hline
\end{tabular}

\section{Cuadro 4.45: Estadísticos descriptivos del Ibex Small Cap para el efecto cambio de mes}

Este cuadro muestra los principales estadísticos descriptivos de las rentabilidades medías de los días cambio de mes y del resto de días del Ibex Small Cap durante el período muestral de julio de 2005 a diciembre de 2015.

\begin{tabular}{lcc}
\hline & Días cambio de mes & Resto de días \\
\hline Media & 0,0002 & \\
Mediana & 0,0010 & $-0,0003$ \\
Desviación estándar & 0,0114 & 0,0006 \\
Varianza de la muestra & 0,0001 & 0,0114 \\
Curtosis & 2,3515 & 0,0001 \\
Coeficiente de asimetría & $-0,6058$ & 3,1380 \\
Rango & 0,0920 & $-0,3398$ \\
Mínimo & $-0,0525$ & 0,1346 \\
Máximo & 0,0395 & $-0,0607$ \\
Observaciones & 630 & 0,0738 \\
\hline \% Observaciones positivas & $54,76 \%$ & 2048 \\
\hline
\end{tabular}




\section{Cuadro 4.46: Estadísticos descriptivos del Ibex Top Dividendo para el efecto cambio de mes}

Este cuadro muestra los principales estadísticos descriptivos de las rentabilidades medías de los días cambio de mes y del resto de días del Ibex Top Dividendo durante el período muestral de mayo de 2007 a diciembre de 2015.

\begin{tabular}{lcc}
\hline & Días cambio de mes & Resto de días \\
\hline Media & $-0,0001$ & \\
Mediana & 0,0006 & $-0,0001$ \\
Desviación estándar & 0,0155 & 0,0005 \\
Varianza de la muestra & 0,0002 & 0,0148 \\
Curtosis & 1,6662 & 0,0002 \\
Coeficiente de asimetría & $-0,3049$ & 3,8773 \\
Rango & 0,1122 & 0,2570 \\
Mínimo & $-0,0579$ & 0,1700 \\
Máximo & 0,0542 & $-0,0689$ \\
Observaciones & 516 & 0,1011 \\
\hline \% Observaciones positivas & $51,94 \%$ & 1690 \\
\hline
\end{tabular}

Examinando los Cuadros 4.42 a 4.46, que reflejan el análisis de los principales estadísticos para los cinco índices objeto de estudio, se observa que el efecto cambio de mes está presente en prácticamente todos los índices, a excepción del Ibex Top Dividendo (Cuadro 4.46) que presenta la misma rentabilidad media tanto para los días cambio de mes como para el resto de días, tomando un valor negativo de rentabilidad del $-0,01 \%$. El índice que presenta una mayor rentabilidad media para los días cambio de mes es el Ibex Medium Cap (Cuadro 4.44) con el 0,11\% de media de rentabilidad, seguido por el IGBM (Cuadro 4.42) con el 0,10\%, el Ibex 35 (Cuadro 4.43) con el 0,09\% y el Ibex Small Cap (Cuadro 4.45) con el 0,02\%. Para el resto de días destacamos la rentabilidad negativa del Ibex Small Cap del -0,03\% (Cuadro 4.45).

El Cuadro 4.47 muestra los resultados del contraste de significatividad de medias para el efecto cambio de mes y se confirma la no existencia de dicho efecto para el Ibex Top Dividendo, pero al contrario que el análisis de los estadísticos, tampoco se observa el efecto en el Ibex Small Cap. Pero para el resto de índices el contraste sí que confirma el efecto cambio de mes para el IGBM, el Ibex Medium Cap y el Ibex 35, aunque para este último con una significatividad débil. 
Cuadro 4.47: Contraste de significatividad de medias para el efecto cambio de mes Este cuadro muestra el contraste de significatividad entre la rentabilidad media de los días cambio de mes frente a la rentabilidad media del resto de días para cada uno de los índices, para el período muestral total.

\begin{tabular}{lccccc}
\hline & IGBM & Ibex 35 & Ibex Medium Cap & Ibex Small Cap & Ibex Top Dividendo \\
\hline Días cambio de mes & $\mathbf{0 , 0 0 1 0}$ & $\mathbf{0 , 0 0 0 9}$ & $\mathbf{0 , 0 0 1 1}$ & 0,0002 & $-0,0001$ \\
& {$[\mathbf{0 , 0 0 1 7 ]}$} & $\mathbf{0 , 0 2 0 6}]$ & {$[\mathbf{0 , 0 0 1 3 ]}$} & {$[0,5953]$} & $-0,0003$ \\
Resto de días & 0,0002 & 0,0001 & 0,0000 & $-0,0001$ & {$[0,9207]$} \\
& {$[0,2757]$} & {$[0,4806]$} & {$[0,9256]$} & {$[0,2308]$} & $0,8762]$ \\
Diferencia & $\mathbf{0 , 0 0 0 8}$ & 0,0007 & $\mathbf{0 , 0 0 1 1}$ & 0,0005 & 0,0000 \\
& {$[\mathbf{0 , 0 2 5 8}]$} & {$[0,0909]$} & $\mathbf{0 , 0 0 4 0 ]}$ & {$[0,2964]$} & {$[0,9877]$} \\
\hline
\end{tabular}

Nota: los valores entre corchetes son la probabilidad crítica ( $p$-values). En negrita, valores significativos para un nivel de significación del 5\%.

Estadísticamente, los días cambio de mes (CM) representan aproximadamente el 24\% del total de días de cotización, y el resto de días (RD) el 76\%. Si suponemos que la rentabilidad se genera de una forma proporcionalmente lineal, el 24\% de la rentabilidad total del índice debería generarse en el período cambio de mes y el 76\% restante en el resto de días. Pero los resultados obtenidos, en el Cuadro 4.48, contradicen lo esperado, a excepción del Ibex Top Dividendo, que es el único en el que coincide la rentabilidad esperada proporcional con la rentabilidad real, para el resto la rentabilidad que se genera los días cambios de mes, representa un porcentaje mucho mayor del $24 \%$ esperado, lo cual corrobora la existencia del efecto y su importancia en la rentabilidad total. Trasladando estos porcentajes a términos mensuales, como se puede ver en el Cuadro 4.49, la rentabilidad media del período cambio de mes representa el 74,60\% de la rentabilidad mensual del IGBM, el $82,61 \%$ de la del Ibex-35 y el 127,50\% del Ibex Medium Cap.

\section{Cuadro 4.48: Rentabilidades totales para el efecto cambio de mes}

Este cuadro muestra la rentabilidad total de cada índice, para el período muestral total, desglosada en la rentabilidad total obtenida en los días cambio de mes y en la rentabilidad total obtenida en el resto de días, comparando ambas con sus esperadas proporcionales.

\begin{tabular}{lccccc}
\hline & Rent. total CM & Esperada proporcional & Rent. total RD & Esperada proporcional & Rent. total del índice \\
\hline IGBM & $167,44 \%$ & $54,41 \%$ & $59,27 \%$ & $172,30 \%$ & $226,71 \%$ \\
Ibex 35 & $109,23 \%$ & $32,08 \%$ & $24,43 \%$ & $101,58 \%$ & $133,65 \%$ \\
Ibex Medium Cap & $107,86 \%$ & $19,93 \%$ & $-24,81 \%$ & $63,12 \%$ & $83,05 \%$ \\
Ibex Small Cap & $11,13 \%$ & $-15,37 \%$ & $-75,17 \%$ & $-48,67 \%$ & $-64,04 \%$ \\
Ibex Top Dividendo & $-9,70 \%$ & $-9,01 \%$ & $-27,82 \%$ & $-28,52 \%$ & $-37,52 \%$ \\
\hline
\end{tabular}

\section{Cuadro 4.49: Rentabilidades mensuales para el efecto cambio de mes}

Este cuadro muestra la rentabilidad medía en el período cambio de mes y la rentabilidad media mensual, para cada uno de los índices, durante el período muestral total.

\begin{tabular}{lcc} 
& Rent. media período CM & Rent. media mensual \\
\hline IGBM & $0,47 \%$ & $0,63 \%$ \\
Ibex 35 & $0,38 \%$ & $0,46 \%$ \\
Ibex Medium Cap & $0,51 \%$ & $0,40 \%$ \\
Ibex Small Cap & $0,09 \%$ & $-0,51 \%$ \\
Ibex Top Dividendo & $-0,09 \%$ & $-0,36 \%$ \\
\hline
\end{tabular}


Para contrastar los resultados anteriores proponemos un modelo econométrico compuesto por 1 variable dummy estacional, para "el resto de días", que toma la siguiente forma:

$$
r_{t}=c+\beta_{2} D_{2 t}+\varepsilon_{t}
$$

Donde:

$r_{t}=$ Es la rentabilidad del índice en el período t.

$\mathrm{c}=$ Es la rentabilidad media de los días cambio de mes.

$\beta_{2}=$ Es la diferencia entre la rentabilidad de los días cambio de mes y el resto de días.

$D_{i t}=$ Es la variable dummy para el resto de días, que tomara los siguientes valores:

$D_{i t}= \begin{cases}1 & \text { Si el rendimiento en el tiempo t corresponde al día } i \\ 0 & \text { de otra forma }\end{cases}$

$\varepsilon_{t}=$ Es un término de error, idéntica e independientemente distribuido.

La hipótesis nula a contrastar, bajo este modelo, es que el coeficiente de la variable dummy es igual a cero. Adicionalmente, un valor negativo del coeficiente dummy debe ser considerado como una prueba de la presencia del efecto cambio de mes. De esta manera, la estimación del coeficiente $\beta_{2}$ en la ecuación revela si el resto de días obtienen unos rendimientos mayores o menores que los días cambio de mes. 
Cuadro 4.50: Resultados para la estimación del efecto cambio de mes con MCO

Este cuadro muestra los resultados de la estimación de la ecuación: $r_{t}=c+\beta_{2} D_{2 t}+\varepsilon_{t}$, con MCO, para los cinco índices y para el período muestral total.

\begin{tabular}{cccccc}
\hline & IGBM & Ibex 35 & Ibex Medium Cap & Ibex Small Cap & Ibex Top Dividendo \\
\hline $\mathrm{C}$ & $\mathbf{0 , 0 0 0 9}$ & $\mathbf{0 , 0 0 0 8}$ & $\mathbf{0 , 0 0 1 0}$ & 0,0002 & $-0,0002$ \\
& {$[\mathbf{0 , 0 0 3 9}]$} & {$[\mathbf{0 , 0 3 8 9 ]}$} & {$[\mathbf{0 , 0 0 1 9 ]}$} & {$[0,6984]$} & {$[0,7749]$} \\
$\beta_{2}$ & $\mathbf{- 0 , 0 0 0 8}$ & $-0,0007$ & $\mathbf{- 0 , 0 0 1 1}$ & $-0,0005$ & 0,0000 \\
& {$[\mathbf{0 , 0 2 5 1 ]}$} & {$[0,0898]$} & {$[\mathbf{0 , 0 0 3 6 ]}$} & {$[0,2970]$} & {$[0,9752]$} \\
$\mathrm{R}^{2}$ & 0,0007 & 0,0005 & 0,0019 & 0,0004 & 0,0000 \\
$\mathrm{~F}$ & $\mathbf{5 , 0 1 6 1}$ & $\mathbf{2 , 8 7 8 2}$ & $\mathbf{8 , 4 8 1 5}$ & 1,0882 & 0,0010 \\
& {$[\mathbf{0 , 0 2 5 1 ]}$} & {$[\mathbf{0 , 0 8 9 8}]$} & {$[\mathbf{0 , 0 0 3 6}]$} & {$[0,2970]$} & {$[0,9752]$} \\
Observaciones & $\mathbf{7 5 3 2}$ & 6067 & 4431 & 2678 & 2206 \\
\hline Arch $(1)$ & $\mathbf{0 , 0 0 0 0}$ & $\mathbf{0 , 0 0 0 0}$ & $\mathbf{0 , 0 0 0 0}$ & $\mathbf{0 , 0 0 0 0}$ & $\mathbf{0 , 0 0 0 0}$ \\
\hline
\end{tabular}

Nota: los valores entre corchetes son la probabilidad crítica (p-values). En negrita, valores significativos para un nivel de significación del 5\%.

Cuadro 4.51: Resultados para la estimación del efecto cambio de mes con el modelo GARCH $(1,1)$

Este cuadro muestra los resultados de la estimación de la ecuación: $r_{t}=c+\beta_{2} D_{2 t}+\varepsilon_{t}$, con el modelo GARCH $(1,1)$, para los cinco índices y para el período muestral total.

\begin{tabular}{cccccc}
\hline & IGBM & Ibex 35 & Ibex Medium Cap & Ibex Small Cap & Ibex Top Dividendo \\
\hline $\mathrm{C}$ & $\mathbf{0 , 0 0 1 5}$ & $\mathbf{0 , 0 0 1 4}$ & $\mathbf{0 , 0 0 1 8}$ & $\mathbf{0 , 0 0 0 9}$ & 0,0003 \\
& {$[\mathbf{0 , 0 0 0 0 ]}$} & {$[\mathbf{0 , 0 0 0 0 ]}$} & {$[\mathbf{0 , 0 0 0 0}$} & {$[\mathbf{0 , 0 1 8 1}]$} & {$[0,5555]$} \\
$\beta_{2}$ & $\mathbf{0 , 0 0 1 0}$ & $\mathbf{- 0 , 0 0 0 8}$ & $-\mathbf{0 , 0 0 1 4}$ & $-0,0007$ & 0,0000 \\
& {$[\mathbf{0 , 0 0 0 2}]$} & {$[\mathbf{0 , 0 1 0 0 ]}$} & {$[\mathbf{0 , 0 0 0 0 ]}$} & {$[0,1268]$} & {$[0,9919]$} \\
\hline $\mathrm{C}$ & $\mathbf{0 , 0 0 0 0}$ & $\mathbf{0 , 0 0 0 0}$ & $\mathbf{0 , 0 0 0 0}$ & $\mathbf{0 , 0 0 0 0}$ & $\mathbf{0 , 0 0 0 0}$ \\
& {$[\mathbf{0 , 0 0 0 0 ]}$} & {$[\mathbf{0 , 0 0 0 0 ]}$} & {$[\mathbf{0 , 0 0 0 0 ]}$} & {$[\mathbf{0 , 0 0 0 0}]$} & {$[\mathbf{0 , 0 0 0 0 ]}$} \\
$\mathrm{ARCH}(1)$ & $\mathbf{0 , 1 1 8 3}$ & $\mathbf{0 , 0 9 4 1}$ & $\mathbf{0 , 1 3 7 4}$ & $\mathbf{0 , 1 6 5 0}$ & $\mathbf{0 , 0 8 6 1}$ \\
& {$[\mathbf{0 , 0 0 0 0 ]}$} & {$[\mathbf{0 , 0 0 0 0 ]}$} & {$[\mathbf{0 , 0 0 0 0 ]}$} & {$[\mathbf{0 , 0 0 0 0}]$} & {$[\mathbf{0 , 0 0 0 0 ]}$} \\
GARCH(1) & $\mathbf{0 , 8 5 7 6}$ & $\mathbf{0 , 8 9 3 9}$ & $\mathbf{0 , 8 5 7 9}$ & $\mathbf{0 , 7 8 2 2}$ & $\mathbf{0 , 8 9 4 9}$ \\
Observaciones & $\mathbf{7 5 3 2}$ & 60067 & 4431 & 2678 & 2206 \\
\hline
\end{tabular}

Nota: los valores entre corchetes son la probabilidad crítica ( $p$-values). En negrita, valores significativos para un nivel de significación del 5\%. 
Cuadro 4.52: Resultados para la estimación del efecto cambio de mes con el modelo EGARCH $(1,1)$

Este cuadro muestra los resultados de la estimación de la ecuación: $r_{t}=c+\beta_{2} D_{2 t}+\varepsilon_{t}$, con el modelo EGARCH $(1,1)$, para los cinco índices y para el período muestral total.

\begin{tabular}{|c|c|c|c|c|c|}
\hline & IGBM & Ibex 35 & Ibex Medium Cap & Ibex Small Cap & Ibex Top Dividendo \\
\hline \multirow[t]{2}{*}{$\mathrm{C}$} & 0,0015 & 0,0009 & 0,0016 & 0,0009 & 0,0000 \\
\hline & {$[0,0000]$} & {$[0,0009]$} & {$[0,0000]$} & {$[0,0176]$} & {$[0,9746]$} \\
\hline \multirow[t]{2}{*}{$\beta_{2}$} & $-0,0012$ & $-0,0007$ & $-0,0014$ & $-0,0008$ & $-0,0001$ \\
\hline & {$[0,0000]$} & {$[0,0303]$} & {$[0,0000]$} & {$[0,0703]$} & {$[0,8644]$} \\
\hline \multirow[t]{2}{*}{$\mathrm{C}$} & $-0,4168$ & $-0,2996$ & $-0,4403$ & $-0,9773$ & $-0,2774$ \\
\hline & {$[0,0000]$} & {$[0,0000]$} & {$[0,0000]$} & {$[0,0000]$} & {$[0,0000]$} \\
\hline \multirow[t]{2}{*}{ |RES|/SQR[GARCH](1) } & 0,1758 & 0,1453 & 0,2164 & 0,2893 & 0,1133 \\
\hline & {$[0,0000]$} & {$[0,0000]$} & {$[0,0000]$} & {$[0,0000]$} & {$[0,0000]$} \\
\hline \multirow[t]{2}{*}{ RES/SQR[GARCH](1) } & $-0,0759$ & $-0,0781$ & $-0,0743$ & $-\mathbf{0 , 0 5 7 5}$ & $-0,0904$ \\
\hline & {$[0,0000]$} & {$[0,0000]$} & {$[0,0000]$} & {$[0,0000]$} & {$[0,0000]$} \\
\hline \multirow[t]{2}{*}{ EGARCH(1) } & 0,9681 & $\mathbf{0 , 9 7 8 8}$ & 0,9709 & 0,9171 & $\mathbf{0 , 9 7 8 0}$ \\
\hline & {$[0,0000]$} & {$[0,0000]$} & {$[0,0000]$} & {$[0,0000]$} & {$[0,0000]$} \\
\hline $\mathrm{R}^{2}$ & 0,0002 & 0,0004 & 0,0009 & $-0,0022$ & 0,0000 \\
\hline \multirow[t]{2}{*}{$\mathrm{F}$} & 0,2725 & 0,4365 & 0,7923 & - & - \\
\hline & {$[0,9284]$} & {$[0,8234]$} & {$[0,5550]$} & - & - \\
\hline Observaciones & 7532 & 6067 & 4431 & 2678 & 2206 \\
\hline Durbin-Watson & 1,8965 & 1,9327 & 1,8463 & 1,7409 & 1,8618 \\
\hline $\operatorname{Arch}(1)$ & 0,1053 & 0,2721 & 0,2957 & 0,7517 & 0,1783 \\
\hline
\end{tabular}

Nota: los valores entre corchetes son la probabilidad crítica ( $p$-values). En negrita, valores significativos para un nivel de significación del 5\%. 
Como se puede ver en el Cuadro 4.50 las estimaciones realizadas a través de MCO, no son los suficientemente consistentes para determinar la presencia del efecto cambio de mes, ya que todas las estimaciones presentan efectos $\mathrm{ARCH}$, por lo que se procede a realizar la estimación a través de los modelos GARCH $(1,1)$ y EGARCH $(1,1)$ y los resultados de las nuevas estimaciones se pueden observar en los Cuadros 4.51 y 4.52. En dichos cuadros se confirma lo inicialmente observado excepto parael Ibex Top Dividendo, el resto índices presentan el efecto cambio de mes, aunque el Ibex Small Cap lo presenta de una forma débil.

\subsubsection{Análisis robustez subperíodos muestrales}

Como se observa en el Cuadro 4.53, el efecto cambio de mes está presente en los dos primeros subperíodos muestrales del IGBM, desapareciendo en el tercero e igualándose la rentabilidad media de los días cambio de mes con la rentabilidad media del resto de días al -0,01\%. La misma circunstancia se produce con el Ibex 35 (Cuadro 4.54), observándose que el efecto desaparece en el subperíodo 2008-2015, pero en este caso, la rentabilidad media de los días cambio de mes $(-0,02 \%)$ se vuelve inferior a la del resto de días $(0,00 \%)$.

El contraste de significatividad de medias que aparece en el Cuadro 4.55, confirma la desaparición del efecto cambio de mes para los dos índices en el subperíodo 2008-2015, pero tampoco presenta significatividad para el período 1986-1997 del IGBM.

La rentabilidad total en los días cambio de mes que aparece reflejada en el Cuadro 4.56, continúa presentando unos valores más elevados que los esperados para ambos índices, a excepción del subperíodo 2008-2015 en ambos. Este resultado guarda coherencia, dada las implicaciones que el período de crisis conlleva. En el Cuadro 4.57 nuevamente se identifican los valores negativos para dichos subperíodos.

Las estimaciones por MCO de la ecuación planteada que aparecen en el Cuadro 4.58 siguen sin ser lo suficientemente consistentes para su estudio al presentar efectos ARCH, por lo tanto, se vuelve a estimar la ecuación con los modelos GARCH $(1,1)$ y EGARCH $(1,1)$, Cuadros 4.59 y 4.60. Los resultados corroboran lo observado en los puntos anteriores, el efecto cambio de mes desaparece en el subperíodo 2008-2015, en ambos índices. Además en el período 1986-1997 en el modelo GARCH $(1,1)$ presenta una significatividad débil y en el EGARCH $(1,1)$ sí que se identifica una significatividad fuerte. 
Cuadro 4.53: Estadísticos descriptivos del IGBM, para el efecto cambio de mes, en diferentes subperíodos muestrales

Este cuadro muestra los principales estadísticos descriptivos de las rentabilidades medías de los días cambio de mes y del resto de días del IGBM durante los subperíodos muestrales de 1986 a 1997, de 1998 a 2007 y de 2008 a 2015.

\begin{tabular}{|c|c|c|}
\hline Subperíodo 1986-1997 & Días cambio de mes & Resto de días \\
\hline Media & 0,0012 & 0,0005 \\
\hline Mediana & 0,0011 & 0,0000 \\
\hline Desviación estándar & 0,0116 & 0,0120 \\
\hline Varianza de la muestra & 0,0001 & 0,0001 \\
\hline Curtosis & 5,0188 & 22,7631 \\
\hline Coeficiente de asimetría & 0,1179 & $-0,2075$ \\
\hline Rango & 0,1345 & 0,2870 \\
\hline Mínimo & $-0,0626$ & $-0,1341$ \\
\hline Máximo & 0,0719 & 0,1529 \\
\hline Observaciones & 720 & 2255 \\
\hline$\%$ Observaciones positivas & $54,86 \%$ & $49,22 \%$ \\
\hline Subperíodo 1998-2007 & Días cambio de mes & Resto de días \\
\hline Media & 0,0018 & 0,0000 \\
\hline Mediana & 0,0020 & 0,0010 \\
\hline Desviación estándar & 0,0122 & 0,0123 \\
\hline Varianza de la muestra & 0,0001 & 0,0002 \\
\hline Curtosis & 2,6088 & 2,5288 \\
\hline Coeficiente de asimetría & $-0,0006$ & $-0,2416$ \\
\hline Rango & 0,1213 & 0,1189 \\
\hline Mínimo & $-0,0624$ & $-0,0650$ \\
\hline Máximo & 0,0589 & 0,0540 \\
\hline Observaciones & 600 & 1914 \\
\hline$\%$ Observaciones positivas & $57,00 \%$ & $53,71 \%$ \\
\hline Subperíodo 2008-2015 & Días cambio de mes & Resto de días \\
\hline Media & $-0,0001$ & $-0,0001$ \\
\hline Mediana & 0,0007 & 0,0004 \\
\hline Desviación estándar & 0,0180 & 0,0169 \\
\hline Varianza de la muestra & 0,0003 & 0,0003 \\
\hline Curtosis & 3,3575 & 7,1255 \\
\hline Coeficiente de asimetría & 0,0810 & 0,5183 \\
\hline Rango & 0,1728 & 0,2395 \\
\hline Mínimo & $-0,0732$ & $-0,0923$ \\
\hline Máximo & 0,0997 & 0,1473 \\
\hline Observaciones & 480 & 1563 \\
\hline$\%$ Observaciones positivas & $51,04 \%$ & $51,18 \%$ \\
\hline
\end{tabular}


Cuadro 4.54: Estadísticos descriptivos del Ibex 35, para el efecto cambio de mes, en diferentes subperíodos muestrales

Este cuadro muestra los principales estadísticos descriptivos de las rentabilidades medías de los días cambio de mes y del resto de días del Ibex 35 durante los subperíodos muestrales de 1992 a 2007 y de 2008 a 2015.

\begin{tabular}{|c|c|c|}
\hline Subperíodo 1992-2007 & Días cambio de mes & Resto de días \\
\hline Media & 0,0014 & 0,0002 \\
\hline Mediana & 0,0014 & 0,0007 \\
\hline Desviación estándar & 0,0129 & 0,0127 \\
\hline Varianza de la muestra & 0,0002 & 0,0002 \\
\hline Curtosis & 2,7578 & 2,7731 \\
\hline Coeficiente de asimetría & $-0,1133$ & $-0,1113$ \\
\hline Rango & 0,1329 & 0,1359 \\
\hline Mínimo & $-0,0708$ & $-0,0707$ \\
\hline Máximo & 0,0621 & 0,0653 \\
\hline Observaciones & 960 & 3064 \\
\hline$\%$ Observaciones positivas & $56,67 \%$ & $52,87 \%$ \\
\hline Subperíodo 2008-2015 & Días cambio de mes & Resto de días \\
\hline Media & $-0,0002$ & 0,0000 \\
\hline Mediana & 0,0007 & 0,0004 \\
\hline Desviación estándar & 0,0172 & 0,0170 \\
\hline Varianza de la muestra & 0,0003 & 0,0003 \\
\hline Curtosis & 1,6906 & 6,9629 \\
\hline Coeficiente de asimetría & $-0,1594$ & 0,4963 \\
\hline Rango & 0,1227 & 0,2358 \\
\hline Mínimo & $-0,0627$ & $-0,0914$ \\
\hline Máximo & 0,0600 & 0,1443 \\
\hline Observaciones & 480 & 1563 \\
\hline$\%$ Observaciones positivas & $51,88 \%$ & $50,99 \%$ \\
\hline
\end{tabular}


Cuadro 4.55: Contraste de significatividad de medias, para el efecto cambio de mes, en diferentes subperíodos muestrales

Este cuadro muestra el contraste de significatividad entre la rentabilidad media de los días cambio de mes frente a la rentabilidad media del resto de días para el IGBM y para el Ibex 35 en diferentes subperíodos muestrales.

\begin{tabular}{lccccc} 
& IGBM & IGBM & IGBM & Ibex 35 & Ibex 35 \\
\cline { 2 - 6 } & Subperíodo 1986-1997 & Subperíodo 1998-2007 & Subperíodo 2008-2015 & Subperíodo 1992-2007 & Subperíodo 2008-2015 \\
\hline Días cambio de mes & $\mathbf{0 , 0 0 1 2}$ & $\mathbf{0 , 0 0 1 8}$ & $-0,0001$ & $\mathbf{0 , 0 0 1 4}$ & $-0,0002$ \\
& {$[\mathbf{0 , 0 0 6 3 ]}$} & {$[\mathbf{0 , 0 0 0 4}]$} & {$[0,8613]$} & {$[\mathbf{0 , 0 0 0 6}]$} & {$[0,7848]$} \\
Resto de días & $\mathbf{0 , 0 0 0 5}$ & 0,0000 & $-0,0001$ & 0,0002 & 0,0000 \\
Diferencia & {$[\mathbf{0 , 0 3 5 6 ]}$} & {$[0,8744]$} & {$[0,8062]$} & {$[0,2852]$} & {$[0,9221]$} \\
& 0,0007 & $\mathbf{0 , 0 0 1 7}$ & 0,0000 & $\mathbf{0 , 0 0 1 2}$ & $-0,0002$ \\
\hline
\end{tabular}

Nota: los valores entre corchetes son la probabilidad crítica (p-values). En negrita, valores significativos para un nivel de significación del 5\%.

\section{Cuadro 4.56: Rentabilidades totales, para el efecto cambio de mes, en diferentes subperíodos muestrales}

Este cuadro muestra la rentabilidad total del IGBM y del Ibex 35, para diferentes subperíodos muestrales, desglosada en la rentabilidad total obtenida en los días cambio de mes y en la rentabilidad total obtenida en el resto de días, comparando ambas con sus esperadas proporcionales.

\begin{tabular}{lccccc} 
& Rent. total CM & Esperada proporcional & Rent. total RD & Esperada proporcional & Rent. total del índice \\
\hline IGBM & & & & & \\
Subperíodo 1986-1997 & $80,62 \%$ & $44,27 \%$ & $103,84 \%$ & $140,19 \%$ & $184,46 \%$ \\
Subperíodo 1998-2007 & $101,47 \%$ & $22,89 \%$ & $-6,08 \%$ & $72,50 \%$ & $95,39 \%$ \\
Subperíodo 2008-2015 & $-14,65 \%$ & $-12,75 \%$ & $-38,49 \%$ & $-40,39 \%$ & $-53,14 \%$ \\
Ibex 35 & & & & & $180,07 \%$ \\
Subperíodo 1992-2007 & $129,69 \%$ & $43,22 \%$ & $50,38 \%$ & $136,85 \%$ & $-46,42 \%$ \\
Subperíodo 2008-2015 & $-20,46 \%$ & $-11,14 \%$ & $-25,96 \%$ & $-35,28 \%$ & \\
\hline
\end{tabular}


Cuadro 4.57: Rentabilidades mensuales, para el efecto cambio de mes, en diferentes subperíodos muestrales

Este cuadro muestra la rentabilidad medía en el período cambio de mes y la rentabilidad media mensual, para el IGBM y el Ibex 35, en diferentes subperíodos muestrales.

\section{Rent. media período CM Rent. media mensual}

\section{IGBM}

Subperíodo 1986-1997

Subperíodo 1998-2007

Subperíodo 2008-2015

$\begin{array}{rr}0,56 \% & 1,28 \% \\ 0,85 \% & 0,79 \%\end{array}$

Ibex 35

Subperíodo 1992-2007

$-0,15 \%$

$-0,55 \%$

Subperíodo 2008-2015

\begin{tabular}{rr}
$0,68 \%$ & $0,94 \%$ \\
$-0,21 \%$ & $-0,48 \%$ \\
\hline
\end{tabular}

Cuadro 4.58: Resultados para la estimación del efecto cambio de mes con MCO, para diferentes subperíodos muestrales

Este cuadro muestra los resultados de la estimación de la ecuación: $r_{t}=c+\beta_{2} D_{2 t}+\varepsilon_{t}$, con MCO, para el IGBM y el Ibex 35, en diferentes subperíodos muestrales.

\begin{tabular}{|c|c|c|c|c|c|}
\hline & IGBM & IGBM & IGBM & Ibex 35 & Ibex 35 \\
\hline & 1986-1997 & 1998-2007 & 2008-2015 & 1992-2007 & 2008-2015 \\
\hline \multirow[t]{2}{*}{$\mathrm{C}$} & 0,0011 & 0,0017 & $-0,0003$ & 0,0014 & $-0,0004$ \\
\hline & {$[0,0121]$} & {$[0,0008]$} & {$[0,6958]$} & {$[0,0010]$} & {$[0,6395]$} \\
\hline \multirow[t]{2}{*}{$\beta_{2}$} & $-0,0007$ & $-0,0017$ & 0,0001 & $-0,0012$ & 0,0002 \\
\hline & {$[0,1980]$} & {$[0,0028]$} & {$[0,9473]$} & {$[0,0118]$} & {$[0,8408]$} \\
\hline $\mathrm{R}^{2}$ & 0,0006 & 0,0035 & 0,0000 & 0,0016 & 0,0000 \\
\hline \multirow[t]{2}{*}{$\mathrm{F}$} & 1,6577 & 8,9205 & 0,0044 & 6,3418 & 0,0403 \\
\hline & {$[0,1980]$} & {$[0,0028]$} & {$[0,9473]$} & {$[0,0118]$} & {$[0,8408]$} \\
\hline Observaciones & 2975 & 2514 & 2043 & 4024 & 2043 \\
\hline $\operatorname{Arch}(1)$ & 0,0000 & 0,0000 & 0,0000 & 0,0000 & 0,0000 \\
\hline
\end{tabular}

Nota: los valores entre corchetes son la probabilidad crítica (p-values). En negrita, valores significativos para un nivel de significación del 5\%. 
Cuadro 4.59: Resultados para la estimación del efecto cambio de mes con el modelo GARCH (1,1), para diferentes subperíodos muestrales

Este cuadro muestra los resultados de la estimación de la ecuación: $r_{t}=c+\beta_{2} D_{2 t}+\varepsilon_{t}$, con el modelo GARCH $(1,1)$, para el IGBM y el Ibex 35, en diferentes períodos muestrales.

\begin{tabular}{|c|c|c|c|c|c|}
\hline & IGBM & IGBM & IGBM & Ibex 35 & Ibex 35 \\
\hline & 1986-1997 & 1998-2007 & 2008-2015 & $1992-2007$ & 2008-2015 \\
\hline \multirow[t]{2}{*}{$\mathrm{C}$} & 0,0013 & 0,0020 & 0,0003 & 0,0017 & 0,0003 \\
\hline & {$[0,0005]$} & {$[0,0000]$} & {$[0,5618]$} & {$[0,0000]$} & {$[0,5569]$} \\
\hline \multirow[t]{2}{*}{$\beta_{2}$} & $-0,0008$ & $-0,0016$ & 0,0000 & $-0,0011$ & 0,0000 \\
\hline & {$[0,0716]$} & {$[0,0001]$} & {$[0,9816]$} & {$[0,0027]$} & {$[0,9580]$} \\
\hline \multirow[t]{2}{*}{$\mathrm{C}$} & 0,0000 & 0,0000 & 0,0000 & 0,0000 & 0,0000 \\
\hline & {$[0,0000]$} & {$[0,0000]$} & {$[0,0000]$} & {$[0,0000]$} & {$[0,0000]$} \\
\hline \multirow[t]{2}{*}{ ARCH(1) } & $\mathbf{0 , 1 5 7 8}$ & $\mathbf{0 , 0 9 5 5}$ & 0,1039 & $\mathbf{0 , 0 9 0 7}$ & $\mathbf{0 , 0 9 5 3}$ \\
\hline & {$[0,0000]$} & {$[0,0000]$} & {$[0,0000]$} & {$[0,0000]$} & {$[0,0000]$} \\
\hline \multirow[t]{2}{*}{ GARCH(1) } & $\mathbf{0 , 7 6 0 4}$ & $\mathbf{0 , 8 9 2 4}$ & $\mathbf{0 , 8 7 3 3}$ & 0,8926 & $\mathbf{0 , 8 8 2 8}$ \\
\hline & {$[0,0000]$} & {$[0,0000]$} & {$[0,0000]$} & {$[0,0000]$} & {$[0,0000]$} \\
\hline Observaciones & 2975 & 2514 & 2043 & 4024 & 2043 \\
\hline
\end{tabular}

Nota: los valores entre corchetes son la probabilidad crítica (p-values). En negrita, valores significativos para un nivel de significación del 5\%. 
Cuadro 4.60: Resultados para la estimación del efecto cambio de mes con el modelo EGARCH (1,1), para diferentes subperíodos muestrales

Este cuadro muestra los resultados de la estimación de la ecuación: $r_{t}=c+\beta_{2} D_{2 t}+\varepsilon_{t}$, con el modelo EGARCH $(1,1)$, para el IGBM y el Ibex 35, en diferentes períodos muestrales.

\begin{tabular}{|c|c|c|c|c|c|}
\hline & IGBM & IGBM & IGBM & Ibex 35 & Ibex 35 \\
\hline & 1986-1997 & 1998-2007 & 2008-2015 & 1992-2007 & 2008-2015 \\
\hline \multirow[t]{2}{*}{$\mathrm{C}$} & $\mathbf{0 , 0 0 1 7}$ & $\mathbf{0 , 0 0 1 7}$ & $-0,0007$ & 0,0014 & $-0,0006$ \\
\hline & {$[0,0000]$} & {$[0,0000]$} & {$[0,2232]$} & {$[0,0000]$} & {$[0,2875]$} \\
\hline \multirow[t]{2}{*}{$\beta_{2}$} & $-0,0012$ & $-0,0015$ & 0,0002 & $-0,0010$ & 0,0002 \\
\hline & {$[0,0036]$} & {$[0,0002]$} & {$[0,7087]$} & {$[0,0076]$} & {$[0,7486]$} \\
\hline \multirow[t]{2}{*}{$\mathrm{C}$} & $-0,7707$ & $-0,3353$ & $-0,3385$ & $-0,3063$ & $-0,2854$ \\
\hline & {$[0,0000]$} & {$[\mathbf{0 , 0 0 0 0 ]}$} & {$[0,0000]$} & {$[0,0000]$} & {$[0,0000]$} \\
\hline \multirow[t]{2}{*}{ |RES|/SQR[GARCH](1) } & 0,2189 & 0,1659 & 0,1242 & 0,1509 & 0,1021 \\
\hline & {$[0,0000]$} & {$[0,0000]$} & {$[0,0000]$} & {$[0,0000]$} & {$[0,0000]$} \\
\hline \multirow[t]{2}{*}{ RES/SQR[GARCH](1) } & $-0,0558$ & $-0,0734$ & $-0,1400$ & $-0,0523$ & $-0,1360$ \\
\hline & {$[0,0000]$} & {$[0,0000]$} & {$[0,0000]$} & {$[0,0000]$} & {$[0,0000]$} \\
\hline \multirow[t]{2}{*}{ EGARCH(1) } & $\mathbf{0 , 9 3 2 7}$ & $\mathbf{0 , 9 7 7 5}$ & 0,9710 & 0,9791 & $\mathbf{0 , 9 7 5 4}$ \\
\hline & {$[0,0000]$} & {$[0,0000]$} & {$[0,0000]$} & {$[0,0000]$} & {$[0,0000]$} \\
\hline Observaciones & 2975 & 2514 & 2043 & 4024 & 2043 \\
\hline
\end{tabular}

Nota: los valores entre corchetes son la probabilidad crítica ( $p$-values). En negrita, valores significativos para un nivel de significación del 5\%. 


\subsubsection{Resumen del análisis del efecto cambio de mes}

En este estudio se pone de manifiesto que de entre los índices españoles analizados, destaca el IGBM, el Ibex 35 y el Ibex Medium Cap, por evidenciar el efecto cambio de mes de forma significativa, mientras que el Ibex Small Cap se presenta en una forma débil, y para el Ibex Top Dividendo no se identifica esta anomalía. Estos resultados coinciden parcialmente con los de García (2008), ya que en su estudio encuentra un fuerte efecto cambio de mes para el Ibex-35 y el Ibex Small Cap, mientras que nosotros para este último sólo lo hemos encontrado con significatividad débil.

Por otro lado, la rentabilidad que se produce en el período cambio de mes, representa aproximadamente el 74,60\% de la rentabilidad media mensual del IGBM, el 82,60\% del Ibex 35 y el 127,50\% del Ibex Medium Cap siendo estos resultados superiores a los presentados por Pettengill y Jordan (1988) o Agrawal y Tandon (1994) quienes observan que durante ese período de cambio de mes se producía entre el $55 \%$ y $70 \%$ de la rentabilidad media mensual y con valores muy cercanos a los de Kunkel et al. (2003) quienes elevan esa rentabilidad al $87 \%$.

Finalmente, el análisis de la robustez del efecto cambio de mes en los diferentes subperídos muestrales nos deja como principal conclusión que el efecto desaparece en el subperíodo 2008-2015, para el IGBM y para el Ibex 35, es decir, desaparece coincidiendo con el período de crisis financiera. Estos resultados se contradicen con lo observado en otros estudios, como los de Rodríguez y Yáñez (2015) para Amércia Latina o, Kayaçetin y Lekpek (2016) para Turquía, en los que encuentran significatividad para esos mercados durante la crisis financiera global. 


\subsection{El efecto vacaciones}

\subsubsection{Revisión bibliográfica}

Una de las anomalías más conocidas del efecto calendario es el efecto vacaciones, por la cual se producen rentabilidades anormalmente altas el día previo al comienzo de las vacaciones o a días festivos. Este fenómeno fue identificado por primera vez en la década de 1930 y es, sin duda, uno de los más antiguos identificados y con mayor regularidad en el análisis de las series temporales. Existe numerosa literatura que ha abordado este sesgo con profundidad, destacando la pionera contribución de Fields (1934) quien observa que un alto porcentaje de las rentabilidades positivas se producen los días antes de vacaciones. Merrill (1966) estudia el Dow Jones en el período de 1897 a 1965 llegando a la conclusión de que se producen rentabilidades anormalmente altas los días anteriores a días festivos. Fosback (1976) señala también que el S\&P 500 muestra altas rentabilidades antes de los días festivos y observó un incremento acumulado de la rentabilidad del $778 \%$, en comparación con el promedio de todos los demás días de negociación que oscilaban entorno al 41\%. La existencia de rentabilidades anormales en los períodos de vacaciones también fue estudiada por Lakonishok y Smidt (1988) en el Dow Jones durante el período de 1897 a 1986 encontrando que las rentabilidades diarias son significativamente más altas los días de cotización que preceden inmediatamente las vacaciones. Pettengill (1989) en un período de investigación de 25 años, de 1962 a 1986, encuentra rentabilidades inusualmente altas los días de negociación antes de festivos, tanto para grandes como para pequeñas empresas de Estados Unidos. Este mismo resultado es reportado por Liano et al. (1992), para el período 1973-1989. Ariel (1990) llega a la conclusión de que más de un tercio de la rentabilidad total de los mercados de Estados Unidos, en el período 1963-1982, se ha generado en los ocho días de negociación que preceden cada año a los festivos.

Otras evidencias internacionales, entre las que destaca, Ziemba (1991) examina el efecto en Japón utilizando datos diarios sobre el Nikkei, de 1949 a 1988 y observa que la rentabilidad en los días de negociación que preceden a los festivos es cinco veces superior a los normales. Cadsby y Ratner (1992) examinan el efecto vacaciones en 10 países diferentes, entre 1962 y 1989, lo encuentran significativo en Estados Unidos, Canadá, Japón, Hong Kong y Australia, con referencia a sus propias fiestas locales, pero sin embargo, no encuentran relevancia de este efecto en varios mercados europeos. Además, sugieren que la ausencia del efecto en algunos países indica que podría estar originado por las prácticas institucionales de cada país específicamente; si bien para el caso de Hong Kong sí parece conectar con el patrón de comportamiento de los días previos de las vacaciones de Estados Unidos. Precisamente centrando la atención en el mercado financiero estadounidense, Wilson y Jones (1993) examinan tres índices, 
NYSE, AMEX y NASDAQ (con distintos sistemas de negociación) durante el período 1973 y 1991, aplicando sólidas técnicas de estimación y encontrando que el efecto vacaciones es extremadamente significativo en los tres casos. En un estudio similar, Kim y Park (1994) llegan a la misma conclusión para los tres índices. Por lo tanto, todo apunta a que los factores institucionales, como pueden ser los métodos de negociación, los mecanismos de compensación y de liquidación, entre otros, no parece que puedan explicar el efecto.

En el contexto europeo, Agrawal y Tandon (1994) analizan el efecto vacaciones durante el mes de diciembre (1971 y 1988) en Bélgica, Dinamarca, Francia, Alemania, Italia, Luxemburgo, los Países Bajos y el Reino Unido, observando un efecto positivo sólo en Dinamarca, Bélgica y los Países Bajos. En el Reino Unido, Mills y Coutts (1995) encuentran el efecto vacaciones en los índices FTSE100, Mid 250 y Mid 350, para el período de enero 1986 a octubre 1992 y, Arsad y Coutts (1997) analizan el FT30 para el período 1935-1994. Balbina y Martins (2002) encuentran evidencias de una mayor rentabilidad los días pre-festivos en el mercado de valores portugués y esto es posterioremente confirmado por Silva (2010). Gama y Vieira (2013) en su estudio, también, sobre la bolsa de valores de Portugal, sugieren la prevalencia de un estado anímico positivo o de sentimientos positivos en el inicio de las vacaciones, lo que se traduce en una presión compradora, o renuncia a vender, lo que hace subir los precios de las acciones.

Otros autores asocian factores coyunturales a la determinación del efecto, por ejemplo, Marrett y Worthington (2007) utilizan modelos de regresión para examinar el efecto vacaciones en diferentes industrias partícipes de la bolsa de Australia durante el período de 1996 a 2006. Los autores obtienen evidencias de un efecto pre-vacaciones común en las empresas de pequeña capitalización, a nivel de mercado y únicamente encuentran un efecto pre-vacaciones fuerte en la industria minorista. Alternativamente, Bley y Saad (2010) aportan resultados significativamente positivos en los días previos a las fiestas religiosas de Oriente Medio. Estos hallazgos muestran que existe el efecto festivo en muchos mercados desarrollados y emergentes, y es independiente del tipo de festividad. Bialkowski et al. (2012) investigan el efecto del Ramadán sobre los índices de Morgan Stanley Capital International (MSCI) de 14 bolsas de países predominantemente musulmanes, durante los años 1989-2007. Encuentran que las rentabilidades bursátiles durante el mes del Ramadán son significativamente superiores que el resto del año. Yuan y Gupta (2014) investigan el efecto de la festividad del Año Lunar Nuevo Chino (CLNY) en los principales mercados bursátiles de Asia siendo China, Hong Kong, Japón, Malasia, Corea del Sur y Taiwán objeto de estudio. Este estudio identifica que 
hay un efecto pre-CLNY significativamente positivo para todos los casos, siendo los resultados robustos para la mayoría de mercados excepto China.

Sin embargo, en España se han encontrado estudios contradictorios, Meneu y Pardo (2004) concluyen que las rentabilidades son especialmente altas el día anterior al inicio de las vacaciones, para las acciones más importante que cotizan en el mercado continuo, así como para el Ibex 35, no obstante García (2008) no encuentra el efecto vacaciones ni para el Ibex 35, ni para Ibex Small Cap. En contraste, Lucey y Pardo (2005) investigan el efecto vacaciones demostrando que es posible obtener unas ganancias superiores invirtiendo en días pre-festivos de las que se podrían obtener invirtiendo en días al azar. Meneu y Pardo (2001) en su investigación sobre el efecto vacaciones, también plantean la existencia de posibles interacciones entre dicho efecto y el resto de efectos calendario, aunque la literatura que aborda esta cuestión de investigación es muy escasa para los mercados bursátiles españoles.

Hasta ahora se ha considerado el efecto vacaciones únicamente como el día pre-festivo, dado que es el que mayor literatura aglutina, pero también hay un gran número estudios que también consideran en el efecto vacaciones como el día post-festivo, aunque las conclusiones son un tanto contradictorias. Entre otros autors, French (1980), Rogalski (1984) y, Pettengill (1989) observan rentabilidades positivas en sus trabajos para los días post-festivos en el mercado estadounidense. Sin embargo, Lakonishok y Smidt (1988) y Ariel (1990), utilizan unos períodos muestrales más amplios y no encuentran evidencias significativas de rentabilidades superiores los días post-festivos. Kim y Park (1994) encuentran rentabilidades negativas para los días post-festivos en el Reino Unido. Tonchev y Kim (2004) obtienen resultados similares para Eslovaquia, Eslovenia y la República Checa durante el período 1999-2003. Marrett y Worthington (2007) no encuentran evidencias de un efecto post-vacacional en ningún mercado o industria en la bolsa de Australia durante septiembre de 1996 y noviembre de 2006. Otros autores, incluso analizan ambos períodos, pre y post-festivos, destacando Dodd y Gakhovich (2011) quienes documentan la presencia del efecto vacaciones en 14 mercados emergentes de Europa Central y Oriental. Su estudio, muestra rentabilidades anormales en el período pre-festivo y el post-festivo. Recientemente, Carchano y Pardo (2015) constatan la existencia de los efectos pre-festivo y post-festivo como una anomalía panEuropea, y no como un efecto específico de cada país. Demuestran analíticamente que las altas rentabilidades no están relacionadas con la alta volatilidad, sino más bien por la preferencia de los inversores por evitar vender acciones alrededor de los días festivos dentro de la zona euro. 
El estudio más reconocido sobre el efecto vacaciones en los días post-festivos en el mercado español es el de Rubio y Salvador (1991), realizado sobre el período 19721988, dejando como principal conclusión que existen rentabilidades positivas los días post-festivos, pero no son significativas. Meneu y Pardo (2001) obtienen el mismo resultado para el período 1990-2000.

En sintonía con estudios que abordan los diferentes efectos calendarios, nuevamente se plantea si el efecto vacaciones persiste en el tiempo. Las contribuciones de Vergin y McGinnis (1999), Keef y Roush (2005) y Marquering et al. (2006) han llegado a la conclusión de que el efecto vacaciones ha desaparecido en gran medida para las grandes empresas, pero persiste para las pequeñas empresas, aunque la diferencia de magnitud hace que disminuya con el paso del tiempo. Otro enfoque viene del trabajo de Chong et al. (2005) sobre los mercados de Estados Unidos, Reino Unido y Hong Kong, concluyen que el efecto vacaciones se invierte y pasa a ser negativo desde 1991 hasta 1997, con su posterior eliminación entre 1997 y 2003. Por contra, Dodd y Gakhovich (2011) documentan que el efecto pre-festivo está disminuyendo su importancia con el tiempo por la mejora en la eficiencia de los mercados.

De entre las diferentes justificaciones atribuibles al efecto vacaciones parece que la explicación más aceptada para explicar este efecto recae en la psicología de los inversores. Esta hipótesis sostiene que los inversores tienden a comprar acciones antes de irse de vacaciones debido al estado eufórico asociado al comienzo de las vacaciones, entre otros autores, Thaler (1987b), Jacobs y Levy (1988) y Boyle et al. (2004). Frieder y Subrahmanyam (2004) también consideran que el efecto estaría provocado por el estado anímico de los inversores con la llegada de las vacaciones, lo que se traduce en una mayor presión compradora y en un aumento de los precios. Pettengill (1989) considera la posibilidad de que las altas rentabilidades puedan ser el resultado de la existencia de un efecto cierre. Por ejemplo, muchos estudios identifican altas rentabilidades para los valores en el cierre de los mercados coincidiendo con el fin de semana. Ariel (1990) además de la existencia de un efecto cierre, también considera la explicación más popular, es decir, que los inversores quieren cerrar sus posiciones de riesgo antes de las vacaciones. Aunque, por ejemplo, para Liano et al. (1992) el efecto vacaciones, es producido por otras anomalías del calendario que pueden darse al mismo tiempo como es el caso del efecto enero, cambio de mes, fin de semana, por citar algunos.

Dentro de la diversidad de argumentos asociados al efecto vacaciones, la aportación de Fabozzi et al. (1994) destaca por hallar evidencias de un menor efecto vacaciones antes 
de que los inversores se vayan de vacaciones aún cuando el mercado no está cerrado. Estos autores sugieren que es posible que haya varios componentes en el efecto, para ello se refieren al trabajo de Deldin y Levin (1986) que muestra que el estado psicológico de los individuos varía en función del día de la semana y ello puede ser causa de mayores rentabilidades. En contraste, Meneu y Pardo (2004) justifican el efecto vacaciones por el temor de los pequeños inversores a la aparición de nueva información durante el período de vacaciones y entonces no tendrían la posibilidad de cerrar su posición. Recientemente, Don et al. (2016) encuentran que los inversores reaccionan más positivamente a los anuncios corporativos favorables como por ejemplo a la recompra de acciones, a las adquisiciones o a las ganancias, si éstos se producen inmediatamente antes o durante las vacaciones. Los autores ofrecen argumentos indicativos de que el estado anímico optimista en época de pre-vacaciones es la principal causa de las rentabilidades anormalmente altas que sufren las acciones.

\subsubsection{Resultados}

Antes de realizar el análisis de los datos tendremos que determinar los días festivos en España, para ello se ha recurrido a una fuente oficial como la página web de la Seguridad Social (http://www.seg-social.es), en ella encontramos los siguientes días festivos: 1 de enero (Año Nuevo), 6 de enero (Epifanía del Señor), marzo/abril (Viernes Santo), 1 de mayo (Fiesta del trabajo), 15 de agosto (Asunción de la Virgen), 12 de octubre (Fiesta Nacional), 1 de noviembre (Fiesta de Todos los Santos), 6 de diciembre (Día de la Constitución), 8 de diciembre (La Inmaculada Concepción), 25 de diciembre (Natividad del Señor). Pero además de tener en cuenta los festivos nacionales para los cinco índices, también tendremos que tener en cuenta para el IGBM los festivos locales como el 15 de mayo (San Isidro) o el 9 de noviembre (Nuestra Señora de la Almudena) y los festivos autonómicos como el 2 de mayo (Fiesta de la Comunidad de Madrid) o el 25 de julio (Santiago Apóstol), pero sólo hasta 1997 momento en el cual desaparecen.

Para el tratamiento de datos, se tendrán en cuenta las siguientes consideraciones: i) Cuando un día festivo se produzca en fin de semana, no será tomado en cuenta para el análisis dado que se solapará el efecto pre-festivo con el efecto fin de semana. ii) Si el día festivo se produce en viernes sólo presentará día pre-festivo, y si cae en lunes sólo presentará día post-festivo, y si se produce en fin de semana no presentará ningún efecto, para así intentar aislar el efecto fin de semana del efecto día festivo. iii) El 7 de diciembre es día pre-festivo, excepto si se produce en viernes que es post-festivo. iv) Algunas ocasiones el calendario de festivos nacionales no coincide con el calendario de 
festivos bursátiles, ya que se producen cambios de días festivos, o algunos festivos nos son considerados como tales.

Como hemos observado en la revisión bibliográfica para el estudio del efecto vacaciones se han considerado tanto los días pre-festivos como los días post-festivos, pero en este apartado se ha decidido ampliar el ámbito de investigación del efecto incluyendo en el análisis del mismo los días festivos en los cuales el mercado sigue abierto. Se ha observado que en los mercados bursátiles españoles (a partir del 6 de diciembre de 1989 en el IGBM) se producen días festivos en los cuales el mercado está operativo y se produce cotización, pero no es hasta el año 2005 cuando el fenómeno se generaliza y se hace más significativo, pasando de uno o ninguno a cinco: el 15 de agosto, el 12 de octubre, el 1 de noviembre, el 6 de diciembre y el 8 de diciembre. Esto es debido a que, en 2005, la Bolsa española decidió llevar a cabo una progresiva reducción de sus días festivos para converger con las principales bolsas europeas que presentaban menos días inhábiles que la española. A modo ilustrativo, en el presente año 2017, la Sociedad de Bolsas sólo ha fijado cinco días festivos en los cuales permanecerá inoperativa, siendo el 14 de abril (Viernes Santo), el 17 del mismo mes (Lunes de Pascua), el 1 de mayo (Día del Trabajo), el 25 de diciembre (Navidad) y el 26 de diciembre (San Esteban).

Por lo tanto, podemos concluir que en este apartado se procederá al estudio del efecto vacaciones a través del estudio de tres sub-efectos: i) El efecto pre-festivo, es decir los días pre-festivos que presentan unas rentabilidades anormalmente altas, superiores al resto de días, ii) El efecto festivo, los días festivos que obtienen unas rentabilidades superiores al resto de días, y iii) El efecto post-festivo, los días post-festivos presentan unas rentabilidades superiores al resto de días.

\subsubsection{Análisis totalidad período muestral}

En el Cuadro 4.61, para el IGBM observamos una evidencia preliminar del efectoprefestivo $(0,21 \%)$ y post-festivo $(0,19 \%)$, con unas retabilidades medias muy superiores a la del resto de días $(0,03 \%)$, aunque los días festivos presentan una rentabilidad negativa del (-0,11\%). Para el Ibex 35, ilustrado en el Cuadro 4.62, obtenemos los mismos resultados, pero con unas mayores rentabilidades medias para los días pre-festivos y post-festivos, e inferiores para los días festivos y para el resto de días. El Cuadro 4.63 muestra los estadísticos descriptivos del Ibex Medium Cap presentando el efecto pre-festivo y festivo, pero los días post-festivos reportan una rentabilidad media del $0 \%$, inferior a la rentabilidad media del resto de días. 
Cuadro 4.61: Estadísticos descriptivos del IGBM para el efecto vacaciones

Este cuadro muestra los principales estadísticos descriptivos de las rentabilidades medías de los días prefestivos, festivos, post-festivos y del resto de días del IGBM durante el período muestral de enero de 1986 a diciembre de 2015 .

\begin{tabular}{lcccc}
\hline & Días pre-festivos & Días festivos & Días post-festivos & Resto de días \\
\hline Media & 0,0021 & $-0,0011$ & 0,0019 & 0,0003 \\
Mediana & 0,0020 & $-0,0001$ & 0,0018 & 0,0005 \\
Desviación estándar & 0,0124 & 0,0137 & 0,0150 & 0,0137 \\
Varianza de la muestra & 0,0002 & 0,0002 & 0,0002 & 0,0002 \\
Curtosis & 7,6933 & 9,6845 & 0,7503 & 9,6621 \\
Coeficiente de asimetría & $-0,9977$ & 1,5003 & $-0,2210$ & 0,1317 \\
Rango & 0,1128 & 0,1038 & 0,0842 & 0,2870 \\
Mínimo & $-0,0732$ & $-0,0416$ & $-0,0462$ & $-0,1341$ \\
Máximo & 0,0396 & 0,0622 & 0,0380 & 0,1529 \\
Observaciones & 195 & 50 & 181 & 7106 \\
\hline \% Observaciones positivas & $60,00 \%$ & $48,00 \%$ & $54,14 \%$ & $51,80 \%$ \\
\hline
\end{tabular}

\section{Cuadro 4.62: Estadísticos descriptivos del Ibex 35 para el efecto vacaciones}

Este cuadro muestra los principales estadísticos descriptivos de las rentabilidades medías de los días prefestivos, festivos, post-festivos y del resto de días del Ibex 35 durante el período muestral de enero de 1992 a diciembre de 2015.

\begin{tabular}{lcccc}
\hline & Días pre-festivos & Días festivos & Días post-festivos & Resto de días \\
\hline & & & & \\
Media & 0,0024 & $-0,0014$ & 0,0026 & 0,0002 \\
Mediana & 0,0024 & $-0,0006$ & 0,0019 & 0,0007 \\
Desviación estándar & 0,0126 & 0,0142 & 0,0160 & 0,0143 \\
Varianza de la muestra & 0,0002 & 0,0002 & 0,0003 & 0,0002 \\
Curtosis & 1,6552 & 9,9159 & 0,3564 & 5,3380 \\
Coeficiente de asimetría & $-0,0218$ & 1,6442 & 0,2267 & 0,1097 \\
Rango & 0,0778 & 0,1061 & 0,0826 & 0,2358 \\
Mínimo & $-0,0345$ & $-0,0419$ & $-0,0372$ & $-0,0914$ \\
Máximo & 0,0432 & 0,0642 & 0,0453 & 0,1443 \\
Observaciones & 147 & 48 & 112 & 5760 \\
\hline \% Observaciones positivas & $61,90 \%$ & $41,67 \%$ & $54,46 \%$ & $52,74 \%$ \\
\hline
\end{tabular}


Cuadro 4.63: Estadísticos descriptivos del Ibex Medium Cap para el efecto vacaciones

Este cuadro muestra los principales estadísticos descriptivos de las rentabilidades medías de los días prefestivos, festivos, post-festivos y del resto de días del Ibex Medium Cap durante el período muestral de julio de 1998 a diciembre de 2015.

\begin{tabular}{lcccc}
\hline & Días pre-festivos & Días festivos & Días post-festivos & Resto de días \\
\hline & & & & \\
Media & 0,0028 & 0,0005 & 0,0000 & 0,0002 \\
Mediana & 0,0020 & 0,0013 & 0,0004 & 0,0008 \\
Desviación estándar & 0,0080 & 0,0114 & 0,0110 & 0,0107 \\
Varianza de la muestra & 0,0001 & 0,0001 & 0,0001 & 0,0001 \\
Curtosis & 0,0980 & 3,3842 & 3,1052 & 3,6460 \\
Coeficiente de asimetría & 0,1879 & 0,0624 & $-0,6814$ & $-0,3419$ \\
Rango & 0,0403 & 0,0718 & 0,0726 & 0,1371 \\
Mínimo & $-0,0168$ & $-0,0347$ & $-0,0469$ & $-0,0654$ \\
Máximo & 0,0235 & 0,0370 & 0,0257 & 0,0717 \\
Observaciones & 109 & 46 & 83 & 4193 \\
\hline \% Observaciones positivas & $61,47 \%$ & $52,17 \%$ & $54,22 \%$ & $54,21 \%$ \\
\hline
\end{tabular}

\section{Cuadro 4.64: Estadísticos descriptivos del Ibex Small Cap para el efecto vacaciones}

Este cuadro muestra los principales estadísticos descriptivos de las rentabilidades medías de los días prefestivos, festivos, post-festivos y del resto de días del Ibex Small Cap durante el período muestral de julio de 2005 a diciembre de 2015 .

\begin{tabular}{lcccc}
\hline & Días pre-festivos & Días festivos & Días post-festivos & Resto de días \\
\hline & & & & \\
Media & 0,0027 & 0,0033 & $-0,0010$ & $-0,0003$ \\
Mediana & 0,0015 & 0,0044 & $-0,0005$ & 0,0006 \\
Desviación estándar & 0,0083 & 0,0105 & 0,0125 & 0,0115 \\
Varianza de la muestra & 0,0001 & 0,0001 & 0,0002 & 0,0001 \\
Curtosis & 1,9277 & 6,0842 & 1,7001 & 2,9094 \\
Coeficiente de asimetría & 0,8543 & 0,1237 & $-0,1359$ & $-0,4167$ \\
Rango & 0,0436 & 0,0726 & 0,0749 & 0,1346 \\
Mínimo & $-0,0120$ & $-0,0301$ & $-0,0401$ & $-0,0607$ \\
Máximo & 0,0316 & 0,0425 & 0,0348 & 0,0738 \\
Observaciones & 67 & 44 & 50 & 2517 \\
\hline \% Observaciones positivas & $59,70 \%$ & $70,45 \%$ & $46,00 \%$ & $52,88 \%$ \\
\hline
\end{tabular}




\section{Cuadro 4.65: Estadísticos descriptivos del Ibex Top Dividendo para el efecto vacaciones}

Este cuadro muestra los principales estadísticos descriptivos de las rentabilidades medías de los días prefestivos, festivos, post-festivos y del resto de días del Ibex Small Cap durante el período muestral de julio de 2005 a diciembre de 2015.

\begin{tabular}{lcccc}
\hline & Días pre-festivos & Días festivos & Días post-festivos & Resto de días \\
\hline & & & & \\
Media & 0,0010 & $-0,0008$ & 0,0016 & $-0,0001$ \\
Mediana & 0,0013 & $-0,0028$ & 0,0001 & 0,0006 \\
Desviación estándar & 0,0126 & 0,0151 & 0,0164 & 0,0150 \\
Varianza de la muestra & 0,0002 & 0,0002 & 0,0003 & 0,0002 \\
Curtosis & 3,3439 & 3,9627 & 0,8413 & 3,3391 \\
Coeficiente de asimetría & 0,4939 & 0,8414 & 0,4299 & 0,0877 \\
Rango & 0,0768 & 0,0901 & 0,0792 & 0,1700 \\
Mínimo & $-0,0288$ & $-0,0387$ & $-0,0332$ & $-0,0689$ \\
Máximo & 0,0480 & 0,0514 & 0,0460 & 0,1011 \\
Observaciones & 54 & 34 & 38 & 2080 \\
\hline \% Observaciones positivas & $53,70 \%$ & $44,12 \%$ & $50,00 \%$ & $52,02 \%$ \\
\hline
\end{tabular}

El Ibex Small Cap correspondiente al Cuadro 4.64, presenta el efecto pre-festivo y festivo positivos, pero el efecto post-festivo es negativo, es decir, las rentabilidades medias de los días post-festivos son inferiores a las del resto de días. El Ibex Top Dividendo, representado en el Cuadro 4.65, presenta efecto pre-festivo y post-festivo, pero presenta unas rentabilidades medias negativas $(-0,08 \%)$ para los días festivos.

En el contraste de significatividad de medias que aparece en el Cuadro 4.66 se aprecia que el efecto pre-festivo, aparece de forma significativa en el Ibex 35, el Ibex Medium Cap y el Ibex Small Cap, mientras que de forma débil en el IGBM, y el único que no lo presenta es el Ibex Top Dividendo. El efecto día festivo únicamente es significativo para el Ibex Small Cap. El efecto post-festivo, sin embargo, no es significativo para ningún índice. El contraste de significatividad entre las rentabilidades medias de los días pre-festivos y post-festivos, reporta una significatividad débil para el Ibex Medium Cap y el Ibex Small Cap a favor de una mayor rentabilidad media de los días prefestivos frente a los post-festivos. 


\section{Cuadro 4.66: Contraste de significatividad de medias para el efecto vacaciones}

Este cuadro muestra el contraste de significatividad entre las rentabilidades medias de los días pre-festivos, festivos, post-festivos y resto de días para cada uno de los índices, durante el período muestral total.

\begin{tabular}{|c|c|c|c|c|c|}
\hline & IGBM & Ibex 35 & Ibex Medium Cap & Ibex Small Cap & Ibex Top Dividendo \\
\hline \multirow[t]{2}{*}{ Días pre-festivos } & 0,0021 & 0,0024 & 0,0028 & $\mathbf{0 , 0 0 2 7}$ & 0,0010 \\
\hline & {$[0,0189]$} & {$[0,0220]$} & {$[0,0004]$} & {$[0,0102]$} & {$[0,5731]$} \\
\hline \multirow[t]{2}{*}{ Festivos, post y resto } & 0,0003 & 0,0003 & 0,0002 & $-0,0002$ & $-0,0001$ \\
\hline & {$[0,0291]$} & {$[0,1462]$} & {$[0,2711]$} & {$[0,2711]$} & {$[0,7933]$} \\
\hline \multirow[t]{3}{*}{ Diferencia } & 0,0018 & 0,0021 & 0,0026 & 0,0029 & 0,0011 \\
\hline & {$[0,0534]$} & {$[0,0451]$} & {$[0,0011]$} & {$[0,0062]$} & {$[0,5471]$} \\
\hline & IGBM & Ibex 35 & Ibex Medium Cap & Ibex Small Cap & Ibex Top Dividendo \\
\hline \multirow[t]{2}{*}{ Días festivos } & $-0,0011$ & $-0,0014$ & 0,0005 & $\mathbf{0 , 0 0 3 3}$ & $-0,0008$ \\
\hline & {$[0,5812]$} & {$[0,5055]$} & {$[0,7774]$} & {$[0,0416]$} & {$[0,7691]$} \\
\hline \multirow[t]{2}{*}{ Pre, post y resto } & 0,0004 & 0,0003 & 0,0002 & $-0,0002$ & 0,0000 \\
\hline & {$[0,0105]$} & {$[0,0686]$} & {$[0,1332]$} & {$[0,2962]$} & {$[0,8817]$} \\
\hline \multirow[t]{3}{*}{ Diferencia } & $-0,0015$ & $-0,0017$ & 0,0002 & 0,0036 & $-0,0007$ \\
\hline & {$[0,4498]$} & {$[0,4096]$} & {$[0,8892]$} & {$[0,0311]$} & {$[0,7847]$} \\
\hline & IGBM & Ibex 35 & Ibex Medium Cap & Ibex Small Cap & Ibex Top Dividendo \\
\hline \multirow[t]{2}{*}{ Días post-festivos } & 0,0019 & 0,0026 & 0,0000 & $-0,0010$ & 0,0016 \\
\hline & {$[0,0968]$} & {$[0,0927]$} & {$[0,9927]$} & {$[0,5624]$} & {$[0,5411]$} \\
\hline \multirow[t]{2}{*}{ Pre, festivos y resto } & 0,0004 & 0,0003 & 0,0002 & $-0,0002$ & $-0,0001$ \\
\hline & {$[0,0243]$} & {$[0,1297]$} & {$[0,1241]$} & {$[0,4784]$} & {$[0,7820]$} \\
\hline \multirow[t]{3}{*}{ Diferencia } & 0,0015 & 0,0023 & $-0,0002$ & $-0,0009$ & 0,0017 \\
\hline & {$[0,1834]$} & {$[0,1367]$} & {$[0,8461]$} & {$[0,6260]$} & {$[0,5225]$} \\
\hline & IGBM & Ibex 35 & Ibex Medium Cap & Ibex Small Cap & Ibex Top Dividendo \\
\hline \multirow[t]{2}{*}{ Diferencia pre-post } & 0,0002 & $-0,0002$ & 0,0028 & 0,0037 & $-0,0007$ \\
\hline & {$[0,8688]$} & {$[0,9279]$} & {$[0,0523]$} & {$[0,0723]$} & {$[0,8330]$} \\
\hline
\end{tabular}

Nota: los valores entre corchetes son la probabilidad crítica ( $p$-values). En negrita, valores significativos para un nivel de significación del 5\%. 
Para comprobar los resultados anteriores vamos a proceder a crear tres modelos econométricos compuestos por 4 variables dummy estacionales coincidiendo con: i) una para los días pre-festivos; ii) una para los días festivos; iii) una para los días postfestivos y iv) una para el resto de días que tomarán las siguientes expresiones:

Para el estudio de los días pre-festivos:

$$
\mathrm{r}_{\mathrm{t}}=\mathrm{C}+\beta_{2} \mathrm{FES}_{2 \mathrm{t}}+\beta_{3} \mathrm{POS}_{3 \mathrm{t}}+\beta_{4} \mathrm{RD}_{4 \mathrm{t}}+\varepsilon_{\mathrm{t}}
$$

Donde:

$\mathrm{c}=$ Es la rentabilidad media de los días pre-festivos.

$\beta_{i}=$ Es la diferencia entre la rentabilidad de los días pre-festivos y el día i.

Para el estudio de los días festivos:

$$
r_{t}=\beta_{1} P_{1 t}+c+\beta_{3} \mathrm{POS}_{3 \mathrm{t}}+\beta_{4} \mathrm{RD}_{4 \mathrm{t}}+\varepsilon_{\mathrm{t}}
$$

Donde:

$\mathrm{c}=$ Es la rentabilidad media de los días festivos

$\beta_{i}=$ Es la diferencia entre la rentabilidad de los días festivos y el día i

Para el estudio de los días post-festivos:

$$
r_{t}=\beta_{1} P_{1 t}+\beta_{2} \mathrm{FES}_{2 \mathrm{t}}+\mathrm{c}+\beta_{4} \mathrm{RD}_{4 \mathrm{t}}+\varepsilon_{\mathrm{t}}
$$

Donde:

$\mathrm{c}=$ Es la rentabilidad media de los días post-festivos

$\beta_{i}=$ Es la diferencia entre la rentabilidad de los días post-festivos y el día i

Donde de forma general para las tres:

$r_{t}=$ Es la rentabilidad del índice en el período $\mathrm{t}$.

$P R E_{i t}=$ Es las variable dummy estacional para los días pre-festivos.

$F E S_{i t}=$ Es las variable dummy estacional para los días festivos. 
$P O S_{i t}=$ Es las variable dummy estacional para los días post-festivos.

$R D_{i t}=$ Es las variable dummy estacional para el resto de días.

Las variables dummy tomarán los siguientes valores:

$\mathrm{PRE}_{\mathrm{it}} / \mathrm{FES}_{\mathrm{it}} / \mathrm{POS}_{\mathrm{it}} / \mathrm{RES}_{\mathrm{it}}= \begin{cases}1 & \text { Si el rendimiento en el tiempo t corresponde al día } \mathrm{i} \\ 0 & \text { de otra forma }\end{cases}$ $\varepsilon_{t}=$ Es un término de error, idéntica e independientemente distribuido.

La hipótesis nula a ser probada, bajo estos modelos, es que los coeficientes de las variables dummy son iguales a cero. Adicionalmente, valores negativos de los coeficientes dummy deben ser considerados como una prueba de la presencia de los efectos. De esta manera, la estimación de los coeficientes en la ecuación revela qué días tienen rendimientos mayores/menores a los obtenidos en los días pre-festivos, festivos y post-festivos.

Como observamos en los Cuadros 4.67, 4.70 y 4.73 las estimaciones de los modelos econométricos realizadas a través de MCO no son lo suficientemente consistentes para determinar la presencia de los efectos; dado que todas las estimaciones presentan efecto $\mathrm{ARCH}$, por consiguiente, estimaremos las ecuaciones con los modelos GARCH $(1,1) \mathrm{y}$ EGARCH $(1,1)$.

Del análisis de las estimaciones de los modelos para los índices observamos que el único efecto que se produce de forma significativa es el efecto post-festivo para el IGBM. El efecto pre-festivo se manifiesta de forma débil para el Ibex Medium Cap y el Ibex Small Cap en el modelo GARCH $(1,1)$ y para el Ibex 35 y en el Ibex Medium Cap en el EGARCH $(1,1)$, con rentabilidades superiores de los días pre-festivos sobre el resto, pero algunas de las diferencias no son significativas y, por lo tanto, no se puede afirmar claramente la presencia del efecto. El efecto día festivo se presenta de forma débil en el Ibex Small Cap, y de forma inversa débil, es decir, presentando las rentabilidades medias más bajas para el IGBM y el Ibex 35, y para el Ibex Top Dividendo realizando la estimación en el modelo EGARCH $(1,1)$. El efecto post-festivo además de en la estimación del IGBM con el modelo GARCH $(1,1)$, se da de forma parcial con el modelo EGARCH $(1,1)$, pero también de forma parcial para el Ibex-35 con el modelo GARCH $(1,1)$. El Ibex Top Dividendo lo presenta de forma parcial en el EGARCH $(1,1)$, aunque en el GARCH $(1,1)$ la rentabilidad media de los días postfestivos es superior al resto aunque ni ésta, ni la diferencia de rentabilidad con el resto 
son significativas. También observamos un efecto negativo para los días post-festivos para el Ibex Small Cap en ambos modelos, es decir, la rentabilidad media de los días post-festivos es inferior a la del resto, pero de una forma débil, ya que algunas de las diferencias de rentabilidad no son significativas. 
Cuadro 4.67: Resultados para la estimación del efecto vacaciones, para los días pre-festivos, con MCO

Este cuadro muestra los resultados de la estimación de la ecuación: $r_{t}=c+\beta_{2} \mathrm{FES}_{2 \mathrm{t}}+\beta_{3} \mathrm{POS}_{3 \mathrm{t}}+\beta_{4} \mathrm{RD}_{4 \mathrm{t}}+\varepsilon_{\mathrm{t}}$, con MCO, para los cinco índices y para el período muestral total.

\begin{tabular}{cccccc}
\hline & IGBM & Ibex 35 & Ibex Medium Cap & Ibex Small Cap & Ibex Top Dividendo \\
\hline $\mathrm{C}$ & $\mathbf{0 , 0 0 2 0}$ & $\mathbf{0 , 0 0 2 3}$ & $\mathbf{0 , 0 0 2 8}$ & 0,0026 & 0,0009 \\
& {$[\mathbf{0 , 0 3 8 8}]$} & {$[\mathbf{0 , 0 4 9 8}]$} & {$[\mathbf{0 , 0 0 6 6}]$} & {$[0,0584]$} & {$[0,6598]$} \\
$\beta_{2}$ & $-0,0032$ & $-0,0038$ & $-0,0024$ & 0,0006 & $-0,0018$ \\
& {$[0,1412]$} & {$[0,1113]$} & {$[0,2083]$} & {$[0,7763]$} & {$[0,5882]$} \\
$\beta_{3}$ & $-0,0003$ & 0,0001 & $-0,0028$ & $-0,0038$ & 0,0006 \\
& {$[0,8477]$} & {$[0,9478]$} & {$[0,0693]$} & {$[0,0791]$} & {$[0,8453]$} \\
$\beta_{4}$ & $-0,0018$ & $-0,0022$ & $-\mathbf{0 , 0 0 2 7}$ & $-\mathbf{0 , 0 0 3 0}$ & $-0,0011$ \\
& {$[0,0704]$} & {$[0,0685]$} & {$[\mathbf{0 , 0 1 0 4}]$} & {$[\mathbf{0 , 0 3 3 9 ]}$} & {$[0,5893]$} \\
$\mathrm{R}^{2}$ & 0,0008 & 0,0011 & 0,0015 & 0,0034 & 0,0004 \\
$\mathrm{~F}$ & 1,9717 & 2,2309 & 2,2104 & $\mathbf{2 , 9 9 6 3}$ & 0,2843 \\
& {$[0,1159]$} & {$[0,0825]$} & {$[0,0848]$} & {$[\mathbf{0 , 0 2 9 6}]$} & {$[0,8368]$} \\
Observaciones & 7532 & 6067 & 4431 & 2678 & $\mathbf{0 , 0 0 0 0}$ \\
\hline \multicolumn{2}{c}{ Arch (1) } & $\mathbf{0 , 0 0 0 0}$ & $\mathbf{0 , 0 0 0 0}$ & $\mathbf{0 , 0 0 0 0}$ & $\mathbf{0 , 0 0 0 0}$ \\
\hline Nota: los valores entre corchetes son la probabilidad crítica $(p$-values $)$. En negrita, valores significativos para un nivel de significación del $5 \%$.
\end{tabular}


Cuadro 4.68: Resultados para la estimación del efecto vacaciones, para los días prefestivos, con el modelo GARCH $(1,1)$

Este cuadro muestra los resultados de la estimación de la ecuación: $r_{t}=c+\beta_{2} \mathrm{FES}_{2 \mathrm{t}}+\beta_{3} \mathrm{POS}_{3 \mathrm{t}}+\beta_{4} \mathrm{RD} \mathrm{tt}_{\mathrm{t}}+\varepsilon_{\mathrm{t}}$, con el modelo GARCH $(1,1)$, para los cinco índices y para el período muestral total.

\begin{tabular}{|c|c|c|c|c|c|}
\hline & IGBM & Ibex 35 & Ibex Medium Cap & Ibex Small Cap & Ibex Top Dividendo \\
\hline \multirow[t]{2}{*}{$\mathrm{C}$} & 0,0017 & 0,0019 & 0,0025 & 0,0029 & 0,0013 \\
\hline & {$[0,0529]$} & {$[0,0533]$} & {$[0,0013]$} & {$[0,0412]$} & {$[0,5257]$} \\
\hline \multirow[t]{2}{*}{$\beta_{2}$} & $-0,0023$ & $-0,0034$ & $-0,0013$ & $-0,0004$ & $-0,0034$ \\
\hline & {$[0,2660]$} & {$[0,1431]$} & {$[0,3307]$} & {$[0,8253]$} & {$[0,2878]$} \\
\hline \multirow[t]{2}{*}{$\beta_{3}$} & $\mathbf{0 , 0 0 2 4}$ & 0,0006 & $-0,0018$ & $-0,0034$ & 0,0016 \\
\hline & {$[0,0192]$} & {$[0,6566]$} & {$[0,0782]$} & {$[0,0489]$} & {$[0,5324]$} \\
\hline \multirow[t]{2}{*}{$\beta_{4}$} & $-0,0010$ & $-0,0012$ & $-0,0018$ & $-0,0025$ & $-0,0011$ \\
\hline & {$[0,2347]$} & {$[0,2119]$} & {$[0,0204]$} & {$[0,0728]$} & {$[0,6123]$} \\
\hline \multirow[t]{2}{*}{$\mathrm{C}$} & 0,0000 & 0,0000 & 0,0000 & 0,0000 & 0,0000 \\
\hline & {$[0,0000]$} & {$[0,0000]$} & {$[0,0000]$} & {$[0,0000]$} & {$[0,0000]$} \\
\hline \multirow[t]{2}{*}{$\mathrm{ARCH}(1)$} & 0,1243 & 0,0937 & 0,1372 & 0,1645 & 0,0873 \\
\hline & {$[0,0000]$} & {$[0,0000]$} & {$[0,0000]$} & {$[0,0000]$} & {$[0,0000]$} \\
\hline \multirow[t]{2}{*}{ GARCH(1) } & $\mathbf{0 , 8 5 2 3}$ & 0,8942 & 0,8576 & 0,7829 & $\mathbf{0 , 8 9 4 0}$ \\
\hline & {$[0,0000]$} & {$[0,0000]$} & {$[0,0000]$} & {$[0,0000]$} & {$[0,0000]$} \\
\hline Observaciones & 7532 & 6067 & 4431 & 2678 & 2206 \\
\hline
\end{tabular}

Nota: los valores entre corchetes son la probabilidad crítica (p-values). En negrita, valores significativos para un nivel de significación del 5\%. 
Cuadro 4.69: Resultados para la estimación del efecto vacaciones, para los días pre-festivos, con el modelo EGARCH (1,1)

Este cuadro muestra los resultados de la estimación de la ecuación: $r_{t}=c+\beta_{2} \mathrm{FES}_{2 \mathrm{t}}+\beta_{3} \mathrm{POS}_{3 \mathrm{t}}+\beta_{4} \mathrm{RD}_{4 \mathrm{t}}+\varepsilon_{\mathrm{t}}$, con el modelo EGARCH $(1,1)$, para los cinco índices y para el período muestral total.

\begin{tabular}{|c|c|c|c|c|c|}
\hline & IGBM & Ibex 35 & Ibex Medium Cap & Ibex Small Cap & Ibex Top Dividendo \\
\hline \multirow[t]{2}{*}{$\mathrm{C}$} & 0,0035 & 0,0021 & 0,0024 & 0,0025 & 0,0020 \\
\hline & {$[0,0000]$} & {$[0,0194]$} & {$[0,0010]$} & {$[0,0575]$} & {$[0,2859]$} \\
\hline \multirow[t]{2}{*}{$\beta_{2}$} & $-0,0043$ & $-0,0039$ & $-0,0011$ & 0,0003 & $-0,0049$ \\
\hline & {$[0,0222]$} & {$[0,0494]$} & {$[0,3905]$} & {$[0,8984]$} & {$[0,0987]$} \\
\hline \multirow[t]{2}{*}{$\beta_{3}$} & 0,0005 & $-0,0001$ & $-0,0021$ & $-0,0036$ & 0,0009 \\
\hline & {$[0,6041]$} & {$[0,8986]$} & {$[0,0390]$} & {$[0,0333]$} & {$[0,7136]$} \\
\hline \multirow[t]{2}{*}{$\beta_{4}$} & $-0,0031$ & $-0,0018$ & $-0,0020$ & $-0,0022$ & $-0,0023$ \\
\hline & {$[0,0000]$} & {$[0,0512]$} & {$[0,0076]$} & {$[0,0959]$} & {$[0,2297]$} \\
\hline \multirow[t]{2}{*}{$\mathrm{C}$} & $-0,4327$ & $-0,3004$ & $-0,4425$ & $-0,9796$ & $-0,2757$ \\
\hline & {$[0,0000]$} & {$[0,0000]$} & {$[0,0000]$} & {$[0,0000]$} & {$[0,0000]$} \\
\hline \multirow[t]{2}{*}{ |RES|/SQR[GARCH](1) } & 0,1874 & 0,1446 & 0,2149 & 0,2899 & 0,1131 \\
\hline & {$[0,0000]$} & {$[0,0000]$} & {$[0,0000]$} & {$[0,0000]$} & {$[0,0000]$} \\
\hline \multirow[t]{2}{*}{ RES/SQR[GARCH](1) } & $-\mathbf{0 , 0 7 8 5}$ & $-0,0788$ & $-0,0756$ & $-0,0556$ & $-\mathbf{0 , 0 9 3 0}$ \\
\hline & {$[0,0000]$} & {$[0,0000]$} & {$[0,0000]$} & {$[0,0000]$} & {$[0,0000]$} \\
\hline \multirow[t]{2}{*}{ EGARCH(1) } & 0,9674 & $\mathbf{0 , 9 7 8 7}$ & 0,9705 & 0,9169 & 0,9780 \\
\hline & {$[0,0000]$} & {$[0,0000]$} & {$[0,0000]$} & {$[0,0000]$} & {$[0,0000]$} \\
\hline Observaciones & 7532 & 6067 & 4431 & 2678 & 2206 \\
\hline
\end{tabular}

Nota: los valores entre corchetes son la probabilidad crítica ( $p$-values). En negrita, valores significativos para un nivel de significación del 5\%. 
Cuadro 4.70: Resultados para la estimación del efecto vacaciones, para los días festivos, con MCO

Este cuadro muestra los resultados de la estimación de la ecuación: $r_{t}=\beta_{1} \mathrm{PRE}_{1 \mathrm{t}}+c+\beta_{3} \mathrm{POS}_{3 \mathrm{t}}+\beta_{4} \mathrm{RD}_{4 \mathrm{t}}+\varepsilon_{\mathrm{t}}$, con MCO, para los cinco índices y para el período muestral total.

\begin{tabular}{|c|c|c|c|c|c|}
\hline & IGBM & Ibex 35 & Ibex Medium Cap & Ibex Small Cap & Ibex Top Dividendo \\
\hline \multirow[t]{2}{*}{$\beta_{1}$} & 0,0032 & 0,0038 & 0,0024 & $-0,0006$ & 0,0018 \\
\hline & {$[0,1412]$} & {$[0,1113]$} & {$[0,2083]$} & {$[0,7763]$} & {$[0,5882]$} \\
\hline \multirow[t]{2}{*}{$\mathrm{C}$} & $-0,0012$ & $-0,0015$ & 0,0004 & 0,0033 & $-0,0009$ \\
\hline & {$[0,5465]$} & {$[0,4759]$} & {$[0,7923]$} & {$[0,0576]$} & {$[0,7324]$} \\
\hline \multirow[t]{2}{*}{$\beta_{3}$} & 0,0029 & 0,0039 & $-0,0005$ & $-0,0044$ & 0,0024 \\
\hline & {$[0,1816]$} & {$[0,1137]$} & {$[0,8132]$} & {$[0,0637]$} & {$[0,4983]$} \\
\hline \multirow[t]{2}{*}{$\beta_{4}$} & 0,0014 & 0,0016 & $-0,0003$ & $-0,0036$ & 0,0007 \\
\hline & {$[0,4728]$} & {$[0,4375]$} & {$[0,8533]$} & {$[\mathbf{0 , 0 3 6 7 ]}$} & {$[0,7986]$} \\
\hline $\mathrm{R}^{2}$ & 0,0008 & 0,0011 & 0,0015 & 0,0034 & 0,0004 \\
\hline \multirow[t]{2}{*}{$\mathrm{F}$} & 1,9717 & 2,2309 & 2,2104 & 2,9963 & 0,2843 \\
\hline & {$[0,1159]$} & {$[0,0825]$} & {$[0,0848]$} & {$[0,0296]$} & {$[0,8368]$} \\
\hline Observaciones & 7532 & 6067 & 4431 & 2678 & 2206 \\
\hline $\operatorname{Arch}(1)$ & 0,0000 & 0,0000 & 0,0000 & 0,0000 & 0,0000 \\
\hline
\end{tabular}


Cuadro 4.71: Resultados para la estimación del efecto vacaciones, para los días festivos, con el modelo GARCH $(1,1)$

Este cuadro muestra los resultados de la estimación de la ecuación: $r_{t}=\beta_{1} P_{1 t}+c+\beta_{3} \mathrm{POS}_{3 \mathrm{t}}+\beta_{4} \mathrm{RD}_{4 \mathrm{t}}+\varepsilon_{\mathrm{t}}$, con el modelo GARCH $(1,1)$, para los cinco índices y para el período muestral total.

\begin{tabular}{|c|c|c|c|c|c|}
\hline & IGBM & Ibex 35 & Ibex Medium Cap & Ibex Small Cap & Ibex Top Dividendo \\
\hline \multirow[t]{2}{*}{$\overline{\beta_{1}}$} & 0,0023 & 0,0034 & 0,0013 & 0,0004 & 0,0034 \\
\hline & {$[0,2723]$} & {$[0,1449]$} & {$[0,3317]$} & {$[0,8252]$} & {$[0,2878]$} \\
\hline \multirow[t]{2}{*}{$\mathrm{C}$} & $-0,0006$ & $-0,0015$ & 0,0012 & 0,0024 & $-0,0021$ \\
\hline & {$[0,7388]$} & {$[0,4822]$} & {$[0,2799]$} & {$[0,1385]$} & {$[0,3991]$} \\
\hline \multirow[t]{2}{*}{$\beta_{3}$} & $\mathbf{0 , 0 0 4 7}$ & 0,0039 & $-0,0005$ & $-0,0030$ & 0,0050 \\
\hline & {$[0,0162]$} & {$[0,0737]$} & {$[0,7026]$} & {$[0,1134]$} & {$[0,0774]$} \\
\hline \multirow[t]{2}{*}{$\beta_{4}$} & 0,0013 & 0,0021 & $-0,0005$ & $-0,0021$ & 0,0024 \\
\hline & {$[0,5069]$} & {$[0,3096]$} & {$[0,6312]$} & {$[0,2010]$} & {$[0,3480]$} \\
\hline \multirow[t]{2}{*}{$\bar{C}$} & 0,0000 & 0,0000 & 0,0000 & 0,0000 & 0,0000 \\
\hline & {$[0,0000]$} & {$[0,0000]$} & {$[0,0000]$} & {$[0,0000]$} & {$[0,0000]$} \\
\hline \multirow[t]{2}{*}{$\mathrm{ARCH}(1)$} & 0,1243 & $\mathbf{0 , 0 9 3 7}$ & 0,1372 & 0,1645 & 0,0873 \\
\hline & {$[0,0000]$} & {$[0,0000]$} & {$[0,0000]$} & {$[0,0000]$} & {$[0,0000]$} \\
\hline \multirow[t]{2}{*}{ GARCH(1) } & $\mathbf{0 , 8 5 2 1}$ & 0,8942 & 0,8576 & 0,7829 & $\mathbf{0 , 8 9 4 0}$ \\
\hline & {$[0,0000]$} & {$[0,0000]$} & {$[0,0000]$} & {$[0,0000]$} & {$[0,0000]$} \\
\hline Observaciones & 7532 & 6067 & 4431 & 2678 & 2206 \\
\hline
\end{tabular}

Nota: los valores entre corchetes son la probabilidad crítica (p-values). En negrita, valores significativos para un nivel de significación del 5\%. 
Cuadro 4.72: Resultados para la estimación del efecto vacaciones, para los días festivos, con el modelo EGARCH $(1,1)$

Este cuadro muestra los resultados de la estimación de la ecuación: $\mathrm{r}_{\mathrm{t}}=\beta_{1} \mathrm{PRE}_{1 \mathrm{t}}+c+\beta_{3} \mathrm{POS}_{3 \mathrm{t}}+\beta_{4} \mathrm{RD}_{4 \mathrm{t}}+\varepsilon_{\mathrm{t}}$, con el modelo EGARCH $(1,1)$, para los cinco índices y para el período muestral total.

\begin{tabular}{|c|c|c|c|c|c|}
\hline & IGBM & Ibex 35 & Ibex Medium Cap & Ibex Small Cap & Ibex Top Dividendo \\
\hline \multirow[t]{2}{*}{$\beta_{1}$} & $\mathbf{0 , 0 0 4 3}$ & 0,0039 & 0,0011 & $-0,0003$ & 0,0045 \\
\hline & {$[0,0232]$} & {$[0,0507]$} & {$[0,3899]$} & {$[0,8988]$} & {$[0,1269]$} \\
\hline \multirow[t]{2}{*}{$\mathrm{C}$} & $-0,0008$ & $-0,0018$ & 0,0013 & 0,0027 & $-0,0028$ \\
\hline & {$[0,6350]$} & {$[0,3065]$} & {$[0,1997]$} & {$[0,0908]$} & {$[0,2105]$} \\
\hline \multirow[t]{2}{*}{$\beta_{3}$} & 0,0048 & $\mathbf{0 , 0 0 3 8}$ & $-0,0011$ & $-0,0038$ & $\mathbf{0 , 0 0 5 9}$ \\
\hline & {$[\mathbf{0 , 0 0 7 7 ]}$} & {$[0,0470]$} & {$[0,3683]$} & {$[0,0317]$} & {$[0,0195]$} \\
\hline \multirow[t]{2}{*}{$\beta_{4}$} & 0,0012 & 0,0021 & $-0,0009$ & $-0,0024$ & 0,0026 \\
\hline & {$[0,4834]$} & {$[0,2306]$} & {$[0,3887]$} & {$[0,1302]$} & {$[0,2459]$} \\
\hline \multirow[t]{2}{*}{$\mathrm{C}$} & $-\mathbf{0 , 4 3 7 7}$ & $-0,2998$ & $-0,4423$ & $-0,9796$ & $-0,2737$ \\
\hline & {$[0,0000]$} & {$[0,0000]$} & {$[0,0000]$} & {$[0,0000]$} & {$[0,0000]$} \\
\hline \multirow[t]{2}{*}{ |RES|/SQR[GARCH](1) } & 0,1898 & 0,1445 & 0,2148 & 0,2899 & $\mathbf{0 , 1 1 3 7}$ \\
\hline & {$[0,0000]$} & {$[0,0000]$} & {$[0,0000]$} & {$[0,0000]$} & {$[0,0000]$} \\
\hline \multirow[t]{2}{*}{ RES/SQR[GARCH](1) } & $-0,0791$ & $-\mathbf{0 , 0 7 8 7}$ & $-\mathbf{0 , 0 7 5 5}$ & $-0,0556$ & $-0,0926$ \\
\hline & {$[0,0000]$} & {$[0,0000]$} & {$[0,0000]$} & {$[0,0000]$} & {$[0,0000]$} \\
\hline \multirow[t]{2}{*}{ EGARCH(1) } & 0,9670 & 0,9787 & 0,9705 & 0,9169 & 0,9785 \\
\hline & {$[0,0000]$} & {$[0,0000]$} & {$[0,0000]$} & {$[0,0000]$} & {$[0,0000]$} \\
\hline Observaciones & 7532 & 6067 & 4431 & 2678 & 2206 \\
\hline
\end{tabular}

Nota: los valores entre corchetes son la probabilidad crítica ( $p$-values). En negrita, valores significativos para un nivel de significación del 5\%. 
Cuadro 4.73: Resultados para la estimación del efecto vacaciones, para los días post-festivos, con MCO

Este cuadro muestra los resultados de la estimación de la ecuación: $r_{t}=\beta_{1} \mathrm{PRE}_{1 \mathrm{t}}+\beta_{2} \mathrm{FES}_{2 \mathrm{t}}+\mathrm{c}+\beta_{4} \mathrm{RD}_{4 \mathrm{t}}+\varepsilon_{\mathrm{t}}$, con MCO, para los cinco índices y para el período muestral total.

\begin{tabular}{|c|c|c|c|c|c|}
\hline & IGBM & Ibex 35 & Ibex Medium Cap & Ibex Small Cap & Ibex Top Dividendo \\
\hline \multirow[t]{2}{*}{$\beta_{1}$} & 0,0003 & $-0,0001$ & 0,0028 & 0,0038 & $-0,0006$ \\
\hline & {$[0,8477]$} & {$[0,9478]$} & {$[0,0693]$} & {$[0,0791]$} & {$[0,8453]$} \\
\hline \multirow[t]{2}{*}{$\beta_{2}$} & $-0,0029$ & $-0,0039$ & 0,0005 & 0,0044 & $-0,0024$ \\
\hline & {$[0,1816]$} & {$[0,1137]$} & {$[0,8132]$} & {$[0,0637]$} & {$[0,4983]$} \\
\hline \multirow[t]{2}{*}{$\mathrm{C}$} & 0,0018 & 0,0024 & 0,0000 & $-0,0011$ & 0,0015 \\
\hline & {$[0,0847]$} & {$[0,0720]$} & {$[0,9665]$} & {$[0,4928]$} & {$[0,5327]$} \\
\hline \multirow[t]{2}{*}{$\beta_{4}$} & $-0,0015$ & $-0,0023$ & 0,0002 & 0,0007 & $-0,0017$ \\
\hline & {$[0,1384]$} & {$[0,0928]$} & {$[0,8851]$} & {$[0,6465]$} & {$[0,4796]$} \\
\hline $\mathrm{R}^{2}$ & 0,0008 & 0,0011 & 0,0015 & 0,0034 & 0,0004 \\
\hline \multirow[t]{2}{*}{$\mathrm{F}$} & 1,9717 & 2,2309 & 2,2104 & 2,9963 & 0,2843 \\
\hline & {$[0,1159]$} & {$[0,0825]$} & {$[0,0848]$} & {$[0,0296]$} & {$[0,8368]$} \\
\hline Observaciones & 7532 & 6067 & 4431 & 2678 & 2206 \\
\hline $\operatorname{Arch}(1)$ & 0,0000 & 0,0000 & 0,0000 & 0,0000 & 0,0000 \\
\hline
\end{tabular}


Cuadro 4.74: Resultados para la estimación del efecto vacaciones, para los días post-festivos, con el modelo GARCH (1,1)

Este cuadro muestra los resultados de la estimación de la ecuación: $r_{t}=\beta_{1} \mathrm{PRE}_{1 \mathrm{t}}+\beta_{2} \mathrm{FES}_{2 \mathrm{t}}+\mathrm{c}+\beta_{4} \mathrm{RD}_{4 \mathrm{t}}+\varepsilon_{\mathrm{t}}$, con el modelo GARCH $(1,1)$, para los cinco índices y para el período muestral total.

\begin{tabular}{|c|c|c|c|c|c|}
\hline & IGBM & Ibex 35 & Ibex Medium Cap & Ibex Small Cap & Ibex Top Dividendo \\
\hline \multirow[t]{2}{*}{$\beta_{1}$} & $-0,0024$ & $-0,0006$ & 0,0018 & 0,0034 & $-0,0016$ \\
\hline & {$[0,0191]$} & {$[0,6565]$} & {$[0,0782]$} & {$[0,0490]$} & {$[0,5344]$} \\
\hline \multirow[t]{2}{*}{$\beta_{2}$} & $-\mathbf{0 , 0 0 4 7}$ & $-0,0039$ & 0,0005 & 0,0030 & $-0,0050$ \\
\hline & {$[0,0159]$} & {$[0,0726]$} & {$[0,7042]$} & {$[0,1136]$} & {$[0,0773]$} \\
\hline \multirow[t]{2}{*}{$\mathrm{C}$} & 0,0040 & 0,0025 & 0,0007 & $-0,0006$ & 0,0029 \\
\hline & {$[0,0000]$} & {$[0,0019]$} & {$[0,2519]$} & {$[0,5949]$} & {$[0,0502]$} \\
\hline \multirow[t]{2}{*}{$\beta_{4}$} & $-0,0034$ & $-0,0018$ & $-0,0001$ & 0,0009 & $-0,0027$ \\
\hline & {$[0,0000]$} & {$[0,0246]$} & {$[0,9225]$} & {$[0,4145]$} & {$[0,0810]$} \\
\hline \multirow[t]{2}{*}{$\mathrm{C}$} & 0,0000 & 0,0000 & 0,0000 & 0,0000 & 0,0000 \\
\hline & {$[0,0000]$} & {$[0,0000]$} & {$[0,0000]$} & {$[0,0000]$} & {$[0,0000]$} \\
\hline \multirow[t]{2}{*}{$\mathrm{ARCH}(1)$} & 0,1243 & 0,0937 & 0,1372 & 0,1645 & 0,0873 \\
\hline & {$[0,0000]$} & {$[0,0000]$} & {$[0,0000]$} & {$[0,0000]$} & {$[0,0000]$} \\
\hline \multirow[t]{2}{*}{ GARCH(1) } & $\mathbf{0 , 8 5 2 2}$ & 0,8942 & 0,8576 & 0,7829 & $\mathbf{0 , 8 9 4 0}$ \\
\hline & {$[0,0000]$} & {$[0,0000]$} & {$[0,0000]$} & {$[0,0000]$} & {$[0,0000]$} \\
\hline Observaciones & 7532 & 6067 & 4431 & 2678 & 2206 \\
\hline
\end{tabular}

Nota: los valores entre corchetes son la probabilidad crítica (p-values). En negrita, valores significativos para un nivel de significación del 5\%. 
Cuadro 4.75: Resultados para la estimación del efecto vacaciones, para los días post-festivos, con el modelo EGARCH (1,1)

Este cuadro muestra los resultados de la estimación de la ecuación: $r_{t}=\beta_{1} P_{12}+\beta_{2} \mathrm{FES}_{2 \mathrm{t}}+\mathrm{c}+\beta_{4} \mathrm{RD}_{4 \mathrm{t}}+\varepsilon_{\mathrm{t}}$, con el modelo EGARCH $(1,1)$, para los cinco índices y para el período muestral total.

\begin{tabular}{|c|c|c|c|c|c|}
\hline & IGBM & Ibex 35 & Ibex Medium Cap & Ibex Small Cap & Ibex Top Dividendo \\
\hline \multirow[t]{2}{*}{$\beta_{1}$} & $-0,0005$ & 0,0001 & 0,0021 & 0,0036 & $-0,0014$ \\
\hline & {$[0,5895]$} & {$[0,8988]$} & {$[0,0388]$} & {$[\mathbf{0 , 0 3 3 3 ]}$} & {$[0,5663]$} \\
\hline \multirow[t]{2}{*}{$\beta_{2}$} & $-0,0047$ & $-0,0038$ & 0,0011 & 0,0038 & $-0,0059$ \\
\hline & {$[0,0087]$} & {$[0,0452]$} & {$[0,3665]$} & {$[0,0318]$} & {$[0,0192]$} \\
\hline \multirow[t]{2}{*}{$\mathrm{C}$} & 0,0039 & 0,0019 & 0,0003 & $-0,0011$ & 0,0031 \\
\hline & {$[0,0000]$} & {$[0,0083]$} & {$[0,7017]$} & {$[0,2868]$} & {$[0,0164]$} \\
\hline \multirow[t]{2}{*}{$\beta_{4}$} & $-0,0035$ & $-0,0016$ & 0,0002 & 0,0014 & $-0,0033$ \\
\hline & {$[0,0000]$} & {$[0,0292]$} & {$[0,7979]$} & {$[0,2022]$} & {$[0,0129]$} \\
\hline \multirow[t]{2}{*}{$\mathrm{C}$} & $-0,4268$ & $-0,3002$ & $-0,4418$ & $-0,9800$ & $-0,2727$ \\
\hline & {$[0,0000]$} & {$[0,0000]$} & {$[0,0000]$} & {$[0,0000]$} & {$[0,0000]$} \\
\hline \multirow[t]{2}{*}{ |RES|/SQR[GARCH](1) } & $\mathbf{0 , 1 8 7 0}$ & 0,1446 & 0,2147 & $\mathbf{0 , 2 8 9 7}$ & 0,1135 \\
\hline & {$[0,0000]$} & {$[0,0000]$} & {$[0,0000]$} & {$[0,0000]$} & {$[0,0000]$} \\
\hline \multirow[t]{2}{*}{ RES/SQR[GARCH](1) } & $-0,0778$ & $-0,0788$ & $-0,0755$ & $-0,0558$ & $-0,0925$ \\
\hline & {$[0,0000]$} & {$[0,0000]$} & {$[0,0000]$} & {$[0,0000]$} & {$[0,0000]$} \\
\hline \multirow[t]{2}{*}{ EGARCH(1) } & 0,9680 & $\mathbf{0 , 9 7 8 7}$ & 0,9705 & 0,9168 & 0,9785 \\
\hline & {$[0,0000]$} & {$[0,0000]$} & {$[0,0000]$} & {$[0,0000]$} & {$[0,0000]$} \\
\hline Observaciones & 7532 & 6067 & 4431 & 2678 & 2206 \\
\hline
\end{tabular}

Nota: los valores entre corchetes son la probabilidad crítica ( $p$-values). En negrita, valores significativos para un nivel de significación del 5\%. 


\subsubsection{Análisis robustez subperíodos muestrales}

\section{Cuadro 4.76: Estadísticos descriptivos del IGBM, para el efecto vacaciones, en diferentes subperíodos muestrales}

Este cuadro muestra los principales estadísticos descriptivos de las rentabilidades medías de los días prefestivos, festivos, post-festivos y del resto de días del IGBM durante los subperíodos muestrales de 1986 a 1997, de 1998 a 2007 y de 2008 a 2015.

\begin{tabular}{|c|c|c|c|c|}
\hline Subperíodo 1986-1997 & Días pre-festivos & Días festivos & Días post-festivos & Resto de días \\
\hline Media & 0,0024 & 0,0005 & 0,0005 & 0,0006 \\
\hline Mediana & 0,0014 & $-0,0001$ & 0,0004 & 0,0001 \\
\hline Desviación estándar & 0,0093 & 0,0011 & 0,0145 & 0,0119 \\
\hline Varianza de la muestra & 0,0001 & 0,0000 & 0,0002 & 0,0001 \\
\hline Curtosis & 3,5898 & - & 1,5184 & 19,8439 \\
\hline Coeficiente de asimetría & 0,8182 & 1,7137 & $-0,8469$ & $-0,1110$ \\
\hline Rango & 0,0665 & 0,0020 & 0,0717 & 0,2870 \\
\hline Mínimo & $-0,0269$ & $-0,0002$ & $-0,0462$ & $-0,1341$ \\
\hline Máximo & 0,0396 & 0,0018 & 0,0255 & 0,1529 \\
\hline Observaciones & 84 & 3 & 77 & 2811 \\
\hline$\%$ Observaciones positivas & $57,14 \%$ & $33,33 \%$ & $51,95 \%$ & $50,37 \%$ \\
\hline Subperíodo 1998-2007 & Días pre-festivos & Días festivos & Días post-festivos & Resto de días \\
\hline Media & 0,0050 & 0,0002 & 0,0025 & 0,0003 \\
\hline Mediana & 0,0042 & 0,0003 & 0,0013 & 0,0010 \\
\hline Desviación estándar & 0,0120 & 0,0052 & 0,0143 & 0,0123 \\
\hline Varianza de la muestra & 0,0001 & 0,0000 & 0,0002 & 0,0002 \\
\hline Curtosis & 1,2712 & 0,0607 & 0,8944 & 2,6244 \\
\hline Coeficiente de asimetría & 0,0251 & 0,4504 & 0,2227 & $-0,2119$ \\
\hline Rango & 0,0640 & 0,0179 & 0,0739 & 0,1239 \\
\hline Mínimo & $-0,0262$ & $-0,0077$ & $-0,0366$ & $-0,0650$ \\
\hline Máximo & 0,0378 & 0,0102 & 0,0374 & 0,0589 \\
\hline Observaciones & 62 & 17 & 61 & 2374 \\
\hline$\%$ Observaciones positivas & $74,19 \%$ & $52,94 \%$ & $55,74 \%$ & $53,96 \%$ \\
\hline Subperíodo 2008-2015 & Días pre-festivos & Días festivos & Días post-festivos & Resto de días \\
\hline Media & $-0,0020$ & $-0,0020$ & 0,0034 & $-0,0001$ \\
\hline Mediana & 0,0000 & $-0,0051$ & 0,0022 & 0,0004 \\
\hline Desviación estándar & 0,0161 & 0,0173 & 0,0171 & 0,0172 \\
\hline Varianza de la muestra & 0,0003 & 0,0003 & 0,0003 & 0,0003 \\
\hline Curtosis & 7,7872 & 6,2439 & $-0,3717$ & 6,2139 \\
\hline Coeficiente de asimetría & $-1,8171$ & 1,4377 & 0,0150 & 0,4371 \\
\hline Rango & 0,1105 & 0,1038 & 0,0692 & 0,2395 \\
\hline Mínimo & $-0,0732$ & $-0,0416$ & $-0,0312$ & $-0,0923$ \\
\hline Máximo & 0,0374 & 0,0622 & 0,0380 & 0,1473 \\
\hline Observaciones & 49 & 30 & 43 & 1921 \\
\hline$\%$ Observaciones positivas & $46,94 \%$ & $46,67 \%$ & $55,81 \%$ & $51,22 \%$ \\
\hline
\end{tabular}


Cuadro 4.77: Estadísticos descriptivos del Ibex 35, para el efecto vacaciones, en diferentes subperíodos muestrales

Este cuadro muestra los principales estadísticos descriptivos de las rentabilidades medías de los días prefestivos, festivos, post-festivos y del resto de días del Ibex 35 durante los subperíodos muestrales de 1992 a 2007 y de 2008 a 2015.

\begin{tabular}{|c|c|c|c|c|}
\hline Subperíodo 1992-2007 & Días pre-festivos & Días festivos & Días post-festivos & Resto de días \\
\hline Media & 0,0036 & $-0,0003$ & 0,0028 & 0,0004 \\
\hline Mediana & 0,0035 & $-0,0002$ & 0,0030 & 0,0007 \\
\hline Desviación estándar & 0,0125 & 0,0056 & 0,0155 & 0,0127 \\
\hline Varianza de la muestra & 0,0002 & 0,0000 & 0,0002 & 0,0002 \\
\hline Curtosis & 1,5945 & 0,3275 & 0,7959 & 2,8337 \\
\hline Coeficiente de asimetría & 0,1244 & 0,6634 & 0,1638 & $-0,1315$ \\
\hline Rango & 0,0739 & 0,0192 & 0,0826 & 0,1360 \\
\hline Mínimo & $-0,0307$ & $-0,0082$ & $-0,0372$ & $-0,0708$ \\
\hline Máximo & 0,0432 & 0,0110 & 0,0453 & 0,0653 \\
\hline Observaciones & 97 & 18 & 78 & 3831 \\
\hline$\%$ Observaciones positivas & $65,98 \%$ & $33,33 \%$ & $57,69 \%$ & $53,48 \%$ \\
\hline Subperíodo 2008-2015 & Días pre-festivos & Días festivos & Días post-festivos & Resto de días \\
\hline Media & 0,0000 & $-0,0020$ & 0,0019 & $-0,0001$ \\
\hline Mediana & 0,0005 & $-0,0049$ & $-0,0004$ & 0,0005 \\
\hline Desviación estándar & 0,0124 & 0,0175 & 0,0173 & 0,0171 \\
\hline Varianza de la muestra & 0,0002 & 0,0003 & 0,0003 & 0,0003 \\
\hline Curtosis & 1,9182 & 6,7907 & $-0,1940$ & 5,7620 \\
\hline Coeficiente de asimetría & $-0,3283$ & 1,5482 & 0,3651 & 0,3248 \\
\hline Rango & 0,0702 & 0,1061 & 0,0723 & 0,2358 \\
\hline Mínimo & $-0,0345$ & $-0,0419$ & $-0,0318$ & $-0,0914$ \\
\hline Máximo & 0,0357 & 0,0642 & 0,0405 & 0,1443 \\
\hline Observaciones & 50 & 30 & 34 & 1929 \\
\hline$\%$ Observaciones positivas & $54,00 \%$ & $46,67 \%$ & $47,06 \%$ & $51,27 \%$ \\
\hline
\end{tabular}

En el Cuadro 4.76, de entre los tres subperíodos muestrales analizados para el IGBM, en el primer y segundo subperíodos únicamente se presenta el efecto pre-festivo, ya que las rentabilidades medias de los días festivos y post-festivos, son inferiores a la del resto de días. En el tercer subperíodo (2008-2015) se confirma el caso contrario, pues únicamente se observa el efecto post-festivo, y las rentabilidades de los días pre-festivos y festivos son inferiores a la del resto de días. En el Cuadro 4.77 correspondiente al Ibex 35 obtenemos el mismo resultado para ambos períodos, pero con unas rentabilidades muy inferiores en el subperíodo de crisis, se identifican los efectos pre-festivo y festivo, pero no el efecto festivo, ya que los días festivos presentan una rentabilidad media inferior al resto de días. 
Cuadro 4.78: Contraste de significatividad de medias para el efecto vacaciones

Este cuadro muestra el contraste de significatividad entre las rentabilidades medias de los días pre-festivos, festivos, post-festivos y resto de días para el IGBM y para el Ibex 35 en diferentes subperíodos muestrales.

\begin{tabular}{|c|c|c|c|c|c|}
\hline & IGBM & IGBM & IGBM & Ibex 35 & Ibex 35 \\
\hline & Subperíodo 1986-1997 & Subperíodo 1998-2007 & Subperíodo 2008-2015 & Subperíodo 1992-2007 & Subperíodo 2008-2015 \\
\hline \multirow[t]{2}{*}{ Días pre-festivos } & 0,0024 & $\mathbf{0 , 0 0 5 0}$ & $-0,0020$ & $\mathbf{0 , 0 0 3 6}$ & 0,0000 \\
\hline & {$[0,0211]$} & {$[0,0018]$} & {$[0,3767]$} & {$[0,0053]$} & {$[0,9944]$} \\
\hline \multirow[t]{2}{*}{ Festivos, post y resto } & 0,0006 & 0,0003 & $-0,0001$ & 0,0005 & $-0,0001$ \\
\hline & {$[0,0041]$} & {$[0,1705]$} & {$[0,8630]$} & {$[0,0261]$} & {$[0,8247]$} \\
\hline \multirow[t]{3}{*}{ Diferencia } & 0,0018 & 0,0046 & $-0,0020$ & 0,0032 & 0,0001 \\
\hline & {$[0,0964]$} & {$[0,0038]$} & {$[0,3985]$} & {$[0,0153]$} & {$[0,9571]$} \\
\hline & Subperíodo 1986-1997 & Subperíodo 1998-2007 & Subperíodo 2008-2015 & Subperíodo 1992-2007 & Subperíodo 2008-2015 \\
\hline \multirow{2}{*}{ Días festivos } & 0,0005 & 0,0002 & $-0,0020$ & $-0,0003$ & $-0,0020$ \\
\hline & {$[0,5206]$} & {$[0,8674]$} & {$[0,5389]$} & {$[0,8231]$} & {$[0,5326]$} \\
\hline \multirow[t]{2}{*}{ Pre, post y resto } & $\mathbf{0 , 0 0 0 7}$ & 0,0005 & $-0,0001$ & 0,0005 & $-0,0001$ \\
\hline & {$[0,0016]$} & {$[0,0648]$} & {$[0,8213]$} & {$[0,0083]$} & {$[0,8874]$} \\
\hline \multirow[t]{3}{*}{ Diferencia } & $-0,0002$ & $-0,0002$ & $-0,0019$ & $-0,0008$ & $-0,0020$ \\
\hline & {$[0,8091]$} & {$[0,8539]$} & {$[0,5595]$} & {$[0,5397]$} & {$[0,5461]$} \\
\hline & Subperíodo 1986-1997 & Subperíodo 1998-2007 & Subperíodo 2008-2015 & Subperíodo 1992-2007 & Subperíodo 2008-2015 \\
\hline \multirow[t]{2}{*}{ Días post-festivos } & 0,0005 & 0,0025 & 0,0034 & 0,0028 & 0,0019 \\
\hline & {$[0,7549]$} & {$[0,1803]$} & {$[0,1981]$} & {$[0,1098]$} & {$[0,5199]$} \\
\hline \multirow[t]{2}{*}{ Pre, festivos y resto } & $\mathbf{0 , 0 0 0 7}$ & 0,0004 & $-0,0002$ & 0,0005 & $-0,0001$ \\
\hline & {$[0,0016]$} & {$[0,1022]$} & {$[0,6206]$} & {$[0,0167]$} & {$[0,7586]$} \\
\hline \multirow[t]{3}{*}{ Diferencia } & $-0,0002$ & 0,0021 & 0,0036 & 0,0024 & 0,0020 \\
\hline & {$[0,9140]$} & {$[0,2656]$} & {$[0,1790]$} & {$[0,1861]$} & {$[0,4985]$} \\
\hline & Subperíodo 1986-1997 & Subperíodo 1998-2007 & Subperíodo 2008-2015 & Subperíodo 1992-2007 & Subperíodo 2008-2015 \\
\hline \multirow[t]{2}{*}{ Diferencia pre-post } & $\begin{array}{c}0,0019 \\
{[03342]}\end{array}$ & $\begin{array}{c}0,0025 \\
002943]\end{array}$ & $\begin{array}{l}-0,0055 \\
{[01198]}\end{array}$ & $\begin{array}{c}0,0008 \\
07163]\end{array}$ & $-0,0019$ \\
\hline & {$[0,3342]$} & {$[0,2943]$} & {$[0,1198]$} & {$[0,7163]$} & {$[0,5803]$} \\
\hline
\end{tabular}

Nota: los valores entre corchetes son la probabilidad crítica ( $p$-values). En negrita, valores significativos para un nivel de significación del 5\%. 
En el Cuadro 4.78 que refleja el contraste de significatividad de medias para el efecto vacaciones, observamos que el único efecto que es significativo para ambos índices es el efecto pre-festivo, que se reporta en el IGBM de forma débil en el subperíodo 19861987, se atribuye en el subperíodo 1998-2007 de forma significativa, y desaparece en el tercer subperíodo (2008-2015), el asociado con etapa de crisis. Para el Ibex 35 se da de forma significativa en el subperíodo 1992-2007, pero desaparece también en el período 2008-2015 como en el IGBM.

Como ocurría en el período muestral total las estimaciones de los modelos econométricos realizadas a través de MCO no son lo suficientemente consistentes para determinar la presencia de los efectos, según Cuadros 4.79, 4.82 y 4.85, por lo tanto, se estimarán las ecuaciones con los modelos GARCH $(1,1)$ y EGARCH $(1,1)$.

El efecto día pre-festivo se daría de forma débil en el subperíodo 1998-2007 para el IGBM, y en el subperíodo 1992-2007 para el Ibex 35, desapareciendo en ambos índices en el subperíodo 2008-2015. Se daría un efecto día festivo débil, pero inverso, es decir los días festivos presentarían unas rentabilidades inferiores al resto media al resto, para el subperíodo de crisis 2008-2015, tanto para el IGBM como para el Ibex 35. Los postfestivos presentarían unas rentabilidades significativamente positivas para casi todos los subperíodos, dándose el efecto de forma significativa para el subperíodo 2008-2015 del IGBM, y débil para el subperíodo 1986-1997 del IGBM y para el subperíodo 20082015 del Ibex 35. 
Cuadro 4.79: Resultados para la estimación del efecto vacaciones, para los días pre-festivos, con MCO, para diferentes subperíodos muestrales

Este cuadro muestra los resultados de la estimación de la ecuación: $r_{t}=c+\beta_{2} \mathrm{FES}_{2 t}+\beta_{3} \mathrm{POS}_{3 \mathrm{t}}+\beta_{4} \mathrm{RD}_{4 \mathrm{t}}+\varepsilon_{\mathrm{t}}$, con MCO, para el IGBM y el Ibex 35, en diferentes subperíodos muestrales.

\begin{tabular}{cccccc} 
& IGBM & IGBM & IGBM & Ibex 35 & Ibex 35 \\
\hline & $\mathbf{1 9 8 6 - 1 9 9 7}$ & $\mathbf{1 9 9 8 - 2 0 0 7}$ & $\mathbf{2 0 0 8 - 2 0 1 5}$ & $\mathbf{1 9 9 2 - 2 0 0 7}$ & $\mathbf{2 0 0 8 - 2 0 1 5}$ \\
\hline $\mathrm{C}$ & 0,0023 & $\mathbf{0 , 0 0 4 9}$ & $-0,0022$ & $\mathbf{0 , 0 0 3 5}$ & $-0,0001$ \\
& {$[0,0722]$} & {$[\mathbf{0 , 0 0 1 8}]$} & {$[0,3724]$} & {$[\mathbf{0 , 0 0 6 2}]$} & {$[0,9789]$} \\
$\beta_{2}$ & $-0,0018$ & $-0,0047$ & 0,0001 & $-0,0039$ & $-0,0021$ \\
& {$[0,7929]$} & {$[0,1641]$} & {$[0,9854]$} & {$[0,2381]$} & {$[0,5919]$} \\
$\beta_{3}$ & $-0,0019$ & $-0,0025$ & 0,0054 & $-0,0008$ & 0,0019 \\
& {$[0,3052]$} & {$[0,2560]$} & {$[0,1277]$} & {$[0,6695]$} & {$[0,6246]$} \\
$\beta_{4}$ & $-0,0018$ & $\mathbf{- 0 , 0 0 4 7}$ & 0,0019 & $\mathbf{- 0 , 0 0 3 2}$ & $-0,0002$ \\
& {$[0,1807]$} & {$[\mathbf{0 , 0 0 3 1 ]}$} & {$[0,4381]$} & {$[\mathbf{0 , 0 1 4 1 ]}$} & {$[0,9434]$} \\
$\mathrm{R}^{2}$ & 0,0006 & 0,0041 & 0,0014 & 0,0021 & 0,0004 \\
$\mathrm{~F}$ & 0,6057 & $\mathbf{3 , 4 5 8 6}$ & 0,9319 & $\mathbf{2 , 8 7 2 8}$ & 0,2911 \\
& {$[0,6113]$} & {$[\mathbf{0 , 0 1 5 8}]$} & {$[0,4244]$} & $\mathbf{0 , 0 3 4 9 ]}$ & {$[0,8319]$} \\
Observaciones & 2975 & 2514 & $\mathbf{0 , 0 0 0 0}$ & $\mathbf{0 , 0 2 4}$ & 2043 \\
\hline Arch $(1)$ & $\mathbf{0 , 0 0 0 0}$ & $\mathbf{0 , 0 0 0 0}$ & $\mathbf{0 , 0 0 0}$ & $\mathbf{0 , 0 0 0 0}$ \\
\hline
\end{tabular}

Nota: los valores entre corchetes son la probabilidad crítica (p-values). En negrita, valores significativos para un nivel de significación del 5\%. 
Cuadro 4.80: Resultados para la estimación del efecto vacaciones, para los días prefestivos, con el modelo GARCH (1,1), para diferentes subperíodos muestrales

Este cuadro muestra los resultados de la estimación de la ecuación: $r_{t}=c+\beta_{2} \mathrm{FES}_{2 \mathrm{t}}+\beta_{3} \mathrm{POS}_{3 \mathrm{t}}+\beta_{4} \mathrm{RD}_{4 \mathrm{t}}+\varepsilon_{\mathrm{t}}$, con el modelo GARCH $(1,1)$, para el IGBM y el Ibex 35, en diferentes subperíodos muestrales.

\begin{tabular}{|c|c|c|c|c|c|}
\hline & IGBM & IGBM & IGBM & Ibex 35 & Ibex 35 \\
\hline & 1986-1997 & 1998-2007 & 2008-2015 & 1992-2007 & 2008-2015 \\
\hline \multirow[t]{2}{*}{$\mathrm{C}$} & 0,0007 & $\mathbf{0 , 0 0 3 1}$ & $-0,0013$ & 0,0024 & 0,0001 \\
\hline & {$[0,5780]$} & {$[0,0092]$} & {$[0,5677]$} & {$[0,0223]$} & {$[0,9776]$} \\
\hline \multirow[t]{2}{*}{$\beta_{2}$} & 0,0007 & $-0,0025$ & $-0,0021$ & $-0,0024$ & $-0,0037$ \\
\hline & {$[0,9935]$} & {$[0,4195]$} & {$[0,5833]$} & {$[0,4864]$} & {$[0,3634]$} \\
\hline \multirow[t]{2}{*}{$\beta_{3}$} & $\mathbf{0 , 0 0 5 7}$ & $-0,0008$ & 0,0069 & $-0,0003$ & 0,0044 \\
\hline & {$[0,0000]$} & {$[0,5997]$} & {$[0,0106]$} & {$[0,8044]$} & {$[0,1359]$} \\
\hline \multirow[t]{2}{*}{$\beta_{4}$} & $-0,0001$ & $-0,0024$ & 0,0015 & $-0,0017$ & 0,0003 \\
\hline & {$[0,9319]$} & {$[0,0441]$} & {$[0,4921]$} & {$[0,1185]$} & {$[0,9135]$} \\
\hline \multirow[t]{2}{*}{$\mathrm{C}$} & $\mathbf{0 , 0 0 0 0}$ & 0,0000 & 0,0000 & $\mathbf{0 , 0 0 0 0}$ & $\mathbf{0 , 0 0 0 0}$ \\
\hline & {$[0,0000]$} & {$[0,0000]$} & {$[0,0000]$} & {$[0,0000]$} & {$[0,0000]$} \\
\hline \multirow[t]{2}{*}{$\mathrm{ARCH}(1)$} & $\mathbf{0 , 1 9 3 1}$ & $\mathbf{0 , 0 9 3 9}$ & 0,1025 & 0,0900 & 0,0942 \\
\hline & {$[0,0000]$} & {$[0,0000]$} & {$[0,0000]$} & {$[0,0000]$} & {$[0,0000]$} \\
\hline \multirow[t]{2}{*}{ GARCH(1) } & 0,7376 & $\mathbf{0 , 8 9 3 8}$ & 0,8766 & $\mathbf{0 , 8 9 3 2}$ & $\mathbf{0 , 8 8 5 3}$ \\
\hline & {$[0,0000]$} & {$[0,0000]$} & {$[0,0000]$} & {$[0,0000]$} & {$[0,0000]$} \\
\hline Observaciones & 2975 & 2514 & 2043 & 4024 & 2043 \\
\hline
\end{tabular}

Nota: los valores entre corchetes son la probabilidad crítica ( $p$-values). En negrita, valores significativos para un nivel de significación del 5\%. 
Cuadro 4.81: Resultados para la estimación del efecto vacaciones, para los días pre-festivos, con el modelo EGARCH (1,1), para diferentes subperíodos muestrales

Este cuadro muestra los resultados de la estimación de la ecuación: $r_{t}=c+\beta_{2} \mathrm{FES}_{2 \mathrm{t}}+\beta_{3} \mathrm{POS}_{3 \mathrm{t}}+\beta_{4} \mathrm{RD}_{4 \mathrm{t}}+\varepsilon_{\mathrm{t}}$, con el modelo EGARCH $(1,1)$, para el IGBM y el Ibex 35, en diferentes subperíodos muestrales.

\begin{tabular}{|c|c|c|c|c|c|}
\hline & IGBM & IGBM & IGBM & Ibex 35 & Ibex 35 \\
\hline & 1986-1997 & 1998-2007 & $2008-2015$ & $1992-2007$ & 2008-2015 \\
\hline \multirow[t]{2}{*}{$\mathrm{C}$} & 0,0047 & 0,0031 & $-0,0009$ & 0,0024 & 0,0001 \\
\hline & {$[0,0000]$} & {$[0,0051]$} & {$[0,6529]$} & {$[0,0125]$} & {$[0,9794]$} \\
\hline \multirow[t]{2}{*}{$\beta_{2}$} & $-0,0029$ & $-0,0030$ & $-0,0035$ & $-0,0031$ & $-0,0048$ \\
\hline & {$[0,9122]$} & {$[0,2425]$} & {$[0,3094]$} & {$[0,2731]$} & {$[0,2002]$} \\
\hline \multirow[t]{2}{*}{$\beta_{3}$} & 0,0004 & $-0,0016$ & 0,0051 & $-0,0007$ & 0,0029 \\
\hline & {$[0,7657]$} & {$[0,2864]$} & {$[0,0352]$} & {$[0,5781]$} & {$[0,2863]$} \\
\hline \multirow[t]{2}{*}{$\beta_{4}$} & $-0,0041$ & $-0,0026$ & 0,0002 & $-0,0019$ & $-0,0005$ \\
\hline & {$[0,0000]$} & {$[0,0196]$} & {$[0,9051]$} & {$[0,0574]$} & {$[0,8144]$} \\
\hline \multirow[t]{2}{*}{$\mathrm{C}$} & $-0,6506$ & $-0,3378$ & $-0,3225$ & $-0,3059$ & $-0,2780$ \\
\hline & {$[0,0000]$} & {$[0,0000]$} & {$[0,0000]$} & {$[0,0000]$} & {$[0,0000]$} \\
\hline \multirow[t]{2}{*}{$|\mathrm{RES}| / \mathrm{SQR}[\mathrm{GARCH}](1)$} & 0,2049 & 0,1654 & 0,1226 & 0,1494 & 0,1025 \\
\hline & {$[0,0000]$} & {$[0,0000]$} & {$[0,0000]$} & {$[0,0000]$} & {$[0,0000]$} \\
\hline \multirow[t]{2}{*}{ RES/SQR[GARCH](1) } & $-0,0527$ & $-0,0750$ & $-0,1370$ & $-0,0531$ & $-0,1345$ \\
\hline & {$[0,0000]$} & {$[0,0000]$} & {$[0,0000]$} & {$[0,0000]$} & {$[0,0000]$} \\
\hline \multirow[t]{2}{*}{ EGARCH(1) } & 0,9450 & 0,9771 & 0,9726 & 0,9790 & 0,9763 \\
\hline & {$[0,0000]$} & {$[0,0000]$} & {$[0,0000]$} & {$[0,0000]$} & {$[0,0000]$} \\
\hline Observaciones & 2975 & 2514 & 2043 & 4024 & 2043 \\
\hline
\end{tabular}

Nota: los valores entre corchetes son la probabilidad crítica ( $p$-values). En negrita, valores significativos para un nivel de significación del 5\%. 
Cuadro 4.82: Resultados para la estimación del efecto vacaciones, para los días festivos, con MCO, para diferentes subperíodos muestrales

Este cuadro muestra los resultados de la estimación de la ecuación: $r_{t}=\beta_{1} \mathrm{PRE}_{1 \mathrm{t}}+c+\beta_{3} \mathrm{POS}_{3 \mathrm{t}}+\beta_{4} \mathrm{RD}_{4 \mathrm{t}}+\varepsilon_{\mathrm{t}}$, con MCO, para el IGBM y el Ibex 35, en diferentes subperíodos muestrales.

\begin{tabular}{|c|c|c|c|c|c|}
\hline & IGBM & IGBM & IGBM & Ibex 35 & Ibex 35 \\
\hline & 1986-1997 & 1998-2007 & 2008-2015 & 1992-2007 & 2008-2015 \\
\hline \multirow[t]{2}{*}{$\beta_{1}$} & 0,0018 & 0,0047 & $-0,0001$ & 0,0039 & 0,0021 \\
\hline & {$[0,7929]$} & {$[0,1641]$} & {$[0,9854]$} & {$[0,2381]$} & {$[0,5919]$} \\
\hline \multirow[t]{2}{*}{$\mathrm{C}$} & 0,0005 & 0,0002 & $-0,0021$ & $-0,0003$ & $-0,0022$ \\
\hline & {$[0,9420]$} & {$[0,9460]$} & {$[0,4998]$} & {$[0,9170]$} & {$[0,4848]$} \\
\hline \multirow[t]{2}{*}{$\beta_{3}$} & $-0,0001$ & 0,0022 & 0,0054 & 0,0030 & 0,0040 \\
\hline & {$[0,9898]$} & {$[0,5208]$} & {$[0,1867]$} & {$[0,3631]$} & {$[0,3532]$} \\
\hline \multirow[t]{2}{*}{$\beta_{4}$} & 0,0001 & 0,0000 & 0,0018 & 0,0006 & 0,0019 \\
\hline & {$[0,9917]$} & {$[0,9976]$} & {$[0,5575]$} & {$[0,8318]$} & {$[0,5368]$} \\
\hline $\mathrm{R}^{2}$ & 0,0006 & 0,0041 & 0,0014 & 0,0021 & 0,0004 \\
\hline \multirow[t]{2}{*}{$\mathrm{F}$} & 0,6057 & 3,4586 & 0,9319 & 2,8728 & 0,2911 \\
\hline & {$[0,6113]$} & {$[0,0158]$} & {$[0,4244]$} & {$[0,0349]$} & {$[0,8319]$} \\
\hline Observaciones & 2975 & 2514 & 2043 & 4024 & 2043 \\
\hline $\operatorname{Arch}(1)$ & 0,0000 & 0,0000 & 0,0000 & 0,0000 & 0,0000 \\
\hline
\end{tabular}

Nota: los valores entre corchetes son la probabilidad crítica (p-values). En negrita, valores significativos para un nivel de significación del $5 \%$. 
Cuadro 4.83: Resultados para la estimación del efecto vacaciones, para los días festivos, con el modelo GARCH (1,1), para diferentes subperíodos muestrales

Este cuadro muestra los resultados de la estimación de la ecuación: $r_{t}=\beta_{1} \mathrm{PRE}_{1 \mathrm{t}}+c+\beta_{3} \mathrm{POS}_{3 \mathrm{t}}+\beta_{4} \mathrm{RD} 4 \mathrm{t}+\varepsilon_{\mathrm{t}}$, con el modelo GARCH $(1,1)$, para el IGBM y el Ibex 35, en diferentes subperíodos muestrales.

\begin{tabular}{|c|c|c|c|c|c|}
\hline & IGBM & IGBM & IGBM & Ibex 35 & Ibex 35 \\
\hline & 1986-1997 & 1998-2007 & $2008-2015$ & 1992-2007 & 2008-2015 \\
\hline \multirow[t]{2}{*}{$\beta_{1}$} & $-0,0007$ & 0,0025 & 0,0021 & 0,0024 & 0,0037 \\
\hline & {$[0,9929]$} & {$[0,4182]$} & {$[0,5834]$} & {$[0,4873]$} & {$[0,3635]$} \\
\hline \multirow[t]{2}{*}{$\mathrm{C}$} & 0,0014 & 0,0006 & $-0,0034$ & 0,0000 & $-0,0037$ \\
\hline & {$[0,9863]$} & {$[0,8372]$} & {$[0,2768]$} & {$[0,9919]$} & {$[0,2564]$} \\
\hline \multirow[t]{2}{*}{$\beta_{3}$} & 0,0051 & 0,0017 & $\mathbf{0 , 0 0 9 0}$ & 0,0020 & 0,0082 \\
\hline & {$[0,9494]$} & {$[0,5645]$} & {$[0,0080]$} & {$[0,5433]$} & {$[0,0206]$} \\
\hline \multirow[t]{2}{*}{$\beta_{4}$} & $-0,0008$ & 0,0001 & 0,0037 & 0,0007 & 0,0040 \\
\hline & {$[0,9924]$} & {$[0,9773]$} & {$[0,2419]$} & {$[0,8275]$} & {$[0,2169]$} \\
\hline \multirow[t]{2}{*}{$\mathrm{C}$} & $\mathbf{0 , 0 0 0 0}$ & $\mathbf{0 , 0 0 0 0}$ & $\mathbf{0 , 0 0 0 0}$ & 0,0000 & $\mathbf{0 , 0 0 0 0}$ \\
\hline & {$[0,0000]$} & {$[0,0000]$} & {$[0,0000]$} & {$[0,0000]$} & {$[0,0000]$} \\
\hline \multirow[t]{2}{*}{$\mathrm{ARCH}(1)$} & 0,1978 & $\mathbf{0 , 0 9 3 9}$ & 0,1025 & $\mathbf{0 , 0 8 9 9}$ & 0,0942 \\
\hline & {$[0,0000]$} & {$[0,0000]$} & {$[0,0000]$} & {$[0,0000]$} & {$[0,0000]$} \\
\hline \multirow[t]{2}{*}{ GARCH(1) } & 0,7321 & $\mathbf{0 , 8 9 3 9}$ & 0,8766 & $\mathbf{0 , 8 9 3 2}$ & $\mathbf{0 , 8 8 5 3}$ \\
\hline & {$[0,0000]$} & {$[0,0000]$} & {$[0,0000]$} & {$[0,0000]$} & {$[0,0000]$} \\
\hline Observaciones & 2975 & 2514 & 2043 & 4024 & 2043 \\
\hline
\end{tabular}

Nota: los valores entre corchetes son la probabilidad crítica ( $p$-values). En negrita, valores significativos para un nivel de significación del 5\%. 
Cuadro 4.84: Resultados para la estimación del efecto vacaciones, para los días festivos, con el modelo EGARCH (1,1), para diferentes subperíodos muestrales

Este cuadro muestra los resultados de la estimación de la ecuación: $r_{t}=\beta_{1} \mathrm{PRE}_{1 \mathrm{t}}+c+\beta_{3} \mathrm{POS}_{3 \mathrm{t}}+\beta_{4} \mathrm{RD}_{4 \mathrm{t}}+\varepsilon_{\mathrm{t}}$, con el modelo EGARCH $(1,1)$, para el IGBM y el Ibex 35, en diferentes subperíodos muestrales.

\begin{tabular}{|c|c|c|c|c|c|}
\hline & IGBM & IGBM & IGBM & Ibex 35 & Ibex 35 \\
\hline & 1986-1997 & 1998-2007 & 2008-2015 & $1992-2007$ & 2008-2015 \\
\hline \multirow[t]{2}{*}{$\beta_{1}$} & 0,0030 & 0,0030 & 0,0033 & 0,0031 & 0,0048 \\
\hline & {$[0,8983]$} & {$[0,2420]$} & {$[0,3358]$} & {$[0,2754]$} & {$[0,1984]$} \\
\hline \multirow[t]{2}{*}{$\mathrm{C}$} & 0,0018 & 0,0001 & $-0,0042$ & $-0,0007$ & $-0,0047$ \\
\hline & {$[0,9383]$} & {$[0,9796]$} & {$[0,1186]$} & {$[0,7912]$} & {$[0,0945]$} \\
\hline \multirow[t]{2}{*}{$\beta_{3}$} & 0,0039 & 0,0014 & 0,0085 & 0,0024 & $\mathbf{0 , 0 0 7 7}$ \\
\hline & {$[0,8657]$} & {$[0,5729]$} & {$[0,0037]$} & {$[0,3946]$} & {$[0,0125]$} \\
\hline \multirow[t]{2}{*}{$\beta_{4}$} & $-0,0012$ & 0,0004 & 0,0036 & 0,0013 & 0,0042 \\
\hline & {$[0,9573]$} & {$[0,8634]$} & {$[0,1777]$} & {$[0,6411]$} & {$[0,1322]$} \\
\hline \multirow[t]{2}{*}{$\mathrm{C}$} & $-0,9183$ & $-0,3378$ & $-0,3233$ & $-0,3059$ & $-0,2781$ \\
\hline & {$[0,0000]$} & {$[0,0000]$} & {$[0,0000]$} & {$[0,0000]$} & {$[0,0000]$} \\
\hline \multirow[t]{2}{*}{ |RES|/SQR[GARCH](1) } & $\mathbf{0 , 2 8 3 9}$ & 0,1654 & 0,1232 & 0,1495 & 0,1025 \\
\hline & {$[0,0000]$} & {$[0,0000]$} & {$[0,0000]$} & {$[0,0000]$} & {$[0,0000]$} \\
\hline \multirow[t]{2}{*}{ RES/SQR[GARCH](1) } & $-0,0635$ & $-\mathbf{0 , 0 7 5 0}$ & $-0,1376$ & $-\mathbf{0 , 0 5 3 1}$ & $-0,1345$ \\
\hline & {$[0,0000]$} & {$[0,0000]$} & {$[0,0000]$} & {$[0,0000]$} & {$[0,0000]$} \\
\hline \multirow[t]{2}{*}{ EGARCH(1) } & 0,9220 & 0,9771 & 0,9727 & 0,9790 & 0,9763 \\
\hline & {$[0,0000]$} & {$[0,0000]$} & {$[0,0000]$} & {$[0,0000]$} & {$[0,0000]$} \\
\hline Observaciones & 2975 & 2514 & 2043 & 4024 & 2043 \\
\hline
\end{tabular}


Cuadro 4.85: Resultados para la estimación del efecto vacaciones, para los días post-festivos, con MCO, para diferentes subperíodos muestrales

Este cuadro muestra los resultados de la estimación de la ecuación: $\mathrm{r}_{\mathrm{t}}=\beta_{1} \mathrm{PRE}_{1 \mathrm{t}}+\beta_{2} \mathrm{FES}_{2 \mathrm{t}}+\mathrm{c}+\beta_{4} \mathrm{RD}_{4 \mathrm{t}}+\varepsilon_{\mathrm{t}}$, con MCO, para el IGBM y el Ibex 35, en diferentes subperíodos muestrales.

\begin{tabular}{|c|c|c|c|c|c|}
\hline & IGBM & IGBM & IGBM & Ibex 35 & Ibex 35 \\
\hline & 1986-1997 & 1998-2007 & 2008-2015 & $1992-2007$ & 2008-2015 \\
\hline \multirow[t]{2}{*}{$\beta_{1}$} & 0,0019 & 0,0025 & $-0,0054$ & 0,0008 & $-0,0019$ \\
\hline & {$[0,3052]$} & {$[0,2560]$} & {$[0,1277]$} & {$[0,6695]$} & {$[0,6246]$} \\
\hline \multirow[t]{2}{*}{$\beta_{2}$} & 0,0001 & $-0,0022$ & $-0,0054$ & $-0,0030$ & $-0,0040$ \\
\hline & {$[0,9898]$} & {$[0,5208]$} & {$[0,1867]$} & {$[0,3631]$} & {$[0,3532]$} \\
\hline \multirow[t]{2}{*}{$\mathrm{C}$} & 0,0004 & 0,0024 & 0,0033 & 0,0027 & 0,0018 \\
\hline & {$[0,7625]$} & {$[0,1328]$} & {$[0,2106]$} & {$[0,0597]$} & {$[0,5403]$} \\
\hline \multirow[t]{2}{*}{$\beta_{4}$} & 0,0002 & $-0,0022$ & $-0,0035$ & $-0,0024$ & $-0,0020$ \\
\hline & {$[0,9066]$} & {$[0,1763]$} & {$[0,1811]$} & {$[0,1009]$} & {$[0,4918]$} \\
\hline $\mathrm{R}^{2}$ & 0,0006 & 0,0041 & 0,0014 & 0,0021 & 0,0004 \\
\hline \multirow[t]{2}{*}{$\mathrm{F}$} & 0,6057 & 3,4586 & 0,9319 & 2,8728 & 0,2911 \\
\hline & {$[0,6113]$} & {$[0,0158]$} & {$[0,4244]$} & {$[0,0349]$} & {$[0,8319]$} \\
\hline Observaciones & 2975 & 2514 & 2043 & 4024 & 2043 \\
\hline $\operatorname{Arch}(1)$ & 0,0000 & 0,0000 & 0,0000 & 0,0000 & 0,0000 \\
\hline
\end{tabular}


Cuadro 4.86: Resultados para la estimación del efecto vacaciones, para los días post-festivos, con el modelo GARCH (1,1), para diferentes subperíodos muestrales

Este cuadro muestra los resultados de la estimación de la ecuación: $r_{t}=\beta_{1} \mathrm{PRE}_{1 \mathrm{t}}+\beta_{2} \mathrm{FES}_{2 \mathrm{t}}+\mathrm{c}+\beta_{4} \mathrm{RD} 4 \mathrm{t}+\varepsilon_{\mathrm{t}}$, con el modelo GARCH $(1,1)$, para el IGBM y el Ibex 35, en diferentes subperíodos muestrales.

\begin{tabular}{|c|c|c|c|c|c|}
\hline & IGBM & IGBM & IGBM & Ibex 35 & Ibex 35 \\
\hline & 1986-1997 & 1998-2007 & 2008-2015 & 1992-2007 & 2008-2015 \\
\hline \multirow[t]{2}{*}{$\beta_{1}$} & $-0,0056$ & 0,0008 & $-0,0069$ & 0,0003 & $-0,0044$ \\
\hline & {$[0,0000]$} & {$[0,6003]$} & {$[0,0106]$} & {$[0,8041]$} & {$[0,1369]$} \\
\hline \multirow[t]{2}{*}{$\beta_{2}$} & $-0,0048$ & $-0,0017$ & $-0,0090$ & $-0,0020$ & $-0,0082$ \\
\hline & {$[0,9560]$} & {$[0,5670]$} & {$[0,0079]$} & {$[0,5484]$} & {$[0,0205]$} \\
\hline \multirow[t]{2}{*}{$\mathrm{C}$} & 0,0063 & $\mathbf{0 , 0 0 2 3}$ & 0,0056 & $\mathbf{0 , 0 0 2 0}$ & 0,0045 \\
\hline & {$[0,0000]$} & {$[0,0256]$} & {$[0,0002]$} & {$[0,0268]$} & {$[0,0052]$} \\
\hline \multirow[t]{2}{*}{$\beta_{4}$} & $-0,0057$ & $-0,0016$ & $-0,0053$ & $-0,0013$ & $-0,0042$ \\
\hline & {$[0,0000]$} & {$[0,1202]$} & {$[0,0007]$} & {$[0,1600]$} & {$[0,0128]$} \\
\hline \multirow[t]{2}{*}{$\mathrm{C}$} & $\mathbf{0 , 0 0 0 0}$ & 0,0000 & 0,0000 & $\mathbf{0 , 0 0 0 0}$ & $\mathbf{0 , 0 0 0 0}$ \\
\hline & {$[0,0000]$} & {$[0,0000]$} & {$[0,0000]$} & {$[0,0000]$} & {$[0,0000]$} \\
\hline \multirow[t]{2}{*}{$\mathrm{ARCH}(1)$} & $\mathbf{0 , 1 9 3 1}$ & 0,0940 & 0,1025 & 0,0900 & 0,0942 \\
\hline & {$[0,0000]$} & {$[0,0000]$} & {$[0,0000]$} & {$[0,0000]$} & {$[0,0000]$} \\
\hline \multirow[t]{2}{*}{ GARCH(1) } & $\mathbf{0 , 7 3 7 0}$ & $\mathbf{0 , 8 9 3 7}$ & 0,8766 & 0,8932 & $\mathbf{0 , 8 8 5 3}$ \\
\hline & {$[0,0000]$} & {$[0,0000]$} & {$[0,0000]$} & {$[0,0000]$} & {$[0,0000]$} \\
\hline Observaciones & 2975 & 2514 & 2043 & 4024 & 2043 \\
\hline
\end{tabular}

Nota: los valores entre corchetes son la probabilidad crítica ( $p$-values). En negrita, valores significativos para un nivel de significación del 5\%. 
Cuadro 4.87 Resultados para la estimación del efecto vacaciones, para los días post-festivos, con el modelo EGARCH (1,1), para diferentes subperíodos muestrales

Este cuadro muestra los resultados de la estimación de la ecuación: $r_{t}=\beta_{1} \mathrm{PRE}_{1 \mathrm{t}}+\beta_{2} \mathrm{FES}_{2 \mathrm{t}}+\mathrm{c}+\beta_{4} \mathrm{RD} \mathrm{D}_{4}+\varepsilon_{\mathrm{t}}$, con el modelo EGARCH $(1,1)$, para el IGBM y el Ibex 35, en diferentes subperíodos muestrales.

\begin{tabular}{|c|c|c|c|c|c|}
\hline & IGBM & IGBM & IGBM & Ibex 35 & Ibex 35 \\
\hline & 1986-1997 & 1998-2007 & $2008-2015$ & $1992-2007$ & 2008-2015 \\
\hline \multirow[t]{2}{*}{$\beta_{1}$} & $-0,0056$ & 0,0016 & $-0,0052$ & 0,0007 & $-0,0029$ \\
\hline & {$[0,0000]$} & {$[0,2863]$} & {$[0,0303]$} & {$[0,5781]$} & {$[0,2889]$} \\
\hline \multirow[t]{2}{*}{$\beta_{2}$} & $-0,0029$ & $-0,0014$ & $-0,0085$ & $-0,0024$ & $-\mathbf{0 , 0 0 7 7}$ \\
\hline & {$[0,9181]$} & {$[0,5730]$} & {$[0,0037]$} & {$[0,3916]$} & {$[0,0124]$} \\
\hline \multirow[t]{2}{*}{$\mathrm{C}$} & 0,0047 & 0,0014 & 0,0043 & 0,0017 & 0,0029 \\
\hline & {$[0,0000]$} & {$[0,1647]$} & {$[0,0008]$} & {$[0,0676]$} & {$[0,0251]$} \\
\hline \multirow[t]{2}{*}{$\beta_{4}$} & $-0,0041$ & $-0,0010$ & $-0,0048$ & $-0,0011$ & $-0,0034$ \\
\hline & {$[0,0000]$} & {$[0,3473]$} & {$[0,0002]$} & {$[0,2201]$} & {$[0,0107]$} \\
\hline \multirow[t]{2}{*}{$\mathrm{C}$} & $-0,6811$ & $-0,3378$ & $-0,3233$ & $-0,3059$ & $-0,2781$ \\
\hline & {$[0,0000]$} & {$[0,0000]$} & {$[0,0000]$} & {$[0,0000]$} & {$[0,0000]$} \\
\hline \multirow[t]{2}{*}{ |RES|/SQR[GARCH](1) } & 0,1883 & 0,1654 & 0,1232 & 0,1494 & 0,1025 \\
\hline & {$[0,0000]$} & {$[0,0000]$} & {$[0,0000]$} & {$[0,0000]$} & {$[0,0000]$} \\
\hline \multirow[t]{2}{*}{ RES/SQR[GARCH](1) } & $-\mathbf{0 , 0 3 9 7}$ & $-0,0750$ & $-0,1376$ & $-0,0531$ & $-0,1346$ \\
\hline & {$[0,0000]$} & {$[0,0000]$} & {$[0,0000]$} & {$[0,0000]$} & {$[0,0000]$} \\
\hline \multirow[t]{2}{*}{ EGARCH(1) } & 0,9404 & 0,9771 & $\mathbf{0 , 9 7 2 7}$ & 0,9790 & 0,9763 \\
\hline & {$[0,0000]$} & {$[0,0000]$} & {$[0,0000]$} & {$[0,0000]$} & {$[0,0000]$} \\
\hline Observaciones & 2975 & 2514 & 2043 & 4024 & 2043 \\
\hline
\end{tabular}

Nota: los valores entre corchetes son la probabilidad crítica ( $p$-values). En negrita, valores significativos para un nivel de significación del 5\%. 


\subsubsection{Resumen de los resultados del análisis del efecto vacaciones}

Esta sección presenta las conclusiones más relevantes del efecto vacaciones, destacándose que el efecto día pre-festivo se identifica de forma débil en el Ibex-35, en el Ibex Medium Cap y en el Ibex Small Cap. El efecto día festivo se presenta de forma débil en el Ibex Small Cap, y de forma inversa débil, es decir, presentando las rentabilidades medias más bajas para el IGBM y el Ibex 35, y para el Ibex Top Dividendo realizando la estimación en el modelo EGARCH $(1,1)$. El efecto post-festivo se observa de forma significativa para el IGBM, y de forma débil para el Ibex-35 y el Ibex Top Dividendo, produciéndose el efecto inverso débilmente para el Ibex Small Cap. En línea con la literatura, nuestros resultados para el efecto pre-festivo coinciden con los observados por Meneu y Pardo (2004) quienes encuentran el efecto pre-festivo para el Ibex 35 pero, sin embargo, contradicen las conclusiones de García (2008) quien identifica una ausencia del efecto tanto para el Ibex 35, como para el Ibex Small Cap. Para el efecto post-festivo, Meneu y Pardo (2001) evidencian que existen rentabilidades positivas los días post-festivos, pero no son significativas. Nosotros presentamos resultados similares con significatividad débil, aunque sí identificamos significatividad para el IGBM.

Del análisis de la robustez de los efectos en los diferentes subperíodos muestrales observamos que el único efecto que se confirma de forma significativa es el efecto postfestivo, para el subperíodo 2008-2015, dándose de forma débil en el primer subperíodo (1986-1997 y desapareciendo en el subperíodo intermedio de 1998-2007. Este comportamiento ya fue descrito por Olson et al. (2015) observando que las anomalías pueden resurgir después de su desaparición inicial, presentando un comportamiento errante. Para el caso del Ibex 35 se confirma significatividad de forma débil en el subperíodo 2008-2015. Es decir, el efecto aparece en el período de crisis para el Ibex 35 y reaparece para el IGBM en el subperíodo de crisis. El efecto pre-festivo sólo aparece de forma débil en el período 1998-2007 en el IGBM y en el período 1992-2007 en el Ibex 35, desapareciendo en ambos en el subperíodo de crisis. El efecto festivo aparece en el IGBM y el Ibex 35, de forma inversa a la inicialmente planteada, es decir, los días festivos son los que presentan una menor rentabilidad media, pero de forma débil, y únicamente dándose en el tercer subperíodo, coincidiendo con la crisis. 


\subsection{Conclusiones}

A nivel general, los resultados obtenidos únicamente muestran estadísticamente significatividad para el efecto cambio de mes en el IGBM, el Ibex 35 y el Ibex Medium Cap y el efecto día post-festivo para el IGBM, aunque sí que podemos destacar que se han encontrado de forma débil los siguientes efectos: i) El efecto enero para el IGBM, el Ibex Medium Cap y en el Ibex Small Cap. ii) El efecto lunes para el Ibex 35, el Ibex Medium Cap y el Ibex Top Dividendo y un efecto viernes para el IGBM, el Ibex 35 y el Ibex Medium Cap. iii) El efecto cambio de mes para el Ibex Small Cap. iv) El efecto día pre-festivo en el Ibex-35, el Ibex Medium Cap y en el Ibex Small Cap; y el post-festivo para el Ibex-35, y un efecto día post-festivo inverso, es decir, presentando una rentabilidades anormalmente bajas los días post-festivos, para el Ibex Top Dividendo. El efecto día festivo en el Ibex Small Cap y de forma inversa, es decir, presentando las rentabilidades medias más bajas para el IGBM y el Ibex 35, y para el Ibex Top Dividendo con el modelo EGARCH $(1,1)$. A diferencia de las conclusiones que presenta García (2008) quien encuentra una mayor significatividad de los efectos calendario en las empresas de pequeña y mediana capitalización que en los blue chips, en nuestro caso sólo lo podemos evidenciar claramente en el efecto enero.

Estos resultados como se ha podido observar a lo largo del capítulo, difieren parcialmente de la literatura existente sobre los efectos del calendario en los mercados bursátiles españoles. En dichos estudios sí que se encuentran significativos un gran número de efectos calendario, como en el caso de García $(2007,2008)$ para el efecto fin de semana, y el efecto enero para el Ibex Small Cap, mientras que Meneu y Pardo (2004) identifican el efecto día pre-festivo para el Ibex 35.

El análisis de robustez de los efectos calendario para el IGBM y el Ibex 35 en diferentes subperíodos muestrales nos deja como principales conclusiones las siguientes: i) Para el efecto enero hay una disminución del efecto para ambos índices en el transcurso del tiempo hasta presentar rentabilidades negativas el subperíodo muestral 2008-2015. ii) Para el efecto día de la semana encontramos una evolución contraria, el efecto viernes aparece de forma débil en los primeros subperíodos muestrales y desaparece en el último, y el efecto lunes, al contrario, no aparece en los primeros subperíodos muestrales, pero sí en el último de forma débil, coincidiendo con el subperíodo de crisis. iii) Para el efecto cambio de mes que es el único que se presenta estadísticamente significativo para ambos índices, se observa que desaparece en el período de crisis 2008-2015. iv) El efecto días pre-festivos aparece en el subperíodo anterior de la crisis en los dos índices de forma débil para desaparecer en el subperíodo de crisis. El efecto días post-festivos aparece en el período de crisis para el Ibex 35 y reaparece para el 
IGBM en el subperíodo de crisis. Además, detectamos un nuevo efecto, de forma débil, que aparece en el período de crisis, el efecto día festivo, es decir, en los días festivos se producen unas rentabilidades sensiblemente inferiores a las del resto de días. 


\section{Capítulo 5}

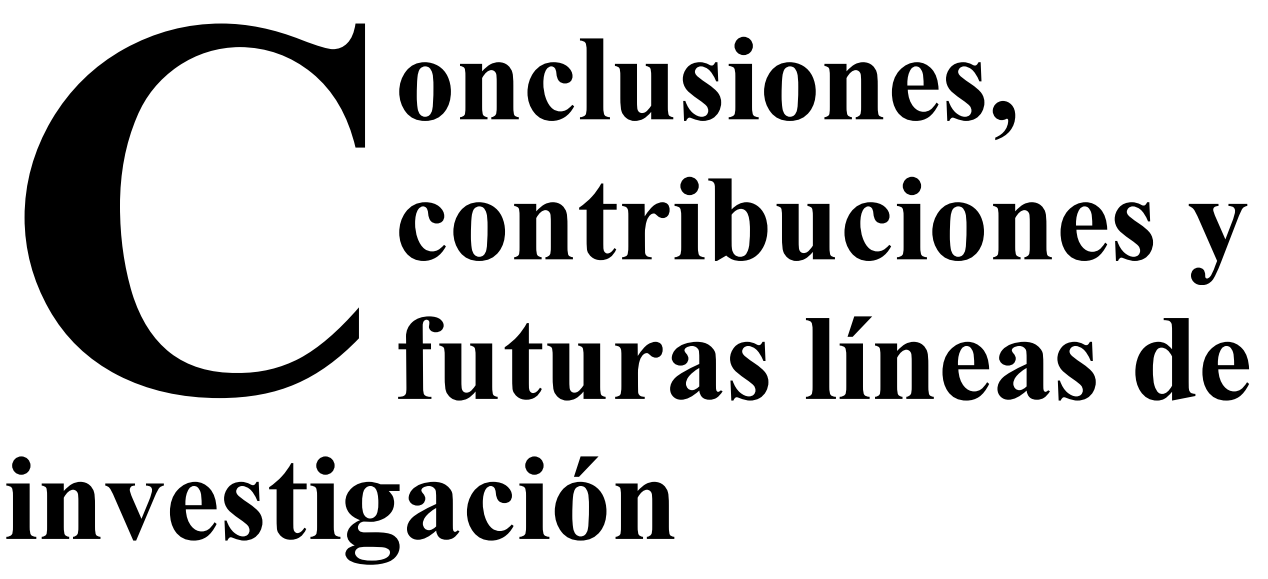

\subsection{Introducción}

Durante décadas el estudio de las Finanzas del Comportamiento (FC) ha venido experimentando un creciente interés en la literatura financiera. Es por ello que el objeto principal de la presente tesis ha sido encontrar evidencias en línea con alguna de las dos principales corrientes de opinión existentes sobre las FC. Por un lado, se erige la que las considera como un simple conjunto de anomalías de mercado o modelos de laboratorio que difícilmente pueden darse en la realidad en base a autores como: Myagkov y Plott (1997), Fama (1998), Sullivan et al. (2001) y Borges (2009), entre otros; frente a los postulados que sí considera a las FC como una pieza importante dentro de la economía financiera y que pueden fácilmente atribuirse a situaciones reales de mercado, de acuerdo a Rabin (1998), Ritter (2003), Sewell (2007) y Singh (2012), por citar algunos. Para conducir dicho análisis se ha venido utilizando la metodología tradicional de contrastes estadísticos aplicada al estudio de las FC, centrándose en el estudio de diferentes anomalías observadas en el mercado. Específicamente, en este estudio se contrasta empíricamente la existencia, en entornos reales, de tres de las principales anomalías como son: el dividend puzzle, el efecto disposición y el efecto calendario, dedicándose sendos capítulos. En este capítulo se presentan las conclusiones extraídas 
que van en línea de anteriores investigaciones pero que además aportan evidencias sobre aspectos cuyo estadio de desarrollo se encuentra en una etapa temprana. A continuación se presentan las contribuciones y futuras líneas de investigación de esta tesis. 


\subsection{Conclusiones}

El segundo capítulo de la tesis se centra en el análisis del dividend puzzle. Para ello se ha aplicado una metodología similar a la de Carhart (1997) consistente en la creación de dos carteras de inversión: una formada por las empresas del Ibex 35 que presentan una mayor rentabilidad por dividendo cada año (D+) y otra con las que menos (D-), durante el período muestral de 2000 a 2014. La primera parte del estudio empírico se ha basado en el análisis de la evolución de los valores liquidativos mensuales de ambas carteras de inversión, observándose que el valor liquidativo de la cartera $\mathrm{D}+$ siempre ha sido superior al de la cartera D-, durante todo el período analizado, y por consiguiente ha presentado unas mayores rentabilidades. Concluyendo que estos mejores resultados de la cartera $\mathrm{D}+$, no eran sólo debidos al cobro de dividendos, sino también a la obtención de unas mayores ganancias de capital en el momento de la venta, ya que de las acciones que componían la cartera $\mathrm{D}+$ presentaban una mayor demanda por parte de los inversores, y por lo tanto un mayor valor de cotización.

En una segunda etapa se ha examinado la performance o eficiencia de las dos carteras a través del alfa de Jensen y el modelo de tres factores de Fama y French, utilizando como referencia de rentabilidad del mercado el Ibex 35 y el Ibex 35 con dividendos. Los resultados obtenidos utilizando como referencia de rentabilidad del mercado el Ibex 35 , exhiben un alfa (rentabilidad obtenida por la composición especifica de la cartera) positiva y significativa de la cartera $\mathrm{D}+$, frente a un alfa sensiblemente inferior y no significativa de la cartera D-. Utilizando como referencia de mercado el Ibex 35 con dividendos, el alfa de la cartera $\mathrm{D}^{+}$, sigue siendo superior a la de la cartera D-, pero no significativa.

Por último, se ha procedido a analizar el comportamiento de ambas carteras tomando como punto de inflexión la crisis financiera de 2008, y por tanto considerando dos subperíodos: uno pre-crisis y otro de crisis. Los resultados obtenidos son similares a los del período muestral total: la cartera $\mathrm{D}+$ presenta valores positivos y superiores para todas las alfas, siendo significativas únicamente las de la cartera D+, cuando el Ibex 35 es la referencia de mercado. Debemos resaltar que el subperíodo de expansión o precrisis es el único que presenta una diferencia significativa, aunque débil, entre las alfas de las dos carteras. Como principales conclusiones del análisis de la performance podemos resaltar: i) el alfa de la cartera $\mathrm{D}+$ es sensiblemente superior a la de la cartera D-, en todos los períodos analizados, aunque significativa únicamente cuando se utiliza como referencia de mercado el Ibex 35 (hecho previsible dado que la cartera $\mathrm{D}+$ es casi una réplica del Ibex 35 con dividendos). ii) el dividend puzzle alcanza su mayor intensidad en los períodos de crecimiento económico. De acuerdo con la metodología 
aplicada, consideramos que los resultados obtenidos ponen de manifiesto la existencia del dividend puzzle en un entorno real como los mercados bursátiles españoles.

El capítulo tercero que versa sobre el efecto disposición profundiza en el patrón de comportamiento que experimentan los inversores de fondos socialmente responsables en el contexto estadounidense. En concreto, este estudio ahonda en el análisis del sesgo o la tendencia existente entre los inversores a mantener (vender) sus carteras de inversión cuando reportan pérdidas (ganancias), o en otras palabras, la cuestión de investigación es si existe evidencia empírica sobre la existencia del efecto disposición para los inversores de esta tipología de fondos. Para ello se toma como referencia la información histórica de los flujos monetarios definiéndose ésta como la variable clave objeto de análisis. Por otro lado, se establece como variable explicativa la medición de los resultados del fondo y se toman dos indicadores, por un lado, la rentabilidad pasada del fondo y, por otro lado, la performance, eficiencia o valora añadido del gestor.

El presente estudio proporciona evidencias de que las rentabilidades pasadas tienen un impacto sobre los flujos monetarios futuros, es decir, se identifica una clara sensibilidad de los inversores hacia los fondos que han obtenido mejores resultados en el pasado, concluyéndose que a mayor rentabilidad pasada del fondo mayor capacidad de atraer dinero de los inversores. Anecdóticamente, se constata además que los fondos con peores resultados siguen atrayendo el dinero de los inversores pudiendo dar cabida a comportamientos en base a una estrategia contraria que se apoyaría en el precepto de que los fondos perdedores pueden ser ganadores en el futuro. Para dotar de robustez al estudio, el período muestral se divide en dos subperíodos coincidiendo con etapa de precrisis (1999-2007) y post-crisis (2008-2016). Los resultados arrojan consistencia en la fase anterior a la crisis y, exceptuando la contención de inversión propia de un período posterior a la crisis, se identifica que sólo los fondos con mejores resultados reciben mayores entradas monetarias para esta última fase.

Para la determinación de la existencia del efecto disposición, el estudio de los outflows o de las salidas monetarias resulta de especial importancia ya que contrariamente a lo esperado, los fondos con una menor (mayor) rentabilidad pasada son los que experimentan unas menores (mayores) salidas de dinero. Así, este estudio evidencia la existencia del efecto disposición puesto que los inversores de fondos socialmente responsables presentan una propensión a ser menos sensibles a la hora de desinvertir en los fondos que peores resultados han reportado. Por otro lado, el enfoque que analiza la relación entre flujos monetarios y eficiencia parece ser menos evidente, aunque nuevamente atribuye una relación positiva entre las salidas de dinero y el grado de eficiencia; ésta puede considerarse indicativa de un sesgo de comportamiento, 
mostrándose un grado de sensibilidad mayor de los inversores especialmente en la etapa postcrisis tras un hito de innegable impacto económico-social como ha sido el caso de la reciente crisis financiera global.

El cuarto capítulo de la tesis se ha dedicado a estudiar el fenómeno de la estacionalidad en los rendimientos bursátiles asociando determinadas tendencias en el calendario, es decir, refiere al denominado efecto calendario y más concretamente se han analizado exhaustivamente cuatro de las anomalías más significativas relacionadas con este efecto: el efecto enero, el efecto día de la semana, el efecto cambio de mes y el efecto vacaciones. La metodología empleada en este capítulo ha sido el análisis estadístico de las rentabilidades diarias de los cinco índices analizados (el Índice General de la Bolsa de Madrid (IGBM), el Ibex 35, el Ibex Medium Cap, el Ibex Small Cap y el Ibex Top Dividendo) y la aplicación de modelos ARCH. Como principal conclusión podemos destacar que de los cuatro efectos analizados únicamente se ha identificado significatividad en los resultados para el efecto cambio de mes para el IGBM, el Ibex 35 y el Ibex Medium Cap y, el efecto día post-festivo para el IGBM. Aunque se han encontrado otros efectos con una significatividad débil para el caso del efecto enero en base a datos del IGBM, el Ibex Medium Cap y el Ibex Small Cap, coincidiendo así con los resultados obtenidos en trabajos anteriores, como es el caso de García (2008) y Beyer et al. (2013) quienes relacionan directamente este efecto con las compañías de pequeña capitalización. Estos resultados difieren en parte con la literatura previa, que con mayor significatividad para los mercados bursátiles españoles, observa un amplio número de efectos calendario. La respuesta a estas diferencias la podemos encontrar en el trabajo de Olson et al. (2015), donde los autores observan que las anomalías pueden desaparecer, resurgir y presentar un comportamiento errante, pero con el tiempo, desde una perspectiva de largo plazo, éstas tienden a desaparecer, como predice la hipótesis de los mercados eficientes o $E M H$. La mayor parte de la literatura previa sobre el efecto calendario analiza períodos temporales que no van más allá de los primeros años del presente siglo, al ampliar el presente estudio el horizonte temporal hasta 2015, muchos de ellos han disminuido en intensidad o directamente han desaparecido. Esta hipótesis se ve respaldada con los resultados del análisis de robustez en los diferentes subperíodos muestrales, para el IGBM y el Ibex-35, especialmente en el subperíodo de crisis 20082015. Aunque en algunos casos como en el efecto lunes, de marcado carácter negativo, no sólo no ha desaparecido sino que se ha intensificado en el subperíodo de crisis. 


\subsection{Contribuciones}

Como principales aportaciones del segundo capítulo centrado en el estudio del dividend puzzle se puede resaltar el uso de una metodología diferente a la tradicional para su análisis como la aplicación de una metodología similar a la de Carhart (1997), a través de la elaboración de dos carteras de inversión, y el análisis de la robustez del efecto en diferentes subperíodos muestrales (expansión y crisis) centrando el esfuerzo investigador en la reciente crisis financiera de 2008. Pero además de su interés en el ámbito académico, este hallazgo puede ser útil a los inversores a la hora de reestructurar sus carteras de inversión, ya que queda demostrado que las empresas que ofrecen una mayor rentabilidad por dividendo conseguirán un mayor valor de sus acciones, coincidiendo así con el estudio de Sewell (2007) según el cual el conocimiento de las teorías de las FC puede ayudar a los inversores en cuanto éstas contribuyen a mejorar sus procesos de toma de decisiones.

Las contribuciones del capítulo referido al efecto disposición son las siguientes: i) se analizan los flujos monetarios de una tipología de fondos, los FSR cuyo auge ha venido creciendo en los últimos años y que aún presenta un limitado número de estudios con datos recientes; ii) se presenta un análisis más completo presentando distintos indicadores de medida de resultados de los fondos: rentabilidad pasada y eficiencia, siendo habitual en la literatura financiera considerar un único indicador; iii) se incluye un análisis de robustez incluyendo la crisis financiera como punto de inflexión para diferenciar los subperíodos y establecer conexiones entre las posibles diferencias temporales.

Como principales contribuciones del cuarto capítulo que corresponde al estudio del efecto calendario, además de la ampliación del horizonte temporal de análisis de los efectos, podemos destacar: i) la utilización de índices bursátiles de reciente creación en el mercado financiero español, como el Ibex Small Cap y el Ibex Top Dividendo, cuyo uso está planteado por Lucey y Whelan (2001) como una de las posibles soluciones frente al problema del data snooping o data mining; ii) el estudio de la evolución de los diferentes efectos en el contexto de la reciente crisis financiera de 2008; iii) la revelación de un nuevo efecto calendario, el efecto día festivo, el cual puede definirse como la aparición de rentabilidades anormalmente bajas coincidiendo con los días festivos en los cuales la bolsa cotiza. 


\subsection{Futuras líneas de investigación}

Hasta la reforma fiscal de 2015, España contaba con una de las fiscalidades más favorables a nivel internacional en el tratamiento del cobro de dividendos, estando los primeros 1.500 euros exentos de tributación, pero a partir de ese año los inversores empezaron a tributar por el $100 \%$ de las cantidades percibidas. Como futura línea de investigación planteamos el seguimiento de la evolución del dividend puzzle a partir de ese cambio de fiscalidad, ya que una de las principales imperfecciones del mercado que afecta a la política de dividendos son los impuestos. Según el trabajo de Jacob y Jacob (2013) la penalización de los impuestos sobre los dividendos frente a las ganancias de capital está directamente relacionada con la política de dividendos de las empresas. Actualmente España se sitúa como uno de los principales países pagadores de dividendos, a nivel europeo, sólo por detrás de Francia, Alemania y Suiza, un posible estudio de investigación futuro consistiría en replicar la metodología utilizada en esta tesis para el resto de principales países pagadores de dividendos realizando un estudio comparativo de los resultados.

En referencia al capítulo que versa sobre el efecto disposición se identifica que la inclusión de otros hitos, como por ejemplo, el Brexit en el contexto de la Unión Europea brinda una excelente oportunidad para abordar posibles direcciones en una investigación futura. Así, entre otros aspectos reseñables, la inclusión de eventos inéditos con trascendencia económico-social puede brindar una mejor oportunidad para entender las estrategias de inversión y la complejidad que entraña la toma de decisiones cuando existe un contexto que claramente condiciona el comportamiento del inversor. Entender y profundizar en los sesgos puede ser clave pues aún en la actualidad está por determinar si su carácter es temporal o permanente, en este sentido, se precisa ahondar en la posible relación entre el efecto disposición y un análisis de persistencia. Además, un análisis combinado del efecto disposición con otros sesgos, por ejemplo, el herding tomando en consideración varios países y realizando comparativas, podría ser interesante.

Una interesante línea de investigación a tener en cuenta para futuros trabajos que refieren el efecto calendario puede ser la realización de un estudio que aborde en profundidad la combinación o interacción entre los diferentes sesgos del comportamiento ya identificados. Por ejemplo, dado que los algunos comparten días de cotización y, por lo tanto, podrían estar bajo el efecto de influencias que atañen al comportamiento de una forma simultánea, así se podría averiguar si puede existir una sobreestimación del número de efectos calendario. Se identifica que en la actualidad existen pocos trabajos que dedican atención a este tema y dada su relevancia se entiende 
que precisa de un mayor esfuerzo investigador. En el capítulo se han utilizado dos especificaciones de la familia ARCH (GARCH y EGARCH), para determinar la existencia de los diferentes efectos calendario, otra propuesta para futuras investigaciones sería la realización de un estudio comparativo entre los resultados obtenidos aplicando las diferentes especificaciones existentes de modelos $\mathrm{ARCH}$ : MGARCH, IGARCH, TGARCH, etc.; y verificar si es realmente el GARCH $(1,1)$ el que mejores resultados obtiene como postulan Hansen y Lunde (2005).

Esta tesis ha abordado algunos de los principales sesgos en el comportamiento de los inversores y en sus decisiones financieras. En un futuro se podría profundizar realizando un análisis simultáneo de diferentes índices de distintos países pudiendo establecer relaciones sincrónicas entre los efectos analizados. Adicionalmente la consideración de distintas tipologías de activos distinguiendo, por ejemplo, entre fondos de inversión convencionales versus fondos socialmente responsables es otra extensión que se considera idónea ya que esta comparativa aún en la actualidad reporta conclusiones dispares. Finalmente, un estudio multipaís de las diferencias entre tipos de fondos, brinda una excelente oportunidad para estudios futuros. 


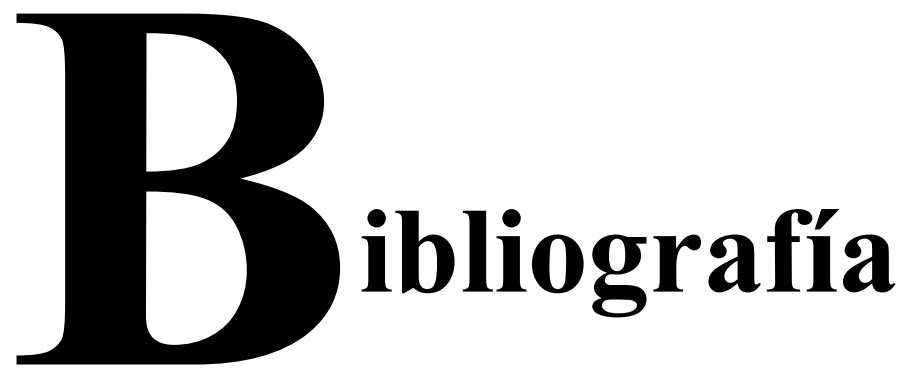

Abraham, A., e Ikenberry, D. L. (1994). The individual investor and the weekend effect. Journal of Financial and Quantitative Analysis, 29(02), 263-277.

Acharya, V., Philippon, T., Richardson, M., y Roubini, N. (2009). The financial crisis of 2007-2009: Causes and remedies. Financial markets, institutions \& instruments, 18(2), 89-137.

Ackert, L. F., y Deaves, R. (2010). Behavioral Finance: Psychology. Decision-Making, and Markets. Mason, USA: South-Western Cengage Learning.

Aggarwal, R., y Rivoli, P. (1989). Seasonal and day of the week effects in four emerging stock markets. The Financial Review, 24(4), 541-550.

Agrawal, A., y Tandon, K. (1994). Anomalies or illusions? Evidence from stock markets in eighteen countries. Journal of international Money and Finance, 13(1), 83106.

Aharony, J. y Swary, I. (1980). Quarterly dividend and earnings announcements and stockholders' returns: an empirical analysis. Journal of Finance, 35(1), 1-12.

Akerlof, G. A., y Shiller, R. J. (2009). Animal spirits: How human psychology drives the economy, and why it matters for global capitalism. Princeton University Press.

Aksoy, M., Secme, Z. O., Karatepe, S., y Benli, F. (2012). Day of The Week Anomaly During Financial Crisis: Portugal, Italy, Greece, Spain and Ireland. In S. Bojnek, J. C. Brada, \& M. Kuboniwa (Eds.), Overcoming the Crisis Economic and Financial Developments in Asia and Europe. University of Primorska Press. 
Alamá, L., y Fuertes, A.M. (2009). Cronología de la crisis económica y debilidades de la globalización: la economía española en el contexto internacional. Revista de treball, economia i societat, 53, 9-17.

Allen, F., y Michaely, R. (2003). Payout policy. Handbook of the Economics of Finance, $1,337-429$.

Al-Malkawi, H. A. N (2007). Determinants of corporate dividend policy in Jordan: an application of the Tobit model. Journal of Economic and Administrative Sciences, 23(2), 44-70.

Alt, R., Fortin, I., y Weinberger, S. (2011). The Monday effect revisited: An alternative testing approach. Journal of Empirical Finance, 18(3), 447-460.

Álvarez, J. A. (2008). La banca española ante la actual crisis financiera. Estabilidad financiera, 15, 21-38.

Amihud, Y., y Murgia, M. (1997). Dividends, taxes, and signaling: evidence from Germany. The Journal of Finance, 52(1), 397-408.

Andrés Sánchez, J. D., y Fernández Bariviera, A. (2004). Análisis de la estacionalidad diaria en el Mercado español de bonos y obligaciones del Estado. Boletín ICE Económico: Información Comercial Española, (2804), 21-29.

Andreu, L., Diez, N., Ortiz, C. y Sarto, J. L. (2012). What Determines Investors' Purchases and Redemptions?. Journal of Behavioral Finance, 13(4), 241-250.

Andreu, L., y Sarto, J. L. (2016). Financial consequences of mutual fund mergers. The European Journal of Finance, 22(7), 529-550.

Ang, J. S. (1987). Do dividends matter?: A review of corporate dividend theories and evidence (No. 2). Salomon Brothers Center for the Study of Financial Institutions, Graduate School of Business Administration, New York University.

Apolinario, R. M. C., Santana, O. M., Sales, L. J., y Caro, A. R. (2006). Day of the week effect on European stock markets. International research journal of Finance and Economics, 2(1), 53-70. 
Aragó Manzana, V., y Fernández Izquierdo, M.A. (2003). Monthly seasonality of the returns and volatility of the IBEX-35 index and its futures contract. Applied Economics Letters, 10(3), 129-133.

Ariel, R. A. (1987). A monthly effect in stock returns. Journal of Financial Economics, 18(1), 161-174.

Ariel, R. A. (1990). High stock returns before holidays: Existence and evidence on possible causes. The Journal of Finance, 45(5), 1611-1626.

Arsad, Z., y Andrew Coutts, J. (1997). Security price anomalies in the London International Stock Exchange: a 60 year perspective. Applied Financial Economics, 7(5), 455-464.

Asquith, P., y Mullins Jr, D. W. (1983). The impact of initiating dividend payments on shareholders' wealth. Journal of business, 77-96.

Atanasova, C. V., y Hudson, R. S. (2010). Technical trading rules and calendar anomalies-Are they the same phenomena?. Economics Letters, 106(2), 128-130.

Ayadi, R., Arbak, E., y Pieter De Groen, W. (2011). Business Models in European Banking: A pre-and post-crisis screening. Center for European Policy Studies.

Baele, L., Bekaert, G., y Inghelbrecht, K. (2010). The determinants of stock and bond return comovements. Review of Financial Studies, 23(6), 2374-2428.

Baker, H. K., y Powell, G. E. (1999). How corporate managers view dividend policy. Quarterly Journal of Business and Economics, 17-35.

Baker, H. K., Rahman, A., y Saadi, S. (2008). The day-of-the-week effect and conditional volatility: Sensitivity of error distributional assumptions. Review of Financial Economics, 17(4), 280-295.

Baker, M. P., y Wurgler, J. (2002). Why are dividends disappearing? An empirical analysis. Working Paper, Harvard Business School.

Balbina, M., y Martins, N. C. (2002). The analysis of calendar effects on the daily returns of the Portuguese stock market: the weekend and public holiday effects. Banco de Portugal Economic Bulletin, 8, 31-8. 
Ball, C., Torous, W., y Tschoegl, A. (1982). Gold and the weekend effect. Journal of Futures Markets, 2(2), 175-182.

Bange, M. M., y Miller, T. W. (2004). Return momentum and global portfolio allocations. Journal of Empirical Finance, 11(4), 429-459.

Barber, B. M., Odean, T. y Zheng, L. (2005). Out of sight, out of mind: The effects of expenses on mutual fund flows. The Journal of Business, 78(6), 2095-2120.

Barberis, N., Huang, M. y Santos, T. (2001). Prospect theory and asset prices. Quarterly Journal of Economics, 116(1), 1-53.

Barberis, N. y Xiong, W. (2009). What Drives the Disposition Effect? An Analysis of a Long-Standing Preference-Based Explanation. The Journal of Finance, 64(2), 751-784.

Barberis, N. y Xiong, W. (2012). Realization utility. Journal of Financial Economics, 104(2), 251-271.

Barclay, M. J., Smith, C. W., y Watts, R. L. (1995). The determinants of corporate leverage and dividend policies. Journal of applied corporate finance, 7(4), 4-19.

Barone, E. (1990). The Italian stock market: efficiency and calendar anomalies. Journal of Banking \& Finance, 14(2), 483-510.

Barrell, R., y Davis, E. P. (2008). The Evolution of the Financial Crisis of 20078. National Institute Economic Review, 206(1), 5-14.

Basher, S. A., y Sadorsky, P. (2006). Day of the week effects in emerging stock markets. Applied Economics Letters, 13(10), 621-628.

Benartzi, S., Michaely, R., y Thaler, R. (1997). Do changes in dividends signal the future or the past?. The Journal of Finance, 52(3), 1007-1034.

Ben-David, I. (2010). Dividend policy decisions. Hoboken: Wiley.

Ben-David, I., Franzoni, F., y Moussawi, R. (2012). Hedge fund stock trading in the financial crisis of 2007-2009. Review of Financial Studies, 25(1), 1-54. 
Ben-David, I. y Hirshleifer, D. (2012). Are investors really reluctant to realize their losses? Trading responses to past returns and the disposition effect. Review of Financial Studies, 25(8), 2485-2532.

Benson, K. L. y Humphrey, J. E. (2008). Socially responsible investment funds: Investor reaction to current and past returns. Journal of Banking \& Finance, 32(9), 1850-1859.

Berument, H., y Kiymaz, H. (2001). The day of the week effect on stock market volatility. Journal of economics and finance, 25(2), 181-193.

Beyer, S., Garcia-Feijoo, L., y Jensen, G. R. (2013). Can you capitalize on the turn of the year effect?. Applied Financial Economics, 23(18), 1457-1468.

Bhattacharya, S. (1979). Imperfect information, dividend policy, and "the bird in the hand" fallacy. Bell journal of economics, 10(1), 259-270.

Bialkowski, J., Etebari, A., y Wisniewski, T. P. (2012). Fast profits: Investor sentiment and stock returns during Ramadan. Journal of Banking \& Finance, 36(3), 835-845.

Bialkowski, J. y Starks, L. T. (2016). Sri funds: Investor demand, exogenous shocks and ESG profiles. (No. 16/11).

Bildik, R. (2004). Are calendar anomalies still alive? Evidence from Istanbul stock exchange. Istanbul Stock Exchange.

Billett, M. T., Jiang, Z., y Rego, L. L. (2014). Glamour brands and glamour stocks. Journal of Economic Behavior \& Organization, 107, 744-759.

Birau, F. R. (2012). The impact of behavioral finance on stock markets. AnnalsEconomy Series, 3, 45-50.

Black, F. (1972). Capital market equilibrium with restricted borrowing. The Journal of Business, 45(3), 444-455.

Black, F., y Scholes, M. (1974). The effects of dividend yield and dividend policy on common stock prices and returns. Journal of financial economics, 1(1), 1-22.

Black, F. (1976). The dividend puzzle. The Journal of Portfolio Management, 2(2), 5-8. 
Bley, J., y Saad, M. (2010). Cross-cultural differences in seasonality. International Review of Financial Analysis, 19(4), 306-312.

Bollen, N. P. (2007). Mutual fund attributes and investor behavior. Journal of Financial and Quantitative Analysis, 42(03), 683-708.

Bollerslev, T. (1986). Generalized autoregressive conditional heteroskedasticity. Journal of econometrics, 31(3), 307-327.

Booij, A. S., Leuven, E., y Oosterbeek, H. (2008). The role of information in the takeup of student loans. Tinbergen Institute Discussion Paper No. TI 2008-039/3.

Borges, M. (2009). Calendar effects in stock markets: Critique of previous methodologies and recent evidence in european countries (No. 2009/37). ISEG-School of Economics and Management, Department of Economics, University of Lisbon.

Bouman, S., y Jacobsen, B. (2002). The Halloween indicator, "Sell in May and go away": Another puzzle. The American Economic Review, 92(5), 1618-1635.

Boyle, G., Hagan, A., O'connor, R. S., y Whitwell, N. (2004). Emotion, fear and superstition in the New Zealand stockmarket. New Zealand Economic Papers, 38(1), 65-86.

Branch, B. (1977). A tax loss trading rule. The Journal of Business, 50(2), 198-207.

Brav, A., y Heaton, J. B. (2002). Competing theories of financial anomalies. Review of Financial Studies, 15(2), 575-606.

Brav, A., Graham, J. R., Harvey, C. R., y Michaely, R. (2005). Payout policy in the 21st century. Journal of financial economics, 77(3), 483-527.

Brealey, R., Leland, H. E., y Pyle, D. H. (1977). Informational asymmetries, financial structure, and financial intermediation. The journal of Finance, 32(2), 371-387.

Brealey, R. A. y Myers, S. C. (2003). Principles of corporate finance, 7th edition. McGraw-Hill, New York.

Brealey, R. A., Myers, S. C., Allen, F., y Mohanty, P. (2005). Principles of corporate finance, 8th edition. McGraw-Hill, New York. 
Brennan, M. J. (1970). Taxes, market valuation and corporate financial policy. National Tax Journal, 23(4), 417-427.

Brevers, D., He, Q., Xue, G., y Bechara, A. (2017). Neural correlates of the impact of prior outcomes on subsequent monetary decision-making in frequent poker players. Biological Psychology, 124, 30-38.

Brown, P., Keim, D. B., Kleidon, A. W., y Marsh, T. A. (1983). Stock return seasonalities and the tax-loss selling hypothesis: Analysis of the arguments and Australian evidence. Journal of Financial Economics, 12(1), 105-127.

Brown, P., Chappel, N., da Silva Rosa, R. y Walter, T. (2006). The reach of the disposition effect: Large sample evidence across investor classes. International Review of Finance, 6(1-2), 43-78.

Brusa, J., Liu, P., y Schulman, C. (2000). The weekend effect, 'reverse' weekend effect, and firm size. Journal of Business Finance \& Accounting, 27(5-6), 555-574.

Brusa, J., Liu, P., y Schulman, C. (2003). The weekend and 'reverse' weekend effects: an analysis by month of the year, week of the month, and industry. Journal of Business Finance \& Accounting, 30(5-6), 863-890.

Brusa, J., Liu, P., y Schulman, C. (2005). Weekend effect, 'reverse'weekend effect, and investor trading activities. Journal of Business Finance \& Accounting, 32(7-8), 14951517.

Cáceres, R. M., Santana, O. M., Sales, L. J., y Caro, A. R. (2006). Day of the week effect on European stock markets. International research journal of Finance and Economics, 2(1), 53-70.

Cadsby, C. B., y Ratner, M. (1992). Turn-of-month and pre-holiday effects on stock returns: Some international evidence. Journal of Banking \& Finance, 16(3), 497-509.

Camerer, C. F., Loewenstein, G., y Prelec, D. (2004). Neuroeconomics: Why economics needs brains. The Scandinavian Journal of Economics, 106(3), 555-579.

Camino, D. (1997). Efectos intradía y día de la semana en la Bolsa de Madrid. Información y volumen de contratación. Revista Española de Financiación y Contabilidad, 90, 51-75. 
Campbell, J. Y., Lo, A. W. C., y MacKinlay, A. C. (1997). The econometrics of financial markets, 2, 149-180. Princeton, NJ: Princeton University Press.

Campbell, J. Y., Sunderam, A., y Viceira, L. M. (2013). Inflation bets or deflation hedges? The changing risks of nominal bonds. Working Paper, Harvard University.

Campello, M. (2012). Contemporary corporate finance research on South America. Journal of Corporate Finance, 18(4), 879-882.

Carchano, Ó., y Pardo, Á. (2015). The pan-European holiday effect. Spanish Journal of Finance and Accounting/Revista Española de Financiacion y Contabilidad, 44(2), 134145.

Carhart, M. M. (1997). On persistence in mutual fund performance. The Journal of finance, 52(1), 57-82.

Cassar, A., y Wydick, B. (2010). Does social capital matter? Evidence from a fivecountry group lending experiment. Oxford Economic Papers, 62(4), 715-739.

Cerqueira Leal, C., Rocha Armada, M. J. y Duque, J. C. (2010). Are all individual investors equally prone to the disposition effect all the time? New evidence from a small market. Frontiers in Finance and Economics, 7(2), 38-68.

Chandra, M. (2006). The day of the week effect in conditional correlation. Review of Quantitative Finance and Accounting, 27(3), 297-310.

Chang, E. C., Pinegar, J. M., y Ravichandran, R. (1993). International evidence on the robustness of the day of the week effect. Journal of Financial and quantitative Analysis, 28(04), 497-513.

Chang, T. Y., Solomon, D. H. y Westerfield, M. M. (2016). Looking for someone to blame: Delegation, cognitive dissonance, and the disposition effect. The Journal of Finance, 71(1), 267-302.

Chantarat, S., y Barrett, C. B. (2007). Social network capital, economic mobility and poverty traps. MRA Paper 1947: 1-56.

Charles, A. (2010). Does the day of the week effect on volatility improve the volatility forecasts? Applied Economics Letters, 17(3), 257-262. 
Chen, C. R., y Chan, A. (1997). From T-Bills to Stocks: Seasonal Anomalies Revisited. Journal of Business Finance \& Accounting, 24(5), 573-592.

Chen, H., y Singal, V. (2003). Role of speculative short sales in price formation: The case of the weekend effect. The Journal of Finance, 58(2), 685-706.

Chen, H., y Singal, V. (2004). All things considered, taxes drive the January effect. Journal of Financial Research, 27(3), 351-372.

Cheng, T. Y., Lee, C. I., Lin, C. H. y Li, H. C. (2009). A direct test of the link between the disposition effect and profitability in futures market. Working Paper.

Chevalier, J. y Ellison, G. (1997). Risk taking by mutual funds as a response to incentives. Journal of Political Economy, 105(6), 1167-1200.

Chiang, R. C., y Tapley, T. C. (1983). Day of the week effects and the futures market. Review of Research in Futures Markets, 2(3), 356-410.

Cho, Y. H., Linton, O., y Whang, Y. J. (2007). Are there Monday effects in stock returns: A stochastic dominance approach. Journal of Empirical Finance, 14(5), 736755.

Choe, H. y Eom, Y. (2009). The disposition effect and investment performance in the futures market. Journal of Futures Markets, 29(6), 496-522.

Chong, R., Hudson, R., Keasey, K., y Littler, K. (2005). Pre-holiday effects: International evidence on the decline and reversal of a stock market anomaly. Journal of International Money and Finance, 24(8), 1226-1236.

Choudhry, T. (2000). Day of the week effect in emerging Asian stock markets: evidence from the GARCH model. Journal of Financial Economics, 10(3), 235-242.

Chow, E. H., Hsiao, P., y Solt, M. E. (1997). Trading returns for the weekend effect using intraday data. Journal of Business Finance \& Accounting, 24(3), 425-444.

Christophe, S. E., Ferri, M. G., y Angel, J. J. (2009). Short selling and the weekend effect in Nasdaq stock returns. Financial Review, 44(1), 31-57. 
Ciccone, S. J. (2011). Investor optimism, false hopes and the January effect. Journal of Behavioral Finance, 12(3), 158-168.

Coleman, L. (2007). Risk and decision making by finance executives: a survey study. International Journal of Managerial Finance, 3(1), 108-124.

Comment, R., y Jarrell, G. A. (1991). The relative signalling power of Dutch-auction and fixed-price self-tender offers and open-market share repurchases. The Journal of Finance, 46(4), 1243-1271.

Compton, W., A. Kunkel, R., y Kuhlemeyer, G. (2013). Calendar anomalies in Russian stocks and bonds. Managerial Finance, 39(12), 1138-1154.

Connolly, R. A. (1989). An examination of the robustness of the weekend effect. Journal of Financial and quantitative Analysis, 24(02), 133-169.

Connolly, R. A. (1991). A posterior odds analysis of the weekend effect. Journal of Econometrics, 49(1), 51-104.

Corredor, P., y Santamaría, R. (1996). El efecto día de la semana: resultados sobre algunos mercados de valores europeos. Revista Española de Financiación y Contabilidad, 25(86), 235-252.

Coval, J. D. y Shumway, T. (2005). Do behavioral biases affect prices? The Journal of Finance, 60(1), 1-34.

Crain, S. J., y Lee, J. H. (1996). Volatility in wheat spot and futures markets, 1950-1993: Government farm programs, seasonality, and causality. The journal of finance, 51(1), 325-343.

Cronqvist, H. y Siegel, S. (2014). The genetics of investment biases. Journal of Financial Economics, 113(2), 215-234.

Cross, F. (1973). The behavior of stock prices on Fridays and Mondays. Financial Analysts Journal, 29(6), 67-69.

Cyert, R., y March, J. (1993). A behavioral theory of the firm. Massachusetts: Blackwell. 
Da Costa, N., Goulart, M., Cupertino, C., Macedo, J. y Da Silva, S. (2013). The disposition effect and investor experience. Journal of Banking \& Finance, 37(5), 16691675.

Darrat, A. F., Li, B., Liu, B., y Su, J. J. (2011). A fresh look at seasonal anomalies: An international perspective. International Journal of Business and Economics, 10(2), 93.

Davidson, S., y Faff, R. (1999). Some additional Australian evidence on the day of the week effect. Applied Economics Letters, 6(4), 247-249.

De Andrés Sánchez, J. (2007). Los efectos "enero" y "cambio de año" en los mercados españoles de renta fija a medio y largo plazo: evidencia empírica 2000-2005. In Decisiones basadas en el conocimiento y en el papel social de la empresa: XX Congreso anual de AEDEM (p. 8). Asociación Española de Dirección y Economía de la Empresa (AEDEM).

De Bondt, W. F., y Thaler, R. (1985). Does the stock market overreact?. The Journal of finance, 40(3), 793-805.

De Meza, D., Irlenbusch, B., y Reyniers, D. (2008). Financial capability: A behavioural economics perspective. London: Financial Services Authority.

De Mingo López, D.V. y Matallín Sáez, J.C. (2017). Should investors care about fund portfolio turnover? Working Paper.

DeAngelo, H., DeAngelo, L., y Skinner, D. J. (1992). Dividends and losses. The Journal of Finance, 47(5), 1837-1863.

DeAngelo, H., DeAngelo, L., y Stulz, R. M. (2006). Dividend policy and the earned/contributed capital mix: a test of the life-cycle theory. Journal of Financial economics, 81(2), 227-254.

DeAngelo, H., y DeAngelo, L. (2006). The irrelevance of the MM dividend irrelevance theorem. Journal of financial economics, 79(2), 293-315.

Deldin, P. J., y Levin, I. P. (1986). The effect of mood induction in a risky decisionmaking task. Bulletin of the Psychonomic Society, 24(1), 4-6. 
Demyanyk, Y., y Van Hemert, O. (2011). Understanding the subprime mortgage crisis. Review of financial Studies, 24(6), 1848-1880.

Deshmukh, S. (2005). The effect of asymmetric information on dividend policy. Quarterly Journal of Business and Economics, 107-127.

Díez Esteban, J. M., y López de Foronda Pérez, Ó. (2001). La política de dividendos de las empresas españolas: un ajuste parcial al objetivo de reparto. Cuadernos de Estudios Empresariales, (Vol. 11), 141-159.

D'Mello, R., Ferris, S. P., y Hwang, C. Y. (2003). The tax-loss selling hypothesis, market liquidity, and price pressure around the turn of the year. Journal of Financial Markets, 6(1), 73-98.

Dodd O. y Gakhovich A. (2011). The holiday effect in central and eastern European financial market. Investment Management and Financial Innovation, 8(4), 29-35.

Doeswijk, R. Q. (2008). The optimism cycle: Sell in May. De Economist, 156(2), 175200.

Don, M., Bergsma, K., y Jiang, D. (2016). The pre-holiday corporate announcement effect. Unpublished paper.

Dubois, M., y Louvet, P. (1996). The day of the week effect: The international evidence. Journal of Banking \& Finance, 20(9), 1463-1484.

Duflo, E., y Sáez, E. (2003). The role of information and social interactions in retirement plan decisions: Evidence from a randomized experiment. The Quarterly journal of economics, 118(3), 815-842.

Dyl, E. A. (1977). Capital gains taxation and year-end stock market behavior. The Journal of Finance, 32(1), 165-175.

Easterbrook, F. H. (1984). Two agency-cost explanations of dividends. The American Economic Review, 74(4), 650-659.

Easterday, K. E., y Sen, P. K. (2016). Is the January effect rational? Insights from the accounting valuation model. The Quarterly Review of Economics and Finance, 59, 168185. 
Edmans, A. (2011). Does the stock market fully value intangibles? Employee satisfaction and equity prices. Journal of Financial Economics, 101(3), 621-640.

El Ghoul, S. y Karoui, A. (2017). Does corporate social responsibility affect mutual fund performance and flows?. Journal of Banking \& Finance, 77, 53-63.

Enders, W. (2004). Applied Econometric Time Series, 2nd Edition. Wiley Series in Probability and Statistics.

Engle, R. F. (1982). Autoregressive conditional heteroscedasticity with estimates of the variance of United Kingdom inflation. Econometrica: Journal of the Econometric Society, 50, 987-1008.

Ersoy, E., y Çetenak, E. H. (2015). The impact of ownership concentration on dividend payout policy: Evidence from Turkey. Ege Academic Review (2015), 15(4), 509-521.

Espitia Escuer, M., y Ruiz Cabestre, F. J. (1996). El pago de dividendos en el mercado bursátil español: análisis de la rentabilidad exdividendo. Moneda y Crédito: Revista de Economía, (203), 123-148.

Fabozzi, F. J., Ma, C. K., y Briley, J. E. (1994). Holiday trading in futures markets. The Journal of Finance, 49(1), 307-324.

Fama, E. F. (1965). The behavior of stock market prices. The journal of Business, 28, 34-105.

Fama, E. F. (1970). Efficient capital markets: A review of theory and empirical work. The Journal of Finance, 25(2), 383-417.

Fama, E. F. (1991). Efficient capital markets: II. The journal of finance, 46(5), 15751617.

Fama, E. F., y French, K. R. (1993). Common risk factors in the returns on stocks and bonds. Journal of financial economics, 33(1), 3-56.

Fama, E. F. (1998). Market efficiency, long-term returns, and behavioral finance. Journal of financial economics, 49(3), 283-306. 
Fama, E. F., y French, K. R. (2001). Disappearing dividends: changing firm characteristics or lower propensity to pay?. Journal of Financial economics, 60(1), 3-43.

Farrelly, G. E., y Baker, H. K. (1989). Corporate dividends: views of institutional investors. Akron Business and Economic Review, 20, 89-100.

Farre-Mensa, J., Michaely, R., y Schmalz, M. C. (2014). Dividend policy. Ross School of Business Paper, (1227).

Feldstein, M. S., y Green, J. R. (1983). Why do companies pay dividends?. American Economic Review, 73, 7-30.

Feng, L. y Seasholes, M. S. (2005). Do investor sophistication and trading experience eliminate behavioral biases in financial markets?. Review of Finance, 9(3), 305-351.

Fernández, P., e Yzaguirre, J. (1995). IBEX 35: Análisis e investigaciones. Barcelona: Ediciones Internacionales Universitarias.

Ferris, S. P., Haugen, R. A. y Makhija, A. K. (1988). Predicting contemporary volume with historic volume at differential price levels: Evidence supporting the disposition effect. The Journal of Finance, 43(3), 677-697.

Fidrmuc, J. P., y Jacob, M. (2010). Culture, agency costs, and dividends. Journal of Comparative Economics, 38(3), 321-339.

Fields, M. J. (1931). Stock prices: a problem in verification. The Journal of Business of the University of Chicago, 4(4), 415-418.

Fields, M. J. (1934). Security prices and stock exchange holidays in relation to short selling. The Journal of Business of the University of Chicago, 7(4), 328-338.

Fisher, L. (1966). Some new stock market indexes. The Journal of Business, 39(1), 191225.

Fosback, N. G. (1976). Stock Market Logic: A sophisti-cated approach to profits on Wall Street. The Institute for Econometric Research, Fort Lauderdale, Fla.

Frankfurter, G. M., y Lane, W. R. (1984). The rationality of dividends. International Review of Financial Analysis, 1, 115-130. 
Frankfurter, G. M., y Wood Jr, B. G. (1997). The evolution of corporate dividend policy. Journal of Financial Education, 16-33.

Frazzini, A. (2006). The disposition effect and underreaction to news. The Journal of Finance, 61(4), 2017-2046.

French, K. R. (1980). Stock returns and the weekend effect. Journal of financial economics, 8(1), 55-69.

Friday, H. S., y Hoang, N. (2015). Seasonality in the Vietnam Stock Index. The International Journal of Business and Finance Research, 9(1), 103.

Frieder, L., y Subrahmanyam, A. (2004). Nonsecular regularities in returns and volume. Financial Analysts Journal, 60(4), 29-34.

Frydman, C. y Rangel, A. (2014). Debiasing the disposition effect by reducing the saliency of information about a stock's purchase price. Journal of economic behavior \& organization, 107, 541-552.

Frydman, C. y Camerer, C. (2016). Neural evidence of regret and its implications for investor behavior. Review of Financial Studies, 29(11), 3108-3139.

Gama, P. M., y Vieira, E. F. (2013). Another look at the holiday effect. Applied Financial Economics, 23(20), 1623-1633.

Gao, P., Hao, J., Kalcheva, I., y Ma, T. (2015). Short sales and the weekend effectEvidence from a natural experiment. Journal of Financial Markets, 26, 85-102.

García, J. (2007). Return autocorrelation anomalies in two European stock markets. Revista de Análisis Económico, 22(1), 59-70.

García, J. (2008). Rendimientos estacionales en la bolsa española: importancia del tamaño de la empresa. Spanish Journal of Finance and Accounting/Revista Española de Financiación y Contabilidad, 37(139), 527-540.

García-Borbolla Fernández, A., y Larrán Jorge, M. (2005). Factores explicativos de la política de dividendos: evidencias empíricas en mercados bursátiles europeos. Boletín de Estudios Económicos, 60(185), 209-227. 
Gardeazabal, J., y Regulez, M. (2004). A factor model of seasonality in stock returns. The Quarterly Review of Economics and Finance, 44(2), 224-236.

Gaver, J. J., y Gaver, K. M. (1993). Additional evidence on the association between the investment opportunity set and corporate financing, dividend, and compensation policies. Journal of accounting and economics, 16(1), 125-160.

Gay, G. D., y Kim, T. H. (1987). An investigation into seasonality in the futures market. Journal of Futures Markets, 7(2), 169-181.

Gerlach, J. R. (2007). Macroeconomic news and stock market calendar and weather anomalies. Journal of Financial Research, 30(2), 283-300.

Ghazani, M. M., y Araghi, M. K. (2014). Evaluation of the adaptive market hypothesis as an evolutionary perspective on market efficiency: Evidence from the Tehran stock exchange. Research in International Business and Finance, 32, 50-59.

Gibbons, M. R., y Hess, P. (1981). Day of the week effect and asset returns. Journal of Business, 54(4), 579-596.

Gimenez, A. P. (1994). La estacionalidad diaria del mercado de acciones español. Investigaciones Económicas, 18(3), 557-569.

Giner, E., y Fumás, V. S. (1995). Explicaciones alternativas para la política de dividendos: análisis empírico con datos empresariales espanyoles. Investigaciones Económicas, 19(3), 329-348.

Golembiewski, R. T. (1988). Nobel Laureate Simon" Looks Back": A low-frequency model. Public Administration Quarterly, 12, 259-274.

Gonedes, N. J. (1978). Corporate signaling, external accounting, and capital market equilibrium: Evidence on dividends, income, and extraordinary items. Journal of Accounting Research, 26-79.

Gordon, M. J. (1959). Dividends, earnings, and stock prices. The review of economics and statistics, 41, 99-105. 
Gottschalk, K., Bohl, M. T., Henke, H., y Pál, R. (2006). Institutional investors and stock market efficiency: The case of the January anomaly. European University Viadrina Postgraduate Research Programme Working Paper.

Grinblatt, M. y Keloharju, M. (2001). What makes investors trade?. The Journal of Finance, 56(2), 589-616.

Grossman, S. J., y Stiglitz, J. E. (1980). On the impossibility of informationally efficient markets. The American economic review, 70(3), 393-408.

Grullon, G., y Michaely, R. (2000). Dividends, share repurchases, and the substitution hypothesis. Unpublished working paper, Rice University and Cornell University.

Grullon, G., y Michaely, R. (2002). Dividends, share repurchases, and the substitution hypothesis. The Journal of Finance, 57(4), 1649-1684.

Grullon, G., Michaely, R., Benartzi, S., y Thaler, R. H. (2005). Dividend changes do not signal changes in future profitability. Journal of Business, 78(5), 1659-1682.

Gu, A. Y. (2003). The declining January effect: evidences from the US equity markets. The Quarterly Review of Economics and Finance, 43(2), 395-404.

Guler, S. (2013). January effect in stock returns: Evidence from emerging markets. Interdisciplinary Journal of Contemporary Research in Business, 5(4),641-648.

Gultekin, M. N., y Gultekin, N. B. (1983). Stock market seasonality: International evidence. Journal of Financial Economics, 12(4), 469-481.

Guo, J. (2015). Causal relationship between stock returns and real economic growth in the pre-and post-crisis period: evidence from China. Applied Economics, 47(1), 12-31.

Hansen, P. R., y Lunde, A. (2005). A forecast comparison of volatility models: does anything beat a GARCH $(1,1)$ ?. Journal of applied econometrics, 20(7), 873-889.

Harford, J. (1999). Corporate cash reserves and acquisitions. The Journal of Finance, 54(6), 1969-1997.

Harford, J., Mansi, S. A., y Maxwell, W. F. (2005). Corporate governance and a firm's cash holdings. Journal of Financial Economics, 87, 535-555. 
Hashmi, M. A. (2014). January effect in Pakistan: A Time Series Analysis. Market Forces, 9(1).

Haug, M., y Hirschey, M. (2006). The january effect. Financial Analysts Journal, 62(5), 78-88.

Haugen, R. A., y Lakonishok, J. (1988). The Incredible January Effect: The Stock market's unsolved mystery, Irwin, Homewood, IL.

Healy, P. M., y Palepu, K. G. (1988). Earnings information conveyed by dividend initiations and omissions. Journal of financial Economics, 21(2), 149-175.

Heath, C., Huddart, S. y Lang, M. (1998). Psychological factors and stock option exercise. The Quarterly Journal of Economics, 114(2), 601-628.

Heitmann, A. (2016). Yes, the January effect still exists. Empirical evidence from Germany.

Hellström, G., e Inagambaev, G. (2012). Determinants of dividend payout ratios: a study of Swedish large and medium caps. Sweden Umeå School of Business and Economics.

Hens, T. y Vlcek, M. (2011). Does prospect theory explain the disposition effect?. Journal of Behavioral Finance, 12(3), 141-157.

Heras, A. D. L., y Nave Juan, M. (2004). Análisis no paramétrico de estacionalidad en los rendimientos de la Deuda Pública española. Revista de Economía financiera, (2), $65-79$.

Hindmarch, S., Jentsch, D., y Drew, D. (1984). A note on Canadian stock returns and the weekend effect. Journal of Business Administration, 14(2), 163-172.

Hirshleifer, D., Subrahmanyam, A., y Titman, S. (2006). Feedback and the success of irrational investors. Journal of Financial Economics, 81(2), 311-338.

Hoberg, G., y Prabhala, N. R. (2009). Disappearing dividends, catering, and risk. Review of financial studies, 22(1), 79-116. 
Holden, K., Thompson, J., y Ruangrit, Y. (2005). The Asian crisis and calendar effects on stock returns in Thailand. European Journal of Operational Research, 163(1), 242252.

Holm, C., y Rikhardsson, P. (2006). Experienced and novice investors: Does environmental information influence on investment allocation decisions? (Vol. 2006, No. 02). University of Aarhus, Aarhus School of Business, Department of Business Studies.

Hsieh, D. A. (1988). The statistical properties of daily foreign exchange rates: 19741983. Journal of international economics, 24(1-2), 129-145.

Huang, J., Wei, K. D. y Yan, H. (2007). Participation costs and the sensitivity of fund flows to past performance. The Journal of Finance, 62(3), 1273-1311.

Huber, J., Kirchler, M., y Stefan, M. (2014). Experimental evidence on varying uncertainty and skewness in laboratory double-auction markets. Journal of Economic Behavior \& Organization, 107, 798-809.

Hui, E. C., y Chan, K. K. K. (2015). Testing calendar effects on global securitized real estate markets by Shiryaev-Zhou index. Habitat International, 48, 38-45.

Hull, M., y McGroarty, F. (2014). Do emerging markets become more efficient as they develop? Long memory persistence in equity indices. Emerging Markets Review, 18, 45-61.

Hung, A., Meijer, E., Mihaly, K., y Yoong, J. (2009). Building up, spending down: financial literacy, retirement savings management, and decumulation (No.712). RAND Corporation Publications Department.

Hwang, S., y Salmon, M. (2004). Market stress and herding. Journal of Empirical Finance, 11(4), 585-616.

Hytönen, K., Baltussen, G., Van den Assem, M. J., Klucharev, V., Sanfey, A. G., y Smidts, A. (2014). Path dependence in risky choice: Affective and deliberative processes in brain and behavior. Journal of Economic Behavior \& Organization, 107, 566-581. 
Ikenberry, D., Lakonishok, J., y Vermaelen, T. (1995). Market underreaction to open market share repurchases. Journal of financial economics, 39(2), 181-208.

Ikenberry, D., Lakonishok, J., y Vermaelen, T. (2000). Stock repurchases in Canada: Performance and strategic trading. Journal of Finance, 55(5), 2373-2397.

Inyiama, E., Okwo, M., y Oliver, I. (2015). Dividend payout policy determinants of selected brewery firms in Nigeria. A meta analysis (2000-2013).

Ivković, Z. y Weisbenner, S. (2009). Individual investor mutual fund flows. Journal of Financial Economics, 92(2), 223-237.

Jacob, M., y Jacob, M. (2013). Taxation, dividends, and share repurchases: Taking evidence global. Journal of Financial and Quantitative Analysis, 48(04), 1241-1269.

Jacobs, B. I., y Levy, K. N. (1988). Calendar anomalies: Abnormal returns at calendar turning points. Financial Analysts Journal, 44(6), 28-39.

Jacobsen, B., y Visaltanachoti, N. (2009). The Halloween effect in US sectors. Financial Review, 44(3), 437-459.

Jacobsen, B., y Zhang, C. Y. (2013). Are monthly seasonals real? A three century perspective. Review of Finance, 17(5), 1743-1785.

Jacobsen, B., Lee, J. B., Marquering, W., y Zhang, C. Y. (2014). Gender differences in optimism and asset allocation. Journal of Economic Behavior \& Organization, 107, 630-651.

Jaffe, J. F., y Westerfield, R. (1985). The weekend effect in common stock returns: The international evidence. The journal of finance, 40(2), 433-454.

Jaffe, J. F., Westerfield, R., y Ma, C. (1989). A twist on the Monday effect in stock prices: Evidence from the U.S. and foreign stock markets. Journal of Banking \& Finance, 13(4-5), 641-650.

Jensen, M. C. (1968). The performance of mutual funds in the period 1945-1964. The Journal of finance, 23(2), 389-416. 
Jensen, M. C. (1986). Agency cost of free cash flow, corporate finance, and takeovers. Corporate Finance, and Takeovers. American Economic Review, 76, 323-329.

Jensen, G. R., y Johnson, J. M. (1995). The dynamics of corporate dividend reductions. Financial Management, 31-51.

Jo, H., y Kim, D. M. K. (2008). Recent development of behavioral finance. International Journal of Business Research, 8(2).

John, K., y Williams, J. (1985). Dividends, dilution, and taxes: A signalling equilibrium. Journal of Finance, 40(4), 1053-1070.

John, K., y Knyazeva, A. (2008). Corporate governance and payout commitments. Working paper, New York University.

Jones, C. P., Pearce, D. K., y Wilson, J. W. (1987). Can tax-loss selling explain the January effect? A note. The Journal of Finance, 42(2), 453-461.

Jones, E. (2008). International weekend-effect: 1998-2007. Journal of International Business \& Economics, 8, 55-69.

Junkus, J. C. (1986). Weekend and day of the week effects in returns on stock index futures. Journal of Futures Markets, 6(3), 397-407.

Jureviciene, D., y Jermakova, K. (2012). The impact of individuals' financial behaviour on investment decisions. In Electronic International Interdisciplinary Conference (pp. 242-250).

Kahneman, D., y Tversky, A. (1979). Prospect theory: An analysis of decision under risk. Econometrica: Journal of the econometric society, 263-291.

Kahneman, D. (2002). Nobel lecture. Stockholm, Sweden.

Kahneman, D. (2003). Maps of bounded rationality: Psychology for behavioral economics. The American economic review, 93(5), 1449-1475.

Kalay, A., y Loewenstein, U. (1986). The informational content of the timing of dividend announcements. Journal of Financial Economics, 16(3), 373-388. 
Kamara, A. (1997). New evidence on the Monday seasonal in stock returns. Journal of Business, 70(1), 63-84.

Kamstra, M. J., Kramer, L. A., y Levi, M. D. (2003). Winter blues: A SAD stock market cycle. The American Economic Review, 93(1), 324-343.

Kannadhasan, M. (2006). Role of behavioural finance in investment Decisions. Retrieved December, 29, 2014.

Kato, K., y Schallheim, J. S. (1985). Seasonal and size anomalies in the Japanese stock market. Journal of Financial and Quantitative Analysis, 20(02), 243-260.

Kaustia, M. (2010). Prospect Theory and the Disposition Effect. Journal of Financial and Quantitative Analysis, 45(03), 791-812.

Kayaçetin, V., y Lekpek, S. (2016). Turn-of-the-month effect: New evidence from an emerging stock market. Finance Research Letters, 18, 142-157

Keef, S. P., y Roush, M. L. (2005). Day of the week effects in the pre-holiday returns of the Standard \& Poor's 500 stock index. Applied Financial Economics, 15(2), 107-119.

Keim, D. B. (1983). Size-related anomalies and stock return seasonality: Further empirical evidence. Journal of financial economics, 12(1), 13-32.

Keim, D. B., y Stambaugh, R. F. (1984). A further investigation of the weekend effect in stock returns. The journal of finance, 39(3), 819-835.

Keim, D. B. (1989). Trading patterns, bid-ask spreads, and estimated security returns: The case of common stocks at calendar turning points. Journal of Financial Economics, 25(1), 75-97.

Khaled, M. S., y Keef, S. P. (2012). A note on the turn of the month and year effects in international stock returns. The European Journal of Finance, 18(6), 597-602.

Kim, C. W., y Park, J. (1994). Holiday effects and stock returns: Further evidence. Journal of Financial and Quantitative Analysis, 29(01), 145-157. 
Kim, S. H., y Kim, D. (2014). Investor sentiment from internet message postings and the predictability of stock returns. Journal of Economic Behavior \& Organization, 107, 708-729.

Knight, J. y Satchell, S. (2007). Forecasting Volatility in the Financial Markets. 3rd Edition, Butterworth Heinemann.

Kohers, G., Kohers, N., Pandey, V., y Kohers, T. (2004). The disappearing day-of-theweek effect in the world's largest equity markets. Applied Economics Letters, 11(3), 167-171.

Kohers, T., y Kohli, R. K. (1991). The anomalous stock market behavior of large firms in January: the evidence from the S\&P composite and component indexes. Quarterly Journal of Business and Economics, 30(3), 14-32.

Kumar, S. y Goyal, N. (2015). Behavioural biases in investment decision making-a systematic literature review. Qualitative Research in financial markets, 7(1), 88-108.

Kunkel, R. A., Compton, W. S., y Beyer, S. (2003). The turn-of-the-month effect still lives: the international evidence. International Review of Financial Analysis, 12(2), 207-222.

La Porta, R., Lopez-de-Silanes, F., Shleifer, A., y Vishny, R. W. (2000). Agency problems and dividend policies around the world. The journal of finance, 55(1), 1-33.

Lakonishok, J. y Smidt, S. (1986). Volume for winners and losers: Taxation and other motives for stock trading. The Journal of Finance, 41(4), 951-974.

Lakonishok, J., y Smidt, S. (1988). Are seasonal anomalies real? A ninety-year perspective. Review of Financial Studies, 1(4), 403-425.

Lakonishok, J., y Maberly, E. (1990). The weekend effect: Trading patterns of individual and institutional investors. The Journal of Finance, 45(1), 231-243.

Leroy, S. F. (1973). Risk aversion and the martingale property of stock prices. International Economic Review, 14, 436-446.

Levy, M., y Levy, H. (2002). Prospect theory: much ado about nothing?. Management Science, 48(10), 1334-1349. 
Liano, K., Marchand, P. H., y Huang, G. C. (1992). The holiday effect in stock returns: Evidence from the OTC market. Review of Financial Economics, 2(1), 45-54.

Lie, E. (2005). Financial flexibility, performance, and the corporate payout choice. The Journal of Business, 78, 1-23.

Lin, H. W. (2011). Does the disposition effect exhibit during financial crisis. In International Conference on Economics and Finance Research (IPEDR) (Vol. 4, pp. 110). Conference paper.

Lintner, J. (1956). Distribution of incomes of corporations among dividends, retained earnings, and taxes. The American Economic Review, 46(2), 97-113.

Lintner, J. (1965). The valuation of risk assets and the selection of risky investments in stock portfolios and capital budgets. The review of economics and statistics, 47(1), 1337.

Litzenberger, R. H., y Ramaswamy, K. (1979). The effect of personal taxes and dividends on capital asset prices: Theory and empirical evidence. Journal of financial economics, 7(2), 163-195.

Liu, N., y Espahbodi, R. (2014). Does dividend policy drive earnings smoothing?. Accounting Horizons, 28(3), 501-528.

Lo, A. W. (2004). The adaptive markets hypothesis. The Journal of Portfolio Management, 30(5), 15-29.

Locke, P. y Mann, S. C. (2000). Do professional traders exhibit loss realization aversion?. Working paper, The George Washington University and Texas Christian University.

Lu, X., y Gao, H. (2016). The day of the week effect in chinese stock market. The Journal of Asian Finance, Economics and Business, 3(3), 17-26.

Lucas, R. E. (1978). Asset prices in an exchange economy. Econometrica: Journal of the Econometric Society, 46, 1429-1445.

Lucey, B. M., y Whelan, S. (2001). A promising strategy in equity markets. Journal of the Statistical and Social Inquiry Society of Ireland, XXXI, 74-110. 
Lucey, B. M., y Pardo, A. (2005). Why investors should not be cautious about the academic approach to testing for stock market anomalies. Applied Financial Economics, 15(3), 165-171.

Lusardi, A. (2008). Household saving behavior: The role of financial literacy, information, and financial education programs (No. w13824). National Bureau of Economic Research.

Lyons, A. C. (2005). Financial education and program evaluation: Challenges and potentials for financial professionals. Journal of Personal Finance, 4(4), 56-68.

Lyons, A. C., Rachlis, M., Staten, M., y Xiao, J. J. (2006). Translating financial education into knowledge and behavior change. Consumer Interests Annual, 52, 397403.

Lyons, A. C. (2010). Consideraciones clave para una evaluación eficaz de los programas de educación económica y financiera, presented at the 4th Simposio La educación económica y financiera en México, México D.F.: Museo Interactivo de Economía, MIDE, 10 Septiembre, 2010.

Ma, C. K. (1986). A further investigation of the day of the week effect in the gold market. Journal of Futures Markets, 6(3), 409-420.

Manahov, V., y Hudson, R. (2014). A note on the relationship between market efficiency and adaptability - New evidence from artificial stock markets. Expert Systems with Applications, 41(16), 7436-7454.

Marhuenda, J. (1998). Estacionalidad de la prima por riesgo en el mercado de capitales español. Revista Española de Financiación y Contabilidad, 27(94), 13-36.

Markese, J. (1989). Stock market anomalies: Folklore that may not be myth. American Association of Individual Investors Journal, 11, 30-33.

Markiewicz, A., y Pick, A. (2014). Adaptive learning and survey data. Journal of Economic Behavior \& Organization, 107, 685-707.

Markowitz, H. (1952). Portfolio selection. The journal of finance, 7(1), 77-91. 
Maroto, A., R. Cáceres., L. Jordán., y A. Rodríguez. (2007). Estacionalidad en la Rentabilidad y Volatilidad de los Títulos que cotizan en el Latibex. Revista de Administración, Finanzas y Economía, 1(1), 84-95

Marquering, W., Nisser, J., y Valla, T. (2006). Disappearing anomalies: a dynamic analysis of the persistence of anomalies. Applied Financial Economics, 16(4), 291-302.

Marrett, G. J., y Worthington, A. C. (2007). An empirical note on the holiday effect in the Australian stock market, 1996-2006. Applied Economics Letters, 16(17), 1769-1772.

Mastrobuoni, G. (2009). The role of information for retirement behavior: evidence based on the stepwise introduction of the social security statement. Working Papers, Center for Retirement Research at Boston College, Center for Retirement Research.

Matallín Sáez, J. C., y Fernández Izquierdo, M. Á. (1999). Análisis de la performance a través del estilo del fondo de inversión. Revista Española de Financiación y Contabilidad, 28(99), 413-442.

McConnell, J. J., y Xu, W. (2008). Equity returns at the turn-of-the-month. Financial Analysts Journal, 64(2), 49-64.

McFarland, J. W., Pettit, R. R., y Sung, S. K. (1982). The distribution of foreign exchange price changes: trading day effects and risk measurement. The Journal of Finance, 37(3), 693-715.

McNichols, M. (1988). A comparison of the skewness of stock return distributions at earnings and non-earnings announcement dates. Journal of Accounting and Economics, 10(3), 239-273.

Mehdian, S., y Perry, M. J. (2001). The reversal of the Monday effect: new evidence from US equity markets. Journal of Business Finance \& Accounting, 28(7-8), 10431065.

Mehdian, S., y Perry, M. J. (2002). Anomalies in US equity markets: A re-examination of the January effect. Applied Financial Economics, 12(2), 141-145.

Meneu, V., y Pardo, A. (2001). El efecto festivo en la Bolsa Española. Moneda y Crédito, 213, 97-127. 
Meneu, V., y Pardo, A. (2004). Pre-holiday effect, large trades and small investor behaviour. Journal of Empirical Finance, 11(2), 231-246.

Meng, J. y Weng, X. (2017). Can prospect theory explain the disposition effect? A new perspective on reference points. Management Science. Forthcoming.

Merrill, A. (1966). The behavior of prices on wall street. Chappaqua, New York: Analysis Press.

Michaely, R. (1991). Ex-dividend day stock price behavior: the case of the 1986 Tax Reform Act. The Journal of Finance, 46(3), 845-859.

Michaely, R., Thaler, R. H., y Womack, K. L. (1995). Price reactions to dividend initiations and omissions: Overreaction or drift?. Journal of Finance, 50(2), 573-608.

Miller, M. H., y Modigliani, F. (1961). Dividend policy, growth, and the valuation of shares. The Journal of Business, 34(4), 411-433.

Miller, M. H., y Scholes, M. S. (1983). Dividends and taxes: Some empirical evidence. Journal of Political Economy, 90, 1118-1141.

Miller, M. H., y Rock, K. (1985). Dividend policy under asymmetric information. The Journal of finance, 40(4), 1031-1051.

Miller, M. H. (1986). Behavioral rationality in finance: The case of dividends. Journal of Business, 59, S451-S468.

Mills, T. C., y Coutts, J.A. (1995). Calendar effects in the London Stock Exchange FTSE indices. The European Journal of Finance, 1(1), 79-93.

Mills, T. C., Siriopoulos, C., Markellos, R. N., y Harizanis, D. (2000). Seasonality in the Athens stock exchange. Applied Financial Economics, 10(2), 137-142.

Moller, N., y Zilca, S. (2008). The evolution of the January effect. Journal of Banking \& Finance, 32(3), 447-457.

Moosa, I. (2007). The vanishing January effect. International Research Journal of Finance and Economics, 1(7), 92-103. 
Moshirian, F., Ng, D., y Wu, E. (2008). The value of stock analysts' recommendations: Evidence from emerging markets. International Review of Financial Analysis, 18(1), 74-83.

Mossin, J. (1966). Equilibrium in a capital asset market. Econometrica: Journal of the econometric society, 34(4), 768-783.

Myagkov, M., y Plott, C. R. (1997). Exchange economies and loss exposure: Experiments exploring prospect theory and competitive equilibria in market environments. The American Economic Review (AER), 87(5), 801-828.

Nelson, D. B. (1991). Conditional heteroskedasticity in asset returns: A new approach. Econometrica: Journal of the Econometric Society, 59, 347-370.

Nikkinen, J., Sahlström, P., y Äijö, J. (2007a). Turn-of-the-month and intramonth effects: Explanation from the important macroeconomic news announcements. Journal of Futures markets, 27(2), 105-126.

Nikkinen, J., Sahlström, P., y Äijö, J. (2007b). Do the US macroeconomic news announcements explain turn-of-the-month and intramonth anomalies on European stock markets. Journal of Applied Business and Economics, 7(3).

Nofsinger, J. y Varma, A. (2014). Socially responsible funds and market crises. Journal of Banking \& Finance, 48, 180-193.

Nolte, I. (2012). A detailed investigation of the disposition effect and individual trading behavior: a panel survival approach. The European Journal of Finance, 18(10), 885-919.

Odean, T. (1998). Are investors reluctant to realize their losses?. The Journal of finance, 53(5), 1775-1798.

Odean, T. (1999). Do investors trade too much?. American Economic Review, 89(5), 1279-1298.

Officer, M.S. (2007). Dividend policy, dividend initiations, and governance. Working paper, University of Southern California.

Ogden, J. P. (1990). Turn of month evaluations of liquid profits and stock returns: A common explanation for the monthly and January effects. The Journal of Finance, 45(4), 1259-1272. 
Olsen, R. A. (2008). Cognitive dissonance: The problem facing behavioral finance. Journal of Behavioral Finance, 9, 1-4.

Olson, D., Mossman, C., y Chou, N. T. (2015). The evolution of the weekend effect in US markets. The Quarterly Review of Economics and Finance, 58, 56-63.

Opiela, N. (2005). Rational investing despite irrational behaviors. Journal of Financial Planning, 18(1), 34-42.

Osborne, M. F. M. (1962). Periodic structure in the Brownian motion of stock prices. Operations Research, 10(3), 345-379.

Palacín-Sánchez, M. J. (2007). La política de dividendos en las empresas del IBEX-35. In Empresa global y mercados locales: XXI Congreso Anual AEDEM, Universidad Rey Juan Carlos, Madrid, 6, 7 y 8 de junio de 2007 (p. 60). Escuela Superior de Gestión Comercial y Marketing, ESIC.

Pantzalis, C., y Park, J. C. (2014). Exuberance out of left field: Do sports results cause investors to take their eyes off the ball? Journal of Economic Behavior \& Organization, 107, 760-780.

Patel, J. B. (2016). The January effect anomaly reexamined in stock returns. Journal of Applied Business Research, 32(1), 317.

Patell, J. M., y Wolfson, M. A. (1982). Good news, bad news, and the intraday timing of corporate disclosures. Accounting Review, 5, 509-527.

Penman, S. H. (1987). The distribution of earnings news over time and seasonalities in aggregate stock returns. Journal of Financial Economics, 18(2), 199-228.

Peña, J. I. (1995). Daily seasonalities and stock market reforms in Spain. Applied Financial Economics, 5(6), 419-423.

Pettengill, G. N., y Jordan, B. D. (1988). A comprehensive examination of volume effects and seasonality in daily security returns. Journal of Financial Research, 11(1), 57-70.

Pettengill, G. N. (1989). Holiday closings and security returns. Journal of Financial Research, 12(1), 57-67. 
Pettengill, G. N. (1993). An experimental study of the "Blue-Monday" hypothesis. The Journal of Socio-Economics, 22(3), 241-257.

Pettit, R. R. (1972). Dividend announcements, security performance, and capital market efficiency. The Journal of Finance, 27(5), 993-1007.

Pleßner, M. (2017). The disposition effect: a survey. Management Review Quarterly, 130 .

Porter, D. C., Powell, G. E., y Weaver, D. G. (1997). Portfolio rebalancing, institutional ownership, and the small firm-January effect. Review of Financial Economics, 5(1), 1929.

Poterba, J. M., y Weisbenner, S. J. (2001). Capital gains tax rules, tax-loss trading, and turn-of-the-year returns. The Journal of Finance, 56(1), 353-368.

Procianoy, J. L., y Vancin, D. (2014). Dividends: Publicly listed brazilian companies' propensity to pay or not to pay.

Rabin, M. (1998). Psychology and economics. Journal of economic literature, 36(1), $11-46$.

Ranguelova, E. (2001). Disposition effect and firm size: New evidence on individual investor trading activity. Harvard University.

Rathinasamy, R. S., y Mantripragada, K. G. (1996). The January size effect revisited: Is it a case of risk mismeasurement? Journal of Financial and Strategic Decisions, 9(3), 914.

Rau, H. A. (2015). The disposition effect in team investment decisions: Experimental evidence. Journal of Banking \& Finance, 61, 272-282.

Reinganum, M. R. (1983). The anomalous stock market behavior of small firms in January: Empirical tests for tax-loss selling effects. Journal of Financial Economics, 12(1), 89-104.

Rendon, J., y Ziemba, W. T. (2007). Is the January effect still alive in the futures markets?. Financial Markets and Portfolio Management, 21(3), 381-396. 
Renneboog, L., Ter Horst, J. y Zhang, C. (2008). Socially responsible investments: Institutional aspects, performance, and investor behavior. Journal of Banking \& Finance, 32(9), 1723-1742.

Renneboog, L., Ter Horst, J. y Zhang, C. (2011). Is ethical money financially smart? Nonfinancial attributes and money flows of socially responsible investment funds. Journal of Financial Intermediation, 20(4), 562-588.

Richards, D. W., Rutterford, J., Kodwani, D. y Fenton-O'Creevy, M. (2017). Stock market investors' use of stop losses and the disposition effect. The European Journal of Finance, 23(2), 130-152.

Riepe, M. W. (1998). Is publicity killing the January effect? Journal of Financial Planning, 11(1), 64-70.

Ritter, J. R. (1988). The buying and selling behavior of individual investors at the turn of the year. The Journal of Finance, 43(3), 701-717.

Ritter, J. R. (2003). Behavioral finance. Pacific-Basin finance journal, 11(4), 429-437.

Robin, A. J. (1991). The impact of the 1986 tax reform act on ex-dividend day returns. Financial Management, 20 (1), 60-70.

Rodríguez Enriquez, E., Andrés Suárez, J. D., y Lorca Fernández, P. (2003). La estabilidad de la política de dividendos: una contrastación empírica en las compañías cotizadas por ramas de actividad. Análisis Financiero, (92), 24-31.

Rodríguez, W. K., y Yáñez, T. A. (2015). The turn-of-the-month effect still exists in the main Latin American stock markets, including the level of individual stocks. Contaduría y Administración, 60(1), 53-86.

Rogalski, R. J. (1984). New findings regarding day of the week returns over trading and non-trading periods: a note. The Journal of Finance, 34, 1603-1614.

Rogalski, R. J., y Tinic, S. M. (1986). The January size effect: anomaly or risk mismeasurement?. Financial Analysts Journal, 42(6), 63-70.

Roll, R. (1983). Vas ist dat: The turn of the year effect and the return premia of small firms. Journal of Financial Economics, 3, 18-28. 
Rosenberg, B., Reid, K., y Lanstein, R. (1985). Persuasive evidence of market inefficiency. The Journal of Portfolio Management, 11(3), 9-16.

Ross, S. A. (1977). The determination of financial structure: the incentive-signalling approach. The bell journal of economics, 8(1), 23-40.

Ross, S. A. (1989). Information and volatility: The no-arbitrage martingale approach to timing and resolution irrelevancy. The Journal of Finance, 44(1), 1-17.

Ross, S. A. (2001). The Princeton Lectures in Finance, Lecture 2: Efficient Markets, working paper, MIT.

Rozeff, M. S., y Kinney, W. R. (1976). Capital market seasonality: The case of stock returns. Journal of financial economics, 3(4), 379-402.

Rubio, G., y Salvador, L. (1991). Estacionalidad diaria de los precios en el mercado español de capitales. Revista Española de Financiación y Contabilidad, 20(67), 307336.

Rystrom, D. S., y Benson, E. D. (1989). Investor psychology and the day of the week effect. Financial Analysts Journal, 45(5), 75-78.

Sadeghnia, M., Hooshmand, A. H., y Habibniko. (2013). Behavioural finance and neuro finance and research conducted in this area. Interdisciplinary Journal of Contemporary Research in Business, 4(12).

Samuelson, P. A. (1965). Proof that properly anticipated prices fluctuate randomly. Industrial Management Review, 6, 41-49.

Sánchez, M. J. P., y di Pietro, F. (2011). El valor informativo de los dividendos en las empresas españolas/Dividend Changes and Changes in Future Profitability in the Spanish Market. Revista Europea de Dirección y Economía de la Empresa, 20(2), 9.

Santesmases, M. (1986). An investigation of the Spanish stock market seasonalities. Journal of Business Finance \& Accounting, 13(2), 267-276.

Sawicki, J. (2009). Corporate governance and dividend policy in Southeast Asia pre-and post-crisis. The European Journal of Finance, 15(2), 211-230. 
Schwert, G. W. (2002). Anomalies and market efficiency (No. w9277). National Bureau of Economic Research.

Serna, M. I. M., Sánchez, A. L., y Guirao, J. Y. (2000). Análisis empírico del efecto día de la semana en la Bolsa de Madrid. Revista europea de dirección y economía de la empresa, 9(1), 105-118.

Sewell, M. (2007). Behavioural finance. University of Cambridge.

Shapira, Z. y Venezia, I. (2001). Patterns of behavior of professionally managed and independent investors. Journal of Banking \& Finance, 25(8), 1573-1587.

Sharma, S. S., y Narayan, P. K. (2014). New evidence on turn-of-the-month effects. Journal of International Financial Markets, Institutions and Money, 29, 92-108.

Sharpe, W. F. (1964). Capital asset prices: A theory of market equilibrium under conditions of risk. The journal of finance, 19(3), 425-442.

Sharpe, W. F. (1966). Mutual fund performance. The Journal of business, 39(1), 119138.

Sharpe, W. F. (1991). The arithmetic of active management. Financial Analysts Journal, 47(1), 7-9.

Shefrin, H., y Statman, M. (1984). Explaining investor preference for cash dividends. Journal of financial economics, 13(2), 253-282.

Shefrin, H. y M. Statman. (1985). "The Disposition to Sell Winners Too Early and Ride Losers Too Long: Theory and Evidence.” The Journal of Finance, 40, 777-790.

Shefrin, H. (2002). Beyond greed and fear: Understanding behavioral finance and the psychology of investing. Oxford University Press on Demand.

Shefrin, H. (2007). Behavioral corporate finance: Decisions that create value. New York: McGraw-Hill.

Shefrin, H. (2009). How psychological pitfalls generated the global financial crisis. Working paper, Santa Clara University. 
Shiller, R. J. (1981). Do stock price move too much to be justified by subsequent changes in dividends? The American Economic Review, 71(3), 421-436.

Shiller, R. J. (2003). From efficient markets theory to behavioral finance. The Journal of Economic Perspectives, 17(1), 83-104.

Shiller, R. J. (2005). Irrational exuberance. Princeton, NJ: Princeton University Press.

Shiller, R. J. (2008). The subprime solution: how today's global financial crisis happened, and what to do about it. Princeton, NJ: Princeton University Press.

Shimp, K. G., Mitchell, M. R., Beas, B. S., Bizon, J. L., y Setlow, B. (2015). Affective and cognitive mechanisms of risky decision making. Neurobiology of learning and memory, 117, 60-70.

Sias, R. W., y Starks, L. T. (1995). The day of the week anomaly: The role of institutional investors. Financial Analysts Journal, 51(3), 58-67.

Sias, R. W., y Starks, L. T. (1997). Institutions and individuals at the turn of the year. The Journal of Finance, 52(4), 1543-1562.

Siegel, J. (1998). Stocks for the Long Run. New York: McGraw Hill.

Siganos, A., Vagenas-Nanos, E., y Verwijmeren, P. (2014). Facebook's daily sentiment and international stock markets. Journal of Economic Behavior \& Organization, 107, 730-743.

Silva, P. M. (2010), Calendar "anomalies" in the Portuguese stock market. Investment Analysts Journal, 71, 37-50.

Singh, S. (2012). Investor irrationality and self-defeating behavior: Insights from behavioral finance. Journal of Global Business Management, 8(1), 116-122.

Singleton, J. C., y Wingender, J. R. (2003). The Monday effect: A disaggregation analysis. Quarterly Journal of business and Economics, 42, 91-114.

Sirri, E. R. y Tufano, P. (1998). Costly search and mutual fund flows. The journal of finance, 53(5), 1589-1622. 
Skinner, D. J., y Soltes, E. (2011). What do dividends tell us about earnings quality?. Review of Accounting Studies, 16(1), 1-28.

Spiegel, M. y Zhang, H. (2013). Mutual fund risk and market share-adjusted fund flows. Journal of Financial Economics, 108(2), 506-528.

Solnik, B., y Bousquet, L. (1990). Day of the week effect on the Paris Bourse. Journal of Banking \& Finance, 14(2), 461-468.

Soufian, M., Forbes, W., y Hudson, R. (2014). Adapting financial rationality: Is a new paradigm emerging?. Critical Perspectives on Accounting, 25(8), 724-742.

Spindler, G. (2011). Behavioural finance and investor protection regulations. Journal of consumer policy, 34(3), 315-336.

Starks, L. T., Yong, L., y Zheng, L. (2006). Tax-loss selling and the January effect: evidence from municipal bond closed-end funds. The Journal of Finance, 61(6), 30493067.

Statman, M. (2000). Socially responsible mutual funds. Financial Analysts Journal, 3039.

Steeley, J. (2001). A note on information seasonality and the disappearance of the weekend effect in the UK stock market. Journal of Banking \& Finance, 25(10), 19411956.

Stigler, G. J. (1967). Imperfections in the capital market. The Journal of Political Economy, 75(3), 287-292.

Suárez, A. S. (1986). Decisiones óptimas de inversión y financiación en la empresa. Ediciones Pirámide.

Suárez-García, P., y Gómez-Ullate, D. (2014). Multifractality and long memory of a financial index. Physica A: Statistical Mechanics and its Applications, 394, 226-234.

Sullivan, R., Timmermann, A., y White, H. (2001). Dangers of data mining: The case of calendar effects in stock returns. Journal of Econometrics, 105(1), 249-286. 
Swinkels, L., y Van Vliet, P. (2012). An anatomy of calendar effects. Journal of Asset Management, 13(4), 271-286.

Talpsepp, T. (2009). Reverse disposition effect of foreign investors. Journal of Behavioral Finance, 12(4), 183-200.

Thaler, R. H., y Shefrin, H. (1981). An economic theory of self-control. The Journal of Political Economy, 89, 392-410.

Thaler, R. H. (1987a). Amomalies: The January effect. The Journal of Economic Perspectives, 1(1), 197-201.

Thaler, R. H. (1987b). Anomalies: weekend, holiday, turn-of-the-month, and intraday effects. Journal of Economic Perspectives, 1(2), 169-178.

Thaler, R. H. (1987c). Anomalies: seasonal movements in security prices II: weekend, holiday, turn of the month, and intraday effects. The Journal of Economic Perspectives, 1(2), 169-177.

Thaler, R.H. y Sunstein, C.R. (2008). Nudge: improving decisions about health, wealth, and happiness. New Haven and London: Yale University Press.

Theobald, M., y Price, V. (1984). Seasonality estimation in thin markets. The Journal of Finance, 39(2), 377-392.

Tonchev, D., y Kim, T. (2004). Calendar effects in eastern European financial markets: Evidence from the Czech Republic, Slovakia and Slovenia. Applied Financial Economics, 14, 1035-1043.

Tong, W. (2000). International evidence on weekend anomalies. Journal of financial research, 23(4), 495-522.

Treynor, J. L. (1965). How to rate management of investment funds. Harvard business review, 43(1), 63-75.

Tseng, K. C. (2006). Behavioral finance, bounded rationality, neuro-finance, and traditional finance. Investment Management and Financial Innovations, 3(4), 7-18. 
Uzar, C., y Akkaya, G. C. (2013). The mental and behavioural mistakes investors make. International Journal of Business and Management Studies, 5(1), 120-128.

Van den Bergh, W. M., y Wessels, R. E. (1985). Stock market seasonality and taxes: An examination of the tax-loss selling hypothesis. Journal of Business Finance \& Accounting, 12(4), 515-530.

Vergin, R. C., y McGinnis, J. (1999). Revisiting the holiday effect: is it on holiday?. Applied Financial Economics, 9(5), 477-482.

Verheyden, T., De Moor, L., y Van den Bossche, F. (2015). Towards a new framework on efficient markets. Research in International Business and Finance, 34, 294-308.

Vermeer, A. B. L., Boksem, M. A., y Sanfey, A. G. (2014). Neural mechanisms underlying context-dependent shifts in risk preferences. NeuroImage, 103, 355-363.

Viñolas, P. (1995). Estacionalidad de la bolsa española: el "efecto enero" y el efecto "fin de semana", Análisis financiero, (66), 8-17.

Von Eije, H., y Megginson, W. (2006). Dividend policy in the European Union.

Wachtel, S. B. (1942). Certain observations on seasonal movements in stock prices. The journal of business of the University of Chicago, 15(2), 184-193.

Waller Jr, W. T. (1988). The concept of habit in economic analysis. Journal of Economic Issues, 22(1), 113-126.

Wang, K., Li, Y., y Erickson, J. (1997). A new look at the Monday effect. The Journal of Finance, 52(5), 2171-2186.

Watts, R. (1973). The information content of dividends. Journal of Business, 46(2), 191-211.

Weber, M. y Camerer, C. F. (1998). The disposition effect in securities trading: An experimental analysis. Journal of Economic Behavior \& Organization, 33(2), 167-184.

Weber, M. y Welfens, F. (2007). An individual level analysis of the disposition effect: empirical and experimental evidence. Working paper. 
Wilson, J. W., y Jones, C. P. (1993). Comparison of seasonal anomalies across major equity markets: A note. Financial Review, 28(1), 107-115.

Wong, A., y Quesada, J. A. (2009). El comportamiento humano en las finanzas. México, D.F.: Instituto Mexicano de Ejecutivos de Finanzas (IMEF).

Yalcin, Y., e Yucel, E. (2003). The day of the week effect on stock market volatility: evidence from emerging markets. Banco Central de la República de Turquia.

Yuan, T., y Gupta, R. (2014). Chinese lunar New Year effect in Asian stock markets, 1999-2012. The Quarterly Review of Economics and Finance, 54(4), 529-537.

Yunita, A., y Martain, S. M. (2012). Analysis of calendar effects: Day-of-the-week effects in Indonesia, Singapore, and Malaysia stock markets. African Journal of Business Management, 6(11), 3880-3887.

Zhang, B., y Li, X. (2006). Do calendar effects still exist in the Chinese stock markets? Journal of Chinese Economic and Business Studies, 4(2), 151-163.

Ziemba, W. T. (1991). Japanese security market regularities: Monthly, turn-of-themonth and year, holiday and golden week effects. Japan and the world Economy, 3(2), 119-146. 
